\title{
Cities and Green Growth: A Conceptual Framework
}
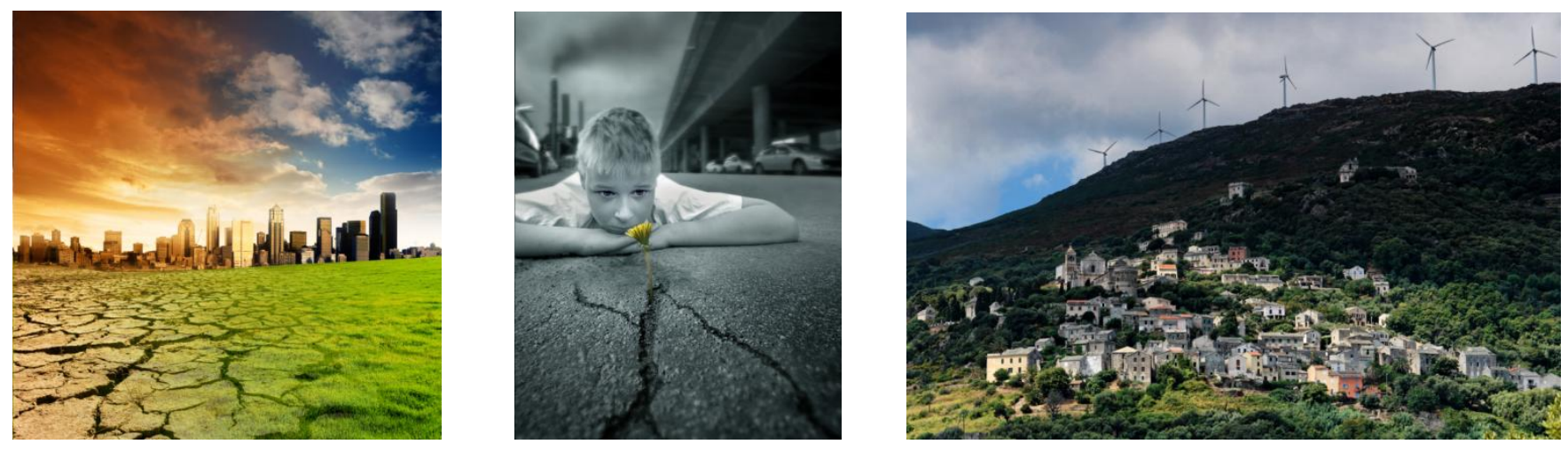

Please cite this paper as:

Hammer, S. et al. (2011), "Cities and Green

Growth: A Conceptual Framework", OECD

Regional Development Working Papers 2011/08,

OECD Publishing.

http://dx.doi.org/10.1787/5kg0tflmzx34-en

\section{OECD Regional Development Working Papers 2011/08}

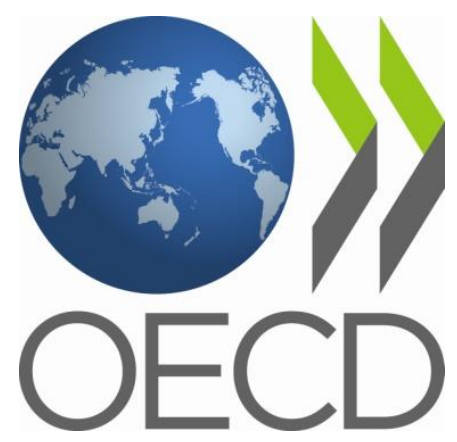

Stephen Hammer, Lamia Kamal-Chaoui, Alexis Robert and Marissa Plouin

JEL Classification: 01, O3, Q1, Q2, Q3, Q4, Q5, R1, R4, R5 


\section{OECD REGIONAL DEVELOPMENT WORKING PAPERS}

This series is designed to make available to a wider readership selected studies on regional development issues prepared for use within the OECD. Authorship is usually collective, but principal authors are named.

The papers are generally available only in their original language, English or French, with a summary in the other if available.

The opinions expressed in these papers are the sole responsibility of the author(s) and do not necessarily reflect those of the OECD or the governments of its member countries.

Comment on the series is welcome, and should be sent to gov.contact@oecd.org or the Public Governance and Territorial Development Directorate, 2, rue André Pascal, 75775 PARIS CEDEX 16, France.

OECD Regional Development Working Papers are published on www.oecd.org/gov/regional/workingpapers

Applications for permission to reproduce or translate all or part of this material should be made to: OECD

Publishing, rights@oecd.org or by fax +33145249930.

(C) OECD 2011 


\begin{abstract}
This report examines the current state of knowledge about green growth in cities and outlines the key research questions and protocols that will guide the OECD Green Cities programme. It builds the case for an urban green growth agenda by examining the economic and environmental conditions that have pushed the green growth agenda to the forefront of policy debate and assessing the critical role of cities in advancing green growth. Section 1 lays the context for the paper, examining why green growth is important and how it can be defined in an urban context. Section 2 focuses on policies and tools that enable the transition to green growth in cities. It concludes with a proposal for a policy framework for an urban green growth agenda that is based on a set of hypotheses of desirable economic scenarios. Section 3 examines the main challenges to advancing an urban green growth agenda. It explores the roles that multi-level governance, measuring and monitoring tools and finance must play in delivering green growth in cities. The report concludes with suggestions for future research, including recommendations on how national policymakers responsible for regional and urban policies can advance an urban green growth agenda.
\end{abstract}

JEL classification: O1, O3, Q1, Q2, Q3, Q4, Q5, R1, R4, R5

Keywords: Climate, Global Warming, Sustainable Development, Government Policy, Planning, Regional, Urban, Cities, Territorial, Regional Economics, Urban Sustainability, Green Growth 


\section{ACKNOWLEDGEMENTS}

This report is part of the series of OECD Working Papers on Regional Development of the OECD Public Governance and Territorial Development Directorate, directed by Joaquim Oliveira Martins, Head of the Regional Development Policy Division.

The report has been undertaken within the framework of the OECD Green Cities programme of the Regional Development Policy Division. It was produced and edited by Lamia Kamal-Chaoui, Head of the OECD Urban Development Programme, Alexis Robert (Urban Policy Analyst) and Marissa Plouin (Urban Policy Analyst). The report draws on a number of internal contributions, including from Olaf Merk (urban finance), Tadashi Matsumoto (compact cities) and Xiao Wang (local green growth plans). Statistical data were produced by Monica Brezzi, Head of the Statistical Analysis, Daniel Sanchez-Serra, Mario Piacentini and Konstantin Rosina.

Stephen A. Hammer, PhD, Department of Urban Studies and Planning, Massachusetts Institute of Technology (MIT), provided a major contribution to this report.

Special thanks are given to Jeremy Rifkin, (President, Foundation on Economic Trends), David Miller (Counsel at Aird \& Berlis LLP, former Mayor of Toronto and former Chair of C40 Climate Leadership Group), Remi Dorval (Vinci - Fabrique de la Cité), Pierre-Noel Giraud (Ecole des Mines Paris) and Fabio Grazi (Agence Française de Développement).

We would also like to acknowledge those who have provided valuable comments on the report and relevant background material. In the OECD, they are Jan Corfee-Morlot, Xavier Leflaive, Chris Kennedy and Natasha Crespin (Environment Directorate); Claire Charbit and Aziza Akhmouch (Public Governance and Territorial Development Directorate).

The paper has also benefitted from comments of individuals outside the OECD Secretariat, including from Alain Ayong Le Kama (French Ministry of the Environment), Dominique Bureau (French Ministry of the Environment), Paul Cheshire (London School of Economics), Ian Cochran (Caisse des Dépôts et Consignations - France), Patrick Dubarle (Consultant), Graham Floater (The Climate Centre - UK), Nicky Gavron (Member of the London Assembly), Benoit Lefevre (IDDRI/Sciences-Po, Paris), Martine Liotard (Institut d'Aménagement et d'Urbanisme de l'Ile-deFrance), Barbara Norman (University of Canberra), Bert Provan (London School of Economics, formerly at the Department of Communities and Local Government - UK), Suzanne Salz (ICLEIInternational Council for Local Environmental Initiatives) and Dimitri Zenghelis (London School of Economics). 


\section{TABLE OF CONTENTS}

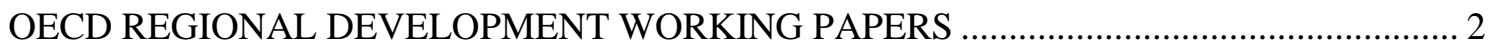

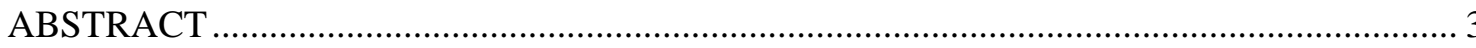

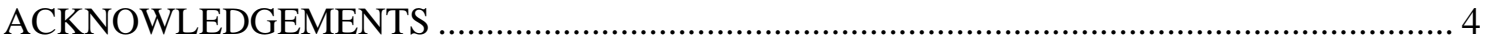

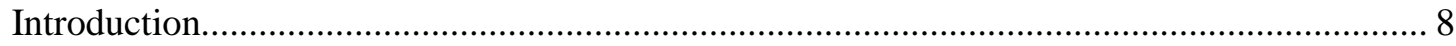

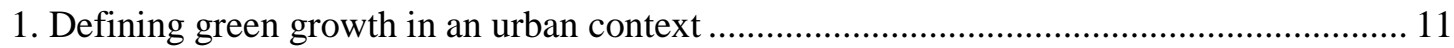

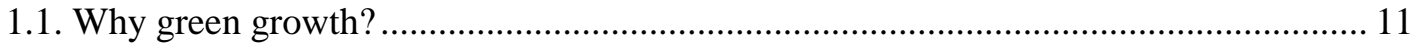

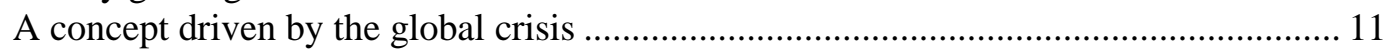

Global environmental and climate threats influencing the push for green growth............ 12

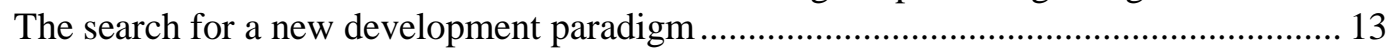

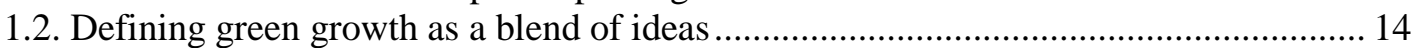

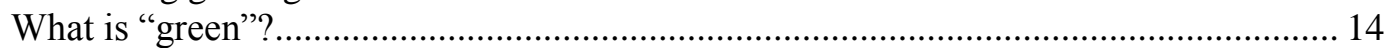

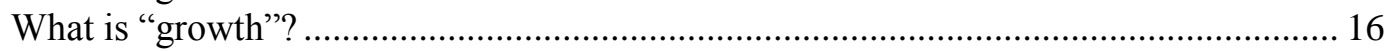

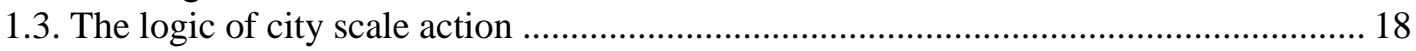

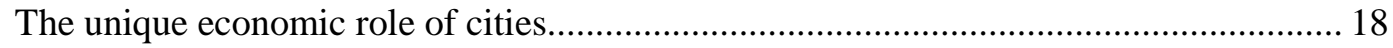

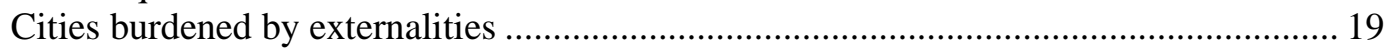

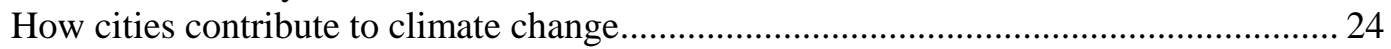

Vulnerabilities to environmental related calamities and climate change ......................... 24

Opportunities for synergies and complementarities ..................................................... 25

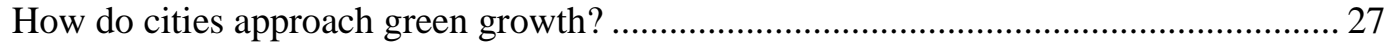

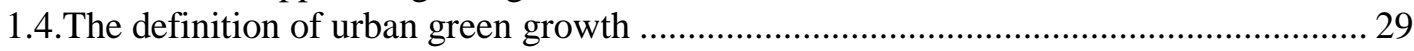

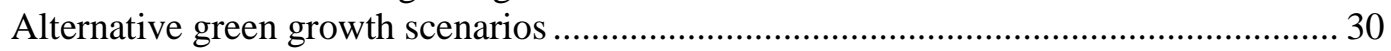

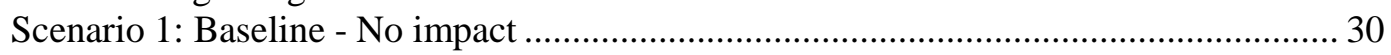

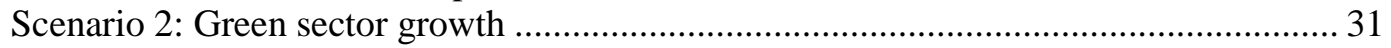

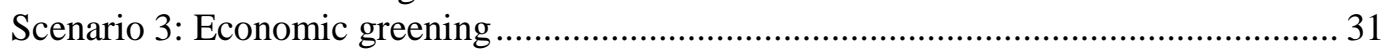

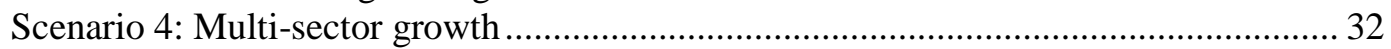

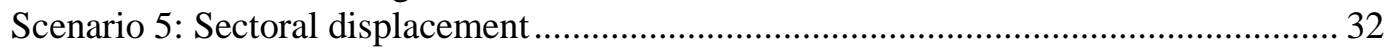

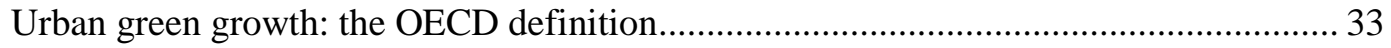

2. Enabling the transition to urban green growth: policies and tools........................................ 34

2.1. A policy framework for an urban green growth agenda ….......................................... 35

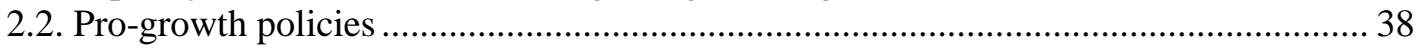

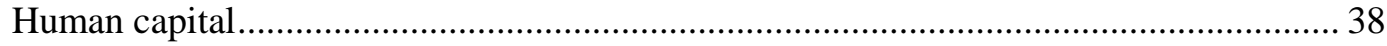

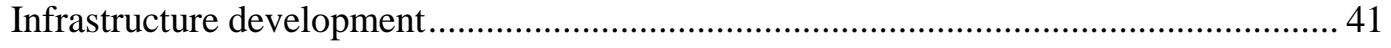

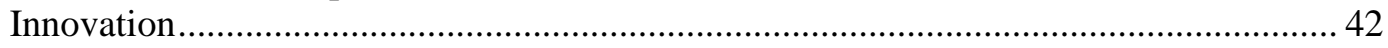

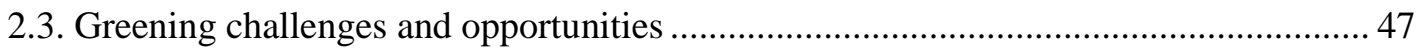

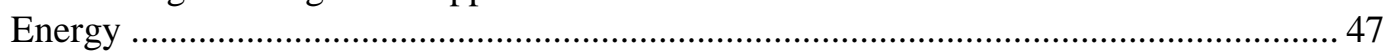

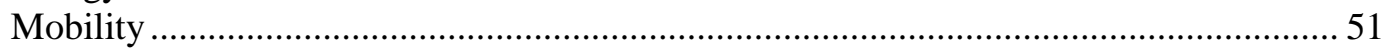

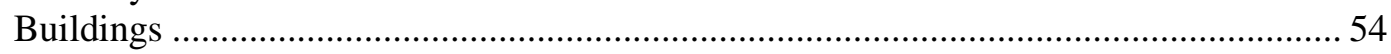

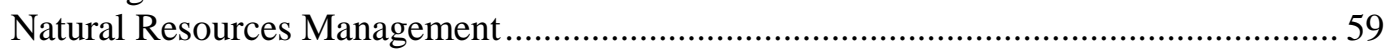

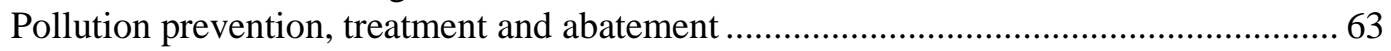

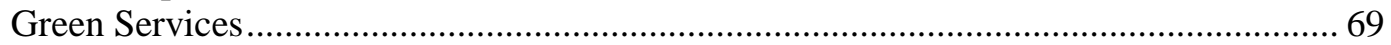

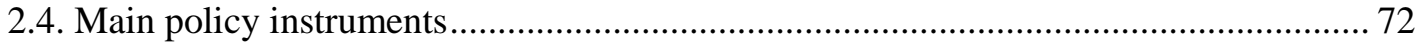

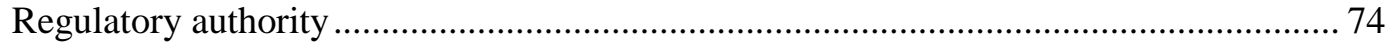

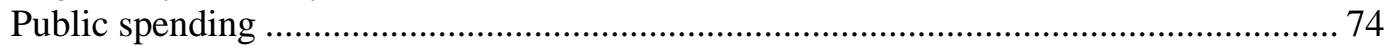

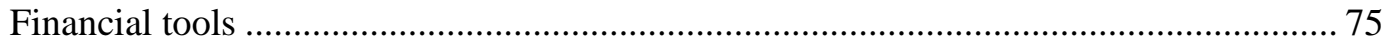

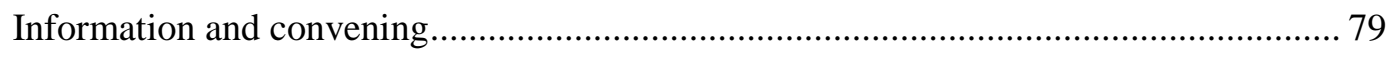




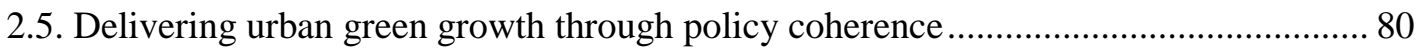

3. Main challenges to advancing an Urban Green Growth Agenda.......................................... 89

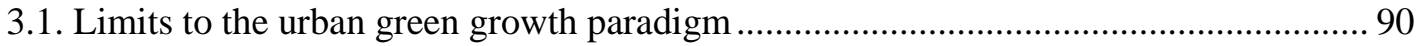

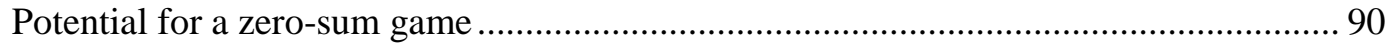

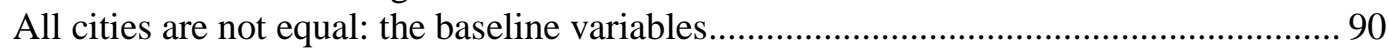

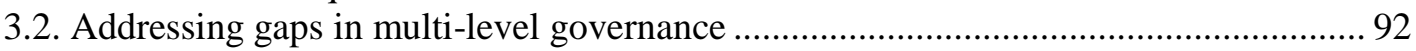

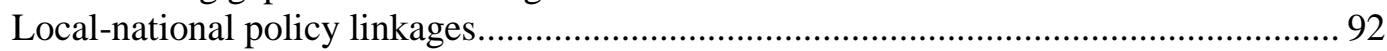

The role of national governments in enabling the advancement of urban green growth.. 93

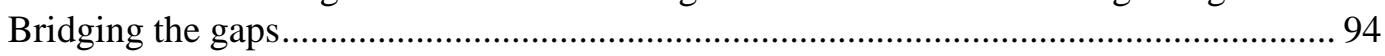

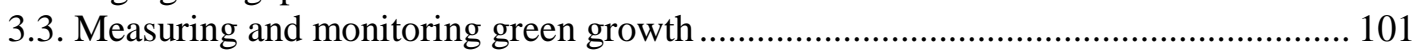

OECD initiatives to measure progress toward green growth ....................................... 103

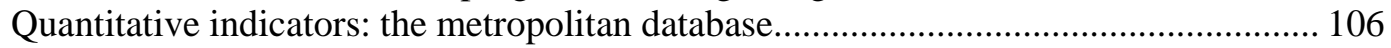

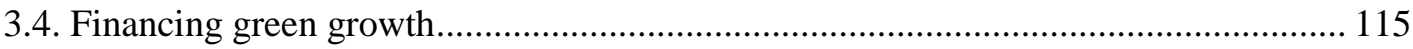

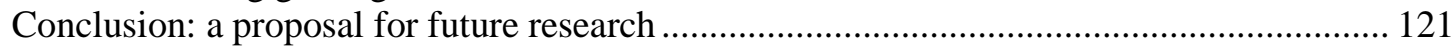

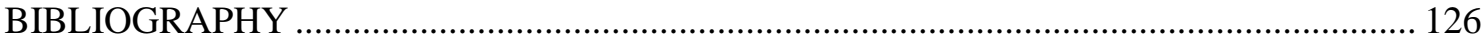

\section{Tables}

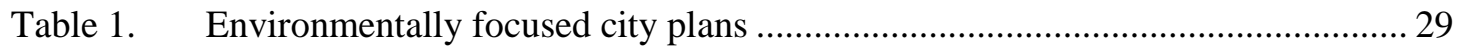

Table 2. Green sectors and jobs..................................................................................... 39

Table 3. Eco-labelled buildings often benefit from higher rental/ sales prices and occupancy rates .......................................................................................... 59

Table 4. Roles and policy levers available to sub-natinoal authorities in

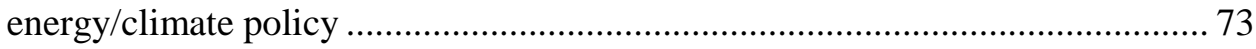

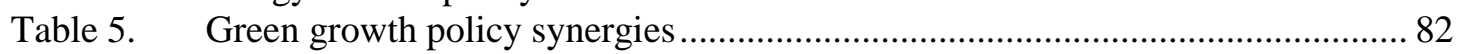

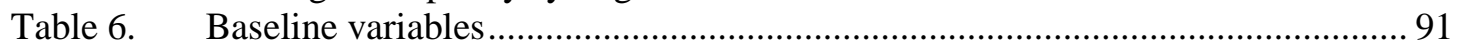

Table 7. Selected water governance gaps in the Venice-city region ................................. 98

Table 8. Selected governance gaps for delivering green growth in Korean cities............ 100

Table 9. Overview of proposed OECD green growth indicators..................................... 105

Table 10. OECD environmental indicators developed for regions an

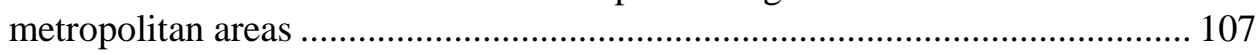

Table 11. High density development index in three OECD metropolitan regions ............. 109

Table 12. High density development index in three OECD metropolitan regions ............ 109

Table 13. Growth of urban land in cores and hinterlands within the largest metropolitan area of each country ................................................................. 110

Table 14. $\mathrm{CO}_{2}$ emissions in the ten largest OECD metro-regions..................................... 112

Table 15. Air pollution (PM 2.5) in the ten largest OECD metropolitan areas .................. 114

\section{Figures}

Figure 1. Green growth and sustainable development................................................... 17

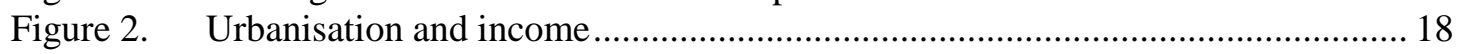

Figure 3. Percent of national GDP in the 10\% TL3 regions with the largest GDP ............ 19

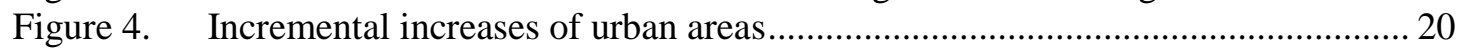

Figure 5. The suburbanisation process in OECD metropolitan regions ............................ 21

Figure 6. $\quad \mathrm{CO}_{2}$ emissions per capita in transport and density in predominantly urban areas 
Figure 7. Electricity consumption per capita and density in predominantly urban areas ... 23

Figure 8. The ecological footprint is highest in urban areas............................................. 24

Figure 9. Change in economic attractiveness and growth across OECD metropolitan regions

Figure 10. Change in economic attractiveness and pollution emission across

OECD metropolitan regions

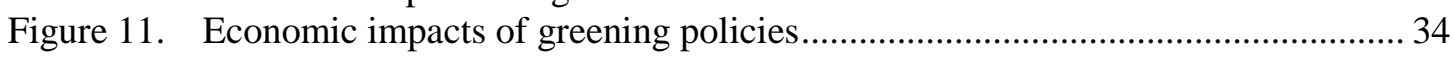

Figure 12. Framework for urban green growth................................................................ 37

Figure 13. The innovation-science link in selected green technologies ............................... 44

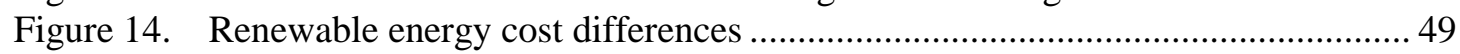

Figure 15. Fuel taxes: little room for local and state involvement .................................. 77

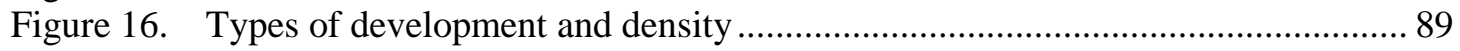

Figure 17. OECD green growth measurement framework ............................................... 104

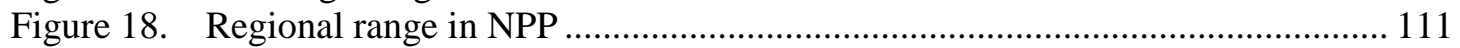

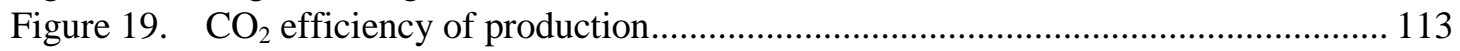

Figure 20. Share of population exposed to health-damaging levels of PM2.5 …............... 115

\section{Boxes}

Box 1. Green measures in investment stimulus packages............................................ 12

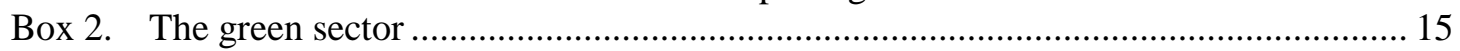

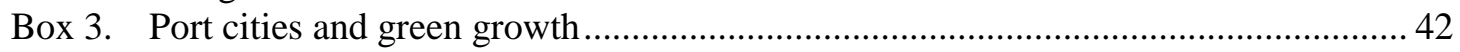

Box 4. Strategic urban economic policy in the recycling sector: the case of Kitakyushu .... 67

Box 5. Local-national government building effiency programmes: a multi-level

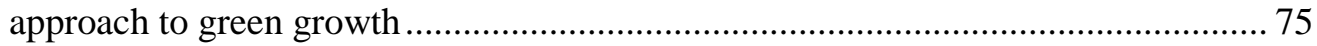

Box 6. The sustainability of urban growth in poor and emerging countries .......................... 86

Box 7. Impediments to developing a worldwide green economy ........................................ 92

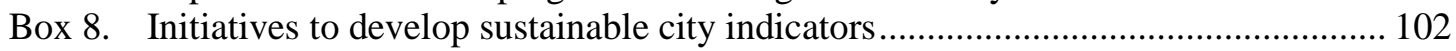

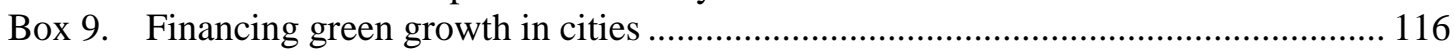

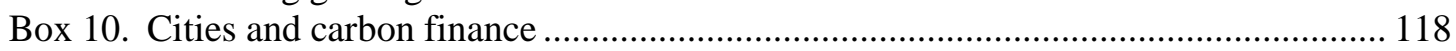

Box 11. PPPs to fund public bicycle rental schemes: the case of Vélib' in Paris ................. 121 


\section{Introduction}

1. The global recession and continued concern over climate change calls into question the ability of current models for economic growth to foster long-term prosperity. Faced with economic hardship and pressing social problems, countries around the globe have pursued a wide range of policy and investment strategies to jumpstart economic recovery. "Green growth", a highly debated term that is generally defined as a means to create jobs and economic growth while reducing costs and environmental impacts over the long run, has emerged as a possible response to address these challenges. The OECD has been an active participant in global efforts to advance green growth. Mandated by a declaration of 34 ministers in June 2009, the OECD conducted a comprehensive programme of work through a multi-disciplinary and inter-governmental process, engaging more than 25 OECD committees in the discussion. This process resulted in the release of the OECD Green Growth Strategy in May 2011. ${ }^{2}$

2. Cities are central part of this work. At the Third Annual Meeting of the OECD Urban Roundtable, mayors and ministers from 21 cities and 34 countries discussed the key role of cities in achieving green growth. A few oft-repeated statistics underscore the importance of cities in meeting impending global economic challenges. More than half of the global population (3.49 billion people) now lives in urban areas, a share that is expected to reach nearly $70 \%$ by 2050 (UNFPA, 2009; UNHabitat, 2010). Within the next decade, there will be nearly 500 cities of more than a million people, including several "megacities" with a population exceeding 20 million. As key engines of economic growth, job creation and innovation, but also as major contributors to global warming and environmental problems, cities are at the heart of the transition to a green global economy. From Paris to Yokohama, Jakarta to Copenhagen, Singapore to Toronto, and Rabat to Dar es Salam, mayors at the Urban Roundtable agreed that because the well-being of cities will be intimately tied to promoting environmental and social inclusion through economically stimulating activities, cities will be central to advancing green growth. Among the key arguments advanced by the Roundtable participants:

- Cities' impact on the environment and the environmental impacts on cities as a result of climate change, especially on cities located in coastal areas.

- Urban form matters: the lower the urban density, the more energy is consumed for electricity and transportation.

- As magnets for highly skilled people and advanced firms and the main centres of innovation, cities can provide the right scale for eco-product markets and large-scale green infrastructure investment. Cities are also promising testing grounds for green technology development, such as electric cars and electric car rental schemes.

- The interactions between the economy and the environment are much more visible at the city scale. Attractiveness is a key factor of city growth performance and can be hampered by a poor environment.

1. Many countries have included a green growth component in their economic recovery and stimulus packages, putting in place structures to evaluate policies from an economic efficiency, environmental quality, and social equity perspective. See OECD (2010a).

2. See www.oecd.org/greengrowth. 
- Because green growth is about synergies between environmental, economic and social inclusion policies, an urban policy package is more likely to deliver green growth than a wide economic approach.

3. These assertions are convincing but still lack solid evidence. In light of increasing subsidies and public programmes dedicated to green growth activities, there is a concern about a trend towards "green washing" in public policies. While a growing number of studies seek to characterise sustainable and green cities, they tend to ignore the impact green growth policies have on job creation, economic attractiveness and environmental quality.

4. Responding to a call from mayors and ministers at the Roundtable, the OECD Green Cities Programme ${ }^{3}$ seeks to fill this information gap by addressing the issue across a range of geographical, economic and national regulatory contexts. The Programme aims to assess how urban green growth and sustainability policies can contribute to improve the economic performance and environmental quality of metropolitan areas, and thus enhance the contribution of urban areas to national growth, quality of life and competitiveness. Four overarching sets of issues form the core of the Programme research agenda:

- Definition and goals. How can green growth be defined in an urban context? Which potential green growth scenarios can be identified, and among them, which ones generate the most desirable outcomes?

- Policy best practices and policy coherence. Which types of policy instruments and programme activities tend to be most successful in delivering green growth in cities? How can policy coherence at the urban scale be ensured to allow synergies and complementarities to occur?

- Measurement. Which economic and environmental performance indicators might indicate the presence of co-benefits and policy complementarities between environmental and economic policies?

- Obstacles to progress. What institutional, regulatory and financing resource barriers inhibit the implementation of green growth strategies?

5. The research agenda will be based on a blend of qualitative and quantitative evidence. Qualitative research will be based on a series of case studies in select metropolitan regions, starting with Paris-IDF, the Chicago Tri-State area, Stockholm and Kitakyushu. This on-the-ground perspective will be critical for linking greening or green growth policy initiatives to measurable outcomes, identifying policy obstacles and outlining the knowledge gaps that must be addressed if green growth is to be pursued in more cities around the world. Quantitative research will include the development of metropolitan environmental performance data to examine the extent to which progress has been made in different cities over time. Data will be drawn from existing OECD datasets and other sources covering a range of cities. A set of comparable and harmonised environmental indicators will be produced for the 90 OECD metropolitan regions with at least 1.5 million inhabitants. These will

3. For more information about the OECD Programme on Cities and Green Growth, see www.oecd.org/greencities. 
complement the existing economic and demographic indicators in the OECD Metropolitan Database (see Section 3.3). ${ }^{4}$

6. The Programme will conclude with an OECD synthesis report on Cities and Green Growth, to be finalised in 2013. Future meetings of the OECD Urban Roundtable of Mayors and Ministers will discuss key findings of the analysis. To foster widespread endorsement of the analysis, each step of the Programme's development will be reviewed by a network of technical experts and city representatives, some of whom will also participate as observers in the case study fieldwork.

7. The present scoping report examines the current state of knowledge of green growth in cities and outlines the research questions that will guide the OECD's Green Cities programme of work. The objective is to propose a framework for defining urban green growth, understand the role of cities in green growth and articulate the core pillars of an urban green growth agenda.

8. Section 1 examines why green growth is important and how it can be defined in an urban context. One key facet discussed is how to differentiate efforts that seek to improve the overall environmental performance of the economy (local and regional) from efforts that are focussed on expanding a specific technology or service sector. The latter is often held up as an explicit strategy adopted by cities to capitalise on growing global demand for new energy technologies and other types of environmental services. This section concludes with a definition of urban green growth.

9. Section 2 addresses the policies and tools that can enable the transition to green growth in cities. Based on a set of desirable scenarios, it proposes a policy framework for an urban green growth agenda. The section first discusses how the three main factors of regional growth - human capital, innovation and infrastructure - can serve as the initial lens through which green growth policies can be understood to contribute to greening the economy. It then explores a set of sectors that represent greening challenges and opportunities in terms of wealth and job creation. Next, a taxonomy of four types of policy levers is proposed, each of which can be adapted to fit any of the green sectors, thereby providing local authorities with considerable flexibility in choosing the instrument(s) best suited to address relevant environmental, energy, or climate challenges. The section concludes with a discussion of the the complementarities that can emerge between urban growth policies and greening opportunities in a green growth policy package.

10. Section 3 examines the role that multi-level governance, effective measurement tools and finance must play in delivering green growth in cities. This discussion focuses on the "gaps" in multilevel governance that can present obstacles to successful green growth initiatives. It also examines monitoring and evaluation mechanisms and the need for comparable indicators of cities' economic and environmental performance. As green growth initiatives will entail significant investments, this section explores innovative financing mechanisms, including the role for public-private partnerships (PPPs).

11. The paper concludes with suggestions for future research, including recommendations on how national policymakers in charge of regional and urban policies in OECD countries can advance the urban green growth agenda. It focuses in particular on the need for better measuring and monitoring of greening and green growth efforts in cities. Data gathering will be critical to determine the efficacy of greening and green growth policies, including whether the most significant outcomes have been produced by policies established at the local, state/provincial, or national government level. It also addresses the issue of policy coherence and policy complementarities that are at the root of a green growth agenda.

4. See http://stats.oecd.org/Index.aspx?datasetcode=METRO. 


\section{Defining green growth in an urban context}

12. This section builds a working definition of urban green growth. In the face of the global financial crisis and pressing environmental and climatic threats, green growth has emerged as a new development paradigm capable of achieving economic and environmental objectives simultaneously. To arrive at a working definition of urban green growth, the terms "green" and "growth" are explored in detail, with a review of green sectors, technologies and practices, followed by a discussion of the metrics that are used to quantify direct and indirect economic impacts (GDP growth, job creation, social and public health benefits, competitiveness, etc.). Cities are central to the green growth debate, as they are both the locus of economic activity and the drivers of energy consumption and greenhouse gas emissions. Because there are signigicant synergies between environmental and economic objectives in urban areas, greening actions at the local scale can reap considerable benefits. Although the term "green growth" has yet to be adopted widely by local governments, cities across the globe are already pursuing greener futures by incorporating environmental objectives into their economic strategies. This section concludes with the introduction of a set of six green growth scenarios that show a range of potential economic outcomes that can result from green growth and economic greening policies at the urban scale.

\subsection{Why green growth?}

\section{A concept driven by the global crisis}

13. Governments are looking to green growth as a strategy to help emerge from the global financial crisis and deliver both economic and environmental gains. Periods of economic recovery are often used to implement structural reforms, including changing or eliminating policies that may be expensive or inefficient. There is growing recognition that economic outcomes are not the only scorecard for societal progress, and that alone, they are an incomplete represetation of the full value of an economy and hide some of the risks and costs inherent in global consumption and production practices. The focus on harmonisation of economic growth and environmental sustainability - or "green growth" - stems from this recognition.

14. The environmentally-focused economic strategies included in several national stimulus and recovery packages vary widely, ranging from investments in "shovel-ready" public transportation and green building projects, research and development (R\&D) into advanced biofuels and different forms of energy technology, funds to remedy crumbling or inadequate water supply and treatment infrastructure (Box 1). Some of the investments had clear job training goals, seeking to create a workforce that can help drive the growth of environment-related business activity. This emphasis on green infrastructure development and R\&D projects varies widely by country, but can be significant, representing over $51 \%$ of the total stimulus package in Belgium, 18\% in France, and $32 \%$ in Korea (OECD, 2009a). In China, green stimulus investments accounted for nearly $40 \%$ of the USD 586 billion package (Girouard, 2010). In other countries, the percentages have been smaller, but nonetheless collectively amount to billions of dollars in new investment aimed at preserving or enhancing environmental quality and reducing resource consumption. In most cases, the funding was allocated to all types of territories. The Korean Green Growth Strategy is an exception, as it includes specific actions directly addressing urban areas as well as binding provisions for sub-national governments to develop their own green growth policy actions in five-year plans (Kamal-Chaoui et al., 2011). 


\section{Box 1. Green measures in investment stimulus packages}

Although most countries included green measures, the share of green elements in the stimulus packages varies significantly. Public investment in Korea was driven in part by the "Green New Deal Policy" announced in January 2009, which included major infrastructure projects such as the Four Major Rivers Restoration Project and railroad construction that boosted short-term public employment. With the new programme, the government hopes to create nearly one million jobs over the next four years, mainly in environmentally focused construction projects and other green programmes. In Australia, AUD 3239 million were announced for energy-efficiency measures for homes. The package included assistance for the installation of insulation in homes and a solar hot water rebate programme. In the United States, the American Recovery and Reinvestment Act (ARRA) contains a focus on the renewable energy sector through wind and solar energy. ARRA requires states to direct part of their stimulus funding to green investment, such as water and domestic renewable energy industry, R\&D, water quality improvement projects, storm water infrastructure and other innovative treatment technologies (Hanak, 2009). In Canada, green measures account for approximately $8 \%$ of the stimulus plan, with a particular focus on sustainable energy.

Source : OECD (2011a), Making the most of public investment in a tight fiscal environment: Multi-level governance lessons from the crisis, OECD, Paris.

Global environmental and climate threats influencing the push for green growth

15. The threat of climate change is a core driver behind the recent interest in green growth, but it is not the only reason why action is necessary. If no new policy actions are taken within the next few decades, society will have irreversibly altered the resource base required for sustained economic prosperity.

16. For example, as developed in the OECD Environmental Outlook to 2030 (OECD, 2009b), by 2030:

- Global emissions of greenhouse gases are projected to grow by a further $37 \%$, and $52 \%$ to 2050. This could result in an increase in global temperature over pre-industrial levels in the range of $1.7^{\circ}-2.4^{\circ}$ Celsius by 2050 , leading to increased heat waves, droughts, storms and floods, and causing severe damage to physical capital, including key infrastructure and crops. The estimated costs of these impacts vary widely, but may be as much as the equivalent of $14.4 \%$ of per capita consumption when all market and non-market impacts are taken into account (Stern, 2007).

- A considerable number of animal and plant species are likely to face extinction. Food and biofuel production together will require a $10 \%$ increase in farmland worldwide, furthering the loss of wildlife habitat. Continued loss of biodiversity is likely to limit the Earth's capacity to provide the valuable ecosystem services that support economic growth and human well-being.

- Water scarcity will worsen due to unsustainable use and management of water resources as well as climate change; the number of people living in areas affected by severe water stress is expected to increase by another 1 billion to over 3.9 billion.

- Health impacts of air pollution will increase worldwide, with the number of premature deaths linked to ground-level ozone quadrupling and those linked to particulate matter more than doubling. Other forms of pollution will also lead to increased degradation of land, drinking water supplies, and the oceans, putting vital fish stocks at risk. 
17. The greatest environmental impacts will be felt by developing countries, which are less equipped to manage and adapt to these changes. Delaying action on these issues will be costly regardless of location. The direct costs from climate change impacts are expected to be staggeringly high. For example, shoreline retreat in the United States is projected to cost between USD 270 billion to USD 475 billion per metre climb in sea level; analogous costs in developing nations can amount to one-third of annual GDP. Indirect impacts may cripple economic activity if transportation, commercial and industrial activities are interrupted due to severe weather events.

18. The economic impacts of climate change, environmental degradation, or unsustainable resource consumption can also have rebound effects in the job market and reduce tax revenue. These stresses on the economy may limit investment opportunities and deplete funds for infrastructure innovations, leaving countries even more vulnerable to future change. Economic loss will also come in the form of hidden costs, such as the costs of rerouting traffic around failed transportation infrastructure, lost productivity, provision of emergency and continued aid, relocation and retraining, lost heritage, and urban ecosystem damage. In addition, higher risk and uncertainty stemming from global climate change imposes additional costs on the insurance, banking, financing and investment industries.

19. Despite the fact that these threats are global in nature, they will ultimately manifest themselves as place-based phenomena, requiring very localised solutions. These solutions may derive from actions taken by governmental entities operating at different geographic scales, the private sector, the non-governmental organisation (NGO) community and individuals. Ideally, planning to address these threats will occur proactively, but because many environmental problems already exist as the legacy of past behaviour and policy and technology decisions, further delay in not an option.

\section{The search for a new development paradigm}

20. Following the recession, a window of opportunity has opened to reconsider sources of longterm, sustainable growth. The gains from growth, while distributed unevenly around the world, have been dramatic, leading to significant improvements in living conditions. However, there are serious questions about the ability of the current model for economic growth to foster long-term prosperity. The resilience of a wide range of environmental systems is now being tested by the requirements of a rapidly growing global population and increased levels of economic activity. This includes meeting the energy and food needs of 9 billion people (increasingly urban) in 2050. Water supplies are coming under increasing pressure, and without new policy action a further 1 billion people are expected to live in severe water-stressed areas by 2030 (OECD, 2011b). Thus the world faces twin challenges: expanding economic opportunities for a growing global population, and addressing environmental pressures that, if left untended, could undermine our ability to seize these opportunities.

21. As a new paradigm that promotes economic development while reducing environmental degradation and preserving natural resources, green growth provides an opportunity to rethink our economic development model. The traditional efficiency paradigm is giving way to a richer definition of societal progress, where efficiency, equity and environmental sustainability are closely interrelated. Traditionally, economic efficiency was seen as a goal separate from equity and environmental objectives. Economic policy was basically assigned the role of reaching the efficiency frontier or maximising growth rates. Governmental action addressing equity and environmental objectives was often designed to avoid interference with the search for efficiency. However, there is a growing uneasiness with this vision. Driven by the climate change debate, public opinion is increasingly questioning the sustainability of our development model and its replication in the developing world. The persistent and growing development gaps, both across and within nations, also lead to questions 
about the assumed separation between efficiency and equity objectives, notably in the context of a globalised world.

22. The debate is still open. Some see green growth as a new industrial revolution. According to Rifkin (2011), we are experiencing a new economic paradigm, with a systematic change in the way we organise economic life, moving beyond carbon and nuclear energy. As the price of oil on global markets continues to climb and peak global oil is within sight in the coming decades, he believes that "we are on a the cusp of a Third Industrial Revolution in which internet technologies and renewable energies merge to create a powerful, new energy infrastructure." This new system would bring a shift from fossil fuel energy systems based on vertical economies of scale and giant, centralised enterprises to a decentralised management system based on renewable energies made of a large number of actors (e.g. small and large firms) who would function in networks more like eco-systems than markets. This vision endorses the fact that green growth will a diffuse wide phenomenon contrary to the ICT, electricity, steam or railway revolution. This Third Industrial Revolution will require a wholesale reconfiguration of the transport, construction and electricity sectors, creating new goods and services, spawning new businesses and providing millions of new jobs whereby cities and regions would function in a collaborative network with other institutions and actors (Rifkin, 2011).

\subsection{Defining green growth as a blend of ideas}

23. To arrive at a comprehensive definition of green growth, it is useful to begin by parsing the phrase "green growth".

What is "green"?

24. "Green" is often used as a catchall term referring to resource protection and practices which emphasise certain core concepts, such as resource efficiency (notably balancing consumption with nature's ability to replenish these resources) and the need to protect the natural systems upon which humans and other species depend (Carley et al., 2011). Green is also used to refer generically to certain policy topics or business sectors, including activities and technology associated with the movement of people and goods; waste management and recycling; pollution prevention, treatment, or abatement; energy that is clean or efficiently produced and consumed; the design, construction, maintenance, and dismantling of buildings; resource extraction; agriculture/gardening; natural resource management (e.g. air, water, land/open space, forests/other ecosystems, fisheries) and other environmental services (e.g. planning, engineering, monitoring, financing, education).

25. Some suggest that green practices, technology and systems should be differentiated from "brown" practices, technology and systems, which result in ecosystem degradation and imbalances in resource use, ultimately producing deleterious outcomes for humans and other species. In practice, however, the line between "green" and "brown" is a relative and dynamic concept (MartinezFernandez et al., 2010). What is seen as green today may not be considered green tomorrow, as tastes, technology or our knowledge of what constitutes acceptable levels of pollution or optimal levels of resource use begin to change. Moreover, brown industries can become greener, as more efficient materials and production processes are adopted. Chapple (2008), for instance, defines the green economy in broad terms as "economic activity that preserves and enhances environmental quality while using natural resources more efficiently" (Box 2). 


\section{Box 2. The green sector}

Chapple (2008) developed a framework for undestanding the "green sector", which encompasses activities focused on reducing energy use and/or improving environmental quality. The map below organises the green economy along two axes:

- The vertical axis ranges from traditional ("brown") businesses operating in a less polluting or resource intensive manner to businesses in emerging green industries or services sectors for which the core business focus is on pollution abatement or remediation, green power production, green project finance, etc.

- $\quad$ Along the horizontal axis, businesses range from those that produce green products to those producing green services. While the output of industrial firms can be imported or exported, lifestyle-focused businesses tend to only serve local markets. This is an important distinction that sub-national regions pursuing green growth must weigh when crafting their growth strategies.

The shading in each box refers to how frequently the sector was referenced in a review of 25 different reports discussing the green economy; the darkest shades represents those sectors most commonly mentioned in the literature. At the bottom of the schematic are important institutions whose activities in some way influence the actions of different elements of the green economy.

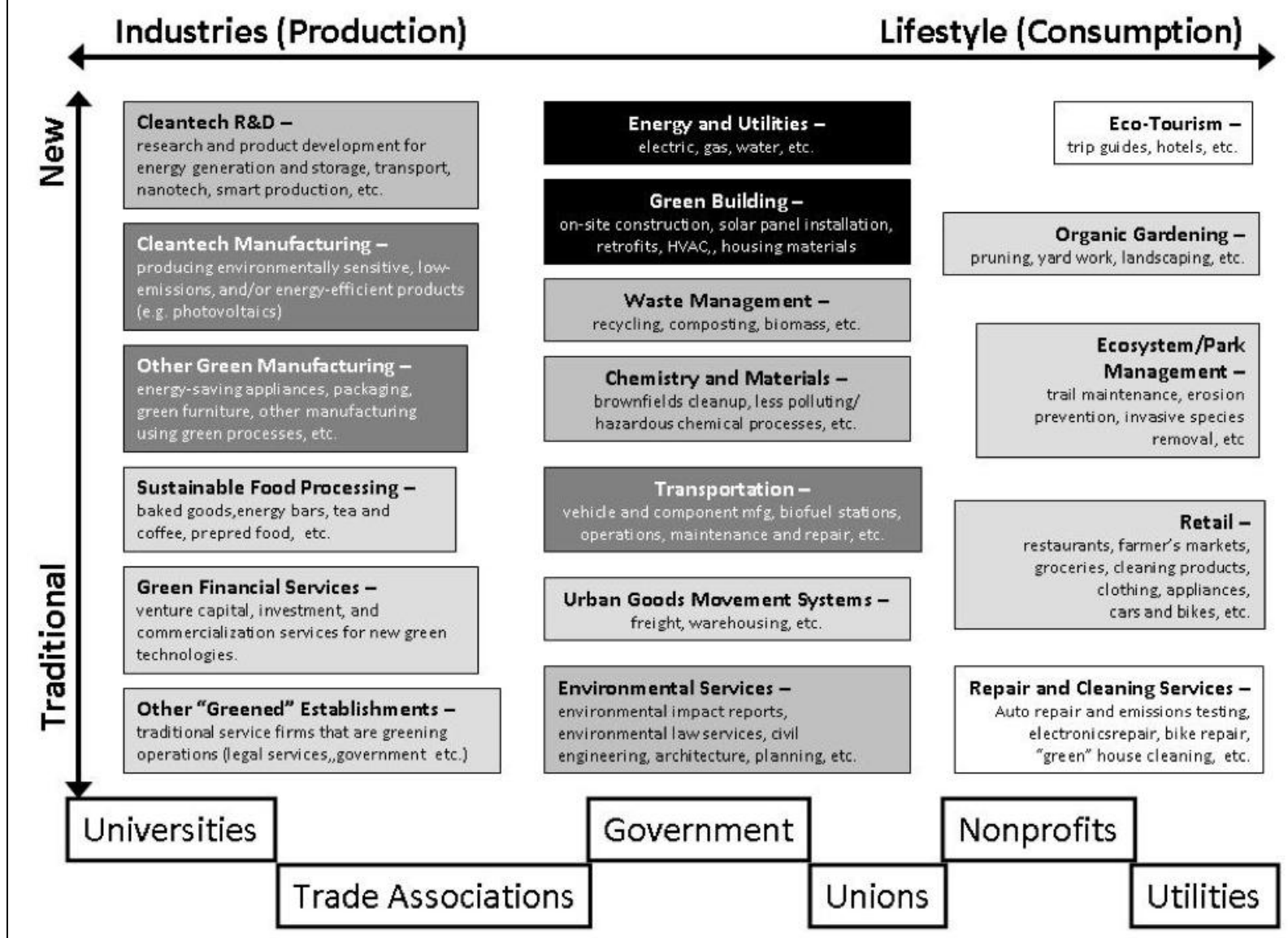

Source : Chapple (2008), "Defining the Green Economy: A Primer on Green Economic Development”, UC Berkeley Center for Community Innovation, Berkeley. 
What is "growth"?

26. "Growth" is a similarly complex concept. From an economic perspective, growth implies wealth creation, as measured by gross domestic product (GDP) or some other metric that can be used to compare changes in the level of economic vitality in a region over time. There are, of course, many indicators beyond GDP per capita or GDP per worker one can potentially employ to gauge the financial implications of different green policies and initiatives. Many of these tend to be location- or user-specific, which can make it challenging to ascertain whether the total value of impacts has been captured. These indicators could include:

\section{Direct economic impacts:}

- $\quad$ Changes in input use resulting in altered costs. Entities or individuals may opt to use fewer or different input materials (e.g. energy, water, other raw materials) in the production of goods or services. This change, which is designed to achieve some environmental improvement, may either increase or decrease the costs associated with producing the good or service.

- Change in waste/pollution output levels resulting in altered costs. A parallel change is one whereby individuals or entities reduce the wastes involved in producing goods or services. Depending on how waste collection or disposal services are priced, there may or may not be any cost savings resulting from these changes.

- Change in asset values of individual properties or areas attributable to environmental initiatives. Some green policies and programmes will affect the value of real estate or other assets, such as green building upgrades that will increase the value of an individual property or the development of transit infrastructure, green belts, or water way improvements that can affect the asset value of a large number of nearby properties.

\section{Indirect economic impacts:}

- Improved local attractiveness due to changed environmental quality or amenities. A less clear-cut financial impact will involve changes in the attractiveness of a location as a result of changes in local air quality, tree cover, etc. For instance, city attractiveness can influence both personal and business relocation or expansion decisions, although the link to specific green policy or programme initiatives may be tangential and/or difficult to assess.

- Public health. Changes in pollution or emission levels or other policies/programmes that enhance public safety or health may influence health care expenditures or otherwise improve employee productivity because of reduced absenteeism due to illness.

- Improved individual utility due to living in a green city or participation in green activities. Individuals or businesses located in a green city might enjoy some reputational benefits that accrue from their location, although again such impacts may be difficult to quantify. Individuals can also enjoy increased personal utility or self-worth if they engage in certain green behaviours (Cohen, 2005). 
27. While debates about whether GDP is still a useful approximation of material well-being are ongoing, ${ }^{5}$ it remains nevetheless the dominant measure of growth. OECD work on going "beyond GDP" to measure societal progress will be discussed further in Section 3.3.

28. Further, Carley et al. (2011) suggest that it is important to differentiate economic growth from economic development, noting the latter adds qualitative or value-laden elements to an otherwise wholly quantitative metric. In this narrative, development efforts focus on catalysing specific industry sectors or improving other factors that help create a more robust economy, including the overall business climate or quality of life for that region. It is the deliberateness of the effort to shape the growth in a certain direction that sets economic development efforts apart from the more abstract, and undirected, notion of economic growth. A similar distinction is made by Chapple (2008), characterising growth as a change in output while development is "qualitative, structure change that can help foster innovation and improve productivity."

29. Finally, green growth is not another name for sustainable development. Green growth emphasises the inter-relatedness of economic and environmental concerns. Thus, green growth policies aim to identify the complementarities between economic and environmental challenges in a way that highlights the opportunities for new sources of economic growth. As green growth focuses on two of the three pillars of sustainable development, ${ }^{6}$ it is a component of sustainable development, not a synonym for it. That is not to say that green growth ignores social equity issues. It has been demonstrated that some green growth initiatives can provide social equity co-benefits; many policymakers are also keen to ensure that the most vulnerable workers are not left out in the transition to a greener economy. Figure 1 depicts the three pillars of sustainable development, which operate primarily on the economy-environment axis, but simultaneously seek to deliver social equity cobenefits where possible.

Figure 1. Green growth and sustainable development

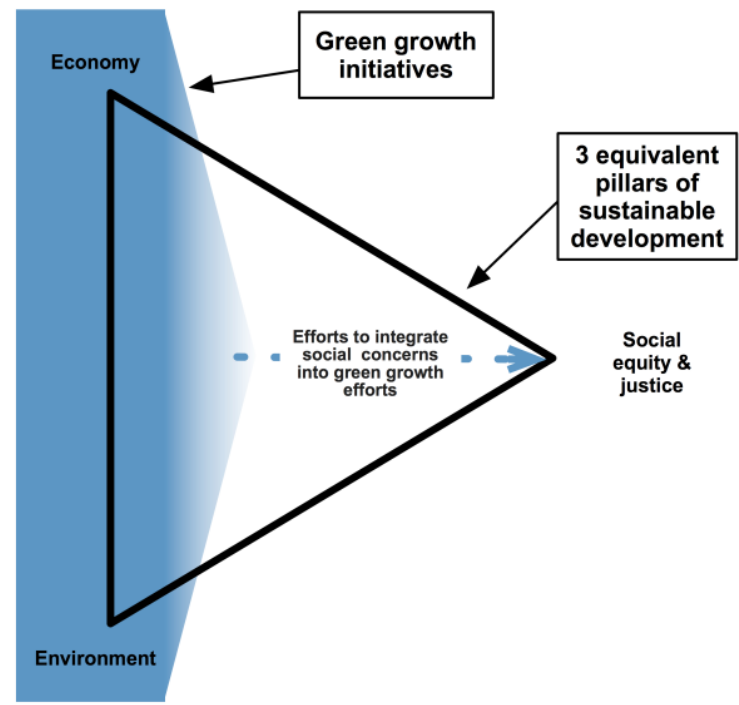

5. See, for instance Stiglitz, Sen and Fitoussi (2009) and Jackson (2009).

6. Sustainable development, which was defined in the 1987 Brundtland report and given formal recognition by governments in the 1992 Rio Declaration, reflects an aspiration to amend the undesirable social and environmental by-products of conventional modes of economic growth. 


\subsection{The logic of city scale action}

\section{The unique economic role of cities}

Discussions about growth must include a focus on the economies of cities, and what types of circumstances can be exploited to foster urban growth. Economic growth does not occur in the abstract; it is a place-based phenomenon, and to a large extent, it is a phenomenon that takes place in regions, with under certain conditions a particular advantage of urban areas (OECD, 2010b and OECD, 2009c). Cities are critical drivers of national and aggregate growth. The contribution to aggregate growth of just the $2 \%$ of "hub" regions - mainly composed of the largest OECD urban areas - is approximately one-third. Urban areas also feature higher income and productivity (Figure 2). The pooled labour market that occurs naturally in urban areas increases the possibility of skills-matching between workers and firms. Firms similarly agglomerate, seeking to reduce risks of contract defaulting, and benefiting from the fact that cities give them access to a wider set of skilled workers and larger numbers of suppliers and buyers. Such agglomeration effects are fuelled by higher wages due to higher productivity that in turn attracts more workers so that centripetal forces are set in motion. As centres of innovation, a critical component for the success of a green growth agenda, cities account for a disproportionately strong share of a country's GDP per capita, lifting not only the city but also the wider regional area. In many OECD countries, more than $40 \%$ of the national GDP is produced by less than $10 \%$ of all regions (OECD, 2011c) (Figure 3).

Figure 2. Urbanisation and income

Share of total population in predominantly urban regions and per capita GDP in OECD countries

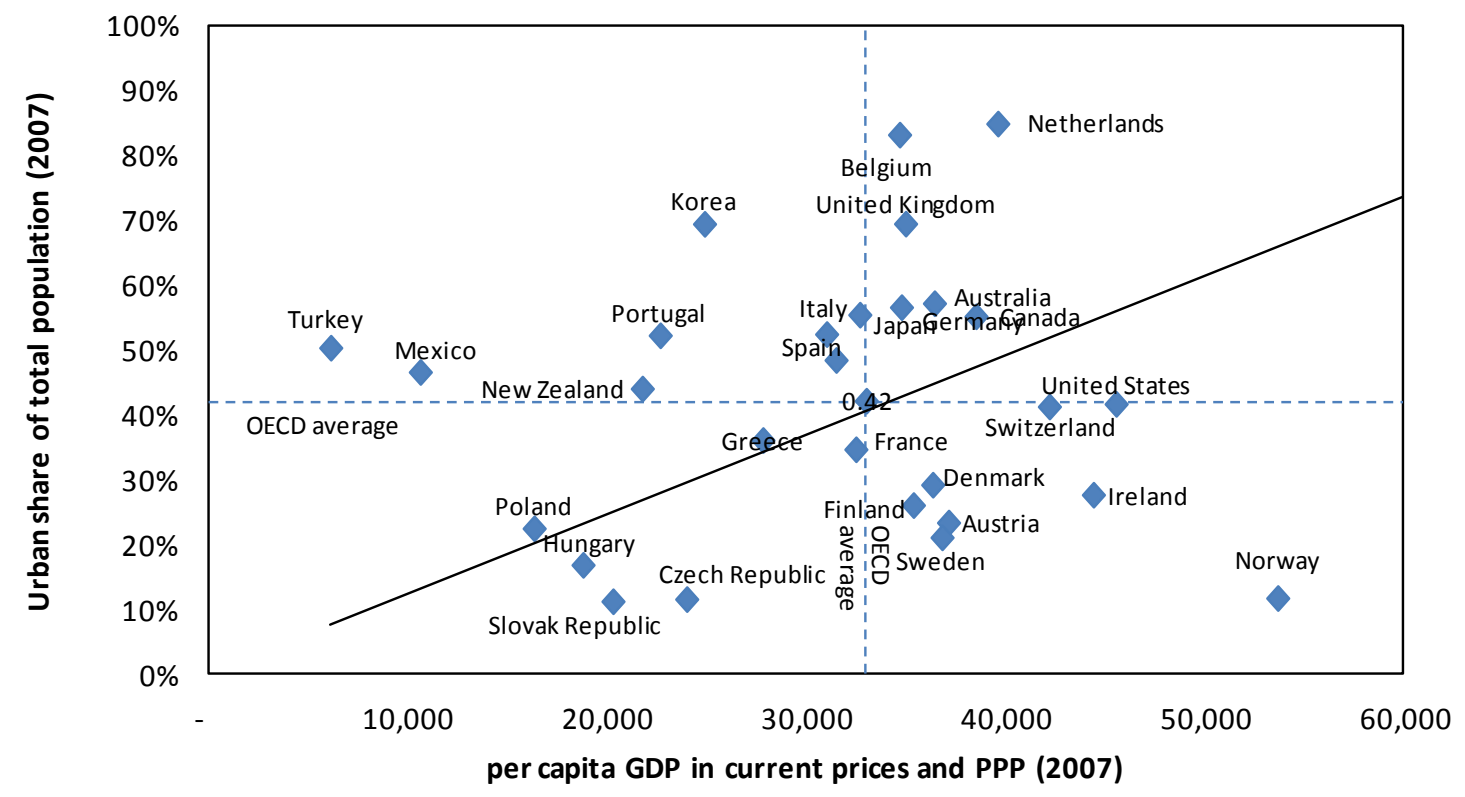

Notes: Urban share of total population by country refers to population in predominantly urban regions as a proportion of total population. Iceland and Luxemburg were not included in the sample as the OECD Regional Database does not identify predominantly urban regions in those countries. Switzerland was not included as GDP figures at sub-national level in that country are not available. Mexico's per capita GDP data refer to 2004; New Zealand's per capita GDP data refer to 2003; Turkey's per capita GDP data refer to 2001. PPP is purchasing power parity.

Source: Own calculations based on data from the OECD Regional Database. 
Figure 3. Percent of national GDP in the $10 \%$ TL3 regions with the largest GDP

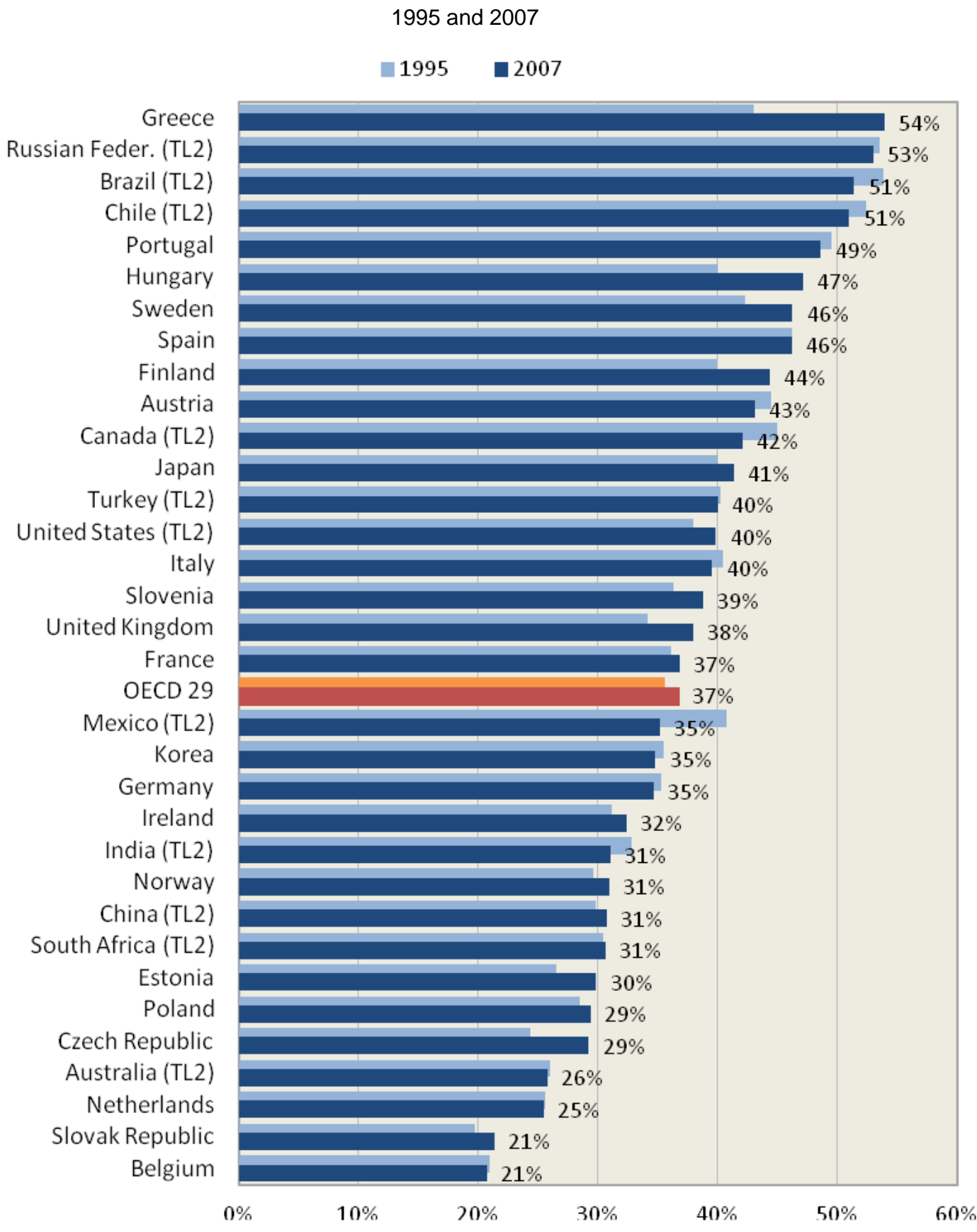

Source: OECD (2011c), Regions at Glance, OECD, Paris.

\section{Cities burdened by externalities}

30. The benefits associated with agglomeration economies are not, however, without limits. Negative externalities including congestion, air and water pollution, and the loss of ecosystems on which the city depends, can, in some cases, reach a point where the metropolitan area becomes less 
competitive (OECD, 2006a). These negative attributes are not internalised by firms and households, and may only show up as direct costs in the long term. They include, for instance: high transportation costs (i.e. congested streets) and loss of productivity due to long commuting times; higher health costs; and environmental degradation. Negative externalities are also associated with a city's historical decisions about how the city should grow. In many OECD countries, growth in metropolitan areas has generally taken the form of an expansion of developed areas through suburbanisation. Overall, urban land area in the OECD has doubled in the second half of last century, and in the vast majority of OECD metropolitan regions, the suburban belt has grown faster than the core (Figures 4 and 5).

Figure 4. Incremental increases of urban areas

$1950-2010$

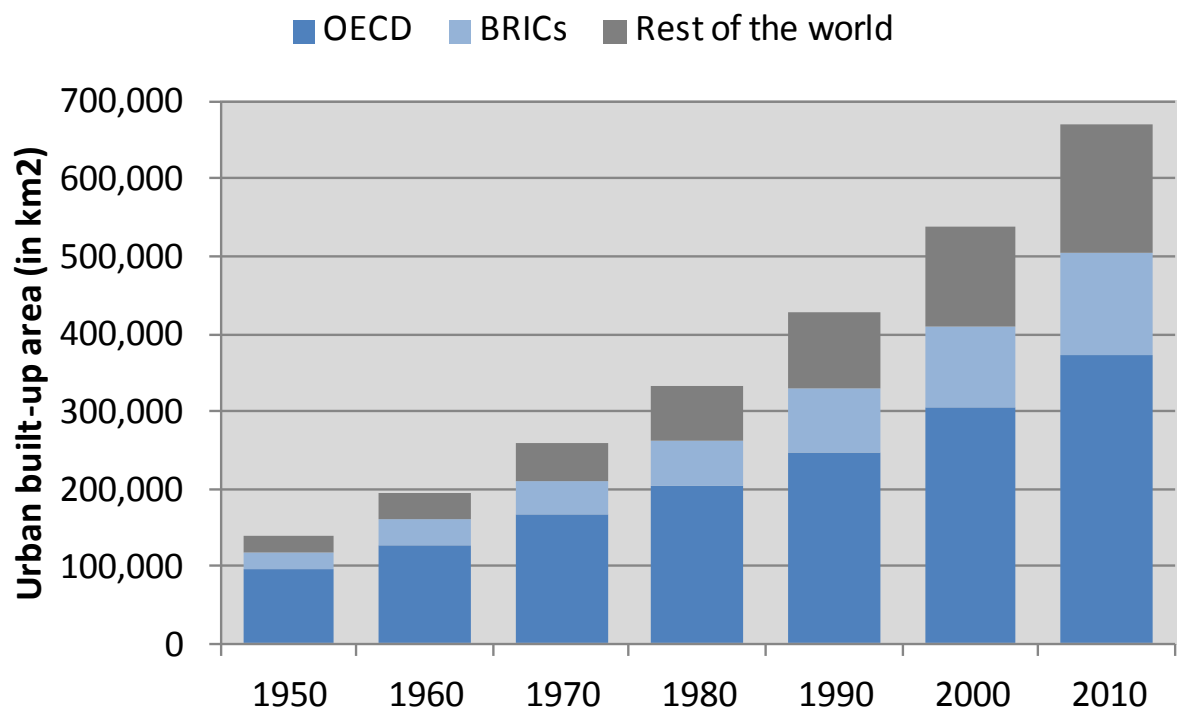

Source: Own calculations based on data from Goldewijk, K, et al. (2010), "Long term dynamic modelling of global population and built-up area in a spatially explicit way", The Holocene 20(4): 565-573. 
Figure 5. The suburbanisation process in OECD metropolitan regions

Annual average total population growth rate (1995-2008)

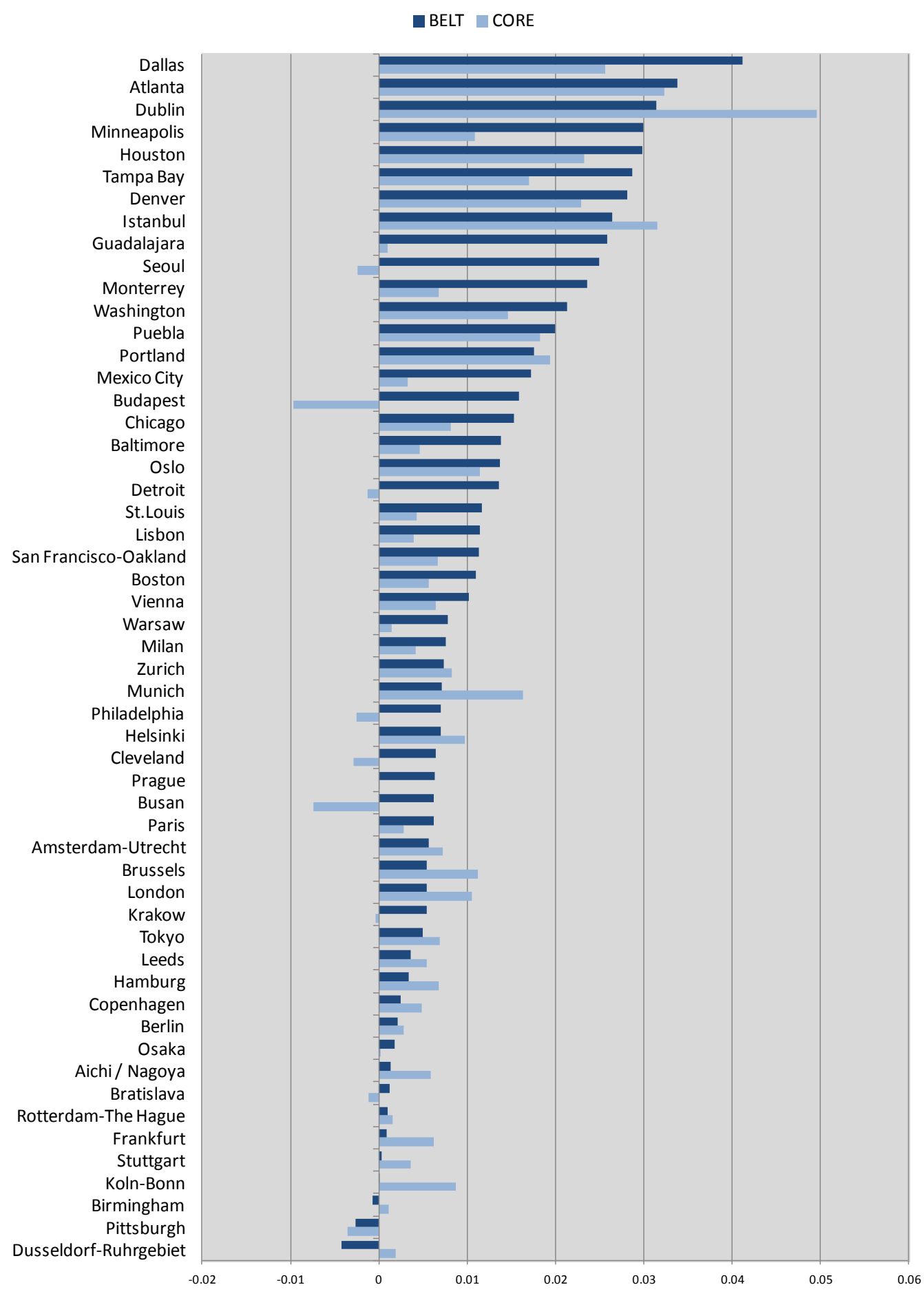

Source: OECD Metropolitan Database. 
31. The urban form is one of several critical factors influencing energy demand and greenhouse gas emission levels. Figure 6 reveals an interesting trend displaying high environment pressure (e.g. highest emissions per capita) that can only occur in low densely populated urban areas (A) and not in high densely populated urban areas (C). While there are a number of low densely populated urban areas with low environmental pressure (B), there are no densely populated urban regions with high emissions per capita. This means the probability of high emissions per capita is indeed much higher in low densely populated areas. Therefore, the urban form of cities is not a necessary condition to attaining lower per capita emissions, but a critical factor among several others, such as energy prices, the productive structure of urban areas or the public transportation networks. As urban areas become denser and rely more on public transport, walking and cycling, carbon emissions tend to be reduced. Therefore there are no densely populated urban regions with high per capita emissions.

Figure 6. $\mathrm{CO}_{2}$ emissions per capita in transport and density in predominantly urban areas

$2005-2006$

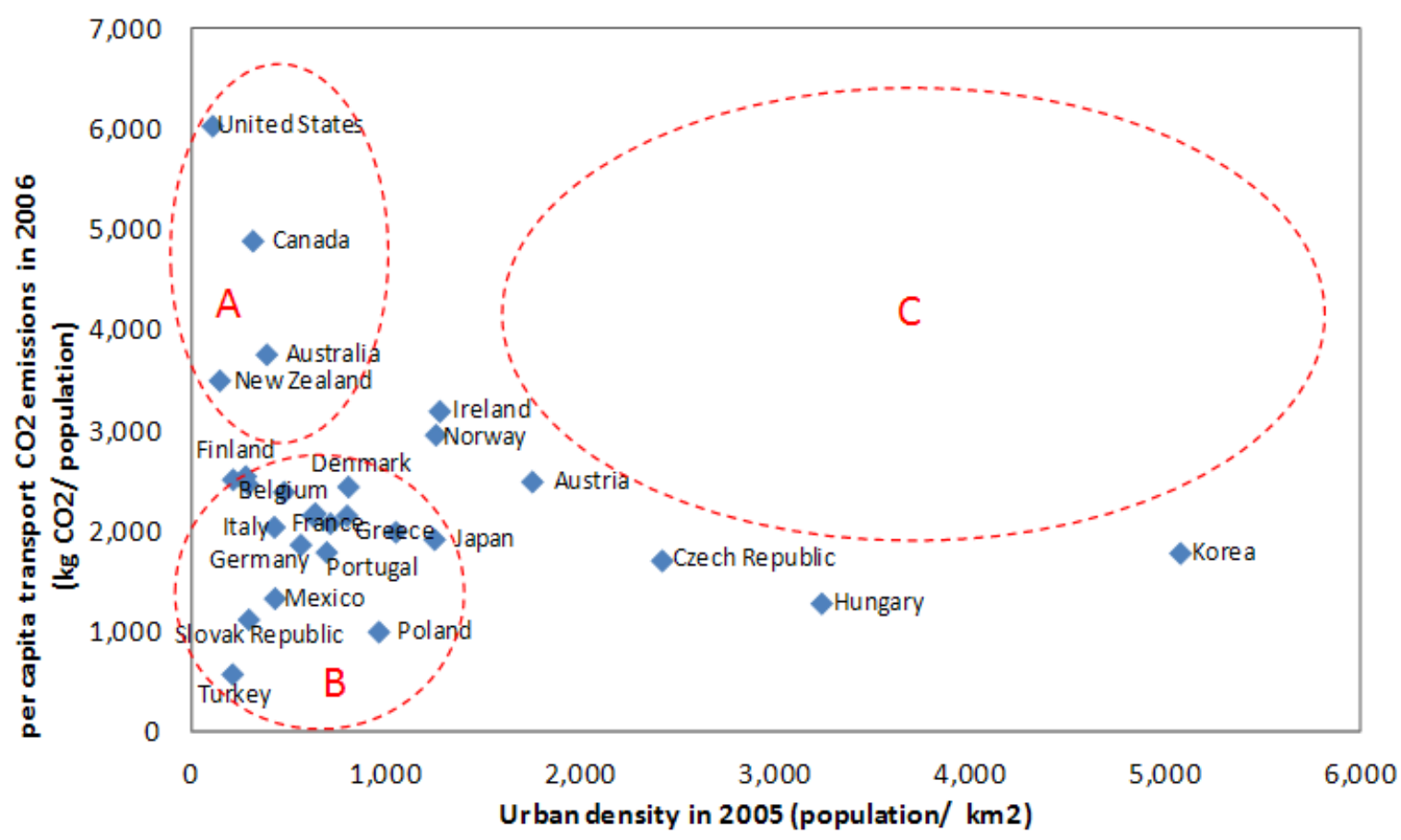

Notes:

$A=$ Low-density urban areas with high emissions $/ B=$ Low-density urban areas with low emissions $/ C=$ Densely populated urban areas with high emissions.

Urban density is calculated based on the OECD definition of "predominantly urban" areas.

Iceland and Luxemburg were not included in the sample as OECD Regional Statistics (database) identifies no predominantly urban (PU) regions in those countries.

Source: Calculations based on data from OECD Regional Statistics (database); International Energy Agency (2008a), $\mathrm{CO}_{2}$ Emissions from Fuel Combustion, OECD/IEA, Paris, http://dx.doi.org/10.1787/co2 fuel-2008-en-fr, and International Energy Agency (2009a), Energy Balances of OECD Countries, OECD/IEA, Paris http://dx.doi.org/10.1787/energy bal oecd-2009-en-fr.

32. Similar findings can be drawn in the electricity sector (Figure 7). For instance, Japan's urban areas are around five times denser than Canada's, and the consumption of electricity per person in Japan's urban areas is around 40\% that of Canada's. Denmark's urban areas are denser than 
Finland's by a factor of four, and people there only consume around $40 \%$ of the electricity consumed by the Finns. However, urban areas in Turkey, Mexico and the Slovak Republic have low levels of both urban density and per capita energy consumption. ${ }^{7}$

Figure 7. Electricity consumption per capita and density in predominantly urban areas

$2005-2006$

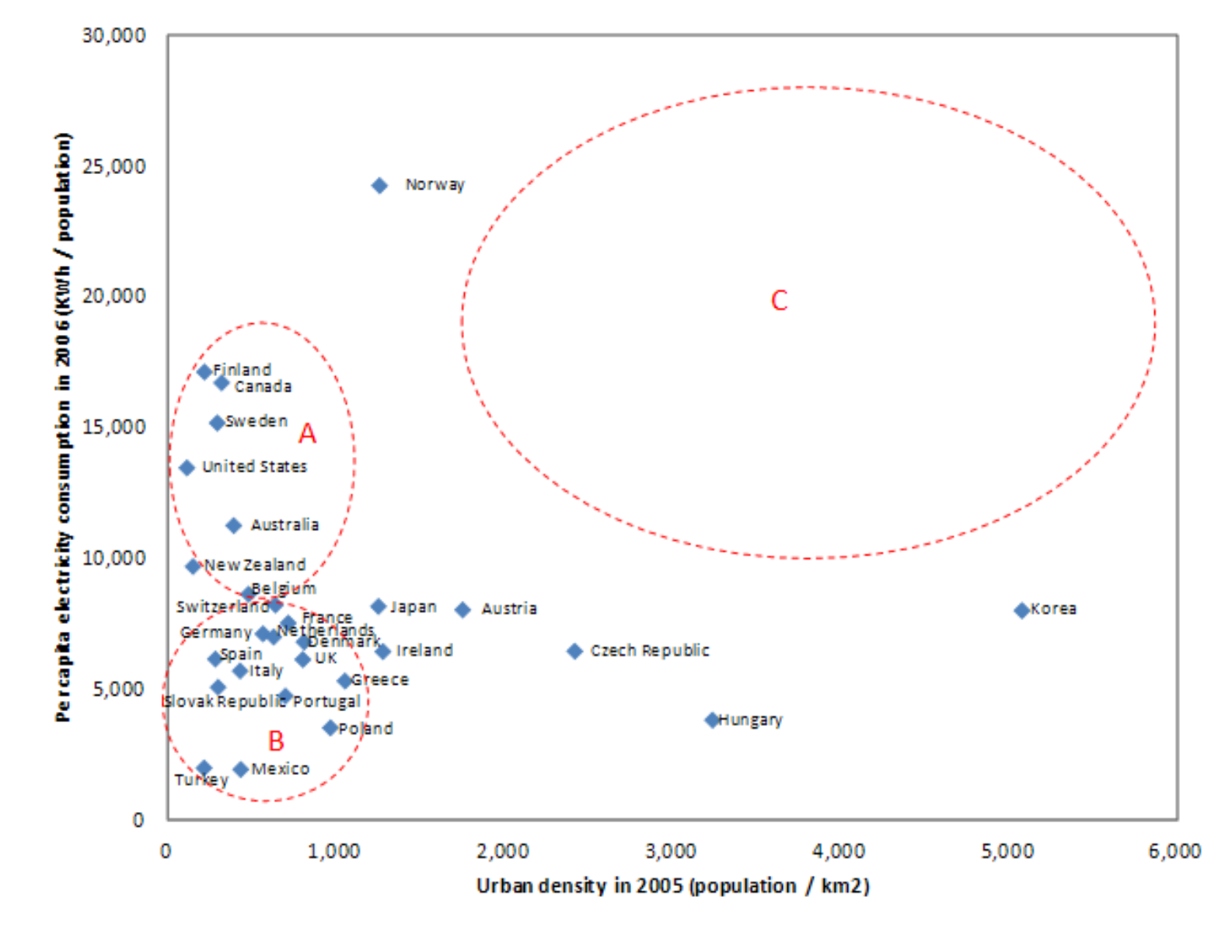

Notes:

$A$ = Low-density urban areas with high electricity consumption / B = Low-density urban areas with low electricity consumption / $\mathrm{C}=$ Densely populated urban areas with high electricity consumption

Urban density is calculated based on the OECD definition of "predominantly urban" areas.

Iceland and Luxemburg were not included in the sample as OECD Regional Statistics (database) identifies no predominantly urban (PU) regions in those countries.

Source: Calculations based on data from OECD Regional Statistics (database); International Energy Agency (2008a), $\mathrm{CO}_{2}$ Emissions from Fuel Combustion, OECD/IEA, Paris, http://dx.doi.org/10.1787/co2 fuel-2008-en-fr, and International Energy Agency (2009a), Energy Balances of OECD Countries, OECD/IEA, Paris, http://dx.doi.org/10.1787/energy bal oecd-2009-en-fr.

7. This is mainly explained by the lower level of economic development and consumption per capita. 


\section{How cities contribute to climate change}

33. The contributions that cities are collectively making to global climate change may come back to haunt them, undermining public health and the key urban infrastructure systems that are fundamental to their long-term competitiveness. The negative externalities associated with urban areas can extend far beyond a city's boundaries. Collectively, cities account for almost two-thirds of the world's energy demand and $\mathrm{CO}_{2}$ emissions (IEA, 2008b). The ecological footprint - the total area required to provide environmental goods and services for a specific region-is particularly severe in cities (Figure 8). For example, London's footprint was found to be 125 times the size of the city and twice the land size of Great Britain (Wackernagel, 2006; London Remade, 2007). Land consumption by sprawled urban development has impacts not only within the built-up area but also for considerable distances around it in terms of how land surfaces are reshaped, with valleys and swamps being filled, large volumes of clay and rock being extracted, and sometimes rivers and streams rechanneled. This increases stress on ecosystems and species (OECD, 2008a). We may be running out of land for agriculture, watershed sustainability and recreation, as urban sprawl takes place at the expense of agricultural land, forest, open space or wetland, with a concomitant loss in the economic, recreational and ecological values that those ecosystems provided (OECD, 2008a). To ensure food security and bio diversity, it is crucial to protect green-fields from urban sprawl.

Figure 8. The ecological footprint is highest in urban areas

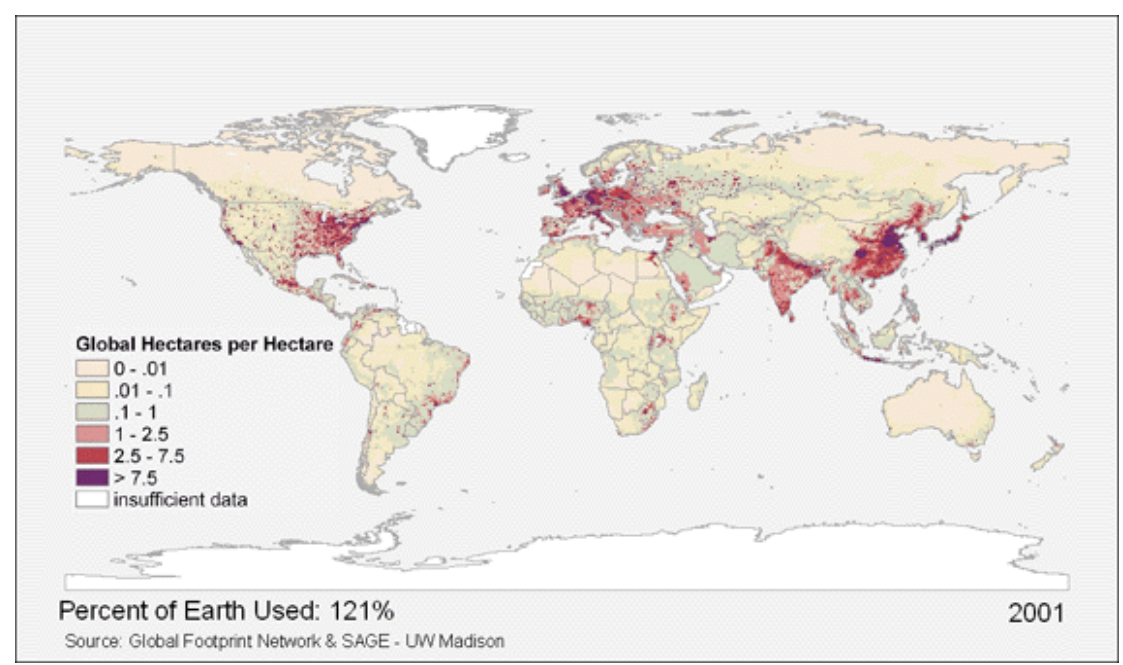

Source: www.footprintstandards.org.

\section{Vulnerabilities to environmental related calamities and climate change}

34. Cities are especially vulnerable to water-related calamities and the effects of climate change. OECD work demonstrates that a $50 \mathrm{~cm}$ sea-level rise, combined with predicted socio-economic development patterns, could result by 2070 in a tripling of the population at risk of coastal flooding and a tenfold increase in the amount of assets exposed, rising from 5\% of global GDP in 2008 to $9 \%$ of GDP in 2070. Port cities most at risk for coastal flooding are located both in rapidly growing developing countries such as India and China (e.g. Kolkata, Shanghai, Guangzhou) and in wealthy countries such as the United States (e.g. Miami, New York City), the Netherlands (e.g. Rotterdam, Amsterdam) and Japan (e.g. Tokyo, Osaka) (Nicholls, et al., 2008). The increasing frequency of severe weather events, combined with sea-level rise, can cause sanitation problems if urban 
infrastructure is ill equipped to accommodate a sudden influx of water. Climate change may also intensify competition for water as cities generally rely on their immediate surroundings for water. Finally, climate change is likely to increase both the severity and duration of heat waves, which will be felt more strongly in urban areas, due to the "urban heat island" suspected of warming urban areas $3.5^{\circ}-4.5^{\circ} \mathrm{C}$ more than surrounding rural areas. Rising temperatures - particularly during the warm weather months - can also impose significant stress on the local energy system, increasing the risk of blackouts, which threaten both the local economy and public health.

\section{Opportunities for synergies and complementarities}

35. Complementarities and synergies between environmental and economic objectives are at the heart of the ongoing green growth debate, and they are particularly strong in cities. Policies that only focus on one element of the system, or one sector, are unlikely to be effective in enhancing overall performance. Shifting towards a more systemic or horizontal approach is far from simple, but holds the promise of greater coherence and better performance. Many cities have developed comprehensive sustainability plans for exactly that reason, seeking to capitalise on the greening synergies and complementarities offered by a wide-ranging plan.

36. Policies that respond to the negative effects of urban agglomeration address both environmental and economic growth priorities. Congestion, pollution and public services constraints affect not just environmental quality but also the efficiency of local economic activities and a city's ability to attract firms and skilled workers. Policies that reduce energy and resource consumption and waste, and increase the attractiveness of the urban environment can thus also support urban economic growth. Findings from a general equilibrium model of OECD metropolitan regions demonstrate that urban density policies and congestion charges can reduce the overall cost to the economy of meeting greenhouse emissions reduction targets (OECD, 2010c). ${ }^{8}$

37. Using a projection model (IMACLIM), OECD (2010c) shows that over the long run improving environmental quality in cities (through curbing local pollution) can strengthen their economic attractiveness. Previous studies define city attractiveness as the appeal for firms of carrying out activities in a particular urban area (Berg and Braun, 1999). This in turn depends on the size of the production the firms may achieve in one location relative to that of others. In the projection model, urban attractiveness is the result of four different factors: expectations over production volume,; capital returns,; market size,; and local environmental conditions. The first three indicators are positively correlated with attractiveness. The modelling exercise shows that the attractiveness of the 78 metropolitan regions included in the OECD metropolitan database is strongly positively correlated to firms' expectations about production and reflected in the average production growth rate (Figure 9).

8. This modelling exercise was developed by Fabio Grazi and Henri Waisman (CIRED) and carried out by employing the spatialised version of the IMACLIM-R CGE model (Crassous et al., 2006). IMACLIM-R allows for simulation of simulating the interactions between changes in energy consumption, carbon emissions and economic growth, given a set of policies and other exogenous factors. In this model, carbon emissions are reduced relative to the baseline following the implementation of densification policies and congestion charges, a form of road toll of the type already implemented in some metropolitan regions (London and Stockholm among others). While densification and congestion charges are not the only effective tools to reduce energy demand and carbon emissions, they are important, as they do not have a detrimental effect on long-term economic growth, when innovation is taken into account. 
Figure 9. Change in economic attractiveness and growth across OECD metropolitan regions

$2001-2030$

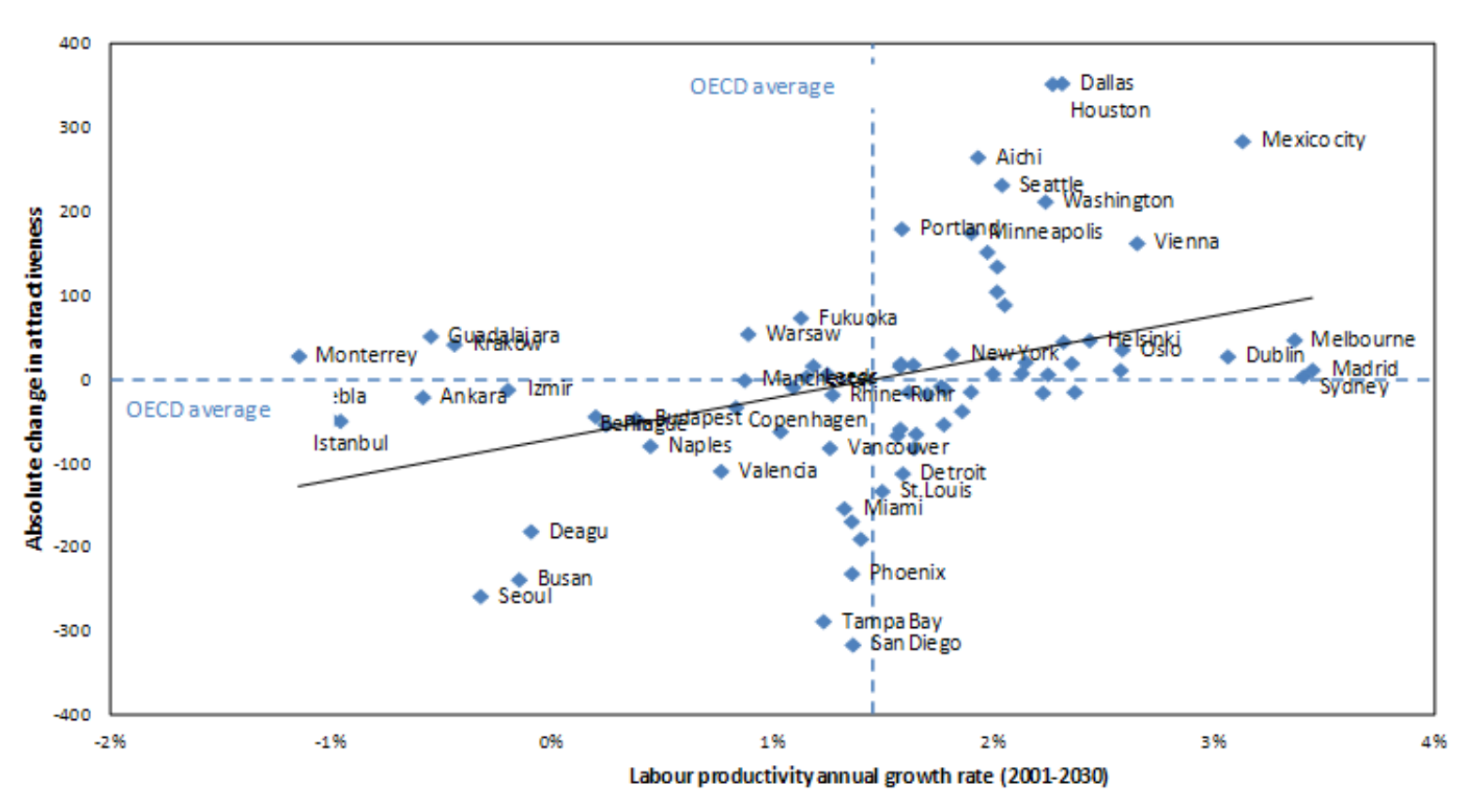

Source: OECD (2010c), Cities and Climate Change, OECD Publishing, http://dx.doi.org/10.1787/9789264091375-en.

38. In this model, local pollution also drives attractiveness. Workers are willing to tolerate the negative externalities that pollution represent if properly compensated by firms in their wages. Higher pollution levels would likely undermine attractiveness of a metropolitan region. The model is able to show that in the next two decades, pollution emission growth rates will affect attractiveness of a number of metropolitan regions in the OECD (Figure 10). The pollution-attractiveness relationship also provides justification for the implementation of local policies aimed at reducing carbon emissions not only for environmental, but also for economic efficiency reasons. 
Figure 10. Change in economic attractiveness and pollution emission across OECD metropolitan regions

$2001-2030$

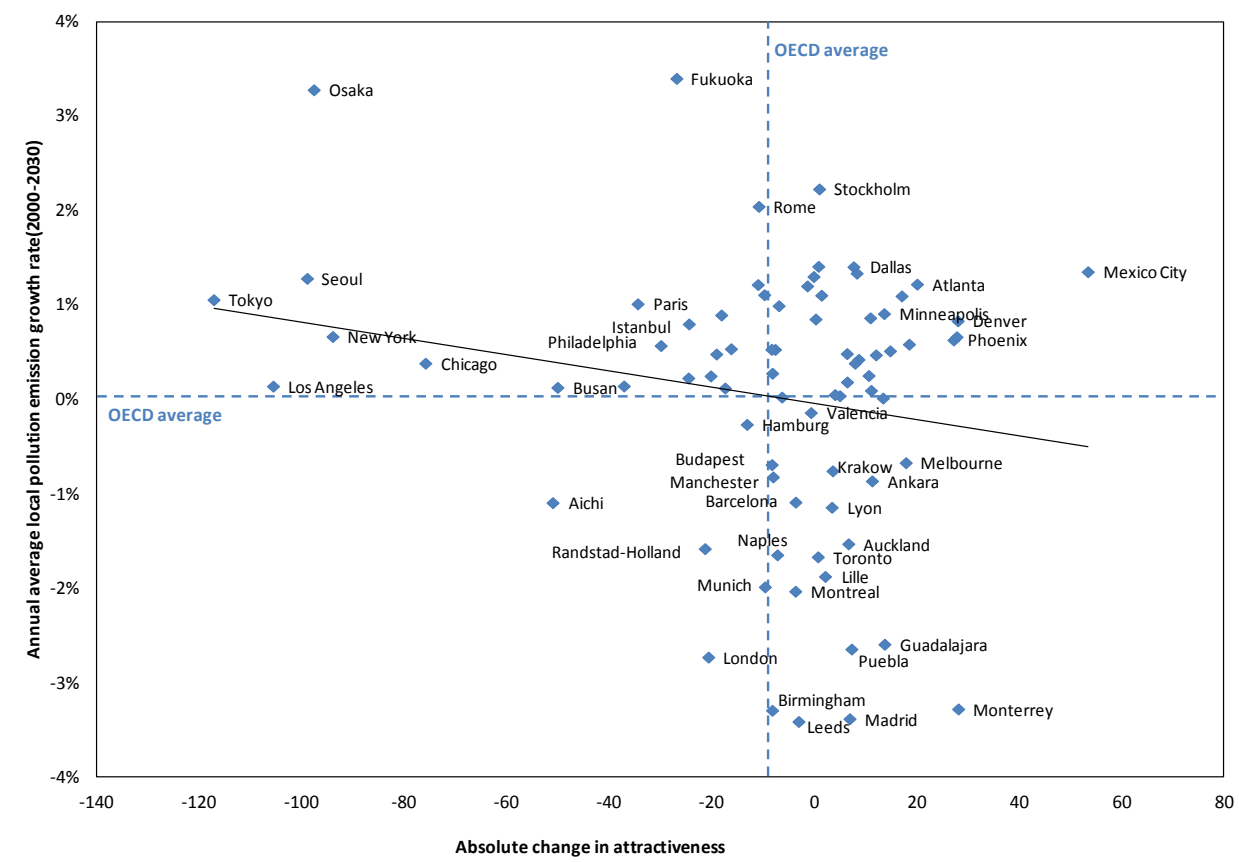

Source: OECD (2010c), Cities and Climate Change, OECD Publishing, http://dx.doi.org/10.1787/9789264091375-en

\section{How do cities approach green growth?}

39. An increasing number of cities have begun to mainstream environmental sustainability considerations into strategic policy making. While green growth is an explicit policy ambition in just a handful of city plans, many local policymakers place environmental issues as a key element of their strategic plans. New York's 30-year Strategic Plan, PlaNYC, cites "an increasingly precarious environment" as one of the top three challenges faced by the city (New York City Council, 2007). Vancouver adopted environmental sustainability in its forthcoming economic strategy as one of the six guiding principles (Vancouver City Council, 2006). Sydney developed Sustainable Sydney 2030 to guide the city's long-term development in the coming decades (Sydney City Council, 2008).

40. In most plans, environmental sustainability is most often addressed in terms of responding to the threats of climate change and/or promoting low-carbon development. Cities understand climate change as a global challenge with local consequences. They also recognise their increasing role in the international community to contribute to the solution. The C40 Cities Climate Leadership Group (C40) climate change action plans have thus far gathered 19 participating cities (e.g. New York, Hong Kong, London, Paris, Seoul, Tokyo, etc.) and ten affiliated cities (e.g. Copenhagen, San Francisco, Yokohama, etc.), all of which have significant global importance in terms of their current environmental footprint (C40, n.d. (a)). The issue is particularly acute in coastal cities, in which a large share of the population and assets are vulnerable to climate change impacts. Port cities most at risk for coastal flooding are located both in rapidly growing developing countries, such as India and China (e.g. Kolkata, Shanghai, Guangzhou) and in wealthy of countries, such as the United States (e.g. 
Miami, New York City), the Netherlands (e.g. Rotterdam, Amsterdam) and Japan (e.g. Tokyo, Osaka) (Nicholls et al., 2008). In its master plan, New York indicates that the city is already feeling the effects of climate change in terms of rising water levels and intensified storms along the Atlantic seaboard (City of New York, 2007). In the case of Rotterdam, the city's coastal location was a key motivating factor behind the development of the Rotterdam Climate Initiative.

41. Nevertheless, most strategic plans also address a diverse range of environmental issues, including energy, water, waste, air quality, biodiversity and ecosystem protection, emphasising the need to protect the long-term viability of the city by enhancing its attractiveness. Challenges, and priorities, differ by city. Air quality is a top concern in New York's plan, asmuch of the metropolitan area has yet to meet federal air quality standards for ozone and soot, and its citizens suffer from one of the worst asthma rates in the United States (City of New York, 2007). Vancouver, considered an environmental champion, continues to stress the importance of addressing public health challenges, such as providing clean water, clean air and reducing carbon footprint in local food production (Vancouver City Council, 2009).

42. The term "green" has been adopted in many of these plans, and is often used as a synonym for environmental sustainability. Underlying the green ambition is a desire to preserve and promote efficient use of natural assets, thus ensuring that a high quality of lifeis maintained over the long term. Seoul's Master Plan for Low-carbon Green Growth defines green as "attaining economic growth while minimising the burden on the ecosystem" (C40, n.d. (b)), while Chicago extends the definition to apply to "activities that respond to resource scarcity issues associated primarily with energy, water supply, and climate change" (Chicago Metropolitan Agency for Planning, 2010). The Green Infrastructure Strategy of Leeds (UK) seeks to leverage natural assets as a means to improve environmental performance, economic vitality, and enhance environmental health of the city region (Leeds City Region Partnership, 2010). The term green has also permeated the recent spatial plans of Hong Kong, New York, and Los Angeles (C40, n.d. (a)). Vancouver's plan is billed as an "Action Plan for Becoming the World's Greenest City by 2020" (Vancouver City Council, 2009).

43. A handful of cities have gone further, introducing the concept of green growth to explore opportunities for new sources of growth. Some strategies seek to increase competitiveness by investing in low-carbon technology or renewable energy. Seoul plans to pursue a comprehensive green innovation strategy that will green the building, urban planning and transportation sectors, and by 2030 become a world leader in green competitiveness (C40, n.d. (b)). Vancouver seeks to create lowcarbon economic development zones to serve as magnets for the low-carbon businesses, technologies, products, and services (Vancouver City Council, 2009).

44. Job creation represents a key feature in city green growth plans, since it reflects both city attractiveness and the concept of growth. City attractiveness is largely attributable to a dynamic economy offering a range of employment opportunities. Vancouver's plan has targeted the creationcreatino of 20000 new green jobs and status as the green economy capital by 2020 . Seoul seeks to create 1 million green jobs by 2030 through a USD 45 billion investment to reduce greenhouse gases by $40 \%$ (compared to 1990 levels) and anticipate climate change impacts in the continued development of the city (C40, n.d. (b)). New York City suggests that green jobs are actually nothing new, but simply represent existing job classifications that have updated or enhanced skills. Chicago echoes the notion that traditional economic sectors-such as construction and freight transportation - can be at the hub of a green economy. Several plans make explicit mention of social equity in green job creation. In Vancouver, for example, the plan notes that $10 \%$ of all green jobs identified by the city have low barriers to employment, and thus should be accessible to residents facing language barriers, mental health issues, or other challenges (Vancouver City Council, 2009). 
Los Angeles emphasises developing green job training programmes for low- and middle-income communities (City of Los Angeles, 2008).

45. Few city plans propose an explicit definition of green growth. For instance, Vancouver's green plan acknowledges that many definitions of green jobs exist, and borrows directly from the UNEP definition "work in agricultural, manufacturing, research and development (R\&D), administrative, and service activities that contributes substantially to preserving or restoring environmental quality." Table 1 summarises the various green component(s) in the recent plans of select cities.

Table 1. Environmentally focused city plans

\begin{tabular}{|l|l|l|}
\hline & $\begin{array}{l}\text { Name of the plan or programme and } \\
\text { year (where available) }\end{array}$ & $\begin{array}{l}\text { How is environmental sustainability } \\
\text { emphasised? }\end{array}$ \\
\hline Beijing & Greening Beijing 2008 for Olympics & Specific programme \\
\hline Chicago & $\begin{array}{l}\text { Green Economic Development } \\
\text { Strategies for the Chicago Region }\end{array}$ & Environmental strategic plan \\
\hline Kitakyushu & Green Frontier Plan to Eco-Model City & Environmental strategic plan \\
\hline London & London Green Fund & Specific programme \\
\hline Los Angeles & $\begin{array}{l}\text { Green LA } \\
\text { Green Building programme }\end{array}$ & $\begin{array}{l}\text { Environmental strategic plan } \\
\text { Specific programme }\end{array}$ \\
\hline New York & PlanNYC, 2007 & $\begin{array}{l}\text { Mainstreamed in master urban } \\
\text { strategic plan }\end{array}$ \\
\hline Seoul & $\begin{array}{l}\text { Master Plan for Low Carbon, Green } \\
\text { Growth }\end{array}$ & Environmental strategic plan \\
\hline Sydney & $\begin{array}{l}\text { Sustainable Sydney 2030 } \\
\text { Green Building programme }\end{array}$ & $\begin{array}{l}\text { Environmental strategic plan } \\
\text { Specific programme }\end{array}$ \\
\hline Tokyo & Green building programme & Specific programme \\
\hline Vancouver & Vancouver 2020 - a green bright future & $\begin{array}{l}\text { Mainstreamed in master urban } \\
\text { strategic plan }\end{array}$ \\
\hline
\end{tabular}

\subsection{The definition of urban green growth}

46. The concept of green growth imposes an explicit, normative judgment about the need to steer economic growth in a different direction, addressing externalities and other factors poorly served by current measures of economic activity. It also recognises that environmental policies that do not support economic growth and wealth creation are not sustainable in the long term. In this spirit, the OECD Green Growth Strategy (2011b) defines the concept as follows:

Green growth means fostering economic growth and development while ensuring that natural assets continue to provide the resources and ecosystem services on which our well-being relies. To do this it must catalyse investment, competition and innovation, which will underpin sustained growth and give rise to new economic opportunities.

47. As will be developed in the following paragraphs, the scope of the OECD definition of green growth can be extended in three ways when applied to urban areas, by taking into account: $i$ ) a need for new sources of urban growth; ii) policy complementarities present at the local level; and iii) the importance of social equity to urban development.

48. First, OECD analysis shows that the average output growth in predominantly urban areas has been lower than other types of regions since 1995. According to the United Nations population projections, urbanisation in OECD countries will continue to slow down, requiring policy responses to foster new sources of growth (UN, 2007). Given the negative externalities generated by urban 
agglomeration and cities' urgent need to reduce their energy consumption and greenhouse gas emissions, urban areas have the opportunity to conduct environmental policies that can foster these new sources of economic growth.

49. Second, there are more opportunities on the local level to enact environmental and economic policies that are complementary, as activities related to environmental protection and economic development are more integrated at the local level than at the national level. Green growth policies benefit from these policy complementarities and can thus be more effective when applied at a local scale.

50. Third, while the OECD Green Growth Strategy focuses on the inter-relatedness of economic and environmental concerns, the implementation of green growth at the local level addresses social issues in a more direct way. There are clear instances where green growth initiatives can provide social co-benefits, and others where the transition might generate concerns for social equity.

\section{Alternative green growth scenarios}

51. It is possible to identify six growth scenarios that embody different economic impacts depending on the greening activities, primarily by differentiating between the impacts on the green and traditional economies. The six green growth scenarios are as follows:

Scenario 1: Baseline - No impact

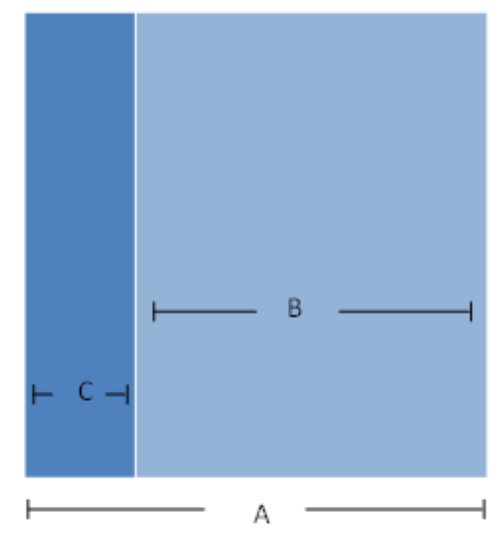

52. Under this baseline scenario, green policies provide no significant long-term economic bump, with the total economy remaining constant (A) and the traditional (B) and green (C) sectors also remaining constant in size. This would occur in two ways: the policies established by the relevant authorities are very ineffective, producing none of the desired environmental or economic impacts, or the policies deliver the desired environmental outcomes but without any demonstrable economic impact. The latter might occur with a tree planting programme designed to improve local air quality, reduce the urban heat island, sequester $\mathrm{CO}_{2}$ emissions, and improve the overall attractiveness of the city. Because most cities will procure the trees from nurseries or tree farms outside of their area and utilise existing staff to plant and maintain the trees, the economic impacts may be relatively small. 
Scenario 2: Green sector growth

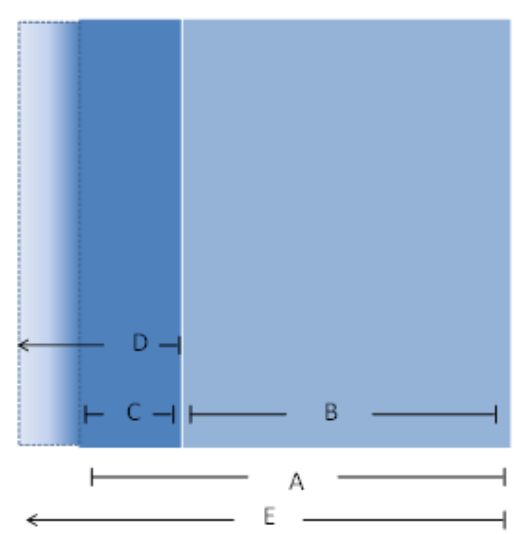

53. Under Scenario 2, the implementation of green policies and other initiatives designed to deliver local and global environmental benefits results in a significant expansion in the total level of economic activity in the region (from A to E). This expanded economic activity primarily occurs in the green technology and service sector, however, which increases in size from $\mathrm{C}$ to $\mathrm{D}$. The balance of the region's traditional economy (B) does not increase in any meaningful way, although there might be some cost savings and other less tangible co-benefits (improved quality of life, etc.) that do occur. In other words, the greening benefits do result in decreased resource use and/or decreased environmental degradation, but the benefits do not have significant spill over in terms of the traditional economy. This scenario might occur in regions that are importing and deploying large quantities of renewable power technology, with the power primarily being exported to other parts of the country. Job growth thus occurs in the renewable sector, but the other localised economic impacts may not be as large as originally hoped.

Scenario 3: Economic greening

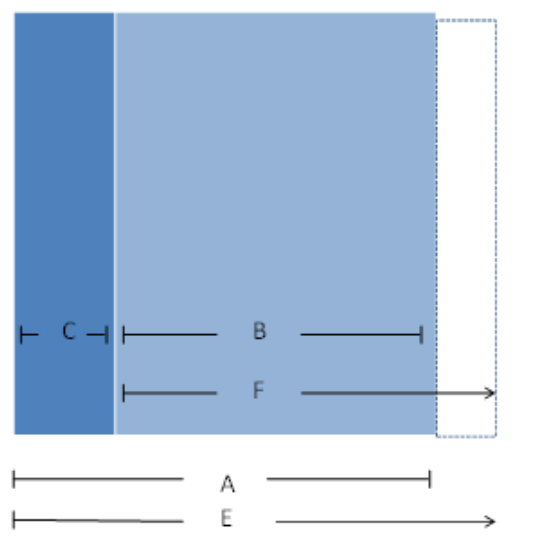

54. By contrast, economic greening occurs when the implementation of multiple green policies and other initiatives results in a significant expansion in the region's economy (from A to E) that is concentrated in the traditional economy, which increases from B to F. This is not to say that there is no increase in economic activity in the green sector (C), but this activity is either offset by other losses in the environmental business sector (from existing companies in that sector losing market share to new firms), or by the fact that the technology being deployed does not involve significant new employment 
or is imported from outside of the region. The imposition of congestion pricing in New York City for instance, which was projected to deliver significant efficiency gains in the local retail, banking, and other service sectors, is an example of economic greening. This scenario may also occur in regions with poor air quality, which dampens the overall economic attractiveness of the area. Resolving the problem may involve deploying imported pollution abatement technology at local industrial facilities, remedying the problem without necessarily increasing the size of the local green economy.

Scenario 4: Multi-sector growth

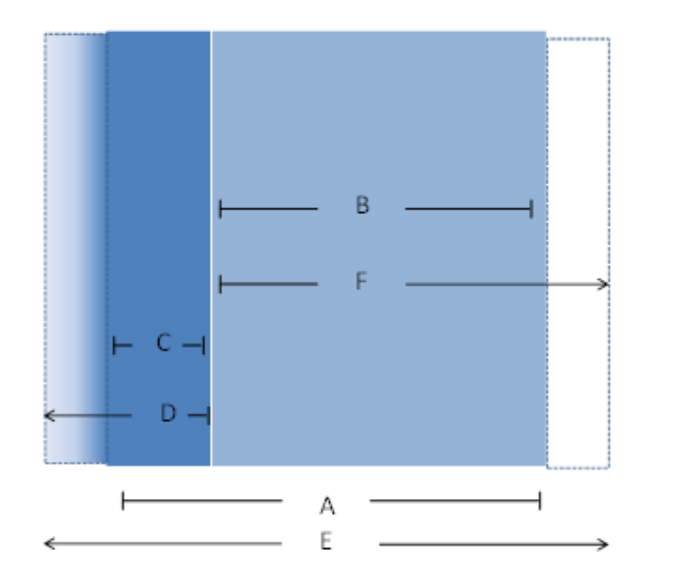

55. This scenario would ordinarily be considered the ideal by most policymakers, as greening strategies result in expansion of both the green business sector (from $\mathrm{C}$ to $\mathrm{D}$ ) and the traditional businesses sectors in the region (from B to F). Accordingly, significant economic growth occurs in the region, increasing the overall size of the economy from A to $\mathrm{E}$. Whether the green and non-green segments of economy grow at equal rates is less important than the notion that significant growth occurs in both sectors, resulting in a noteworthy improvement in the level of economic activity in that region.

Scenario 5: Sectoral displacement

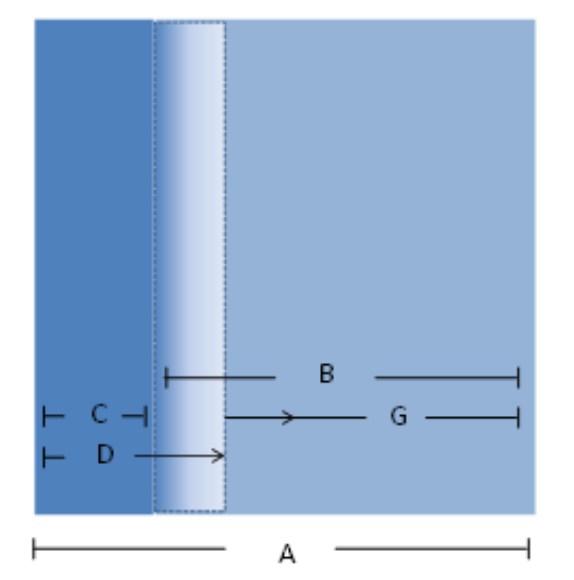

56. One issue of concern to many policymakers is the extent to which growth in one sector may displace, or cannibalise economic activity occurring in another sector. In the case of activities designed to improve a region's environmental performance, this could occur if, for example, policies 
promoting the deployment of renewable energy technology deliberately or inadvertently resulted in the shrinkage of economic activity in other energy sectors, such as the extraction of fossil fuels or operations at fossil fuel-fired power plants. Such a scenario might occur in areas where fossil fuel resources are primarily extracted for local use, or where local fossil fuel-fired power plants are the primary source of power for the region. The Scenario 5 figure embodies this possibility, assuming that growth in the green sector (from C to D) is fully offset by losses in the traditional economy (from B to $\mathrm{G})$, resulting in a situation where overall economic activity for the region remains constant (A).

\section{Scenario 6: Economic stagnation/de-growth}

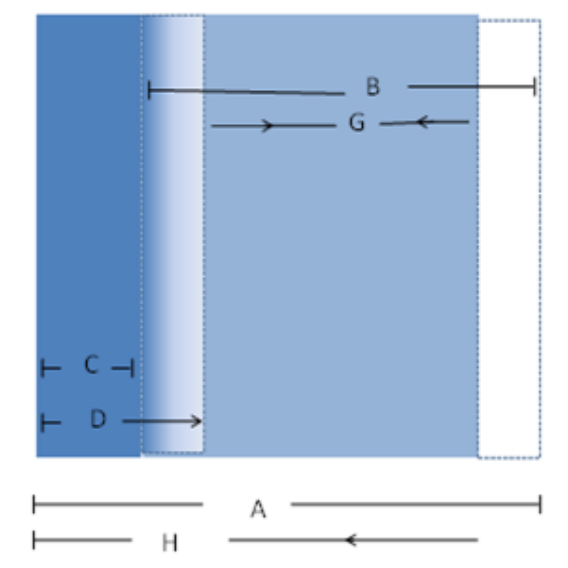

57. The final scenario, perhaps feared most by policymakers, occurs if the imposition or pursuit of greening policies results in significant adverse economic impacts in the region's economy, stunting activity to such a level that the overall economy actually shrinks (from A to $\mathrm{H}$ ). This scenario presumes that greening policies do result in some demonstrable increase in the size or level of activity in the green sector (from $\mathrm{C}$ to $\mathrm{D}$ ), but this is more than offset by sizeable losses in the balance of the extant economy (from B to G). Such a situation could occur if greening policies are excessively onerous, significantly affecting the profitability of businesses operating in the region, or forcing businesses to leave or shut down altogether.

\section{Urban green growth: the OECD definition}

58. Defining green growth in an urban context requires first agreeing on desirable scenarios. Figure 11 illustrates how the six aforementioned scenarios fall along a spectrum, ranging from positive to negative growth outcomes. The dark blue colour indicates the desirable scenarios, the light blue may be considered second-best options in certain cases, and white indicates the undesirable scenarios. Although it is important to understand the extent to which growth occurs in sectors specifically aimed at promoting environmental protection or resource-conservation services or technology, these sectors generally represent a relatively small subset of the larger service and manufacturing economy in a region. What is important, therefore, is the extent to which green growth initiatives contribute to overall economic expansion in a city region, with that growth attributable either to green sector growth (Scenario 2), economic greening (Scenario 3), or multi-sector growth (Scenario 4). In each of these cases, the level of economic activity triggered by a greening strategy is sufficient to grow the entire regional economy by some amount. Scenario 1 envisages no growth occurring, whilst Scenario 5 indicates displacement. Although these scenarios are not optimal, in some cases, they could be desirable. The final scenario (6) displays a situation where environmental policies are sufficiently onerous that they actually result in shrinkage of the region's economy with business closures and job 
losses. This scenario is perhaps the greatest fear of policymakers, implying that environmental protection and economic growth are incompatible goals.

Figure 11. Economic impacts of greening policies

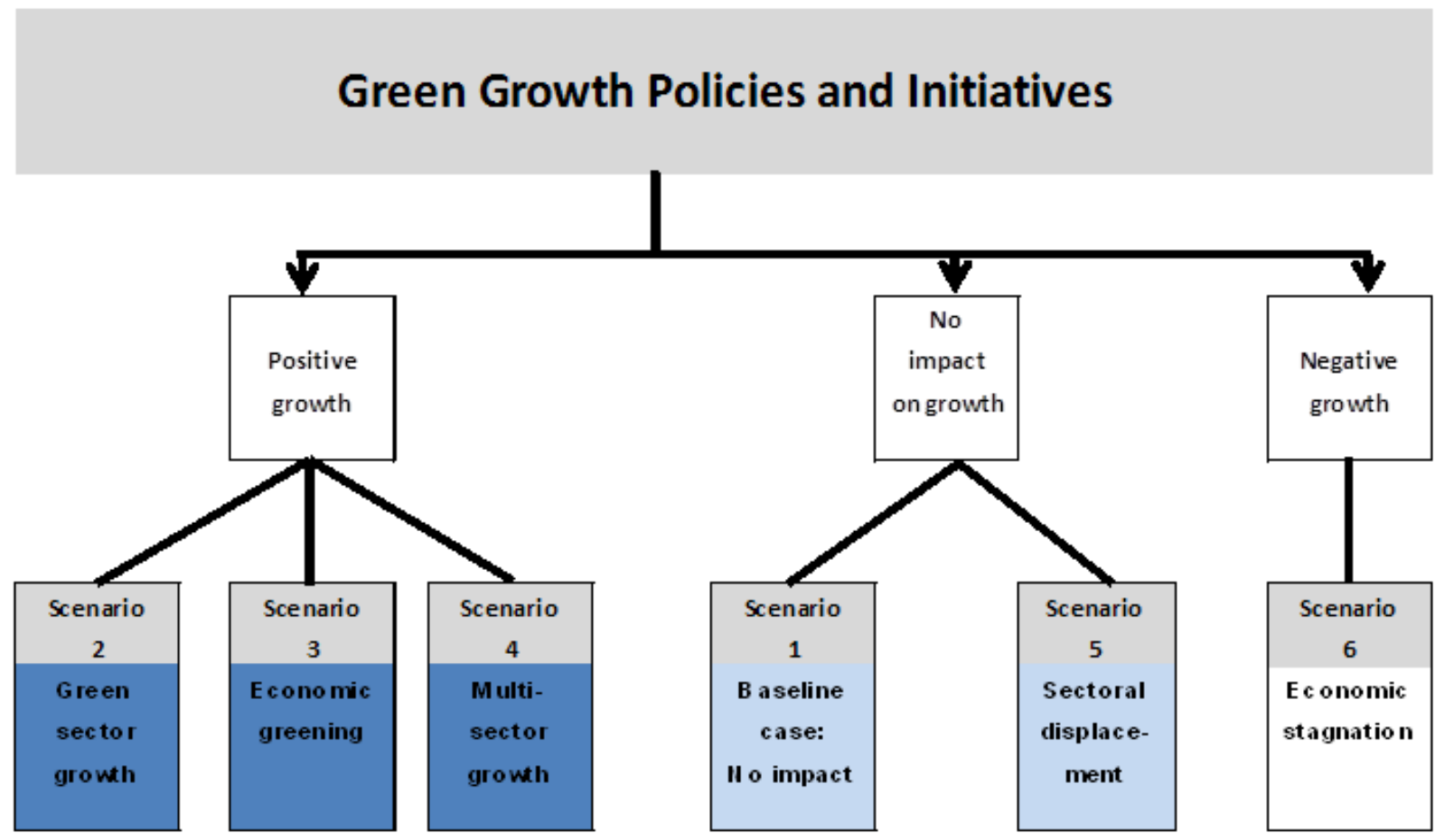

59. Based on this screening of scenarios, green growth in an urban context could be defined as follows:

Urban green growth means fostering economic growth and development through urban activities that reduce negative environmental externalities, the impact on natural resources and the pressure on ecosystem services. The greening of the traditional urban economy and expanding the green urban sector can generate growth (through increased supply and demand), job creation and increased urban attractiveness. These effects are in part the result of stronger interactions at the urban level among economic efficiency, equity and environmental objectives.

\section{Enabling the transition to urban green growth: policies and tools}

60. This section focuses on the policies and tools that can enable the transition to green growth in cities. Based on the set of hypotheses of desirable environmental and economic scenarios discussed in the previous section, we propose a policy framework for an urban green growth agenda. Three main drivers of regional growth - human capital, innovation and infrastructure - can provide a first lens through which green growth policies can be understood to contribute to greening the economy. We then explore a series of economic sectors that represent greening challenges and opportunities in terms of creation of wealth and job creation. Next, in an effort to provide local authorities with considerable flexibility in selecting instruments best suited to meet the relevant environmental, energy, or climate challenges facing their city, we propose a taxonomy of the four types of policy levers that can be adapted to each of the green sectors. Finally, we identify complementary greening policies within and 
across sectors, which can assist local authorities in developing a coherent, integrated urban policy package to address each city's unique greening opportunities and challenges.

\subsection{A policy framework for an urban green growth agenda}

61. There is a vast and ever-expanding literature on the policies that local and national governments are pursuing to promote both urban greening and urban growth. There are four fundamental elements to this discussion:

i) Policies intended to support economic growth. The OECD (2009d) has identified three key strategies for enhancing regional growth: $i$ ) improve the skills of the local workforce; ii) promote innovation; and iii) improve or expand local infrastructure necessary to sustain growth. These are fundamental prerequisites to a growing economy, and policies aimed at addressing these goals will serve as the first lens through which green growth policies will be viewed.

ii) Policy instruments to promote urban greening. We propose a taxonomy involving four generic types of policy levers that can be adapted to fit any of the green sectors, providing local authorities with considerable flexibility in choosing the instrument(s) best suited to addressing the relevant environmental, energy, or climate challenges facing their city. These four types of policy levers are much broader than the simple "carrots or sticks" paradigm often used to characterise government policy options, reflecting both the policymaking competency of the agency in question or their political preferences over the optimum path forward.

iii) Greening challenges and opportunities. Pro-growth policies are applied through policy instruments to greening challenges and opportunities. We identify six different types of urban greening challenges or opportunities. Within each grouping there may be one or more different topical issues (e.g. solid waste, air or water quality), but they are categorised together because they bear some fundamental similarities. The greening opportunities or challenges are highly interconnected, with actions in one policy area having links to many of the other policy silos. For example, promoting compact city design will have impacts related to air quality, transport system viability, energy technology decisions, etc. This concept is further discussed in section 2.5.

iv) Indicators of green growth. We identify three indicators of green growth that result when pro-growth policies are applied to greening challenges and opportunities. These are an increase in jobs, in supply and demand for green products or services, and in urban attractiveness.

62. Underlying these four elements is the issue of policy jurisdiction. Green growth policies must necessarily involve the efforts of both national and sub-national stakeholders, because no single stakeholder (or tier of government) has sufficient policy influence to implement a comprehensive green growth policy on their own. Because cities do not have unlimited policy control powers, they must necessarily engage with other tiers of government who hold the necessary or complementary policymaking powers to help a city meet its green growth goals.

63. Finally, these policy decisions all occur amidst two important backdrops.

i) The first backdrop (the large blue box) represents the underlying goals or values that influence policy decisions. These could relate to environmental or economic aspirations 
policymakers hold for the city/region, or they could relate to social equity goals they also wish to accomplish via a green growth initiative.

ii) The second backdrop (the grey box framing the entire diagram), represents the baseline conditions that implicitly or explicitly shape policymaking behaviour and options in a city. These include to the city's natural resources asset base, the technology deployed in a city (which may be creating path dependency or lock-in), and local soci-economic and demographic conditions which may constrain certain policy choices.

64. In some cases, officials may not even realise how their views have been shaped by these two backdrops, in that the goals, values and baseline conditions might represent long-standing operating procedures, technologies or market practices. Changes might thus be manifested in incremental terms, rather than in paradigm-shattering or generation-skipping technological terms.

65. These elements come together in the Urban Green Growth Policy Framework (Figure 12). The framework diagram seeks to explain both the iterative nature of decision-making on green-growth issues - involving both national and sub national level decision makers - as well as certain key influences shaping green growth policy decisions. 


\section{Figure 12. Framework for urban green growth}

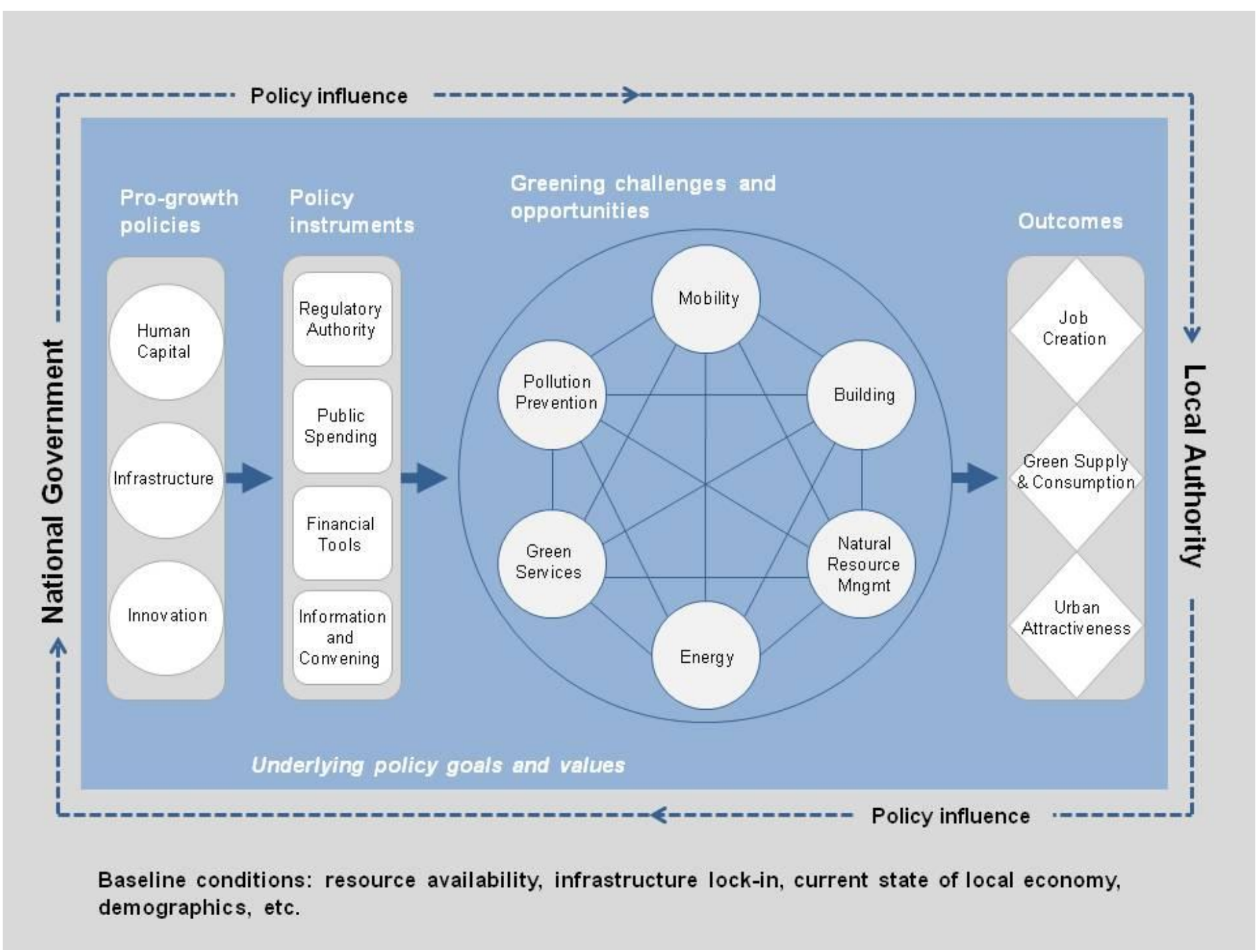




\subsection{Pro-growth policies}

66. Economic growth in urban areas is driven by endogenous factors such as human capital, physical capital (i.e. infrastructure), and innovation, as well as spatial factors such as agglomeration economies and proximity to markets. Using a number of econometric techniques, the OECD has developed a regional economic growth model that highlights the following (OECD, 2009d):

- Human capital is the most robust factor affecting growth and is mainly related to the level of tertiary educational attainment by the local workforce. Improvements in this area take about three years to have an impact.

- Infrastructure has an impact on growth as long as other key factors are also in place (e.g. human capital, innovation, agglomerations, etc.)

- Innovation has an impact on growth, but is an even longer term process and takes between five to ten years to bear fruit.

67. These facts raise several implications for the design of a local green growth strategy.

\section{Human capital}

68. The development of a dynamic, greener economy will hinge on the availability of skilled and trained people to fill the emerging green jobs. As the UNEP notes, "shortages of skilled labour could put the brakes on green expansion... it is important both to prepare the workforce at large for the skills requirements inherent in green jobs and to ensure that green industries and workplaces do not face a shortage of adequately skilled workers" (UNEP, 2008). Cities are well placed to facilitate this transition of the labour force.

69. There is evidence that skill shortages already exist in certain green sectors around the world. In Germany, employers report a lack of skilled solar photovoltaic (PV) technicians, while smart grid design engineers are in short supply in the United Kingdom. Solar technology installers and renewable energy technology project managers are needed in Spain and Denmark, respectively (CEDEFOP and ILO, 2010). It is difficult, however, to assess the severity of these green skills shortages. According to UNEP (2008), almost all energy subsectors lack skilled workers with the most pronounced shortages found in the hydro, biogas and biomass sectors. Skill gaps are also pressing for manufacturing in the renewable energy industry, particularly for engineers, operation and maintenance staff and site management.

70. As businesses evolve during the green transition, demands are placed on education institutions and training systems to adapt. The rising demand for low-carbon products will require the simultaneous development of a very diverse skill set. For example, demand for low-emission residential estates will require developers with knowledge of building materials with low-embedded energy use, engineers and designers able to embed energy efficient products in the building, manual workers with the technical capability to install and maintain these products and salespeople capable of promoting these products in the market.

71. In some cases, filling this skills gap may require the greening of existing skills and processes in the marketplace to minimise displacement as workers are diverted from existing businesses. Briggs et al. (2007) characterise this as the "greening of old jobs", while the ILO suggests that "rather than replace existing jobs with totally different green jobs, it is the content of jobs, the way the work is performed and the skills of workers that will change" (ILO, 2008). In other cases, however, it has been 
posited that new green skills, currently absent from the existing labour market, will need to be developed, possibly involving a convergence of traditional and new skills (Martinez-Fernandez et al., 2010).

72. Skill creation for new green jobs, as well as training to upgrade old jobs, can be more efficiently organised by pooling learning resources of education institutions and industries at the regional level. The challenge will be to anticipate what the employment effects and labour reallocation across industries will imply in terms of future skill needs and possible absorption of laid-off workers (Table 2). In the absence of well-developed frameworks to undertake such analysis at the national level, regional institutions, such as regional and municipal departments or task forces, universities and vocational institutions, business associations and trade unions are better positioned to assess labour effects of the green transition and provide training tailored to local labour market needs (e.g. Oakland Apollo Alliance, USA).

Table 2. Green sectors and jobs

\begin{tabular}{|c|c|}
\hline Category & Examples of jobs \\
\hline Energy & $\begin{array}{l}\text { - Energy engineers } \\
\text { - Electrician and plumbers installing the systems } \\
\text { - Mechanics building the infrastructure } \\
\text { - Renewable energy plant operators } \\
\text { - Engineers and scientists working on energy efficiency } \\
\text { improvements (efficient lighting, smart metering, low energy } \\
\text { monitors...) }\end{array}$ \\
\hline Mobility & $\begin{array}{l}\text { - Public transport drivers and employees } \\
\text { - Bus retrofitters } \\
\text { - Builders of rail networks }\end{array}$ \\
\hline Natural resources management & $\begin{array}{l}\text { - Park and open space planners } \\
\text { - Civil engineers } \\
\text { - Landscape architects and gardeners }\end{array}$ \\
\hline Buildings & $\begin{array}{l}\text { - Employees of firms producing green building materials } \\
\text { (alternative cement, recycled wood...) } \\
\text { - Building contractors and construction workers specialised in } \\
\text { green buildings }\end{array}$ \\
\hline $\begin{array}{l}\text { Pollution prevention, treatment and } \\
\text { abatement }\end{array}$ & $\begin{array}{l}\text { - Workers employed for renewing water infrastructure } \\
\text { - Hazardous material removal workers } \\
\text { - Chemists developing environmentally friendly packaging, } \\
\text { cleaning products and sprays }\end{array}$ \\
\hline $\begin{array}{l}\text { Green services (retail and service } \\
\text { sectors) }\end{array}$ & $\begin{array}{l}\text { - Energy contractors } \\
\text { - Specialised consultants } \\
\text { - Trainers } \\
\text { - Marketing } \\
\text { - Green-civil engineers } \\
\text { - NGOs }\end{array}$ \\
\hline
\end{tabular}

Source: Adapted from UNEP/ILO/IOE/ITUC (2008), Green Jobs: Towards Decent Work in a Sustainable, Low-Carbon World.

73. Local or regional authorities interested in developing a green jobs strategy would benefit from tailoring programmes to local circumstances, ideally consulting with unions, employers and community groups integral to the success of an economic transformation (ITUC, 2009). The Institute for Sustainable Communities, an NGO focused on green growth and environmental protection efforts in a number of countries, suggests there are seven key components of a successful local green jobs plan (Institute for Sustainable Communities, 2010):

i) Co-ordination of key stakeholders around goals to help identify synergies between local groups, thus facilitating collaboration; 
ii) Co-ordination of key stakeholders around tasks to ensure ongoing alignment of activities;

iii) Mapping of current business, institutional, training and financing assets in the community to provide the basis for assessing the potential for economic growth and career paths in different fields;

iv) Assessing the potential for green sector growth, necessary to ensure a co-ordinated perspective on job creation potential, including emerging or potential industry clusters;

v) Identification of gaps in the training, placement and business development system;

vi) Creation of a plan that lays out roles, actions to address gaps, and an assessment strategy; and

vii) Pursuit of strategic funding and resource allocation opportunities to realise the plan.

74. Numerous green job training programmes are underway that can potentially inform efforts in other cities. Some have a specific climate change focus, such as the Silicon Valley Climate Prosperity Initiative which seeks to leverage and expand the expertise already found in California's leading high hub, placing particular emphasis on building energy efficiency, energy storage, smart grid technology, carbon abatement and renewable energy technology deployment (Silicon Valley Climate Prosperity Initiative, 2009). Fifteen local governments, the business community, academia, and NGOs all collaborate as part of this initiative. In Texas (USA), the San Antonio Mission Verde Initiative seeks to foster economic growth by focusing on a wider array of green initiatives, including high performance buildings (including building retrofits), compact city development and a multi-modal public transportation system. The Mission Verde Center is the hub for local green job training activities, which thus far have focused on solar PV system installation, green buildings, certified arborists, weatherisation projects and green entrepreneurship. Over 80 people were trained during the first year of the programme, $75 \%$ of whom immediately found employment in the field. New training programmes are now underway in energy auditing, lead and asbestos abatement and green real estate inspection (Institute for Sustainable Communities, 2010).

75. Partnering with the private sector is an important element of a successful transition to the green economy. Many businesses have already begun to implement in-house training programmes to re-skill their staff; mainly to increase energy efficiency in production methods (GHK, 2009). As it is not yet clear whether green growth will have a systematic impact on overall skill demand, sub-national governments have to work closely with the private sector to communicate their job skill needs to local policymakers, ultimately enhancing the effectiveness of local skill development efforts. Closely connecting local training initiatives with the overall economic development strategy, and if it exists, to an explicit green growth strategy, can help to better assess the needs of the local fabric. Representatives of the private sector in Chicago reported that the supply exceeded the demand in the green sector, with too many people having received green training.

76. A particular focus has to be put on small- and medium-sized firms, which compared to large companies have greater difficulty in providing in-house training to employees. OECD research has shown that problems associated with upgrading worker skills can be particularly acute in small and medium-sized organisations (OECD, 2010). In Korea, since the launch of the National Strategy for Green Growth, the government has actively pursued the development of comprehensive policy infrastructure to promote job growth, with targeted workforce training and skills development programmes to help prepare workers in the transition to the green economy. Among different initiatives, the Small and Medium Business Administration (SMBA) has launched a programme to 
enhance collaboration amongst industry, universities and research institutions by providing financial support for selected SMEs to develop skills and advanced technology. Jointly with local governments, the SMBA selects SMEs, awarding extra points to green businesses and provides $75 \%$ of the financing for spending on technological development. In 2010, the SMBA awarded KRW 56 billion for 1228 projects. In 2000, approximately $42 \%$ of the total spending was distributed to SMEs in the Capital area (Seoul, Incheon and Gyeonggi-do) (Kamal-Chaoui et al., 2011).

\section{Infrastructure development}

77. Investment in physical infrastructure plays a crucial role in urban development. The expectation that improvements in physical infrastructure will generate productivity gains for local businesses and increase the attractiveness of an area for investment has been a recurring theme in OECD reviews. High quality infrastructure and services are accepted as being vital to a strong economy - locally, regionally and nationally. Upgrading transportation infrastructure, for example, can shorten travel times which, in turn can affect property prices and economic rents, and influence decision-making by households (residential location, patterns of consumption) and firms (production location, access to markets and investment decisions). These decisions should then have a net positive impact on the economy, increase tax revenues, create employment and generate resources for further investment. For business, the benefits of transportation infrastructure investment could include: access to a wider and more diversely-skilled labour pool; faster access to suppliers and customers, which reduces transaction costs; expanded market reach, including choice of suppliers and consumers; and a reduction in land use constraints. There are however limits to put on infrastructure as a factors of green growth. For example, OECD reviews suggest that while the construction or upgrading of transportation infrastructure can undoubtedly have a positive influence on a region's economic development, economic growth is not automatic. Growth effects are likely to appear only when positive externalities already exist in the region.

78. This being said, cities have been actively promoting green growth through their purchasing choices and their management of existing and new infrastructure. Over 2008-10, the stimulus packages in several OECD countries injected resources that could drive higher investments to reduce the carbon footprint of cities. Examples of employment-intensive urban investments include: housing and construction, renewable energy and recycling/pollution control projects, promotion of grid interconnection schemes that support modal shifts to public transportation. These initiatives generate short-term employment and improve the overall efficiency of the urban system, which should yield further economic gains over the medium-long term. Whether these investments will have a tangible effect on the carbon footprint of cities depends on the political willingness to steer more resources to green/greener projects and the technical capacity to quantify the impact of the investment on greenhouse gas emissions reductions and other carbon-footprint indicators.

79. Some large scale urban infrastructure programmes can represent huge potential for greening dirty economic sectors, and in some cases, re-employ displaced workers or create new jobs, as well as generate additional growth, occasionally beyond these sectors. An example is extension of port cities and investment in new port terminals (Box 3). Another example of large scale sustainable infrastructure development programmes includes brownfield redevelopment. Brownfield or infill development in many OECD metropolitan regions usually offers few benefits to developers. It also takes more time to complete, and so occurs less frequently unless specifically stipulated by local governments. Suburban municipalities have thus actively pursued the development of previously undeveloped land, or greenfields. Because suburban municipalities typically have a greater supply of greenfields, they can be more attractive to developers and can benefit from the revenues and revenue bases brought in by greenfield development. 


\title{
Box 3. Port cities and green growth
}

\author{
Olaf Merk, Policy Analyst, OECD
}

Port-cities have a large potential in terms of green growth. Shipping related to the port, port activities themselves and port-related hinterland traffic all have an impact on emissions, energy use, biodiversity and waste levels. In addition, many ports are industrial clusters with high concentrations of chemical, petrochemical and industrial activity, which determines to a large extent the economic profile of the port-city. Per definition, port-cities and other coastal cities are more vulnerable to risks of climate change and rising sea levels. There are several possibilities for greening port and port-related activities, which in some cases will generate additional growth in these sectors, and occasionally beyond these sectors.

Shipping uses fuels not allowed for land transportation. Proposals are in discussion for a tax on these bunker fuels to reduce $\mathrm{CO}_{2}$ emissions from global shipping, but implementation of these are most effective on a global scale. In order to limit the impact of emissions from these fuels close to land and in valuable maritime ecosystems, several coastal areas are designated emission control areas, such as the Baltic Sea, and the coastal waters of Singapore. In order to limit exhausts from vessels in ports, some ports such as Göteborg have installed on shore power facilities so that vessels use land-based electricity instead of bunker fuels during their stay in the port (cold ironing).

There are also possibilities for greening port activities, e.g. by making them more energy efficient, by installing better waste capture facilities and by locating in less environmentally sensitive areas. These possibilities for greening ports are particularly pertinent when extending ports or investing in new port terminals, when environmental sustainability is sometimes used as one of the bidding criteria in port extension concessions (e.g. for the Maasvlakte 2 in Rotterdam). Many port extensions have to offer compensation in terms of nature reserves and biodiversity. Dredging activities in order to guarantee access to the port have increasingly taken environmental sustainability into account. Some ports, such as Long Beach and Los Angeles, have banned trucks that do not comply with certain emission standards, or charge dirty trucks (Busan). The tendency to relocate port activities away from cities has led to possibilities for brownfield redevelopment and waterfront development in many port-cities.

Hinterland traffic in many port-cities causes congestion and other negative externalities, e.g. bad air quality. For these reasons, many port-cities are trying to develop alternatives to truck-based hinterland transport. Some countries, such as the Netherlands, have developed dedicated freight railways (Betuwelijn). The ports of Antwerp and Rotterdam depend for around a third of their hinterland traffic on inland waterways. Short sea-shipping is increasingly being seen as an alternative as well. These alternatives to truck traffic could increase the attractiveness of ports as they provide them with possibilities to extend their hinterlands (considering that freight transportation by rail and water start to become more profitable than road transport above a threshold of around $200 \mathrm{kms})$.

An area where port-cities could generate new growth (as opposed to greening existing activities) is in the renewable energy sector. Ports have facilities and storage capacity that can have alternative and multiple uses, e.g. for $\mathrm{CO}_{2}$ capture and storage; and the solar panels on warehouses in the port of Marseille. Several port-cities have developed off shore windparks (e.g. Copenhagen) and are studying the possibilities of tidal energy. Portcities with complex chemical industries and refineries have opportunities in biomass energy production.

\section{Innovation}

80. Innovation serves as an important bridge to the green economy. Innovation and its corollary process of creative destruction lead to new ideas, new business models, new markets and, eventually, new jobs (OECD, 2011d). Green innovation cannot be delivered by "business as usual" approaches. To decouple growth from environmental pressures, it will instead be necessary to create new products, processes and technologies and to promote their diffusion and application (OECD, 2010a).

81. Three primary types of innovation can be identified: incremental, disruptive and radical (or systemic) innovation (Smith, 2009). Incremental innovation is the dominant form, involving some 
modification or improvement in a technology or process without changing its fundamental nature. Disruptive innovation changes how the basic technological functions are fulfilled but does not involve significant changes in the technological system itself. A helpful example is the change from incandescent to fluorescent light bulbs. The light fixture and socket remain the same, as does the electric voltage level; only the light bulb itself has changed. Radical innovation involves a fundamental shift in the technological regime, resulting in changes in other enabling technologies or the overall economic system. An example is the development of the steam engine, which transformed both society and the economy and drove the industrial revolution. Information and communication technologies are similarly credited with driving tremendous economic transformation today. Radical innovation can also be characterised by new or different science or engineering principles; better performance at the same or lower price; the obsoletion of current technologies, knowledge and business models (OECD, 2011d).

82. Innovation affecting green growth can include some or all of these typologies, but in all cases, policy action is needed to overcome different market failures or barriers to innovation. The OECD Green Growth Strategy highlights several key areas for governments to support green innovation: funding relevant research, whether public or private; targeting barriers to early-stage commercial development, including access to finance; and demand-side policies (OECD, 2011b).

83. More funding for research is needed in the development of generic or general purpose technologies (such as materials technologies, nanotechnologies, biotechnologies, green chemistry and ICT), as government spending on energy and environmental $R \& D$ have not kept pace with the growing urgency of environmental challenges. A great deal of transformative innovation in the green technology sector results from spill-over effects from other sectors (Figure 13): for instance, enabling technologies (ICT and nanotechnologies) can significantly decrease the cost and increase the environmental efficiency of new infrastructure and network investments (OECD, 2009c). The Paris suburb of Issy-les-Moulineaux, by providing superior broadband infrastructure, a business-friendly climate and innovative e-services, has managed in less than a decade to radically change its industrial structure, reducing local unemployment to virtually zero. Today, more than half of the 1,500 companies in Issy are in the ICT sector (European Commission, 2010). Korean municipalities are particularly active in the deployment of ICT technologies as a means of enhancing the energy efficiency of urban infrastructure. The Gangnam-gu district of Seoul, home to corporate headquarters, multinationals and IT venture firms, adopted a carbon mileage system and is now pioneering innovative service provision via wireless (Kamal-Chaoui, et al., 2011). Research funding can take the form of R\&D tax credits or subsidy support. Such policies can stimulate private investment, and - in a time of economic crisis or slowdown - help improve a company's cash flow, allowing it to stay afloat (Reimsbach-Kounatze, 2009). Support can come from any tier of government, although central or provincial-level agencies tend to be the most common government funding sources. 
Figure 13. The innovation-science link in selected green technologies

$2000-2007$

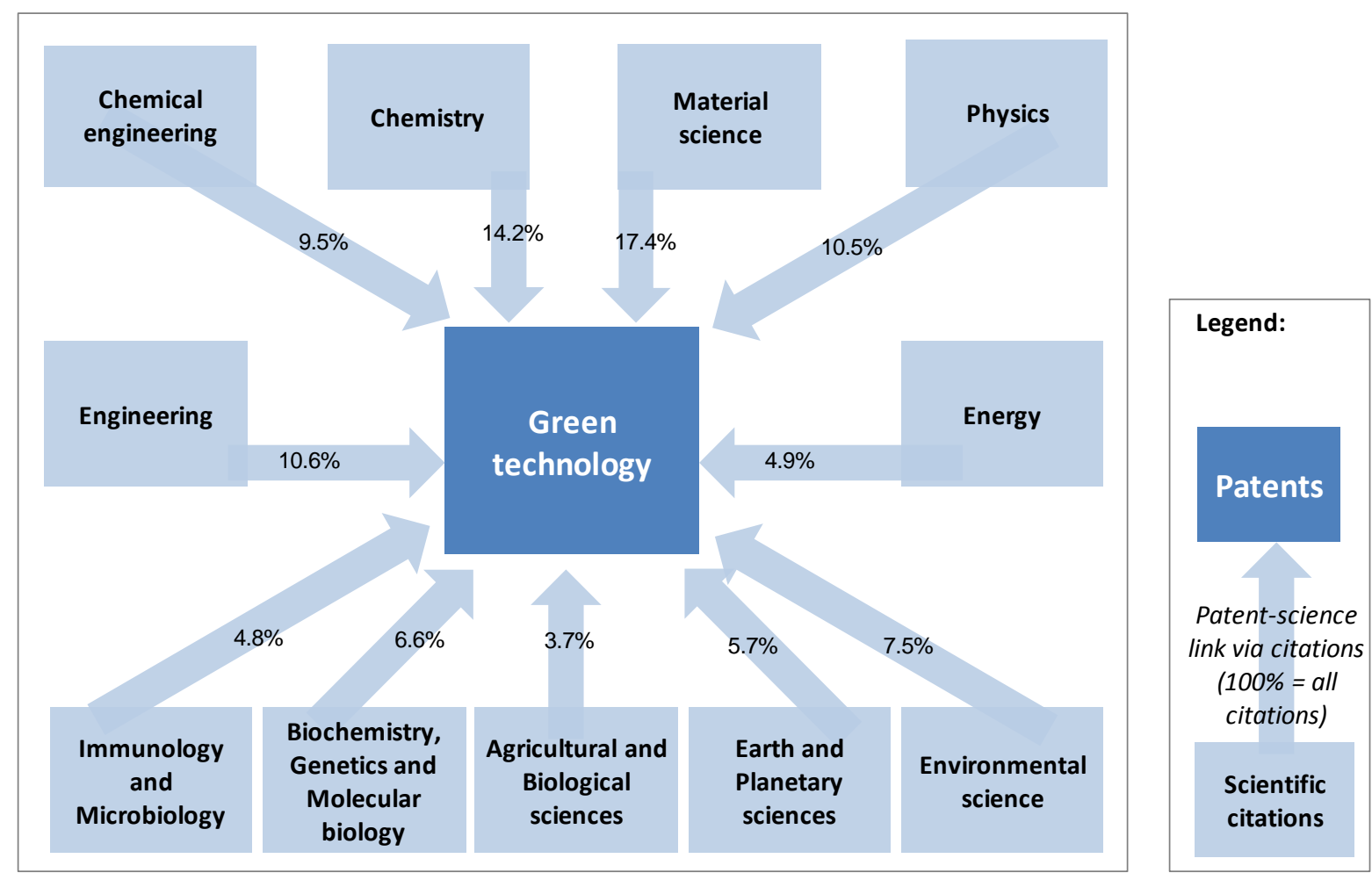

Source: OECD (2010a), Green Growth Strategy Interim Report: Implementing our Commitment for a Sustainable Future, based on Scopus Custom Data, Elsevier, July 2009; OECD, Patent Database, January 2010; and EPO, Worldwide Patent Statistical Database, September 2009.

84. Governments can also support green innovation by targeting barriers to its early-stage commercial development, including access to finance. With a relatively immature market for green innovation, the dominance of existing designs in energy and transport markets can create entry barriers for new technologies due to, for example, the high fixed costs of developing new infrastructures. In particular, when projects face high technology risks and are capital intensive, they are very hard to fund with either project or debt financing or venture capital and can fall into a funding "valley of death". The OECD nevertheless cautions governments against the risk of promoting activities that may have occurred anyway and that could lock in the economy into a less desirable pathway.

85. Demand-side policies can also strengthen green innovation. These include public spending on green technologies and procurement policies that incorporate environmental conditions. Demandside policies can also include government standards and labelling meant to guide individual and private sector consumption, as well as information and incentives that lower the barriers to green consumption. These instruments are further discussed in the section on main policy instruments, particularly the subsection on government spending.

86. According to the OECD (2010a), the type of policy instrument most appropriate for supporting innovation will vary depending on where a technology is in its life cycle.

- For promising but immature technologies, government can support research and large-scale demonstration projects and assess the infrastructure and regulatory changes necessary to 
facilitate or hasten deployment. For example, microgrids (i.e. small-scale smart grid systems) are now being integrated into the grid in new ways at the neighbourhood level. Several pilot programmes - many with the active involvement of local government - have been established that will help inform technology standards and determine whether any regulatory reforms are required (Hyams, et al., 2011).

- For proven technologies that have yet to acquire significant private financing, governments may wish to provide technology-specific support mechanisms (e.g. feed-in tariffs) to jumpstart the market. Both Gainesville, Florida and the City of Los Angeles have begun to provide feed-in-tariffs to help boost deployment of solar PV technology on local rooftops.

- For alternative energy technologies that have become locally cost-competitive but still lack market share, government can play a supportive role by promoting public acceptance/adoption and addressing other informational barriers. San Francisco's solar map website $^{9}$ has been instrumental in documenting the efficacy of rooftop solar technology around the city, in addition to providing helpful information on subsidy programmes and the names of installers doing business in the city.

87. Although national enabling frameworks and funding mechanisms are often essential to foster sustainable green $R \& D$, cities and regions can also catalyse green innovation. Sub-national governments can establish eco-innovation networking platforms, promote small pilot R\&D projects, redesign incentives mechanisms to target innovation in SMEs, develop green regional clusters and support research partnerships with universities.

88. Sub-national governments can seek to establish networking platforms for eco-innovation in partnership with private sector researchers and universities. One example includes the Knowledge Transfer Networks (KTNs) initiated by regional development agencies in the UK. KTNs bring together diverse organisations and sponsor activities that promote the exchange of knowledge and the stimulation of innovation. A review of the KTNs in the UK found that $75 \%$ of business respondents rated KTN services as effective; 50\% developed new R\&D and commercial relationships with people met through these networks; and $25 \%$ made a change to their innovative activities as a result of their engagement within KTN (OECD, 2010d).

89. Cities and regions can also facilitate R\&D by promoting pilot, small-scale $R \& D$ projects within a framework that clearly specifies targets, outputs and indicators so as to allow monitoring and evaluation. Successful projects can qualify for access to other sources of financing and provide large benefits through replication in other cities. Well-designed public technology infrastructures can leverage new private investments in R\&D. Examples of this type of technology infrastructure include the development of joint research projects between public and private laboratories (Co-operative Research and Development Agreements, CRADAs, and publicly sponsored Research Joint Ventures, RJV) and Small Business Innovation Research Awards. In the aforementioned example of the Rhône-Alpes region of France, regional and national investments in R\&D were instrumental to the development of the Tenerrdis competitiveness cluster, which promotes scientific collaboration to develop clean technologies applied to construction, transport and energy production.

90. Sub-national governments can also target green innovation among SMEs by redesigning their incentives mechanisms. Many local governments have not established indicator systems owing to a lack of resources such as finance, personnel, time and technical knowledge as well as motivation and

9.

See http://sf.solarmap.org/ 
awareness. The dilemma is thus how to translate the increasing need for energy efficiency services to an increased demand for these services, given current resource constraints. Targeted innovation vouchers, which provide financing for university-industry collaborations, might do the trick. An innovation voucher is delivered to firms to financing specific innovations. They can enable new SMEs in green industries to collaborate with public research institutions by submitting technical problems to be solved. ${ }^{10}$ Vouchers can be effective in promoting the transfer of knowledge between the research and the business community and also speed the pathway to commercialisation of experimental research in energy efficiency.

91. Eco-innovation can also be facilitated by the development of green regional clusters. These clusters successfully merge excellence in education, frontier research in environmental technologies and job creation through spin-offs, venture capital and integration of enterprises and organise them in a functioning system. Within the cluster, proximity and complementarities generate the critical mass to sustain industrial development in novel and risky fields. Clusters specialised in eco-innovation are not yet as common as in other industries, despite very promising market commercialisation opportunities. Some relevant examples can however be identified. The Lahti Cleantech cluster in Finland encourages innovation and development of environmental technologies by bringing together small and large enterprises, educational organisations and regional authorities. As a result, 20 new clean-tech companies have set up in the Lahti region and the project has attracted more than EUR 30 million in total investment. In the Rhône-Alpes Region of France, regional and national investments in R\&D were instrumental to the development of the Tenerrdis competitiveness cluster, which promotes scientific collaboration to develop clean technologies applied to construction, transport and energy production. Tenerddis brings together 185 stakeholders, who developed, between 2005 and 2008, 226 R\&D projects, for a total of EUR 440 million of investments, of which EUR 200 million came from public funding. ${ }^{11}$

92. Partnerships between government and academia have proven fruitful in the set-up of ecoinnovation clusters. Universities can facilitate local knowledge exchange - the local buzz - and become effective pipelines of information exchange with national and global markets. Universities can effectively contribute to the creation of local knowledge hubs for green technology by:

- $\quad$ educating people (training graduates and continuing education);

- $\quad$ increasing the local stock of codified knowledge (patents, publications);

- providing public space for local and global exchange (hosting forums, meetings and conferences; networks of alumni, faculty exchanges); and

10. An Innovation Vouchers Subsidy Scheme was introduced for the first time by the Dutch Ministry of Economic Affairs and then experimented in several OECD countries. Innovation vouchers were proposed as a key instrument for facilitating university-SME collaborations by Terry Cutler in the report for the Review of the Australian National Innovation System (Cutler \& Company Pty Ltd (2008)). In Cutler's proposed voucher programme, each voucher would be worth up to USD 15000 and would be used to fund collaboration between the small firms and a public sector research organisation. The programme would link 5000 firms per year with public research agencies at a cost of USD 50-75 million per year. The voucher programs can be easily scaled-down at the sub-national level, targeted on energy efficiency innovations and applied by municipal departments in charge of innovation and business support.

11. See www.tenerrdis.fr/en. 
- problem-solving (contract research, incubation services, co-operative research with industry).

93. There is great potential for university involvement in green technologies, but efforts to consolidate their involvement are just emerging. Increasing empirical evidence indicates that partnerships raise the innovative outputs of both firms and universities (OECD, 2009e). For instance, the competences in wind engineering and wind energy at the Danish Technological Institute and at Ålborg and Århus Universities have been essential for the development of the Danish wind energy clusters (Cooke, 2008).

\subsection{Greening challenges and opportunities}

94. We can identify six different types of greening opportunities in a city. Within each grouping there may be one or more different topical issues (e.g. solid waste, air or water quality) with its own unique challenges and opportunities, but which bear some fundamental similarities and thus are logically categorised under this group heading. For each, there is a discussion of the public policies that have been pursued to address the issue and the potential economic impacts (both market and nonmarket impacts) that can result from greening these sectors, although more in-depth analysis is needed to better quantify such impacts. Where possible, evidence of the economic benefits of climate change adaptation measures (e.g. in terms of avoided damages) will also be cited.

Energy

\section{What are cities doing?}

95. As the locus of the major global energy use (IEA, 2008b), cities are increasingly taking action to influence the type and amount of energy consumption with policies to increase energy efficiency and to enable the transition to cleaner energy sources. Local strategies tend to address separately each of the three forms of energy in cities (electricity, thermal energy for buildings and transport fuels), with policies that aim to: $i$ ) improve end-use energy efficiency and conservation through process and technical innovations; ii) increase reliance on non-fossil sources of energy, including renewable energy; iii) improve the efficiency of fossil-based power-generation facilities; iv) transition to less carbon-intensive fuels (for example, from coal to natural gas); or v) employ carbon capture and storage technology. The blend of strategies pursued in a city will vary based on, among other factors, the local authority's policy control powers, the local natural resource base (e.g. wind, solar or geothermal resources), a city's existing energy infrastructure and markets, and the willingness of local energy users to tolerate price impacts or behavioural changes that affect the amount or availability of energy.

96. The existing local energy infrastructure is critically important as it can either create technology lock-in or facilitate change. For instance, cities with significant amounts of power generation capacity may seek to increase fuel efficiency through fuel switching or a "repowering" of existing power plants. Cogeneration technology is particularly relevant in such cases, because it can satisfy both the electric and thermal needs of local customers. Cogeneration systems require an outlet for the thermal energy captured at the power plants, however, and thus tend to work best in cities with district energy networks that distribute steam or hot water to buildings in the vicinity of the plant. Copenhagen, for example, expanded the majority of its comprehensive district energy system in the mid 1980s (C40, n.d. (c)), which now provides $97 \%$ of the city's total heating needs and demonstrates that even modern cities can make significant changes to the local energy system. Cogeneration technology can also be used at the building scale, and is increasingly being deployed by building 
owners or developers to improve energy efficiency, cut costs and increase the reliability of the power supply in their building (IEA, 2009b).

97. Cities that own and operate power generating facilities can seek to directly increase the local supply of renewable energies, as is the case in Los Angeles. The city's GreenLA Climate Action Plan sets targets for the Los Angeles Department of Water and Power to increase its renewable fuel sources to $20 \%$ by the end of 2010 and to $35 \%$ by 2020 , in part by developing four large new renewable energy projects (City of Los Angeles, 2008). In Venice, the Port Marghera Fusina power station, opened in 2009, becoming the world's first industrial-scale, 16 megawatt, hydrogen-fuelled power station. It generates enough electricity to meet the needs of 20000 households each year and avoids the emissions equivalent of 17000 tonnes of carbon dioxide that are typically emitted when using coal-fired plants (OECD, 2010e).

98. Cities and regions that are not municipal power producers can use their regulatory authority to remove obstacles to local renewable energy production and their self-governing authority to purchase renewable energy for city or regional operations (IEA, 2009b). The success of Copenhagen's district heating system depended in part on regulations requiring connections in areas served by the system (OECD, 2009f). The City of Toronto, Canada, enabled the creation of a district cooling system by establishing a corporation that has connected most of the major downtown office buildings to a deep lake water cooling system and which has resulted in a significant decrease in electricity demand for air conditioning (OECD, 2009g).

99. Many cities are rethinking the traditional central station grid model for electricity generation, whereby power generated at very large power plants is distributed to customers via a monopolycontrolled local distribution grid in order to generate economies of scale. There is growing recognition, that alternative system designs can operate efficiently in cities. On-site renewable power technology, such as solar PV and wind power, and the advent of the "smart grid" are changing the urban energy landscape, and will likely have a prominent role in changing the way power is generated and distributed in the future. Advances in the design and functioning of the grid are critical if large quantities of renewable power are to be integrated into the local power supply picture.

100. Some cities (e.g. Tokyo, Athens, London, Toronto, Boston $)^{12}$ have also begun to examine the vulnerabilities of the local energy system to climate change. Although climate risks are largely location-specific, many power plants may be vulnerable to flooding due to sea level rise or stormsurges associated with extreme weather events. Heat waves may become longer and hotter in some cities, increasing the risk of electricty blackouts. Urban heat island effects could further exacerbate cooling demand during the summer months in some cities (Hunt and Watkiss, 2007). In other areas, energy demand peaks during the winter might actually be attenuated to some extent by warmer weather attributable to climate change (Hammer et al, 2011). London, New York, and Chicago have all launched climate change adaptation initiatives that include a focus on the local energy sector, encouraging local utility officials to assess potential risks and develop multi-year action plans to enhance the reliability of their system.

\section{What are the potential economic impacts?}

101. The renewable energy industry has already reached a noteworthy size and continues to grow. In 2003, there were approximately 200000 renewable energy jobs in the EU (European Commission, 2004). Worldwide, 600000 people are employed in the solar thermal industry, 300000 in the wind power industry, and 170000 in the solar PV sector, with half of these jobs located in

12. See Hunt and Watkiss (2007). 
emerging and developing economies (UNEP, 2008). In all renewable energy sectors, costs have fallen dramatically due to improved technologies. Nevertheless, while sizable growth and increasing employment opportunities are expected in the renewables sector in the coming decades, ${ }^{13}$ renewables most appropriate for deployment in urban areas are not yet cost-effective compared to conventional energy sources as they currently require more capital and labour inputs for a given amount of output. Renewable installations are in fact more short-lived (on average 25 years versus 40 years for coal and gas), and have a lower capacity factor (operating on average $25 \%$ of the time, with respect to about $80 \%$ of fossil fuel plants). There are large differences in costs across technologies: distributed generation is currently more expensive than centralised generation, residential solar PV is more expensive than commercial solar PV, solar PV is more expensive than solar thermal, solar is more expensive than wind, and onshore wind can be cheaper than natural gas (Figure 14).

Figure 14. Renewable energy cost differences

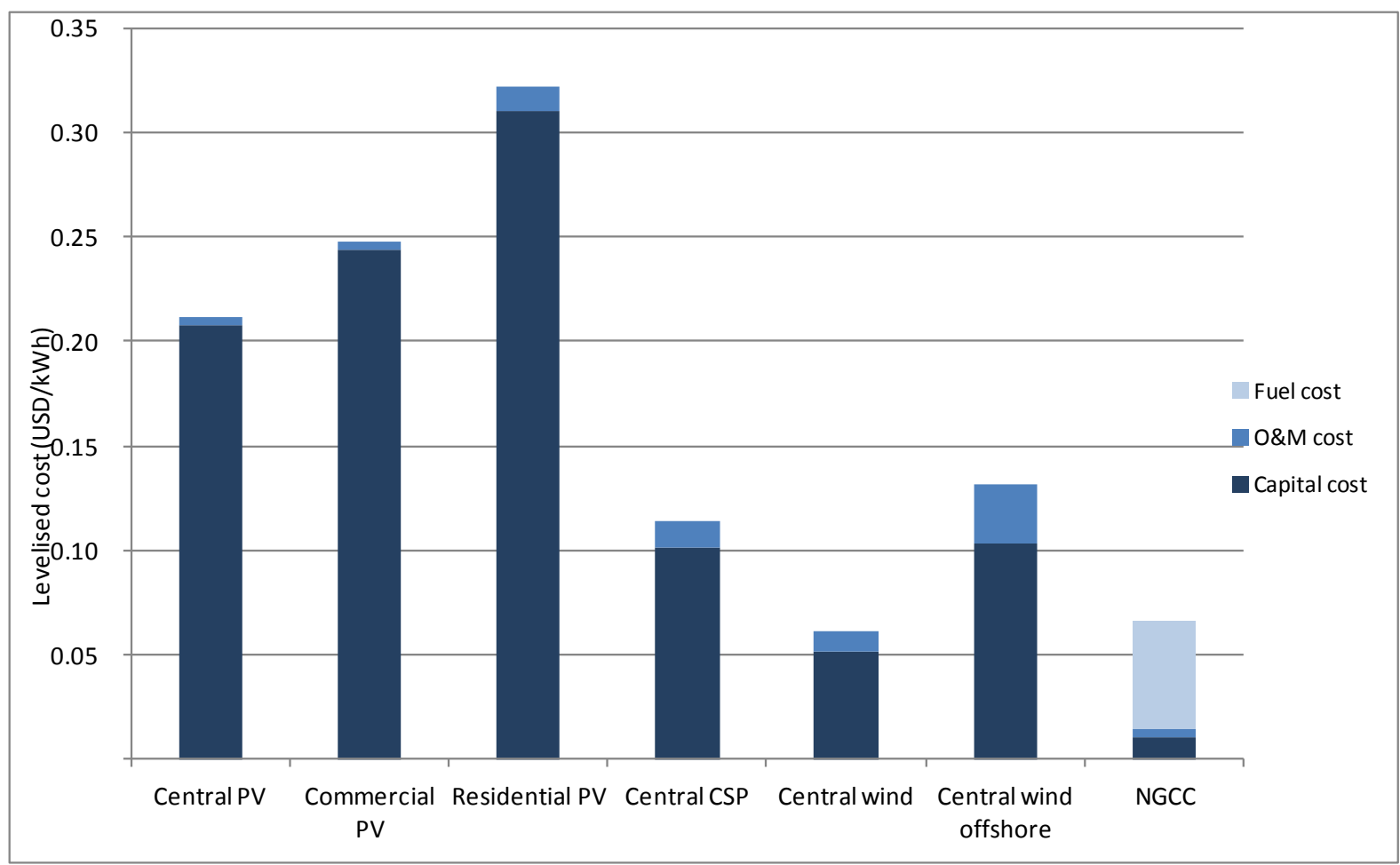

Note: NGCC is combined cycle natural gas. Central CSP is concentrating solar power. PV is photovoltaic. O\&M is operations and maintentance.

Source: Levelised costs are early 2009 estimates based on Kahrl, F., W. Tao and D. Roland Holst (2009), Municipal Climate Policies: Scope, Economics, and Institutions, Center for Energy, Resources, and Economic Sustainability, University of California, Berkeley.

102. Energy efficiency strategies are currently more cost effective in urban areas than renewable energy generation and distribution. Recent empirical analysis for California suggests that at USD $0.027-0.034 / \mathrm{kWh}$, the average resource costs of energy efficiency are well below the cost of generation and significantly below the cost of distributed renewable energy (Shin, 2009). In addition to direct savings, energy efficiency shifts expenditures from a low value-added, capital-intensive

13. Under one growth scenario, the IEA estimates that total investment in building-based solar PV systems could reach USD 653 billion for the period 2010-203 (IEA, 2010a). 
sector (energy) to higher value-added, labour-intensive sectors (e.g. energy efficiency services). For cities, expenditure shifting has the added benefit of redirecting expenditures from energy, whose revenues are likely to be re-invested outside the city, to sectors that are more likely to be local (e.g. services) and can be reinvested in the local economy, producing multiplier effects that have a positive impact on growth.

103. Investments in renewable energy today are nevertheless likely to reap benefits and generate employment over the medium to long-term. Renewable technologies are generally more labourintensive than investments to expand fossil fuel-based energy generation, in which the majority of jobs are in fuel processing, a relatively capital intensive activity. Kammen et al. (2006) estimate that the installation of $1 \mathrm{MWa}$ of wind turbine capacity creates between 0.7-2.9 times as much permanent employment vis-à-vis a comparable natural gas combined cycle (NGCC) power plant, whilst the installation of $1 \mathrm{MWa}$ of rooftop solar PV creates an estimated 7.8 times more employment than a NGCC power plant. In addition, the impact on local employment tends to be higher as the demand for system installers and maintenance engineers is more likely to draw from the local labour pool. A distinction should be made, however, between large-scale, centralised renewable energy installations and small-scale, decentralised renewable energy systems. Distributed solar PV, in particular, has a high level of labour intensity as a result of the large number of systems required to achieve the desired system capacity target. For instance, the installation of a single $100 \mathrm{MW}$ solar PV array in an open field far from the city requires significantly less labour than that of $100 \mathrm{MW}$ of $4 \mathrm{~kW}$ residential rooftop PV systems (i.e. 25000 systems) within an already built-up urban area. There are also significant differences across renewable technologies, in particular concerning labour demands for facility maintenance and operation.

104. Strategies to increase the supply (e.g. feed-in tariffs) or demand for clean energy (e.g. financial incentives to use renewable energy or adopt energy efficiency systems and equipment) can help build the renewable energy market over the medium and long-term. Feed-in tariffs are generally established at the national level (they have played a decisive role in attracting renewable energy investment in Europe), although they can be developed locally, as in the case of two US cities, Gainesville, Florida and Los Angeles, both in 2008 (GRU, 2010). Through feed-in tariffs systems, producers of renewable energy feed solar electricity into the public grid and receive a premium tariff per generated $\mathrm{kWh}$, reflecting the benefits of renewable electricity compared to electricity generated from fossil fuels. Feed-in-tariffs operate over a fixed period of time, reducing uncertainty in anticipated revenues. Other strategies to facilitate renewable energy use include direct purchasing of renewable electricity, biofuels and renewable equipment, possibly jointly by several municipalities, which can support the growth of energy efficiency or renewable energy SMEs. Soft loans and guarantees provided by city or regional governments can also be highly attractive for renewable energy project developers.

105. The employment effects of energy policies may also be significant, particularly in carbonintensive sectors. Adjustment costs resulting from energy policies are likely to lead to job losses in carbon-intensive sectors, as well as additional job losses along the value chain. The extent to which such displacement problems will occur in an individual city are not clear, but may be significant only if renewable power and other distributed forms of power generation become so prominent that they eliminate the need for one or more large central station power plants in the city.

106. A growing number of cities have undertaken assessments that focus on the quantification, rather than the monetisation, of the economic effects of energy use (Hunt and Watkiss, 2007). Most city-level studies have found that rising temperatures will lead to increased energy use in cities, ranging from a $20 \%$ to $40 \%$ increase by 2080 among those cities surveyed. Cayan et al. (2006) estimated that a $3 \%$ increase in electricity demand in California by 2020 would translate to 
approimxately USD 1.2 billion nominal dollars annually in additional electricity expenditures (Cayan et al., 2006).

\section{Mobility}

\section{What are cities doing?}

107. The movement of people and freight in and around urban areas, while fundamental to the functioning of urban economies, can have substantial environmental and economic consequences. The transport sector is responsible for $23 \%$ of world $\mathrm{CO}_{2}$ emissions from fossil fuel combustion $(30 \%$ in OECD countries) and a source of tremendous localised pollution pressures. For example, Cape Town, South Africa, registered 128 days of poor air quality in 2007, in which levels exceeded International World Health Organization air quality guidelines. Vehicles contributed 65\% of that pollution load (OECD, 2008b). The cost of overburdened urban transport networks can create a drag on the local economy. In Randstad-Holland, for example, annual congestion costs were estimated at EUR 1.6 billion, approximately $0.8 \%$ of the regional GDP (OECD, 2007a), whilst traffic congestion costs increased 27\% between 1999 and 2002 in Seoul (OECD, 2005).

108. Governments can employ a range of policy tools to green transportation in their capacity as regulatory authorities, managers of public transit systems and road networks, purchasers, and advocates of local non-governmental action, or through direct expenditures and incentives. Green transportation policies employed by local authorities can seek to:

i. $\quad$ decrease personal vehicle use and manage traffic demand;

ii. increase the use of public transportation systems;

iii. support non-motorised means of travel;

iv. increase vehicle fuel efficiency and use of alternative fuels; and

v. prevent disruptions to the transportation system due to flooding or extreme temperatures, which, as a result of climate change, represent a heightened risk to urban infrastructure.

109. Local governments can discourage personal vehicle use by using their authority to regulate vehicle circulation, parking and speed limits, but reliable alternatives must be provided to maintain competitiveness. To limit vehicles in the city, local authorities can restrict car usage in designated zones or during certain times of day (by implementing congestion charges or toll gates, for instance), increase parking fees, reduce parking spaces or reduce speed limits in certain zones. These restrictions are often applied in central business districts and regional employment or retail centres (Cambridge Systematics, Inc., 2009). To avoid localised displacement impacts, restrictive policies should target zones that strongly attract employees or consumers and therefore can compete with areas that are more easily accessible by personal vehicles. To maximise effectiveness, policies to discourage personal vehicles should be combined with policies to increase mass transit service, quality and multi-modal linkages (ECMT, 1995).

110. Local governments can also decrease personal vehicle use by encouraging employer-based commute strategies. The city of Toronto has partnered with large employers to develop plans that incentivise employees to take alternate forms of transportation in the city's Smart Commute Programme. Some cities have begun to provide shared-car services through concessionaries, including Hanover. Cambridge Systematics, Inc. (2009) estimated that employer-based commute strategies 
(including vanpools, employee parking pricing and tele-work policies) can result in a reduction of up to $1.7 \%$ in baseline greenhouse gas emissions, similar to the results of congestion pricing schemes.

111. To increase ridership on public transit, local authorities can make improvements to the existing transportation network or seek to boost demand by subsidising the cost of transit, as is the case in many Chinese cities (Hu et al., 2010). Physical improvements can include policies to enhance the attractivity and safety of the system or efforts to better communicate service times and delays to customers (ECMT, 1995). Many local transportation agencies, including those in Stuttgart and Paris, have implemented real-time signage systems to communicate expected arrival times to mass transit customers. Improvements to the public transit system should to be carefully planned to provide attractive alternatives to personal vehicle travel and to maximise co-benefits while minimising potentially negative impacts. Transit routes should serve areas with high concentrations of employment, retail and social activities and residential neighbourhoods, without increasing demand for undeveloped land. Expanding services can also result in higher property rents in newly served areas. Noise and other potential environmental impacts, such as pollution from buses, may aggravate discrepancies in pollution and other environmental hazards depending on the location and concentration of expanded services (OECD, 2002).

112. Local governments can use their regulatory control over the road system to increase the share of non-motorised travel, particularly biking and walking. Cities can facilitate biking, for example, by replacing lanes for vehicle traffic with protected bike-only lanes and installing clear signage of bicycle routes and right-of-way. By improving road safety, these efforts can have an even larger impact on the attractivity of biking than the implementation of city-operated shared bicycle rentals, such as Paris' Vélib', Rio de Janeiro's Samba and Montreal's Bixi, which have been widely touted for their potential to reduce greenhouse gas emissions. Traffic calming strategies, which replace intersections with traffic rotaries, the installation of speed reduction humps or road barriers, or the improved design of sidewalks, can all contribute to increased pedestrian and cyclist safety and encourage travel by bike and foot.

113. Local authorities can also pursue alternative modes of transport to manage freight movement in and around the city. Vehicles moving goods compete for scarce road space and produce noise and air pollution. The Greater London Authority has developed a freight plan which seeks to improve the efficiency of freight distribution, which includes modal share, fleet efficiency improvements, off-peak hour deliveries, construction and retail office freight consolidation depots and road user and bio fuel policies (TFL, 2008). Some options might impose short-run costs on freight vehicle operators, while others would result in fuel savings. Whether these policies would result in price changes for customers is unclear (Zanni and Bristow, 2010). Some European port cities provide incentives for alternatives to truck transport: Antwerp provides subsidies for inland river transport, while Rotterdam has dedicated freight railways. Paris imposes restrictions on trucks entering the city centre, and other cities seek to stimulate cleaner truck transport (the Clean Trucks programme in Long Beach/Los Angeles, or charging for polluting trucks in Busan). In addition to strategies to incite a modal shift for freight movement, the greening of freight can also include reconfiguring the location of ports and distribution and logistics centres outside metropolitan areas (e.g. the extended gateway concepts in Antwerp and London, and Helsinki's siting of its port outside the city centre).

114. In their capacity as purchasers and regulators, local governments can increase vehicle fuel efficiency, although their impact may be limited. Many cities have established procurement policies requiring the purchase of hybrid or alternative-fuel vehicles buses and other vehicles in the local government fleet. The City of Toronto, for example, has established the Green Fleet Plan, which has already resulted in a 10\% reduction in emissions from use of the City's 4000 vehicles (Bekkering, 2009). Because government fleets seldom constitute more than $1 \%$ of greenhouse gas emissions within 
most jurisdictions, however, policies focusing on reducing government-owned vehicle emissions are not a substitute for comprehensive approaches to emission reduction. Initiatives like "cash for clunkers" programmes, which pay owners to dispose of old, highly polluting vehicles in order to reduce local pollution levels and encourage the use of more fuel efficient vehicles, have been launched by national governments as part of their economic stimulus package (Hicks, 2009). Some cities, like Beijing, offer up to USD 3700 give up heavily polluting vehicles and provide subsidies to purchase more fuel efficient ones (Hu, 2008).

115. Cities can also take the lead on promoting the use of renewable fuels and power for transportation and supporting the development of new technologies. For example, the Eindhoven metropolitan region in the Netherlands was a key actor in the development of a low-emission public transport vehicle that is controlled by a magnetic system built into the road and that connects various communities within and around Eindhoven to major regional facilities, including the airport (OECD, 2009h). Other cities, like Paris, have provided funding to purchasers of electric motorcycles (City of Paris, 2009).

116. Finally, reducing infrastructure vulnerability to climate change impacts can be a pro-active strategy intended to reduce future economic losses. Transportation infrastructure is increasingly vulnerable to climate change impacts, such as flooding and heat extremes. Public transportation systems are at risk for flooding due to storms and rising sea levels, particularly in - but not limited to coastal areas. It is vital for cities to assess and plan for sea-level rise, storm-surge and other storm impacts that exceed existing 100-200 year plans. Below-ground transportations systems are particularly susceptible to water damage. Effects from extreme temperatures can also disrupt mass transit systems if they exceed the heat thresholds for which roadways and public transportation systems have been designed. Currently, most transit system agencies have not yet started making improvements to infrastructure, although some cities have developed plans for protecting infrastructure from coastal flooding. Copenhagen, for instance, built flood risk into the design of its metro stations. Boston's Deer Island wastewater treatment plant, built in the 1990s, was constructed on higher ground and at higher cost than originally planned to accommodate an anticipated sea-level rise (Heinz, n.d.). Concern about climate change impacts has begun to shape future infrastructure development (see also Hunt and Watkiss, 2007).

\section{What are the potential economic impacts?}

117. Most research on transportation policy outcomes has consisted of environmental impact or co-benefit analyses designed to inform policymaking, rather than ex-post studies investigating the economic impact of these policies in terms of GDP growth, job creation, local real estate asset valuation or individual well-being. Nevertheless, UNEP (2011) summarises the costs and benefits of 10 different transport initiatives in cities around the world, including bus rapid transit projects, congestion pricing schemes and bike rental programmes, with some programmes reportedly delivering savings of many millions of dollars per year. In general, while most public transport revenues are rarely sufficient to cover operating expenses (Singapore is an exception), the public transportation sector often represents a significant public employer: 164,043 persons employed in operating the public transportation sector in Mumbai, 78393 in New York and 24,975 in London. In California, employment in the green transportation sector increased by roughly $16 \%$ between 1990 and 2008, now totalling more than 36000 jobs across 21 regions in the state, although growth rates have been uneven across sub-regions (Center for Community Innovation, 2010).

118. Local authorities may benefit from both ex-ante and ex-post studies of green transport strategies that seek to measure the following types of variables to track change over both the shortand long-term: 
- Employment

- Direct impacts: employment levels of public transit authorities or local vehicle sales/repair/maintenance firms

- Indirect impacts: employment levels at non-transport businesses affected by modal shift (e.g. stores that gain or lose business due to changes in pedestrian or vehicle access to their store) or employment levels at businesses that experience changes in productivity due to reduced vehicle congestion

- Goods and Services

- Direct impacts: public or private transit system revenues, vehicle or bicycle sales/rental revenue, sales of direct and ancillary services (e.g. vehicles, fuel, vehicle repairs and maintenance, car wash sales, tire sales)

- Indirect impacts: business revenues at non-transport businesses affected by modal shift (e.g. stores that gain or lose business due to changes in pedestrian or vehicle access to their store), business revenues or productivity levels resulting from reduced vehicle congestion

- Government revenues

- Direct impacts: public transport system revenues, taxes (e.g. fuel, sales, vehicle license fees, property taxes from areas affected by changes to transport system access)

- Indirect impacts: sales taxes from businesses affected by changes to customer access to their business

- Individuals

- Direct impacts: level of individual productivity or travel time, travel-related expenditures, real estate values (e.g. changes as a result of increased/decreased access to public transportation)

- Indirect impacts: health impacts resulting from changes to local pollution levels, quality of life (noise, air quality) as a result of shifting modal choice or changes to the local transportation network

\section{Buildings}

\section{What are cities doing?}

119. The built environment, in terms of building design and location, is responsible for a large share of energy consumption and greenhouse gas emissions in urban areas and faces challenges from anticipated climate impacts, including urban heat-island effects, flooding and related extreme weather events. For example, greenhouse gas emissions from buildings in the City of New York accounted for $79 \%$ of the city's total emissions in 2005 (City of New York, 2007). Public authorities seek to reduce the carbon footprint of the building sector through a mix of policies that relies heavily on regulatory authority and enforcement (namely permitting and building codes), yet also direct expenditures, subsidies and other financial incentives, technical assistance, and education and advocacy programmes. Greening strategies can target increasing the energy efficiency of the building sector, facilitating the transition to cleaner energies or adapting buildings to resist to climate change threats.

120. Policies to reduce greenhouse gas emissions through increased building energy efficiency can target improved building design (including green roofs), energy retrofits and improved technologies. Increased energy efficiency in buildings can also have tremendous co-benefits in the form of reduced energy expenditures for building occupants, reduced risk of blackouts during extreme heat events, enhanced property values and health benefits associated with lower levels of air pollution due to unnecessary electricity and heat generation. 
121. Building codes are one of the most important policy levers in the development of greener cities. Energy efficiency regulations can be adopted in local building codes, setting building design and placement criteria to reduce the demand for energy to light, heat and cool buildings. In 2006, the city of Shenzhen became the first Chinese city to establish local building energy efficiency regulations and has since set targets to reduce energy consumption by $20 \%$ for existing buildings and by $50 \%$ for new construction (OECD, 2010f).

122. The effectiveness of building codes can be constrained by several factors, however, particularly in terms of compliance and enforcement (UNEP, 2007). Since building codes typically apply only to new construction and renovations, their benefits are only felt over the long term (IEA, 2005). In some cities, stringent efficiency standards often only apply to projects over a certain size, limiting the impact of local regulations. Building codes may also discourage innovation because developers rarely have an incentive to exceed efficiency standards (IEA, 2008c). Performance-based codes, which set a total requirement for the building based on the supply of energy or the resulting environmental impact, may provide more incentives for innovation, but require a comprehensive and reliable method for calculating the energy performance of a building (IEA, 2008c). Finally, due to strong opposition of stakeholders, it is often difficult to set energy efficiency requirements strict enough to generate significant reductions in greenhouse gas emissions or sufficient protection against potential climate change impacts (OECD, 2003a). Some fear that strict local building codes will reduce a city or region's competitiveness if they lead builders to seek locations in adjacent areas with more lenient building regulations; this discussion warrants more in-depth study. National building energy efficiency standards can reduce the risk of regional competition based on building codes and could potentially result in more uniformly strict standards across cities.

123. Large-scale building retrofit programmes represent the most obvious option for a shovelready, green investment to re-employ displaced workers or create new jobs. Jobs can be created immediately, with no need for land acquisition or the repair or replacement ofdeteriorated assets. Further, the technology to reduce energy consumption in buildings already exists and simply needs to be deployed. Current practice in retrofit programmes makes possible a considerable reduction in building maintenance costs and in the repair and replacement of worn-out elements. While regional and city governments may be tempted to focus on standards for new construction projects as the primary means for reducing energy demand from buildings, retrofitting the existing stock is a more labour-intensive activity with greater impact on building energy demand. In most cities, energy retrofits of the existing buidling stock have the greatest potential for achieving large-scale, long-term environmental impacts: in France, for instance, $70 \%$ of the projected 2050 building stock exists in 2005, underscoring the stakes of the evolution in the energy efficiency of the existing stock (IDDRI, 2010). Finally, retrofitting public-owned residential complexes has the important complementary benefit of increasing the market value of dwellings, making residential areas more attractive.

124. Cities can also take on an information dissemination role. In both Osnabruck and Freiburg, Germany, the local authority deployed an aerial laser scanning system to map the rooftops of each building in the city. The orientation and slope of each roof and potential shadowing from trees, chimneys and adjacent buildings is reflected in the database, allowing building owners to know exactly how much solar PV potential they have on their rooftop (IEA, 2009b). In San Francisco, similar data is available via a web page on the local government website. ${ }^{14}$ In the first two years that the solar map was on-line, total solar PV deployment around San Francisco nearly doubled

14. See http://sf.solarmap.org/ 
(Hyams, 2009). The city of Paris has developed an online thermographic map of the city, allowing residents to visualise the energy efficiency of Paris buildings (City of Paris, 2011).

125. Local authorities can also partner with the private sector or provide information and technical support for energy retrofits or support energy-efficient labelling schemes, although the benefits of these strategies are greatest where heating and cooling loads are high. Berlin pioneered a model of enabling retrofitting of privately owned buildings by energy system companies (ESCOs), whose energy efficiency investments are gradually paid back by the building owners through the reduction in energy costs they realise. The Berlin Energy Agency provides technical assistance to local building owners who form "Energy Savings Partnerships" to issue tenders to the ESCOs, with the goal of achieving annual $26 \%$ savings in energy costs $(C 40,2007)$. Toronto provides information and technical support to owners of large buildings to promote energy efficiency retrofits (Bekkering, 2009). Cities can also facilitate the use of voluntary building labelling schemes, like Leadership in Energy and Environmental Design (LEED), to promote the deployment of energy efficiency strategies in new and retrofitted buildings. ${ }^{15}$ A review of 100 LEED certified buildings found that on average, these buildings use $18-39 \%$ less energy per floor area than conventional buildings, although this is not universally true - some $28-35 \%$ of these buildings actually use more energy than their counterparts, which could ultimately undermine developer or policymaker confidence in such labelling schemes (Newsham et al., 2009). At the supranational scale, the European Union has mandated the adoption of energy performance labels for buildings. Whether the labelling scheme has resulted in actual energy upgrades is unclear. There are concerns that consumers are not making full use of the labels, making their value uncertain (Gram-Hanssen et al., 2007). Governance of these kinds of programmes can be complex and require a good monitoring system and a competitive energy performance contracting industry (IEA, 2008c).

126. The installation of energy-efficient technologies in local government-owned properties has become widely promoted in local sustainability and climate action plans (Wheeler, 2008). Such efforts will generally be easier to implement than policies for private buildings, and can serve as a model for privately funded energy efficiency projects. New York City's Greener, Greater Buildings Plan is expected to create 17800 construction-related jobs in energy auditing, retro-commissioning, upgrading lighting, and maintaining equipment (City of New York, 2009). The city of Freiburg, Germany, allocated a budget of EUR 2 million to the renovation of the city's old and historical buildings. This includes the non-intrusive, strategic installation of 180 solar PV panels on the tiled roof of the old City Hall. Cape Town launched an ambitious programme, the Kuyasa Energy Efficiency Project, in which the city retrofits existing houses in low-income neighbourhoods with solar water heaters, insulates ceilings and supplies energy-efficient light bulbs (OECD, 2008b).

127. District heating and cooling systems, which capture heat produced in energy generation to heat or cool water for all buildings connected to the systems, increase the energy efficiency of buildings and have the added benefit of being able to be applied incrementally at appropriate scales. Moreover, given that district energy systems connect to both new and existing buildings, they are an effective way of altering the energy demand of existing building stock. One of the most comprehensive district heating systems is in Copenhagen, providing $97 \%$ of the city's total heating needs; Stockholm, Sweden and Mannheim, Germany also have large district heating systems, and are experimenting with the use of biofuels. Toronto, Canada, has enabled the creation of a district cooling system by establishing a corporation that has connected most of the major downtown office buildings

15. For example, the City of Boston approved a green building zoning code in January 2007 that requires all construction projects exceeding 50,000 square feet to be designed and planned to meet the US Green Building Council's (USGBC) LEED “certified” level standards (City of Boston Redevelopment Authority (n.d.)). 
to a deep lake water cooling system and which has resulted in a significant decrease in electricity demand for air conditioning (Bekkering, 2009). Paris also has a large district cooling system serving commercial buildings in the central business district. Regulatory changes requiring buildings within a designated zone to connect to the system allow district heating and cooling projects to realise energy efficiency gains for a large number of energy consumers.

128. In addition to the aforementioned strategies to improve the energy efficiency of buildings, cities can also implement policies to support the use of clean and/or renewable energy sources. Programmes to require or enable use of renewable or captured energy sources can have a large-scale effect on demand for low-emissions energy sources. Barcelona's Solar Thermal Ordinance, which requires all new buildings and major renovations to use solar thermal collectors to supply at least $60 \%$ of the energy used to heat water, led to similar ordinances in over 60 other Spanish municipalities. In the Greater London area, building codes requiring renewable energy generation have expanded to communities across the UK.

129. Strategies to green the building sector have important impacts on social equity. Many researchers and policymakers have debated the "double jeopardy" of poorer households, often faced with poorly insulated housing that results in higher energy bills. Increased energy efficiency can reduce household energy bills. Nevertheless, energy retrofits of housing in urban areas tend to increase prices (engendering a "green" premium), while newly developed green neighbourhoods are rarely made affordable to low-income households (see IAU study on the Paris region (forthcoming)). Many cities, including Paris, are struggling to build green buildings without displacing low-income residents (and some successful cases do exist). More research is needed to determine how greening policies affect poor or vulnerable populations.

130. Finally, local governments face a challenge in revising local building regulations to address potential climate change scenarios, particularly those that expose the built environment to flooding and extreme storm events. Building codes that require minimum floor height requirements in new developments located in areas at risk for flooding and extreme storms represent an underutilised adaptation opportunity. The challenge for local governments is to assess the nature of the threat compared to existing metrics such as the commonly used 100-200 year flood designation. Building codes are not sufficient to address flood vulnerabilities, however, because they typically only affect new construction and major renovations. They must therefore be combined with additional flood mitigation measures, such as retrofitting and infrastructure investments.

\section{What are the potential economic impacts?}

131. In addition to cost and energy savings, positive economic impacts have been demonstrated in the green building design and construction sector in recent years. For instance, building codes that mitigate urban heat islands provide co-benefits by reducing the demand for energy to cool buildings. Akbari et al. (1999) estimate energy cost savings from cool roof deployment in eleven metropolitan areas around the United States could result in annual electricity savings of $10 \mathrm{TWh}$, peak power demand reductions of $7 \mathrm{GW}$, and a total net annual savings of approximately USD 750000 . The benefits do not accrue equally across all buildings, however. It is estimated that well-insulated buildings in Athens will achieve a total annual energy savings of just 2\% if they are retrofitted with a green roof; by contrast, non-insulated roofs - which are very common in many European cities - can achieve total annual energy savings of 31 to $44 \%$ (Castleton et al., 2010). A study assessing the environmental impacts of the introduction of energy-efficiency recommendations in the building code in Gainesville, Florida, found that homes built after the new building code took effect consumed less energy (on average $48 \mathrm{kWh}$ less electricity and 1.5 fewer therms per month) than homes built just before the introduction of the new code. These energy savings generated a reduction in energy bills of 
up to USD 106 per year; after factoring in the cost premium of installing energy-efficiency equipment, the private payback period was approximately 6.4 years (Jacobson and Kotchen, 2010).

132. The job creation potential of green building design and construction is presumed to be significant. Employment growth in the green building sector has occurred in several US cities, like Chicago and the Boston area, while the presence of third-party certification systems in the green building sector has made it possible to track the number and associated revenues of green design projects. For example, in the US, the 100 largest green design firms generated USD 1.74 billion in revenue in 2007 , representing $7.4 \%$ of these firms' total design revenue (Tulacz, 2008). Total revenue from green design projects among the 100 largest firms increased by 35\% between 2008 and 2010, from USD 2.46 billion to USD 3.33 billion (Tulacz, 2010). By 2010 the revenue was also more diversified, with USD 524 million (around $16 \%$ of the total) in revenue generated by overseas projects.

133. What is more, construction jobs, unlike architecture or design jobs, are primarily seen as local jobs that will not be outsourced to firms outside the region. A report prepared for the US Green Building Council estimates that non-residential and residential green construction projects resulted in USD 175 billion in GDP activity in the US between 2000 and 2008, employing 2.4 million people. Between 2009 and 2013, this market is expected to expand to USD 560 billion in economic activity employing approximately 8 million workers (Booz Allen Hamilton, 2009). In California, green building jobs have increased an average of $1.1 \%$ per year during the period 1990-2008, although this occurred quite unevenly across the state. Los Angeles reportedly has lost green building jobs, while Oakland and other East Bay Area cities have enjoyed annual growth rates of over 7\% (Center for Community Innovation, 2010). Recent studies have found links between green buildings and increased labour productivity (see Kats, 2003 and Miller et al., 2009).

134. Some evidence suggests that green buildings can be sold for a premium, compared to standard buildings. In China, developers of green buildings report they can receive favourable land prices, improved access to financing and higher sales prices, although no hard data is provided to support these claims (Zhang et al., 2011). A study examining the urban real estate market in Taiwan echoed these findings (Chang and Chou, 2010). In the United States, studies have found that properties in eco-labelled ${ }^{16}$ buildings often benefit from higher rental and sales prices and occupancy rates relative to non-labelled buildings and tend to deliver a positive net operating income (Table 3 ). ${ }^{17}$ There is less evidence available as to whether eco-labelled buildings are more profitable to developers (Fuerst and McAllister, 2011b), once any additional costs incurred to achieve the eco-label (such as specialised construction materials, filings, studies or other payments required to obtain ecocertification) are factored in. Some studies suggest there is a cost premium to green building (Kats, 2003), but a recent comparative analysis of 83 green buildings and 138 similar non-green buildings found the construction cost differential to be insignificant (Matheissen and Morris 2007). The "green premium" poses challenges to social equity, however. More research is needed to establish these links and develop best practices for creating socially equitable green building policies.

16. Notably, two programmes: (1) Energy Star, a joint programme of the US Environmental Protection Agency and the US Department of Energy designed to save money and protect the environment through energy efficient products and practices, and (2) the LEED green building certification programme, which encourages and accelerates the global adoption of sustainable green building and development practices through a suite of rating systems that recognise projects that implement strategies for better environmental and health performance.

17. See, for instance, Miller, N., J. Spivey and A. Florance (2008); Wiley, J, J. Benefield and K. Johnson (2010); Fuerst, F. and P. McAllister (2011a), and Fuerst, F. and P. McAllister (2009). 
Table 3. Eco-labelled buildings often benefit from higher rental/ sales prices and occupancy rates

\begin{tabular}{|c|c|c|c|}
\hline Authors & $\begin{array}{l}\text { Office building rent price } \\
\text { premium due to eco- } \\
\text { label }\end{array}$ & $\begin{array}{l}\text { Office building sales } \\
\text { price premium due to } \\
\text { eco-label }\end{array}$ & $\begin{array}{l}\text { Office building } \\
\text { occupancy rate } \\
\text { differential }\end{array}$ \\
\hline Miller et al. (2008) & $\begin{array}{l}\text { No statistically } \\
\text { significant premium for } \\
\text { either Energy Star or } \\
\text { LEED }\end{array}$ & $\begin{array}{l}\text { Energy Star }=+6 \% \\
\text { LEED }=+11 \%\end{array}$ & \\
\hline Wiley et al. (2010) & $\begin{array}{l}\text { Energy Star }=+7 \% \text { to } \\
9 \% \\
\text { LEED }=+15 \% \text { to } 18 \%\end{array}$ & $\begin{array}{l}\text { Energy Star }=+30 / \text { sq.ft } \\
\text { LEED }=+\$ 130 / \text { sq. ft. }\end{array}$ & $\begin{array}{l}\text { Energy Star }=+10 \% \\
\text { to } 11 \% \\
\text { LEED }=+16-18 \%\end{array}$ \\
\hline $\begin{array}{l}\text { Fuerst and McAllister } \\
\text { (2011a) }\end{array}$ & $\begin{array}{l}\text { Energy Star }=+4 \% \\
\text { LEED }=+5 \%\end{array}$ & $\begin{array}{l}\text { Energy Star }=+26 \% \\
\text { LEED }=+25 \%\end{array}$ & \\
\hline $\begin{array}{l}\text { Fuerst and McAllister } \\
(2009)\end{array}$ & & & $\begin{array}{l}\text { Energy Star }=+3 \% \\
\text { LEED }=+8 \%\end{array}$ \\
\hline Eicholtz et al. (2010) & $\begin{array}{l}\text { Energy Star }=+3.3 \% \\
\text { LEED }=\text { no statistically } \\
\text { significant difference }\end{array}$ & $\begin{array}{l}\text { Energy Star }=+19 \% \\
\text { LEED }=\text { no statistically } \\
\text { significant difference }\end{array}$ & \\
\hline $\begin{array}{l}\text { Fuerst and McAllister } \\
(2011 b)\end{array}$ & $\begin{array}{l}\text { Energy Star }=+3 \text { to }+4 \% \\
\text { LEED }=+4 \text { to }+5 \% \\
\text { Dual certification }=+9 \%\end{array}$ & $\begin{array}{l}\text { Energy Star }=+18 \% \\
\text { LEED }=+25 \% \\
\text { Dual certification }=+28 \\
\text { to }+29 \%\end{array}$ & $\begin{array}{l}\text { Energy Star }=+1 \% \text { to } \\
+3 \% \\
\text { LEED }=-5 \% \text { to }-6 \% \\
\text { Dual certification }=-5 \% \\
\text { to }-6 \%\end{array}$ \\
\hline
\end{tabular}

135. The number of individuals with green building certification (e.g. LEED, BREAM, etc.), which has been increasing in cities worldwide, can be an indication of future economic potential. Although LEED-certified professions tend to be most prominent in large US cities, according to the Green Building Certification Institute there is a growing number of certified experts in cities in other countries as well. Should green building certification programmes gain more traction in cities across the globe, resulting in increased demand for local green building expertise, the presence of a skilled workforce in some cities could generate more immediate economic benefits.

\section{Natural Resources Management}

136. Cities are heavily reliant on natural resources, such as water, open space, urban forestry, urban agriculture and local biodiversity, to sustain life and economic activity and provide other ecosystem service functions. Water and land resources are nevertheless under constant pressure from overexploitation and are often given lower priority in terms of public investment, when compared to transportation or economic develompent. Local authorities must ensure an adequate clean water supply and wastewater treatment and balance development needs with those for open space, parks and natural habitats, which are essential to fostering a satisfying quality of life, preventing pollution and maintaining ecosystem services.

Water management ${ }^{18}$

What are cities doing?

137. Ensuring affordable access to clean drinking water is an ongoing challenge in urban areas, particularly in fast-growing cities, and, in both OECD and non-OECD countries, can be mired by significant governance challenges. While water scarcity may pose challenges in some areas, the

18. Wastewater management and water quality issues will be further discussed in the section below on pollution prevention, treatment and abatement. 
current water "crisis" is in reality one of mismanagement and fragmented public governance (OECD, forthcoming). The intersection of the water sector with other related areas (energy, agriculture, land use planning, transportation) makes water governance all the more complex. Not only do water pumping and distribution systems used to supply the city consume significant quantities of energy, they are also vulnerable to hard-to-detect leaks. Water resources feeding dense urban areas are increasingly vulnerable to pollution from agriculture or industrial runoff. Water supplies in many regions are increasingly fought over, pitting urban residents and businesses against agriculture interests outside of the city. These supply challenges are compounded by climate change-related conditions that may affect availability at different times of the year. Water service provision can be costly and carbon intensive because of the energy demanded by water treatment, pumping and other water provision activities. For example, in 2001, approximately 19\% of all the electricity used in California was related to water-related consumption (California Energy Commission, 2005).

138. In both OECD and non-OECD cities, the governance challenges plaguing the water sector are most often insufficient technical and human capacity within local governments to manage water resources, difficulties in cross-sectoral co-ordination (e.g. with the energy, agriculture, transportation and land-use planning sectors), and persistent financing challenges (including debates about water pricing and investment in system retrofits and innovative technologies) (see OECD, 2011e). A lack of cross-sectoral policy coherence poses problems in many OECD and non-OECD countries, with clear implications at the local level. Water processing can require significant amounts of energy (e.g. recycled wastewater or desalination processes). At the same time, because energy generation often requires large amounts of water (many thermoelectric power plants are cooled by fresh water, for instance), rising energy demand also increases the demand for fresh cooling water, thereby creating competition for water when supplies are scarce (Brown et al., 2010; ACEEE, 2010).

139. Climate change requires changes to local water management that anticipate shifts in demand and confront the potential reduction of water availability and quality. Many cities and regions are currently facing the challenge of planning for and financing much-needed investments in water infrastructure retrofits. The development and implementation of technological advances and processes (e.g. green chemicals, nanotechnolgoies, recycled wastewater, and desalination of sea water) will also be key to addressing global water challenges at the local level. Cities also have a role to play in promoting more efficient water management through smart water policies. Neverthless, the impact of infrastructure investments, technological advances, and smart water policies (including stricter standards for water efficiency and consumer education and awareness programmes) on more efficient water management will be limited in the long-run without enhancing water governance at all levels of government.

140. A range of policies can be implemented at the city and regional level to enhance water efficiency. Investing in ageing water infrastructure was identified as a "top water resources priority" by a US Conference of Mayors survey (Anderson, et al., 2006), though financing remains a major impediment. As an alternative to centralised, piped water supply systems, small-scale systems are gaining traction, particularly in fast-growing cities. Flood management often falls under the responsibility of local and regional governments, and can be addressed by rainwater harvesting and eco-system services planning. Agreements between citiesciteis and the rural environment to protect catchment areas can be effective (e.g. the City of New York). While municipal governments may have a limited role in advancing technological solutions and processes to achieve greater water efficiency (e.g. nanotechnologies, chemistry, recycled wastewater, and desalination of sea water), cities can implement these practices in public facilitites and encourage wider use among citizens.

141. Smart water policies that help achieve water conservation and efficiency goals include proper pricing of water to encourage waste reduction, financial incentives for low-flow appliances, 
proper design of subsidy and rebate programmes, new state and national efficiency standards for appliances, education and information outreach, water metering programmes and more aggressive local efforts to promote conservation. Local and regional governments can enact regulations to increase the use of recycled water. For example, more than 40000 homes in Melbourne, Australia, are required to use Class A recycled water, metered and delivered separately in a distinctive purple pipe, rather than potable water for toilet flushing, washing cars and watering outdoor landscaping. Some cities have begun to shift to energy efficient pumps and leak detection programmes to reduce the amount and cost of energy required to move water around the city. Best practices involve developing policy tools that put water efficiency on par with energy efficiency in buildings. In terms of climate change adaptation, some cities, such as New York City and Crisfield in the United States, have begun to incorporate adaptation strategies into their water supply planning processes; others are conducting assessments of water supply vulnerability.

142. The OECD has identified a preliminary set of guidelines for enhacing water governance, which call for improvements at all levels of government. Recommendations include, among others, involving sub-nationalsubnational governments in water policy design, developing and improving water information systems and databases, encouraging performance measurement to measure and monitor policy outcomes and provide incentives for capacity-building, and improving horizontal and vertical co-ordination among different sectors and levels of government (OECD, 2011e).

\section{What are the potential economic impacts?}

143. Recent OECD work has found that adequate water and sanitation services appear to be a key driver for economic growth, but these links have yet to be adequately tracked and measured (OECD, 2011f). There is evidence that the provision of basic water supply and sanitation services can reap considerable benefits that far outstrip the costs (e.g. research has been undertaken to measure the economic benefits of achieving the Millennium Development Goals), including time gains and reductions in waste-borne diseases, particularly in developing countries. A UNEP study found increased benefits of coupling technological investments with institutional reform (UNEP, 2011).

144. Recent estimates by the US Conference of Mayors indicate that one dollar of water and sewer infrastructure investment can increase private long-term output (GDP) by USD 6.35, though this figure has yet to be confirmed (Krop, et al., 2008). Empirical evidence suggests that pricing policies to manage water demand are more cost-effective than non-market-based conservation programmes and also generate additional benefits in terms of monitoring and enforcement. A recent study of 12 cities in the United States and Canada found that replacing two-day per week outdoor watering restrictions with drought pricing could achieve the same level of aggregate water savings, along with welfare gains of approximately USD 81 per household per summer drought (Mansur and Olmstead, 2007). Toronto's WaterSaver programme, which offers cash incentives for industrial, commercial and institutional facilities to reduce water consu mption levels, generates sufficient reductions in consumption for the city to buy back water or sewer capacity (Raissis in OECD, 2009i).

145. A 2008 study estimated that heavy investment in water efficiency could boost overall GDP and create jobs across a range of sectors, including the construction, manufacturing, retail trade and waste sectors. Because many of these jobs are low-skilled, such programmes could also be used to target pockets of endemic employment (Alliance for Water Efficiency, 2008). A US Council of Mayors report found that adding one job in the water and sewage sectors creates 3.68 jobs in the national economy to support these jobs (Krop, et al., 2008). City-specific data is nevertheless limited, as are studies that quantify employment and economic impacts of water efficiency programmes via expost analyses. 
Land and land-based eco-systems

\section{What are cities doing?}

146. Local authorities, in their roles as land owners and planners of development, open space and environmental resources, can establish land use and land-based ecosystems policies to reduce energy demand, absorb $\mathrm{CO}_{2}$, protect against climate impacts and provide habitats for local wildlife. Natural resource policies can also enhance the effectiveness of land-use zoning policies by improving the quality of high-density areas through the provision of parks and other open space. Local governments are also taking measures to protect urban infrastructure and developed land from potential climate change impacts through public investment for storm water management.

147. Local governments have long been making use of their jurisdiction over environmental features within their boundaries to protect developed land from potential climate change impacts. For coastal cities like New Orleans, Helsinki and Rotterdam, public investment to protect against flooding is a primary adaptation tool. Venice has invested EUR 4.3 billion in massive infrastructure improvements and related waterfront reinforcement to protect the cities of Venice and Chioggia, the lagoon's historic centres, and the broader lagoon basin from the detrimental effects of medium-to-high tides and the devastating economic effects of exceptional tides. The system is designed to ensure ongoing port operations even in the event of sea level rise (OECD, 2010e). Such investments are not without controversy, however, as they can lead to the destruction of ecological resources in order to protect the built environment.

148. Numerous local and regional climate plans are looking to the natural environment as a means to absorb $\mathrm{CO}_{2}$ and reduce overall urban greenhouse gas emissions and potential urban heat island effects. Sejong City, a new city in Korea that will be completed by 2014 with an expected population of a half million by 2030, plans to reduce average city temperatures by $2.5^{\circ} \mathrm{C}$ by devoting over half of its total surface area to parks, greenbelts and waterfronts and operating a water circulation system that draws on natural water resources (Sejong City, 2009). Tokyo has initiated policies for greening projects that include tree-lined streets and rooftop greening. In São Paulo, for instance, the development of linear parks along waterways has served to minimise flooding effects, reduce water pollution, and contribute to the planting of more than half a million trees in over four years (Sobrinho in OECD, 2009i).

149. Land use planning has a major role to play in adapting to climate change. Ecosystem-based adaptation is increasingly practiced at the local level. For instance, parks and natural spaces can be used as an adaptation measure when they are sited in areas most vulnerable to flooding. Dresden, Germany and the Dolnoslaskie region in Poland have implemented adaptation programmes to prevent flooding, minimise and manage rain water and storm water (Socher, 2009 and Zathej, 2009). The Swiss Federal Government provides matching funds to cantons, municipalities and infrastructure owners for implementing protective measures against natural hazards (Jeanneret, 2009). Other cities are increasing their capacity to assess potential impacts. The coastal city of Shenzhen, China, has developed a network of 2,000 automatic meteorological data collection stations to provide a monitoring range of $250 \mathrm{~km}(\mathrm{OECD}, 2010 \mathrm{f})$.

What are the potential economic impacts?

150. The economic impacts of land use policies, including urban forestry programmes, have most often been measured in terms of employment capacity, effects on property values and other cost savings. Landscaping and landscape architecture service industries can be sizable in cities (Hall et al. 2006). Urban forests can also have a profound effect on property values: a Finnish study found that 
proximity to urban forest amenities could increase the value of homes by nearly $5 \%$ (Tyrvainen and Miettinen, 2000). In Lisbon, the city spends approximately USD 1.8 million on its street tree programme each year, but receives USD 8.4 million in benefits in the terms of energy savings, air quality improvements, stormwater treatment and increased real estate value. The benefit-cost ratio of 4.48:1 is high, but less than that reported for New York City (5.80:1) and Indianapolis (6.09:1) (Peper et al., 2007, 2008; Soares et al., 2011). Less quantifiable but no less important benefits of urban forestry programmes are their effect on the mental health of city residents (Louv, 2005), their role in encouraging higher rates of physical activity by area residents (CDC, 2007) and their role in decreasing aggression and mental fatigue, ultimately enhancing community cohesion and liveability (Kuo et al,. 1998; Kuo and Sullivan, 2001; Flores et al., 1998).

\section{Pollution prevention, treatment and abatement}

151. To manage air and water pollution and solid waste in urban areas, local, regional and national governments employ regulatory powers, information and advocacy techniques and direct expenditures.

Air pollution

\section{What are cities doing?}

152. Air quality has a number of co-benefits, including effects on public health, and is heavily influenced by policies in other sectors (notably transportation). Many studies have shown that exposure to air pollution can pose serious risks to human health and natural ecosystems. The most severe health effects of air pollution are from exposure to particulate matter and ozone. It is suggested that there is no safe level for either pollutant: they may even pose a health risk at concentrations below current air quality guidelines (WHO, 2006). Air quality can vary within a city depending on traffic intensity, population density, physical topography and weather conditions. At traffic or industry hot spots, high concentrations of pollutants result from local emissions. However, air pollutants such as ozone, particulate matter and other long-lived pollutants can be transported over very great distances, which can frustrate abatement policies at the local scale.

153. Instruments to address air pollution have focused on direct regulation, environmental taxation and emissions trading, though many of these approaches require implementation at the national scale. Direct regulations include standards for fuel quality used by industry and transport, for emissions from cars and industry, as well as air quality standards and goals for protecting health and vegetation. Whilst these command and control measures have been largely successful, they have also been undermined in part by other developments. Increased car ownership, for instance, may reduce the positive effect of improved fuel quality, for example. The ability of local authorities to regulate or influence the sources of local pollution will vary by city. Cities can take a larger role to address air pollution by targeting related sectors (e.g. transportation and land use). For instance, the adoption of a low-emissions public vehicle fleet can help to reduce air pollution, as can land-use policies that promote compact, transit-linked urban development.

154. Economic instruments such as taxation and emissions trading are increasingly popular. They can be more cost-effective than regulation because they provide an incentive to the market (industry, transport sector) to enact the least costly measures, but most often be implemented at the national level. The use of environmental taxes is still limited but growing in many countries. A database operated by the OECD and the European Environment Agency lists approximately 375 environmentally-related taxes in OECD countries within the energy and transport sectors, not including some 250 other measures, such as environmentally related fees and charges. About $90 \%$ of 
the tax revenues stem from taxes on motor vehicle fuels and motor vehicles (OECD, 2007b). In China, a pilot scheme has been implemented to trade emission credits for sulphur dioxide. In the Seoul Metropolitan Area, an emission trading scheme for sulphur dioxide, nitrogen oxides and particulate matter has been initiated. Successful emissions trading systems depend on a formal legal structure, including an effective compliance system with real consequences for non-compliance. More research is needed to dermine how local experiences with carbon trading can be effective at the local level.

\section{What are the potential economic impacts?}

155. The economic implications of air quality and policies to reduce air pollution can be dramatic, and further enhanced by an integrated policy approach (see Bollen et al. (2009)). On the one hand, poor air quality can decrease a city's attractiveness (Love and Crompton, 1999) and impose significant health costs on local residents and workers and a corollary impact on productivity at local businesses. In Hong Kong, local government has already undertaken considerable effort to improve air quality, but estimates are that additional air pollution control measures targeting particulate matter and nitrogen dioxide emissions could result in up to 2700 fewer deaths and approximately 45000 fewer hospital admissions over a ten year period. Overall, the value of these health improvements could range between USD 2.4 billion to 8.5 billion (Brajer et al., 2006). Similar results have been found in Beijing, Mumbai, Santiago, Sao Paulo, and Mexico City (Bell et al., 2006; Patankar and Trivedi, 2011; Guo et al., 2010). On the other hand, there is debate over whether efforts to address air quality problems can incite footloose firms to relocate to areas with less stringent environmental policies, enforcement levels, or a lower cost of compliance with local regulations. There is evidence that FDI is locating in China because of the lower cost of pollution regulation compliance (He, 2006).

156. Opportunities for economic growth relating to air quality will generally occur among firms that specialise in air pollution control installations at factories and power plants, produce low-emitting vehicles and develop and deploy clean power generation technology. Certain types of transport policies may result in growth in demand for public transportation services as well. In California, over $60 \%$ of the clean tech patents that have been issued during the period 2000-08 relate to clean energy or clean transport technologies, both of which are likely to have direct impacts on air quality in the region (Center for Community Innovation, 2010).

Water pollution and wastewater management

\section{What are cities doing?}

157. Wastewater management challenges can vary widely by country, and thus will require different policy responses. A large share of the population in many developing countries lacks access to sewerage infrastructure, suggesting that local governments could prioritise the development of infrastructure. In Latin America and the Caribbean, for example, it was estimated that only $13.7 \%$ of wastewaters discharged by the 241 million people connected to the sewerage network received some degree of treatment in 2004 (Jouravlev, 2004). China has been investing massively in recent years to increase wastewater treatment coverage, going from 52\% of wastewaters treated in 2005 to an estimated $60-65 \%$ in 2011 and projected to reach 70 to $80 \%$ in 2016. Progress in establishing more sewerage infrastructure is expected to continue to 2030, but it is still projected that there will be 1.1 billion more people worldwide in 2030 who lack access to basic sanitation services compared with 2000.

158. On the other hand, whilst most OECD countries have been able to ensure adequate access to a safe water supply for human needs and significant efforts have been made to treat organic pollution from urban wastewater, considerable investments are needed to retrofit wastewater infrastructure and 
little progress has been made to tackle pollution arising from agricultural runoff and other non-point sources of pollution. OECD research suggests that national measures to reduce agricultural runoff and storm water management - including introducing targeted measures to reduce a variety of different pollutants (i.e. arsenic and nitrates) - could yield health benefits in excess of USD 100 million in large OECD economies (2008c and 2008d). Treating wastewater is used in many areas for agricultural and landscaping, but has yet to gain widespread use for drinking water in many OECD countries due to wide public resistence, even if the technologies exist and are in use in other countries (e.g. Singapore).

159. Cities can use natural systems to provide wastewater treatment services. In particular, those systems include land treatment and constructed wetlands (UN, 2003; EPA, 2000), of which the selfpurification capacity reduces pollution. Reed et al. (1988, in UN, 2003) emphasises that they can be the most cost-effective option in terms of construction and operation, in cases where sufficient suitable land is available. Constructed wetlands are often well suited for small communities and rural areas. For municipal and industrial wastewater, land treatment consists predominantly in the controlled application of wastewater to vegetated land. Natural treatment processes occur either when the water percolates through the soil profile or when it flows down a network of vegetated sloping terraces. Constructed wetlands, on the other hand, dispose of vegetation that "provides surfaces for the attachment of bacteria films, aids in the filtration and absorption of waste-water constituents, transfers oxygen into the water column, and controls the growth of algae by restricting the penetration of sunlight" (UN, 2003).

160. Again, infrastructure investments and advancements in technological processes will meet only limited success without a more integrated governance approach to water and wastewater management.

What are the potential economic impacts?

161. The potential benefits to human health and natural resources of treated wastewater have also been widely documented (see, for example, AESN, 2007; Howarth et al., 2001). Poor water quality can also be costly for firms using water for industrial processes, since polluted water requires additional water treatment before it can be used (see OECD, 2011f). It can increase fishing costs and prices for fish (Bingham et al., 2000; Dumas \& Schuhmann, 2004) and diminish interest in angling activities (Church et al., 2008). Poor water quality can lead to reduced tourism revenues (Wilson, 2000, Bingham et al., 2000 and Crouzet et al., 1999) and negatively impact the aesthetic benefits linked to recreation activities near water bodies, like hiking, picnicking or photography (Carson and Mitchell, 1993) and bird watching (Church et al., 2008).

162. Economic activity directly arising from wastewater management take the form of the design, construction, and operation of wastewater treatment facilities, functions which may be either private sector or government jobs depending on the ownership structure of the water system in each city or region. This sector can be sizable: total investment in the water sector for 30 OECD countries exceeded USD 150 billion per year (over 0.5\% of GDP) as of 2001 (OECD, 2001a). Economic activity can also arise from efforts to reduce run-off from farms and to address pollution emitted from industrial activity in urban areas, yet overly onerous pollution abatement costs could lead to displacement if firms choose to close or leave the area. Constructed wetlands may provide a lower cost option of treatment; facilities constructed in agricultural regions near many large cities in China report that these facilities deliver treatment services at approximately one-fifth of the cost of a conventional wastewater treatment plant (Zhang et al., 2009). In short, co-ordination between urban and rural authorities for wastewater management makes good economic sense.

Solid waste management 


\section{What are cities doing?}

163. Solid waste management typically falls under the purview local government, which has considerable latitude in terms of how or who will collect waste, where and how it will be disposed of, and whether some waste will be targeted for recycling or reuse. Waste generation levels, which are influenced by economic and demographic growth, household structure, urbanisation rates, consumption patterns and socio-cultural habits, are projected to increase by $38 \%$ ( $1.3 \%$ annually) from 2005 to 2030 within the OECD region given the expected population growth, even if annual per capita municipal waste general levels have stabilised in OECD countries in recent years $(\mathrm{OECD}$, forthcoming (a)).

164. Although municipal waste management practices in OECD countries have improved overall in the past several decades, with an increasing amount of solid waste being recycled instead of disposed of in landfills, disposal practices still vary widely by country (OECD, forthcoming (a)). In the mid-1990s, approximately 64\% of municipal waste was destined for landfills, $18 \%$ for incineration, and $18 \%$ for recycling (including composting) (OECD, 2001a). Overall, by 2005, only $49 \%$ of municipal waste being disposed of in landfills, $30 \%$ was recycled or composted and $21 \%$ was incinerated or otherwise treated (OECD, forthcoming (a)). Nevertheless, a closer look at the disposal practices of each country revealed that whilst six OECD countries sent less than $10 \%$ of their municipal waste to the landfill in 2005, seven OECD countries still sent more than $80 \%$ of their municipal waste to landfills (with two countries sending nearly $100 \%$ to the landfill) (OECD, forthcoming (a)).

165. To reduce the environmental impacts and costs associated with rising waste generation, a range of policies have been introduced, which have thus far resulted in largely promising trends:

- Waste management planning is on the rise, whereby municipalities forecast the quantities of waste produced, collected and treated, set objectives (e.g. recycling rates for certain materials) and finance waste management.

- Most OECD countries apply the principle of extended producer responsibility for a certain number of products that pose end-of-life problems either because of their volume or because they contain dangerous substances, such as packaging, electrical and electronic waste, used tyres, used oils, batteries, end-of-life vehicles and batteries.

- Economic instruments are increasingly being used to internalise the costs of waste management and the environmental impacts of waste. These costs are passed on to consumers, through taxes or charges on purchase (deposit refund systems) designed to finance the disposal or recovery and recycling of end-of-life products. The instruments most widely used in waste management are charges for the collection of household waste calculated either by weight or at a flat rate (per person, per household or according to the habitable surface area) and taxes on tipping or incineration.

- Administrative structures are also being reorganised to cut costs and ensure more efficient management. In Japan, France and Denmark, for example, local authorities are getting together for the provision of waste removal and treatment services, generating economies of scale.

- Finally, more and more, countries are building partnerships with stakeholders, rather than using command-and-control approaches, to affect consumer and firm behaviour in terms of waste generation and disposal (OECD, 2001b and 2001c). 
166. In the recycling sector, private companies are taking the lead in launching new investments and up-scaling existing ones, the role of city governments being more one of improving the business environment (through public procurement schemes, initial grants for factory facilities, collection schemes for recycled materials, deposit-refund systems and land-use regulations). The example of Kitakyushu City is illustrative of the tremendous employment opportunities that strategic waste management and recycling can open in a globalised economy (Box 4).

\section{Box 4. Strategic urban economic policy in the recycling sector: the case of Kitakyushu}

The recycling sector yields great potentials of employment creation and re-employment of displaced workers, in particular in cities with an industrial history. Kitakyushu City, Japan, once the capital of steel and chemical industries, overcame severe pollution and sought out the growth potential in the recycling sector. Kitakyushu City has now many recycling companies, which handle sludge and waste materials produced as byproducts of industrial production processes. Kitakyushu City launched the Eco-Town project in 1997. In attracting recycling companies, local government emphasised the cheap and vast land available away from residential districts, abundant industrial water from the ocean, subsidies for factory facilities, accumulated human capitals and manufacturing sectors, and clustering of related recycling companies. Local government also facilitated companies' establishment in Eco-town through one-stop support services. As of 2008, 26 companies and 17 research institutions were in operation, employing 1352 people.

According to the public opinion survey of 2007, an increasing number of citizens at Kitakyushu city recognise the recycling sector as one that contributes to environment, partly due to the government's effort for public involvement. Residents' support of the recycling industry is a big attraction for a sector that is often exposed to an attitude of "not in my back yard".

Globalisation is opening new windows of opportunity for Kitakyushu City. For example, China has gradually increased the need for recycling due to serious water contamination and inappropriate waste disposal. Kitakyushu City has begun environmental co-operation with Chinese cities, including Dalian City since the 1990s, Quingtao City since 2007 and Tianjin City since 2008. Kitakyushu International Technology Co-operation Association (KITA), a public training institution for environment policies and technologies, has taught over 5000 people from 130 countries from 1980-2008. The City aims to link environmental co-operation with development of environmental business. In this way, Kitakyushu city's environment strategy is deeply embedded in the economic growth strategy.

Source: Kamal-Chaoui in (2009) Competitive Cities and Climate Change: OECD Conference Proceedings, Milan, Italy, October 9-10, 2008, OECD, Paris; Bank of Japan, Kitakyushu subsidiary (2008), "Recycling Industry in Kitakyushu City", www3.boj.or.jp/kitakyushu/sonota/kitarecycle.pdf, accessed 2 October, 2009; OECD (2009j), OECD Territorial Reviews: Transborder Urban Co-operation in the Pan Yellow Sea Region, OECD, Paris.

167. Reducing the environmental impact of waste disposal processes remains nevertheless a challenge. Technological innovation and extensive regulation, especially concerning landfills and incinerator emissions standards, are reducing emissions and other negative externalities. This is particularly true in Europe as a result of EU directives on landfills, incineration and the management of certain problem waste flows, such as electrical and electronic waste, and products containing dangerous substances such as lead, mercury and cadmium. Poor waste management in the past can create an inherited burden. Insome cases, unsupervised landfills have led to the long-term contamination of soil and groundwater. The costs of restoring the environment are very high and, as a result, must sometimes be assumed by national government, as is the case in Spain.

168. Enabling investments in energy recycling can expedite the regeneration of brownfields. Ecoindustrial parks are a notable example of how innovative industrial land-use planning can create synergies between employment and environmental outcomes. At the heart of these eco-park initiatives is the argument that local industrial network can mimic natural ecosystems, shifting from the current 
wasteful linear model of production to a circular model, where wastes are converted into new inputs and energy cascaded through the local industrial network (Gibbs, 2008). Kalundborg in Denmark is the most well known example of the economic gains that can be achieved by connecting waste and energy exchanges in an eco-industrial park. The diverse firms in the eco-park of Kalundborg utilise each other's surplus heat and waste products, with annual estimated savings of USD 12-15 million. Several other eco-industrial parks have followed this successful model (e.g. Styrian recycling network in Austria, Rotterdam Harbour and Industrial Complex in the Netherlands, Londonderry industrial park in New Hampshire, and Guigang Eco-Industrial Park in China). Japan's Eco-Town programme is an example of a large-scale public programme seeking to maximise business and resource-savings opportunities generated by the proximity of industrial and urban areas. It launched 61 innovative recycling projects, which successfully contributed to raising industrial productivity and generating employment, both to improve environmental amenities (Van Berkel et al., 2008). Among the instruments used to nurture the eco-parks are tax exemptions, offered to companies locating on land owned by or near a power plant that pursue activities of energy cascading, co generation and utilisation of plant by-products for energy generation.

169. Waste management trends in enhanced engagement and non-OECD countries suggest that different policy responses will be needed and should focus primarily on introducing integrated waste management practices and the inclusion of the large number of informal waste recyclers into the official waste management infrastructure (McDougall et al., 2001; World Bank, 2005). In Brazil, it is estimated that some $60 \%$ of all municipal solid waste is disposed of inappropriately (Leslie and Utter, 2006). In China, $48 \%$ of municipal waste is not treated (OECD, 2007c). In India, up to $40 \%$ of the municipal waste across urban areas remains uncollected (Joardar, 2000). In Indonesia, Malaysia, Myanmar, Philippines, Singapore, Thailand and Vietnam, 50-80\% of municipal waste is simply dumped (UNEP, 2004). Only some 5-30\% of municipal waste in these countries is properly disposed of in landfills and about the same amount is composted. In Venezuela, some 4.1 million tonnes of municipal waste are generated annually and disposed of at around 200 sites around the country, mostly in open-air dumps. Informal recycling plays an important role in Latin America and Asia (Nas and Jaffe, 2004; Leslie and Utter, 2006).

170. The rapidly increasing waste generation levels that are projected in these countries by 2030 will further aggravate the existing waste management challenges. In China and India, increasing incomes, rapid urbanisation, population and GDP growth are expected to greatly accelerate municipal waste generation rates: the annual urban municipal waste generation for 2030 is estimated to be at least 485 million tonnes in China $(1.5 \mathrm{~kg} /$ capita/day in urban areas), up $214 \%$ from 2004 , and approximately 250 million tonnes in India (1.4 kg/capita/day in urban areas), up 130\% from 2001 (World Bank, 2005). In urban China, municipal waste generation is already estimated at $444 \mathrm{~kg} / \mathrm{capita} /$ year $(1.2 \mathrm{~kg} / \mathrm{capita} /$ day $)$, while the generation rate in rural areas is largely unknown. Other BRIICS countries (Brazil, Russia, Indonesia and South Africa) have already exceeded their projected 2030 estimated mean daily generation of municipal waste $(0.75 \mathrm{~kg} / \mathrm{capita} / \mathrm{day})$.

171. In the BRIICS countries, strong legislation and policies are broadly in place to support integrated waste management, yet implementation is often weak and waste management infrastructure is still undeveloped (McDougall et al., 2001; World Bank, 2005). One key concern must be whether the availability of disposal capacity (such as incinerators) encourages maximum use in order to amortise the investment, increasing movements of waste (and the environmental impacts of transporting it) and discouraging recycling. 


\section{What are the potential economic impacts?}

172. The solid waste sector provides many opportunities for green urban growth, with most recent opportunities arising in the recycling sector. Waste collection costs can vary widely based on the level of automation involved in the system. Some cities opt for mechanised collection requiring very little human labour; in Delhi, by contrast, there is an army of 89600 recyclers eking out a living by sorting through the trash with almost no mechanised support (Agarwal et al., 2005). In the United States, the recycling industry was found to generate USD 236 billion annually, with 56000 firms employing 1.2 million workers and an annual payroll of USD 37 billion (RW Beck, 2001).

173. Operations promoting reuse can play a valuable role in creating employment or training opportunities for marginalised populations (Curran and Williams, 2010; Sharp and Luckin, 2006). Reuse materials can also be important inputs for organisations with low budgets, such as schools and arts organisations (see Santos, 2011).

174. Nevertheless, there can be challenges to a waste-based growth strategy. Siting waste processing facilities can be difficult, particularly if the materials processed create odour problems in the area. For waste-based businesses to be viable, some locally generated material is needed, which can be an opportunity for cities to partner with nearby communities to consolidate supplies. Cities must also be careful about policy decisions that may upset an informal recovery economy in the area. For example, in Dehli, it is estimated that changing the type of equipment used to collect, transport and process recyclable materials could improve worker safety, create more stable operating conditions and save money - but at the cost of nearly 70000 jobs among the most marginalised populations of the city (Agarwal et al., 2005). With increasingly globalised commodity markets for recyclable materials, materials contaminated by other types of recyclables can quickly lose their value. In some cases, cities adjacent to one another will find completely different market opportunities for recyclable materials in their waste stream, based on the total volume of material available, its level of contamination, the city's ability to transport the material to the market and the city's desire to receive payment in exchange for the materials. Increasingly, cities are opting to establish comprehensive recycling programmes even if they are unable to secure particularly lucrative markets for certain commodities, since it may still be less expensive to sell the recyclable materials to a processer than to pay for disposal in a landfill.

175. Cities may also have difficulty guaranteeing that waste materials generated locally are used locally by recycling or reuse companies, thereby undermining some of the local environmental benefits of recycling (exported waste materials can generate increased environmental impacts due to transport, for instance). In an increasingly globalised market, these commodities may end up being transported long distances for processing. In the United States, efforts to direct waste materials via flow control restrictions to certain processing facilities have come under legal challenge (Tawil, 1999).

\section{Green Services}

\section{What are cities doing?}

176. Green service firms provide the essential support functions to deliver greener growth, often in the form of knowledge to design, finance, permit, build, test or market green products and services. These firms include:

- Planning, architecture and engineering firms: many traditional architecture and engineering firms have developed units specialised in urban sustainability and/or specialised technologies designed to address greening challenges in cities. Services provided by these firms can 
include land use and project master planning aimed to reduce transport-related energy demand, in addition to architecture and engineering services aimed to design highly resource efficient buildings or other essential water, waste or energy infrastructure. The impact of such firms on local employment varies with the geographic reach of these firms, with some larger international firms less inclined to expand their sustainability units in a given city, as well as with the local policy environment. Public policies imposing more stringent green standards on urban infrastructure and the built environment can contribute to the development of a larger local market for green services.

- Permitting and certification services: Regulatory permitting has long been an area of specialisation for many firms, given the intricacies of permitting processes. With the advent of many green design and building energy efficiency labelling systems (e.g. LEED, HQE, BREEAM, Energy Star), some firms are expanding their services to ensure that projects qualify for the desired label or certification. Some firms focus on validating information provided by others; for example, the LEED certification system requires third-party verification to ensure that the project meets the required point threshold for different certification levels (e.g. certified, gold, platinum).

- Environmental testing: Environmental testing firms specialise in measuring the environmental pollution problems related to air, water and soil. Given the specialised equipment and expertise required for this kind of testing, it may be difficult for a city to promote significant job growth in this area. Cities may choose to employ environmental experts (e.g. chemists, technicians) on staff at public environmental agencies, necessitating the purchase, management and maintenance of any laboratory equipment necessary to support the testing regime.

- Brownfield remediation: In cities with a long legacy of industrial pollution, brownfield projects can provide steady business opportunities for firms with expertise in soil remediation. These projects can take different forms: dredging of waterways, soil removal and replacement, phytoremediation (the use of certain plants to extract pollutants from the soil) or simple capping projects to prevent access to the contaminated soil. The range of jobs and expertise required for this work can thus be significant. Because contaminated land may represent significant new development opportunities, many cities may wish to promote the brownfield remediation sector expertise, since it is an important precursor to other types of residential, commercial, and industrial development around a city. This sector will tend to have a fixed lifespan, however: once the brownfields are eliminated the market disappears.

- Construction (including technology installation): Green building development also requires specialised building contractors with the ability to install more complicated energy- or resource-efficient technologies or specialised supply chain knowledge which makes procurement of certain products faster or cheaper. Training for green construction jobs is regularly promoted in many cities as an important step on the path to a green economy, as many labour unions, workforce training organisations and construction firms want to ensure there is a large pool of trained workers capable of implementing these projects.

- Project financing: Cities with a large financial sector may opt to explore the green financial marketplace, where new financial instruments such as carbon credits, renewable energy certificates, and ESCO and green building project financing create opportunities for specialised knowledge. London, New York, Hong Kong, Singapore and Seoul have all expressed ambitions to become the global hub of these markets (Blake, 2009; City of New York, 2009b; Chabarra, 2008). Uncertainty about the future of global or national/regional 
carbon markets has slowed the growth of this sector, however, and in some cases, firms have shifted their carbon credit trading operations from one city to another because of the failure of one market system and the creation of another (Bloomberg News, 2011).

- Eco-tourism: Eco-tourism services can capitalise on consumer demand for recreational or sightseeing opportunities in or near a city, including beaches, sailing/kayaking, bird watching, bicycling, golf, or hotels/resorts. Cities serving as gateway communities to national parks or areas of great natural beauty may have an advantage in this sector. The extent to which a city can generate economic growth from eco-tourism activities depends on the level of development that has already occurred and the attractiveness of the amenity being targeted. For example, the city of Da Nang, Vietnam is enjoying a building boom in the largely undeveloped area that fronts on the China Sea, hoping to attract visitors both to its attractive beaches and many natural and historical monuments in the region.

- Farmers markets in urban areas: Cities located near farming districts or interested in promoting urban farms may look to facilitate the development of farmers markets that sell high quality foodstuffs. Such markets may be popular with the public as well as local restaurants.

177. A range of policy initiatives are available to local governments wishing to promote green service business development (e.g. land use policies and regulations, financial incentives to attract green businesses, technical assistance, etc.), but ultimately, growth in this sector hinges on the level of market demand for such services and the power of local authorities to influence that demand. In the case of services linked to the construction sector, for instance, mandatory green building codes or voluntary guidelines will generally have the biggest impact on new construction projects. The impact on job growth for local building contractors and architecture, engineering and planning firms will depend on the extent to which local firms possess the specialised skills and are able to compete in the marketplace. Local government-led green building projects can require the use of local firms on their projects, but most cities will have limited ability to establish such requirements for privately sponsored construction projects. Educational initiatives aimed at increasing the skills of the local workforce can be helpful precursors to the growth of this sector, but such programmes must be targeted to areas where market demand is significant.

178. Environmental testing initiatives can be driven by requirements to codify pollution emission levels in local manufacturing facilities on a regular basis, although air and water pollution rules are generally established at the state/provincial or national government level. To the extent a city has a natural resource base capable of supporting recreational or tourism-based businesses, cities can have some influence through its land use policies, allocating space for parks and open spaces or allowing development to occur in locations that capitalise on existing natural amenities such as beaches. Many cities also allocate public space to farmers markets one or more days a week, charging nominal fees to vendors selling produce or other farm products there. Cities can also actively seek to attract visitors through advertising or marketing campaigns driving the development of recreation or eco-tourismrelated businesses through its land use policies.

179. Local authorities will generally be less able to establish the protocols necessary to drive the development of cap and trade or other carbon finance schemes. Such programmes tend to fall under the legal purview of state/provincial or national government authorities. Tokyo is a noteworthy exception, having established a mandatory cap-and-trade system for local industrial firms as part of its climate change strategy (City of Tokyo, 2008). Other cities participate in the voluntary carbon market operated by the Chicago Climate Exchange; whether the initiatives involve a significant enough volume of carbon reduction to drive significant employment growth of the carbon finance sector 
remains to be seen. Energy efficiency project financing can be done locally by any bank or investor familiar with new equipment purchases or facility retrofit projects.

\section{What are the potential economic impacts?}

180. Given that green services are often a subset of a larger industry (e.g. eco-tourism as a subset of the tourism industry), quantifying the economic benefits of the green service industry can be difficult without highly discrete data. Nevertheless, economic impacts have been measured - albeit, with very different metrics - in several subsectors, such as building design (see the previous section on green building), carbon finance, and eco-tourism.

181. Data on the size of city-specific carbon finance markets is rather difficult to come by, as most metrics report on the total global deal value taking place rather than the level of revenues or profits achieved by different firms. One study estimated the carbon finance market in London to involve approximately 22650 employees "in the various aspects of carbon finance", conducting deals worth approximately GBP 5.64 billion (London Development Agency, 2010).

182. Whilst the economic impacts of tourism are widely documented - the city of Paris counted 61 million visitors in 2008, EUR 17 billion in tourism-related revenues and 600000 jobs in the sector (IAU-Insee, 2011) - measuring the size of the eco-tourism subsector at the local level can be difficult. Isolating the impacts of eco-tourism is another matter, however. In gateway cities, like Belize, which serve as an arrival point or hub for eco-tourism activities taking place in the region, eco-tourism can be a significant driver of economic activity, although it may vary based on the mode of transport (e.g. air vs. cruise ship) and the extent to which tourists stay overnight in the city or simply pass through (Diedrich, 2010).

183. Strategic urban development planning should also consider the implications for future economic activity in key sectors, such as tourism. Cities with popular beachfront resort areas or close proximity to wilderness destinations often enjoy greater economic benefits as more visitors may stay directly in the city, yet are faced with the need to protect these resources from climate change impacts (e.g. if sea level rise or changing weather patterns destroy property or otherwise diminish the appeal of the area). A recent OECD study assessed key vulnerabilities in the European Alps related with losses in winter tourism and exposure of settlements and infrastructure to natural hazards (OECD, 2007d). There may also be some further impact on Australian tourism related to restrictions/costs imposed on air travel due to the industry's contribution to global climate change. Australia's remote location means it relies heavily on long-haul flights from other countries, so it would be particularly vulnerable to efforts to impose a carbon fee on air travel.

\subsection{Main policy instruments}

184. Sub-national authority and policymaking powers to stimulate green growth encompass a range of instruments. Although government policymaking is sometimes simplistically characterised as a choice between carrots (incentives) and sticks (mandates), the options are actually much more diverse. Meeus and Delarue (2011) note the "tambourine" role that sub-national authorities play when they lead by example, in addition to the powerful influence they have as a convener responsible for conceptualisation and implementation of an action plan. Similarly, the role of the mayoral "bully pulpit", or the ability to exhort consumer and business behavioural changes, is regularly cited as a significant weapon in a mayor's arsenal (Capello et al., 1999, Keirstead and Schulz, 2010; Tang et al., 2011; Energie-Cites, n.d.). Support for technology innovation is an important function of sub-national government seeking to facilitate change within the local energy system (Capello et al., 1999). Subnational authorities can promote the development of local energy services and energy efficiency 
equipment markets via their role as the owner/operator of municipal buildings, district heating, and public street lighting systems (Rezessy et al., 2006). Table 4 lists other types of policy instruments or policy roles that have been assigned to sub-national authorities in the energy literature.

Table 4. Roles and policy levers available to sub-natinoal authorities in energy/climate policy

\begin{tabular}{|c|c|}
\hline Energie-Cites (2006) & $\begin{array}{l}\text { Consumer } \\
\text { Service provider } \\
\text { Model } \\
\text { Planner } \\
\text { Developer } \\
\text { Regulator } \\
\text { Advisor } \\
\text { Motivator } \\
\text { Producer } \\
\text { Supplier }\end{array}$ \\
\hline Tang et al. (2011) & $\begin{array}{l}\text { Leadership power } \\
\text { Regulatory power } \\
\text { Spending and taxation power } \\
\text { Acquisition power } \\
\text { Co-ordination power } \\
\text { Information power }\end{array}$ \\
\hline Rezessy et al. (2006) & $\begin{array}{l}\text { Ability to initiate markets for services and technology } \\
\text { Buyers of services and technology } \\
\text { Implementers of energy efficiency interventions } \\
\text { Ability to borrow funds to support energy efficiency investments }\end{array}$ \\
\hline Keirstead and Schulz (2010) & $\begin{array}{l}\text { Direct service provision } \\
\text { Public information and awareness } \\
\text { Partnerships } \\
\text { Direct intervention (taxation, product regulation) }\end{array}$ \\
\hline Capello et al. (1999) & $\begin{array}{l}\text { Land use planning and building regulations } \\
\text { Regulatory policies } \\
\text { Market-based policies } \\
\text { Stimulation programmes (e.g.grants and information) } \\
\text { Support for technological innovation }\end{array}$ \\
\hline $\begin{array}{l}\text { OECD } 2010 \text { (adapted from } \\
\text { Kern and Alber in OECD } \\
2008 \text { and Bulkeley and Kern } \\
2006 \text { ) }\end{array}$ & $\begin{array}{l}\text { Self governing: the municipality as consumer } \\
\text { Governing by provision: the municipality as provider } \\
\text { Governing by Authority: the municipality as regulator } \\
\text { Governing through enabling: the municipality as a facilitator }\end{array}$ \\
\hline
\end{tabular}

185. The above list can be synthesised into four core policy levers, or types of policy instruments, that can be employed by sub-national authorities: $i$ ) regulatory authority; ii) government spending; iii) financial incentives; and iv) information and advocacy. These levers can be applied internally (i.e. toward internal government operations, facilities, and staff) or externally (i.e. toward the public, local businesses, or others in a position to take action to help implement the city's goals) (Hammer, 2009).

186. Considering a range of policy instruments also allows local authorities to account for internal resource or time constraints, as some strategies might be deployed more quickly or cheaply than others. For example, tree planting programmes aimed at reducing the local urban heat island are a good example of a programmeprogram that can be ramped up relatively quickly. An alternative approach - offering to subsidise building retrofits to better shield building inhabitants from the urban heat island - would likely be much more costly and time consuming to implement, yet may have more significant impacts in the long term. The use of multiple policy levers also allows a local authority to adopt an iterative approach, layering policies one on top of another to derive the maximum impact. An iterative approach might also prove helpful to local authorities hesitant to fully commit the city to one 
approach where they have little knowledge or experience. Some sub-nationalsubnational authorities may wish to start with an education or technical assistance initiative before they move towards a regulatory strategy, believing it makes the most sense to promote voluntary actions before establishing some type of requirement.

\section{Regulatory authority}

187. Local government authorities and agencies are frequently granted certain types of regulatory power by higher levels of government, particularly related to land-use, service provision and master planning. Enforcement can take the form of a pre-condition to regulatory approval, or it can occur after approval has been granted. For example, the "Merton rule" in London, which requires the on-site deployment of renewable energy technology as a precondition for building permit approval, is widely credited with boosting solar PV deployment around London (Day et al., 2010). Local authorities also usually play an enforcement role for policies established by other governmental entities. Buildings codes are a common example, as in many municipalities, these are established at the regional or national level rather than locally. Again, enforcement can occur before or after regulatory approval has been granted. Finally, as managers and operators of local public property and equipment, local authorities can establish and enforce internal rules that promote environmental protection or resource efficiency.

188. In addition to enforcement, local authorities can use their regulatory authority to streamline the regulatory permitting process for projects that support environmental targets, thus reducing costs. Legal and engineering expenses associated with gaining regulatory approval can be significant, especially when the permitting process is delayed. Expedited permitting thus allows a project proponent to gain a faster return on their investment. For example, the City of San Diego launched an expedited permit programme in 2002, cutting the normal 12-18 month-long permit process for large development schemes down to just 5-8 months in return for an agreement to comply with certain green building standards. As of the end of 2008, 2.64 MW of solar PV systems had been installed as a result of the programme, and 51 developments had agreed to pursue LEED green building certification. This impact was achieved at very low cost to the city (Beaudoin, 2009).

\section{Public spending}

189. Cities are responsible for large parts of public spending, including expenditures that could impact green growth objectives, such as environmental protection, transport and buildings. These can take the form of investments, subsidies, loans and tax breaks, as well as capacities for procurement and public-private partnerships that could facilitate green spending. Government spending can help foster markets for new products and services, for example through demonstration effects, and counter gaps in the supply of finance at the early stages. It can also help accelerate the emergence of technologies for which there is an urgent time-bound societal need and that are subject to specific barriers, such as network effects and market dominance. One example is the electric car, where public procurement could potentially play a role in strengthening market acceptance and boosting the development of the necessary network. However, as the OECD Green Growth Strategy (2011) points out, the public sector is not always best placed to support the innovation process, and new capacities may need to be developed. For instance, the traditional focus on cost alone as well as the problem of fragmentation of public demand (often between different levels of government) can limit the potential impact of innovative government spending. 
190. Procurement arrangements play an important role in greening government activities. Several experiences show that sustainability concerns can be successfully integrated in urban spending practices through innovative tools evaluating the environmental impacts of the products or services delivered (e.g. life cycle costing ${ }^{19}$ ), and through institutional solutions. The City of Helsinki established a Procurement Centre, charged with developing operational models for managing markets through systematic dialogue with businesses. The centre is defining environmental criteria for different product groups and co-ordinating training programmes to raise awareness among procurers. Procurement rules developed by sub-national governments can be written in ways to promote the use of alternative energy technology or purchase goods that minimise energy consumption or waste generation levels.

\section{Financial tools}

191. Financial incentives (or disincentives) can influence the behaviour or purchasing decisions of individuals or businesses. A wide range of financial/fiscal instruments including taxes, fees and other smart tools are used by local government as incentives or disincentive to encourage behaviours of agents in transport, land use and housing.

Financial incentives

192. Tax breaks could in some instances reduce the upfront cost hurdles and unit costs of distributed energy technologies. Marginal price incentives can shift preferences of price-sensitive consumers. Direct observation and imitation by other consumers can then lead to wider market penetration. The City of Berkeley's Financing Initiative for Renewable and Solar Technology (FIRST) programme reduces cost hurdles by providing loans to homeowners to purchase and install solar PV systems at interest rates and payback periods similar to those for home mortgages. Borrowers repay the city through an additional, transferrable tax added to their annual property taxes. The California Public Utilities Commission (CPUC) developed a state-wide Solar Hot Water incentive programme. The proposed incentive amount for residential SWH systems is expected to be about USD 1500 per system on average. Effective programmes to facilitate and reduce the cost of green investments often involve multi-level governance co-ordination between national, regional and local governments (Box 5) (OECD, 2010c; IEA, 2009c).

\section{Box 5. Local-national government building effiency programmes: a multi-level approach to green growth}

- The Crown Energy Efficiency Loan, in New Zealand, is a financial instrument to assist central and local government agencies to implement energy efficiency projects. It complements the 2007 National Energy Efficiency and Conservation Strategy, which required $10 \%$ improvement in in-house energy efficiency in central and local government over five years. Local authorities and other publicly agencies borrow funds from the government and repaid over five years; ideally, loan repayments are structured such that the energy cost savings exceed the cost of the loan repayments. The Crown Energy Efficiency Loans finance energy efficiency measures previously recommended by audits carried out by independent energy experts, and are allocated based on the project's cost effectiveness, projected $\mathrm{CO}_{2}$ emission reductions, contribution to renewable energy, potential for replication by public and private sectors, and co-benefits. As of June 2008, loans exceeding USD 23 million have been granted to 230 projects to achieve estimated cost savings of USD 60 million and reductions in $\mathrm{CO}_{2}$ emissions of nearly 23000 tonnes per year - the equivalent of taking 6500 cars off New Zealand roads.

19. Life cycle costing (LCC) is a structured approach that can be used to produce a spend profile of the product or service over its anticipated life-span. The results of an LCC analysis can be used to assist management in the decision-making process where there is a choice of options. See http://ec.europa.eu/environment/gpp/gpp_and_life_costing_en.htm 
- The Low Income Retrofitting Project in Greece is an initiative of the national government in cooperation with municipalities to improve energy efficiency in homes built before the 1980s for families with incomes of less than EUR 60000 a year. The national government works with national associations of private businesses and the local community (municipalities and private business) to identify and inform low-income households about this project. The project focuses on increasing energy and cost savings through projects to increase the energy efficiency of insulation, windows, and heating, and to install solar collectors and cool roofs. The Ministry of Development created an agreement with national business associations to freeze the costs of these services for two years. The programme is evaluated through an "auto-verification" scheme in which the associations must evaluate whether their industry members are implementing technologies that meet the national standards - which can result in a conflict of interest.

- Upper Austria's Regional Market for Third-Party Financing (TPF) links municipal and private energy efficiency projects with financing in order to remove the barrier of high upfront investment costs. This programme originally linked municipalities with investors interested in financing energy efficiency renovations in public buildings, and was later expanded to link building, lighting and renewable energy projects in the public and private sectors with energy financing. TPF projects look to Energy Service Companies (ESCOs), which guarantee that energy costs will be reduced by a certain percentage after energy improvements are made, to provide pre-financing energy-conservation schemes. ESCOs are responsible for financing energy-saving measures as well as implementation, operation and maintenance, and subsequent energy savings are then used to cover investment costs over an agreed pay-back period (typically 10 to 15 years). Out of eleven participating ESCOs, two are publicly owned; the rest are private. Municipalities enter TPF projects on a voluntary basis and are responsible for collecting all relevant data prior to setting up the project. Depending on the status of the owner, the regional government may fund the upfront investment costs for energy performance contracts up to $12 \%$ in the case of private owners, and up to $20 \%$ for municipalities. The upper limit in both cases set at EUR 100,000 per project. Funding comes on top of other State (Upper-Austria) subsidies. The budget comes from the broader climate change programme of Upper Austria.

Source : IEA (2009c), Innovations in Multi-Level Governance for Energy Efficiency: Sharing experience with multi-level governance to enhance energy efficiency, OECD/IEA, Paris.

Transportation fees for sustainable public transport

193. Local fees and taxes can greatly influence the development of sustainable urban transport through discouraging car use and stimulating public transport. Fiscal disincentives for car use will be more effective when alternative traffic solutions, such as public transport, are in place, which is why some metropolitan areas use these types of revenues to finance public transit.

194. Some cities in the OECD have taxing powers to reduce car use. Car users are in many cases not charged for their use of the road network, non-residential parking is free in many cities, and personal income tax regulation often favours automobile use over transit, as the costs of owning, operating and parking a car are in many cases deductible for firms and individuals, whereas transit benefits for employees are not. Some cities and regions have introduced motor vehicle or fuel taxes, although this remains a predominantly national tax in most OECD countries (Figure 16). In Canada, for example, excise taxes on gasoline and diesel are collected by both federal and provincial governments, as well as by some select metropolitan regions (Montreal and Vancouver), with combined excise taxes up to $30.5 \notin / \mathrm{L}$ in Vancouver. Similar effects on fuel consumption could be attained by a pay-as-you drive insurance, although such schemes have not been introduced yet (Parry, 2005). 
Figure 15. Fuel taxes: little room for local and state involvement

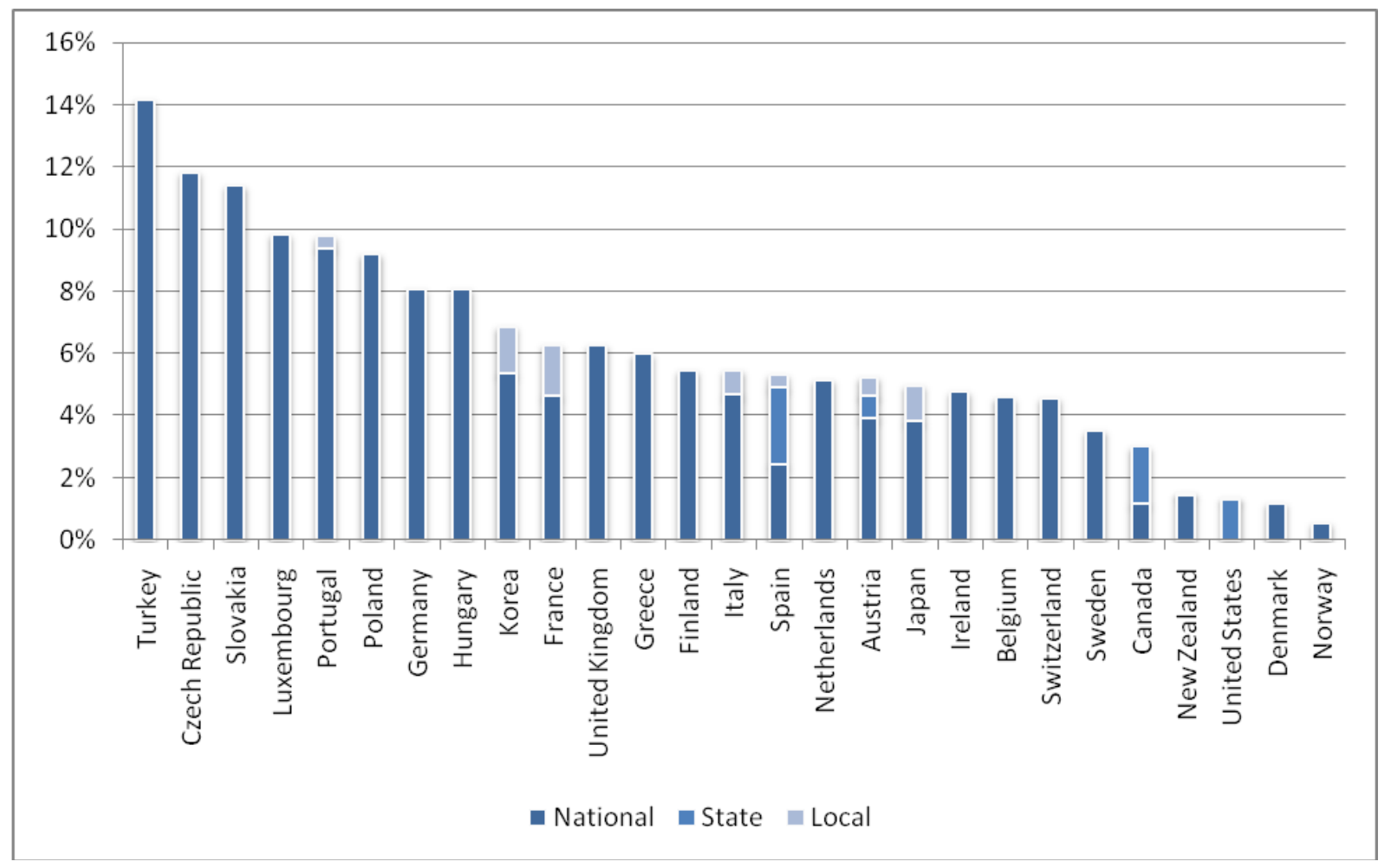

Note: Tax revenues as share of total government revenues (central and local), including petroleum excise taxes.

Source: OECD Revenue Statistics Database.

195. While overall taxing powers to reduce car use may be limited, congestion charges and parking fees could be more widely applied. Congestion charges, as introduced in Singapore, Stockholm and London, have lead to the reduction of traffic volumes, shifts in transit modal shares and reduction of congestion responsible for a considerable part of greenhouse gas emissions. In some cases, the receipts from the congestion charge are used to finance urban public transport; this is the case in London. Alternative effective measures, mostly used in the United States, are high occupancy toll (HOT) lanes. Parking fees and taxes are price-elastic, and there is ample evidence that they are effective in reducing car trips and decreasing the car share in the modal split. Parking fees could be differentiated in order to make them even more effective. A parking surcharge might be levied on drivers who arrived at parking garages during the morning peak hours, and spatially differentiated parking fees could rival time-differentiated congestion fees (Arnott et al., 1991). The cost per minute associated with meter parking is however nominal in most cities, although some cities (such as Los Angeles) charge more for parking during peak hours.

196. Value-capture taxes can fund robust public transport systems. Public transport is supported in almost all cases by public subsidies; there are hardly any cities that run public transport systems exclusively funded by rider revenues or other private funding sources. Public transport is thus developed in cities that have found fiscal resources to fund metropolitan transit. A local tax that is frequently used to finance public transportation is the value capture tax. The base for a value capture tax is an increase in property values arising from public infrastructure development. This increased value results from the increased desirability of the location, better access, and the potential for higher rents, increased resale value and higher-density development. Value capture taxes can be imposed or 
can take the form of a negotiated agreement; they may be levied as an ongoing annual charge or as a one-time tax. Value capture taxes have been used to finance transport infrastructure in cities as different as Hong Kong, Miami, Milan and Bogotá. A value capture tax can only be applied when the property value increase can be unambiguously attributed to infrastructure investment. Value capture taxes are less useful when property taxes are assessed on a yearly or regular basis, since the annual assessment captures any increases in the property value that might result from public infrastructure investment; this does however not take place in most OECD countries.

Fiscal incentives and property taxes for sustainable development.

197. Local property taxes often discourage compact city development and promote low-density development, the primary source of local tax revenue in many OECD cities, which is sometimes skewed in favour of single family houses. Multi-family rental housing in the United States, for example, bears an effective tax rate (tax divided by property value) that is considerably higher than the rate for single-family owner-occupied housing: at least 18\% in 2001 (Goodman, 2006). The higher tax rate for apartments observed in the national totals holds for 10 of the 12 states that are identified in the Residential Finance Survey data. One of the explanations is the explicit policy of sub-national jurisdictions to tax apartments more heavily than single family houses: apartments are often classified as commercial real estate rather than as housing, and many local governments tax commercial property at a higher rate than residential real estate. Implemented like this, the residential property tax promotes low-density development and disproportionally burdens lower-value properties.

198. Some cities have introduced property tax reform to favour compact development. Through differential taxation, a special area tax can be applied on suburban properties or use a set of cascading taxes that gradually increase as one moves away from the city centre towards the periphery. A relatively simple form of such a tax might be a higher standard property rate for suburban inhabitants or preferential rates for multiple dwellings. Although the introduction of such a tax could be politically difficult to implement, there are cities that have introduced a tax along these lines. The City of Austin, USA, introduced a special transportation levy on all city utility bills, based on the estimated average number of daily trips made by individuals residing in different types of property. The levy averages USD 30-40 per year for a typical household, but differentiation takes place according to housing type (Litman, 2009). Depending on local circumstances, such a tax could have social consequences if lower-income groups have difficulties finding affordable housing in city centres and are dependent on car use, which might already be taxed in other ways. Such support could be implicit such as when local authorities allow real estate developers to construct buildings larger than zoning rules would normally allow in return for some type of green amenity or technology deployment.

\section{Brownfield development and disincentive to sprawl to reduce the urban environmental footprint}

199. Most property tax systems tax land and structures on the land at the same rate, so they provide limited incentives to develop undeveloped land within cities. Distortions created by the property tax may result in the inefficient spatial expansion of cities, which makes the tax one possible cause of urban sprawl (Brueckner and Kim, 2003). Sprawl is stimulated when it is more beneficial for developers or other actors to develop on undeveloped land outside of cities rather than within cities. Placing proportionally higher taxes on land than on built structures would make it more costly to hold on to vacant or underutilised, centrally located sites. Reducing the tax burdens on development and redevelopment of urban land could facilitate revitalisation and the replacement of obsolete buildings in older central cities. More compact development can be stimulated by introducing a form of land taxation such as a split-rate property tax. The key characteristics of such a tax, applied in Sydney, Hong Kong, the US cities of Pittsburgh and Harrisburg and other cities within OECD countries such as Denmark and Finland, is that land value is taxed more heavily than the buildings on the land, 
thereby providing an incentive to develop it. This is in contrast to the conventional equal-rate system that applies the same tax rate to land and to build structures on it.

\section{Local energy fees to increase efficiency}

200. Energy-efficiency clusters could be stimulated by mechanisms, such as fees and charges, that put a price on high energy use. These could be effective instruments to signal the higher cost of internalising environmental externalities. Fees and charges are ideal for funding local services where specific beneficiaries can be identified and non-payers excluded, such as in energy. Fees are particularly effective when they recover full costs and when fees are paid according to individual or household use, as these give residents incentives for more efficient use of resources. In addition, charging households for their energy consumption (and not the average household's consumption in a city) might stimulate them to invest in energy efficiency measures, such as isolation and energy renovation measures.

201. Electricity fees are used to a varied extent in cities throughout OECD countries, and are most effective where individual consumption is priced by unit. In several cities, the costs of urban utilities are not (completely) covered by user fees. In this case utilities, such as electricity, are cross-subsidised by local tax resources. Sometimes, cities apply preferential tariffs for large industrial energy users in order to attract manufacturing and other employment. Even when urban utility fees exist, they are in many cases not differentiated to households: households might pay an average price based on total energy consumption in a city, quarter or apartment block. In that case the behavioural effects of fees are limited, as the financial benefits of reduced consumption for a household are marginal. In order for fees to be efficient, they will have to price the number of units consumed by the different consumers. Such a scheme requires equipment in houses and apartments (such as individual energy metres) which is lacking in many cities.

\section{Information and convening}

202. The large scale deployment of low-carbon technologies will depend not only on advanced scientific research but on how fast firms and people learn to appreciate their added value. Behavioural changes are thus as important as end-of-pipe solutions. These changes and learning processes happen at the local level. Better understanding what drives the demand for low-carbon goods and what are the main resistances behind slow adoption of new technologies is thus of critical importance. Most local governments enjoy high visibility in their city, and they can use this fact to their advantage in promoting green technology investment, behaviour, and policies (OECD, 2010c). Cities are also often in a position to facilitate deliberations and goal-setting among a range of local stakeholders, including local governments, the private-sector, civil society organisations and individual residents. These information or facilitation initiatives can be targeted on a citywide scale, at specific geographic areas or business sectors, or at other government agencies.

203. Cities in OECD and in some non-OECD countries are increasingly raising local awareness through consumer education programmes, eco-standards and eco-labelling and best-practice demonstration sites. It makes sense to develop and implement these programmes locally, as local and targeted information is more effective to raise demand (OECD, 2008e). While these initiatives have yet to be rigorously assessed, it is increasingly clear that systemic changes in consumption habits are critical for raising market penetration of green goods and services.

204. Municipal programmes investing in ICT can significantly lower the information asymmetries that often lead to energy overuse. An example is the provision of new smart metres that display and record real-time energy consumption data and analyse electricity demand patterns to 
encourage changes in energy usage, which can be a key tool in city energy conservation awarenessraising campaigns. Recent research at the MIT Portugal Program has shown that smart metres produced energy savings of up to $20 \%$ for households in Lisbon. City-level demonstration projects, even of a limited scale, have been very effective. A multi-year survey in the city of Blacktown, Australia, shows that awareness of the Blacktown Solar City project grew to $44 \%$ two years after its initiation. Of the people surveyed, $91 \%$ had switched to energy-saving light bulbs, $73 \%$ had chosen an appliance because of its energy rating, $42 \%$ had installed insulation to reduce energy use, $30 \%$ had signed up for green electricity and 5\% had installed solar panels during the two years of the project's implementation. ${ }^{20}$ This demonstrates the potential impact of government information campaigns, coupled with wide technology deployment (e.g. roll-out of smart metres), on local and regional green spending and energy efficiency.

205. Cities are also promoting utility green pricing programmes, relying on voluntary contributions from customers are another instrument to support higher levels of local investment in renewable energy. Participating customers in green pricing programmes typically agree to pay a premium on their electric bill to cover the incremental cost, for the utility, of providing additional renewable energy. The number of these programmes has increased steadily in recent years: to date, more than 750 utilities in the US offer a green pricing option. Green pricing programmes involving voluntary contributions from private citizens and from corporations are proliferating in many other OECD countries. In Europe, green power purchasing and utility green pricing have existed since the late 1990s, and have achieved good results in particular in the Netherlands, Finland, Germany, Switzerland, and the United Kingdom. In Japan, there were an estimated 60000 green power consumer-participants by early 2005 . Green power in Japan initially developed through voluntary community organisations, like the Seikatsu Club Hokkaido.

206. In their role as facilitators of long-term strategic planning and enablers non-governmental action, cities can convene key local stakeholders in deliberations to determine goals for green growth policies and leverage the participation of the private sector, civil society organisations and individuals. These enabling activities may take the form of workshops, lectures, public hearings, or inviting written comments on draft plans of action. For example, Seattle, the mayor appointed a "Green Ribbon Commission on Climate Protection", which brought together leaders from Seattle's business, labour, non-profit, academic and government sectors to develop recommendations for local action. This included a metrics sub-committee to develop measures to indicate if Seattle is making progress in meeting its goals and sub-committees for energy, transportation, outreach, and freight (OECD, 2010c; City of Seattle, n.d.).

\subsection{Delivering urban green growth through policy coherence}

207. Green growth involves a paradigm shift in the way economic development policies are conceived at national, regional and local levels and in the way these policies link to the business sector and civic organisations. Urban green growth strategies hold the promise of a new development path where economic growth and higher environmental quality are complementary. Urban green growth policies must be designed as an integrated policy package to realise policy complementarities. However, as will be developed later, urban green growth policies must also be embedded in supportive national frameworks with clear policies and price signals.

208. City and regional governments may more easily identify and combine complementary climate policies within and across sectors than higher levels of government, given the

20. See the second issue of the Solaris newsletter at www.environment.gov.au/settlements/solarcities/publications/solarise/index.html. 
interconnectedness of urban policy sectors. The existence of a policy complementarity signals a benefit in the form of the return generated when one policy is enacted along with another (De Macedo and Oliveira Martins, 2006). Identifying the impact and benefits that policy sectors can have on each other is essential to designing policy packages that enhance the effectiveness of each individual policy. Table 5 demonstrates the integrated urban policy packages that result from combining urban growth policies with policies to address greening opportunities and challenges. 
Table 5. Green growth policy synergies

\begin{tabular}{|c|c|c|c|}
\hline $\begin{array}{l}\text { Pro-Growth Policies } \\
\text { Greening Opportunities } \quad \downarrow\end{array}$ & Infrastructure and Investment Policies & Innovation Policies & Human Capital Policies \\
\hline Energy Policies & $\begin{array}{l}\text { Regulations and investments to support } \\
\text { cogeneration of energy, district } \\
\text { heating/cooling, and city purchase of } \\
\text { renewable energy }\end{array}$ & $\begin{array}{l}\text { Funding and technical assistance for } \\
\text { regionally-located renewable energy } R \& D\end{array}$ & $\begin{array}{l}\text { Retraining of traditional economy } \\
\text { workers for renewable energy } \\
\text { production }\end{array}$ \\
\hline 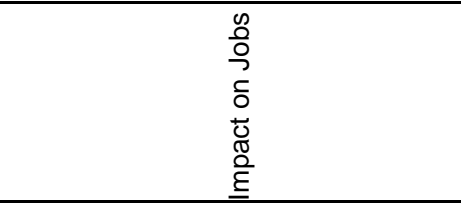 & $\begin{array}{l}\text { Renewable energy production is more } \\
\text { job-intensive than fossil-fuel energy } \\
\text { production. }\end{array}$ & $\begin{array}{l}\text { Low and high-skill job opportunities at } \\
\text { renewable energy start-ups. }\end{array}$ & $\begin{array}{l}\text { Facilitates transition between traditional } \\
\text { economy jobs and renewable sector job } \\
\text { opportunities. }\end{array}$ \\
\hline 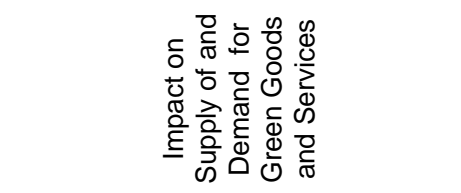 & $\begin{array}{l}\text { District heating/cooling can increase } \\
\text { access to renewable energy by } \\
\text { enabling or requiring participation of } \\
\text { buildings in district. }\end{array}$ & $\begin{array}{l}\text { Lowering barriers to commercial } \\
\text { development of renewables can lower final } \\
\text { cost, thus enabling greater demand. }\end{array}$ & -- \\
\hline 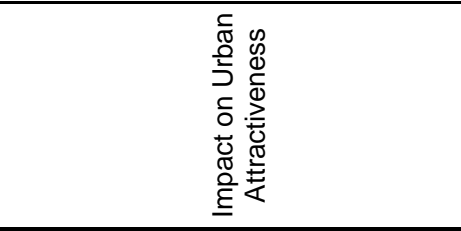 & $\begin{array}{l}\text { Can attract firms given renewable } \\
\text { sources of energy less vulnerable to } \\
\text { price fluctuations than fossil-fuels. }\end{array}$ & $\begin{array}{l}\text { Funding and technical assistance can attract } \\
\text { renewable energy SMEs and R\&D activities, } \\
\text { and add value to local academic institutions }\end{array}$ & $\begin{array}{l}\text { Skilled labour pool can better attract } \\
\text { renewable energy producing firms. }\end{array}$ \\
\hline Mobility Policies & $\begin{array}{l}\text { Investment in public transport, multi- } \\
\text { modal connections, transport-oriented } \\
\text { and high-density development } \\
\text { Purchase of fuel-efficient or alt fuel fleet } \\
\text { Investment in electric car charging } \\
\text { spots }\end{array}$ & $\begin{array}{l}\text { Investment in local development of regional } \\
\text { public transport solutions } \\
\text { Funding and technical assistance for } \\
\text { regionally-located low-carbon car, battery } \\
\text { and public transport } R \& D\end{array}$ & $\begin{array}{l}\text { Retraining of workers for low-carbon } \\
\text { car, battery and public transport sector }\end{array}$ \\
\hline
\end{tabular}




\begin{tabular}{|c|c|c|c|}
\hline $\begin{array}{ll}\text { Pro-Growth Policies } & \rightarrow \\
\text { Greening Opportunities } \quad \downarrow & \end{array}$ & Infrastructure and Investment Policies & Innovation Policies & Human Capital Policies \\
\hline 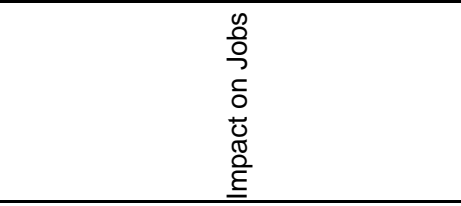 & $\begin{array}{l}\text { Increased public transport and modal } \\
\text { connections can reduce congestion and } \\
\text { facilitate movement within labour } \\
\text { market }\end{array}$ & $\begin{array}{l}\text { Low and high-skill job opportunities at firms } \\
\text { researching and manufacturing low-carbon } \\
\text { cars, batteries and public transport } \\
\text { technologies. }\end{array}$ & $\begin{array}{l}\text { Facilitates transition to job opportunities } \\
\text { in transport sector start-ups and in new } \\
\text { transport infrastructures. }\end{array}$ \\
\hline 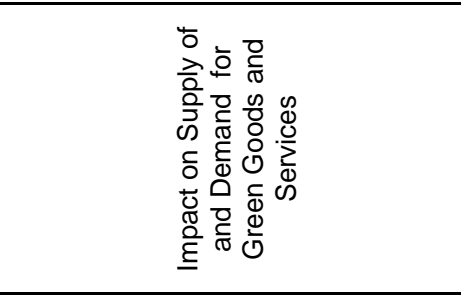 & $\begin{array}{l}\text { Local government investment in public } \\
\text { transport technologies (including ICT). } \\
\text { Local government purchase of fuel- } \\
\text { efficient or non-fossil fuel vehicles. } \\
\text { Charging sites lower logistical barriers } \\
\text { to electric car purchases. }\end{array}$ & $\begin{array}{l}\text { Lowering barriers to commercial } \\
\text { development of low-carbon cars and } \\
\text { batteries can lower final cost, thus enabling } \\
\text { greater demand. }\end{array}$ & -- \\
\hline 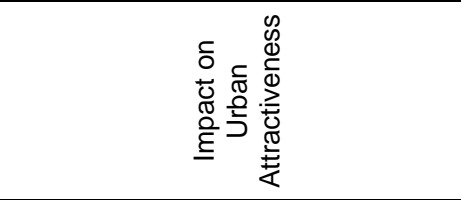 & $\begin{array}{l}\text { Well-managed urban congestion can } \\
\text { attract firms. } \\
\text { Property values tend to increase near } \\
\text { public transport connections. }\end{array}$ & $\begin{array}{l}\text { Funding and technical assistance can attract } \\
\text { low-carbon car, batteries and public } \\
\text { transport SMEs and R\&D activities, and add } \\
\text { value to local academic institutions }\end{array}$ & $\begin{array}{l}\text { Skilled labour pool can better attract } \\
\text { low-carbon car, battery and public } \\
\text { transport firms }\end{array}$ \\
\hline Natural resources management & $\begin{array}{l}\text { Investment in greywater systems. } \\
\text { Open space preservation policies. }\end{array}$ & $\begin{array}{l}\text { Pricing policies to manage water demand. } \\
\text { Support to firms related to water } \\
\text { management }\end{array}$ & $\begin{array}{l}\text { Retraining for jobs in natural resource } \\
\text { and water management }\end{array}$ \\
\hline 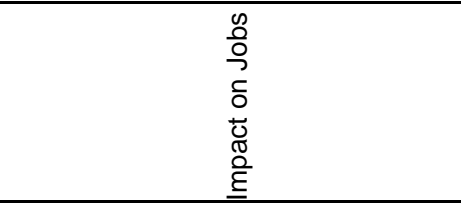 & $\begin{array}{l}\text { Jobs related to installation and } \\
\text { maintenance of greywater systems and } \\
\text { local ecosystem management. }\end{array}$ & -- & $\begin{array}{l}\text { Facilitates transition to job opportunities } \\
\text { in water and ecosystem management. }\end{array}$ \\
\hline 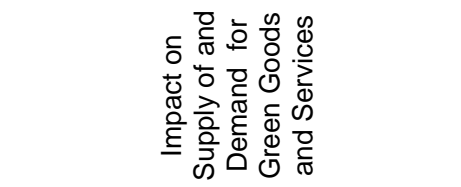 & -- & $\begin{array}{l}\text { Pricing policies can stimulate demand for } \\
\text { water-saving technologies. }\end{array}$ & -- \\
\hline
\end{tabular}




\begin{tabular}{|c|c|c|c|}
\hline $\begin{array}{l}\text { Pro-Growth Policies } \\
\text { Greening Opportunities } \quad \downarrow\end{array}$ & Infrastructure and Investment Policies & Innovation Policies & Human Capital Policies \\
\hline 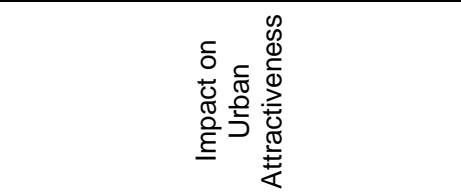 & $\begin{array}{l}\text { High-quality urban open spaces can } \\
\text { attract firms and high-skilled workers. }\end{array}$ & -- & $\begin{array}{l}\text { Skilled labour pool can better attract } \\
\text { water management firms.. }\end{array}$ \\
\hline Buildings & $\begin{array}{l}\text { Retrofitting of public buildings. } \\
\text { Publicly supported financing } \\
\text { mechanisms for individual investment in } \\
\text { energy efficiency technologies. } \\
\text { Publicly supported financing } \\
\text { mechanisms for individual investment in } \\
\text { distributed renewable energies (e.g. } \\
\text { solar PV). }\end{array}$ & $\begin{array}{l}\text { Support for firms producing building energy } \\
\text { efficient technologies. } \\
\text { Labelling and standards for building energy } \\
\text { efficiency. } \\
\text { Facilitation of contracting with Energy } \\
\text { Service Companies (ESCOs) for retrofitting }\end{array}$ & $\begin{array}{l}\text { Retraining of traditional economy } \\
\text { workers for energy efficiency retrofitting } \\
\text { and installation of distributed renewable } \\
\text { energy generation systems. }\end{array}$ \\
\hline 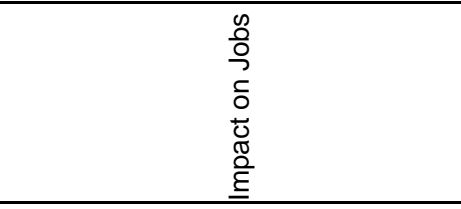 & $\begin{array}{l}\text { Building retrofits and installation of } \\
\text { distributed renewable energies and } \\
\text { energy efficiency technologies is labour } \\
\text { intensive. }\end{array}$ & $\begin{array}{l}\text { Low and high-skill job opportunities at firms } \\
\text { producing building energy efficiency } \\
\text { technologies. }\end{array}$ & $\begin{array}{l}\text { Facilitates transition to job opportunities } \\
\text { in building energy efficiency retrofitting } \\
\text { and installation of distributed renewable } \\
\text { energy technologies. }\end{array}$ \\
\hline 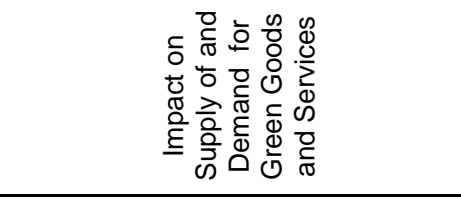 & $\begin{array}{l}\text { Public support lowers barriers to } \\
\text { consumer demand for energy efficiency } \\
\text { and distributed renewable energy } \\
\text { technologies. }\end{array}$ & $\begin{array}{l}\text { Labelling and lowering information barriers to } \\
\text { energy efficiency programmes can increase } \\
\text { consumer awareness and demand. }\end{array}$ & -- \\
\hline 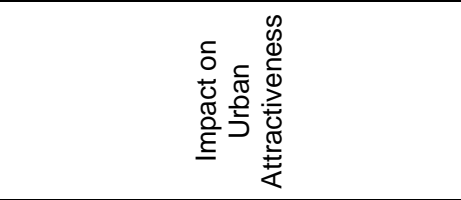 & $\begin{array}{l}\text { New and retrofitted energy efficient or } \\
\text { energy-neutral buildings can attract } \\
\text { firms seeking lower energy costs. }\end{array}$ & $\begin{array}{l}\text { Funding and technical assistance, and clear } \\
\text { labelling standards, can attract energy } \\
\text { efficiency retrofitting and renewable energy } \\
\text { installation firms. }\end{array}$ & $\begin{array}{l}\text { Skilled labour pool can better attract } \\
\text { energy efficiency retrofitting and } \\
\text { renewable energy installation firms. }\end{array}$ \\
\hline $\begin{array}{l}\text { Pollution prevention, treatment } \\
\text { and abatement }\end{array}$ & $\begin{array}{l}\text { Investment in waste-to-energy and } \\
\text { landfill methane capture plants. } \\
\text { Requirements for recycling and } \\
\text { composting of household waste. }\end{array}$ & $\begin{array}{l}\text { Support for firms producing pollution } \\
\text { prevention, treatment and abatement } \\
\text { technologies. }\end{array}$ & $\begin{array}{l}\text { Retraining of workers for waste-to-heat } \\
\text { generation and recycling/composting } \\
\text { activities }\end{array}$ \\
\hline
\end{tabular}




\begin{tabular}{|c|c|c|c|}
\hline $\begin{array}{ll}\text { Pro-Growth Policies } & \rightarrow \\
\text { Greening Opportunities } & \downarrow\end{array}$ & Infrastructure and Investment Policies & Innovation Policies & Human Capital Policies \\
\hline 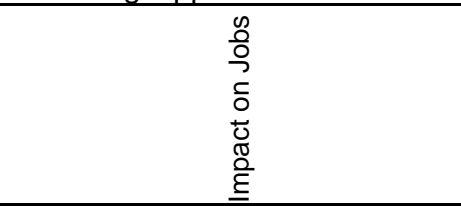 & $\begin{array}{l}\text { Job opportunities in waste-to-energy } \\
\text { production and recycling/composting } \\
\text { collection. }\end{array}$ & $\begin{array}{l}\text { Low and high-skill job opportunities at firms } \\
\text { producing pollution prevention, treatment } \\
\text { and abatement technologies. }\end{array}$ & $\begin{array}{l}\text { Facilitates transition to job opportunities } \\
\text { in waste-to-heat generation and } \\
\text { recycling/composting activities. }\end{array}$ \\
\hline 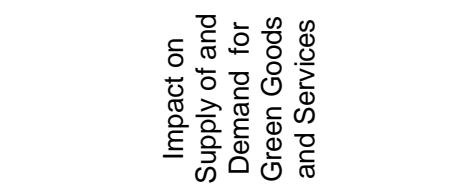 & $\begin{array}{l}\text { Requirements for reducing household } \\
\text { waste share can increase demand for } \\
\text { recycling and composting services. }\end{array}$ & $\begin{array}{l}\text { Lowering barriers to commercial } \\
\text { development of pollution prevention, } \\
\text { treatment and abatement technologies can } \\
\text { lower final cost, thus enabling greater } \\
\text { demand. }\end{array}$ & -- \\
\hline 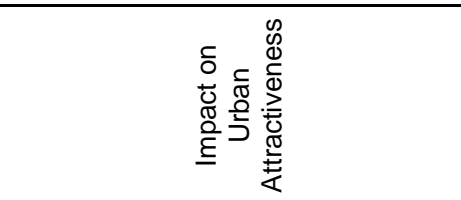 & $\begin{array}{l}\text { Attract firms and high-skilled workers } \\
\text { with good air, water quality and good } \\
\text { waste management }\end{array}$ & $\begin{array}{l}\text { Funding and technical assistance can attract } \\
\text { pollution prevention, treatment and } \\
\text { abatement technologies firms. }\end{array}$ & $\begin{array}{l}\text { Skilled labour pool can better attract } \\
\text { waste-to-heat generation and } \\
\text { recycling/composting firms. }\end{array}$ \\
\hline
\end{tabular}


209. Prioritisation among the different interventions needs to be based on an accurate screening of possible complementarities among the Urban Green Growth Policy Framework greening opportunities and challenges. In other words, within a well-developed strategy, interventions in one domain unlock positive developments in other domains. For example, a large retrofit programme for public buildings can be a powerful boost to skilled and semi-skilled employment generation. However, the impact of the programme on local employment can be maximised only if well trained workers are locally available. Higher competition among suppliers of retrofit services, as well as technological innovations that can reduce the cost and the carbon-intensity of these materials, is also needed to improve the cost-efficiency of public retrofit investments. Synergies and possibilities for leverage do exist, and urban policymakers should develop capacities to spot and use them. More knowledge of how the local economy works and a strong capacity to pursue interdepartmental programmes are essential prerequisites to seize the employment and growth potential of the low-carbon transition. In poor and emerging economy cities, green growth policies that focus on economic and environmental outcomes should be designed and implemented in parallel with equity-driven global sustainability policies (Box 6).

\section{Box 6. The sustainability of urban growth in poor and emerging countries}

\section{Pierre-Noël Giraud (Mines ParisTech)}

In cities, green growth has promising potential to improve both the income of urban dwellers and the quality of the environment, at the local as well as the global level. Green growth, however, deals with only two of the three pillars of sustainable development: economy and the environment. Therefore, the compatibility of green growth policies with the third pillar, social equity, deserves special attention. This compatibility challenge is particularly huge in rapidly growing cities of poor and emerging countries, since absolute as well as relative poverty is rapidly urbanising.

Almost all urban population growth will take place in poor and emerging countries. For the next three decades at least, every year, the urban population in these countries will increase by about 60 million, equivalent to six "megacities", such as Greater London or Shanghai. The sustainability challenges of such rapid urban growth are therefore much greater in poor and emerging countries than in northern cities with stagnating or even declining populations.

In poor and emerging cities, the main sustainability challenge is therefore to make cities "work for everyone", including the poorest populations. This means allowing every urban dweller to benefit from the very advantages of a city: economies of scale and agglomeration (sharing, matching, learning). In other words, the main challenge is to avoid the urban fragmentation and spatial segregation that maintain the poor in poverty traps.

Policies designed to achieve this goal, after decades of trial and error, are at present well known: (1) formalise the informal city, particularly the slums, and (2) provide basic urban services at an affordable price to all urban dwellers.

\section{Formalising the informal city}

From $20 \%$ to $80 \%$ of urban dwellers in poor and emerging cities are presently living in "slums", according to the UN Habitat definition. This will last for decades to come and "slum-free cities" are mere demagogic slogans in the short run. But it is possible to improve the living standards of slums dwellers through (1) recognising the existence of slums and (2) incorporating them into the city through policies based on the provision of some kind of property rights, reducing the risk of brutal eviction without compensation and giving legal access to basic urban services.

\section{Providing access to basic urban services to all}

The provision of basic urban services to all is the second prerequisite to making the cities work for all. These basic services consist of (1) plots without risks of floods and other natural disasters, with minimum road infrastructure, including sidewalks that are designed to host street artisanal and service activities, (2) safe water, (3) improved sanitation, (4) electricity, (5) cellular phone networks, and (6) affordable mass transportation systems that connect people to the rest of the city. 
The challenge is to provide these services at a price affordable to the poorest. Even if low-cost technologies are adopted, it remains that, on average, while the poorest dwellers can generally afford the cost of the services (operating and maintenance costs), they cannot afford the cost of the investments to build the networks. These services should therefore be subsidised to the poor. Ignoring the need to subsidise the construction of infrastructure networks has been the main cause of the almost complete failure of the mere "privatisation" of public urban services. Public private partnerships are indeed a promising tool to improve the efficiency of the provision of basic urban services, but should not be pursued in the form of a mere privatisation.

If cities are to be more inclusive, there is no way to escape that the richest must one way or another subsidise the poorest. This is indeed, in the long run, a win-win deal, since a more inclusive city is able to grow faster, to the greatest benefit of all. But this is not always acknowledged by the richest nor by the politicians representing them.

\section{The environmental challenges}

Poor and emerging cities also face huge environmental challenges to combating local indoor and outdoor air pollution, water and soil pollution, and greenhouse gas emissions.

Very fortunately, policies aimed at inclusiveness - and therefore at social equity and economic efficiency - often yield double benefits in the form of environmental improvements. This is the case of a mass transportation system replacing old and energy-inefficient taxis and small buses. If public transportation policies are combined with land use policies designed to combat urban sprawl, further reductions in local and global air pollution can be achieved. This is also the case with policies aimed at substituting wood and charcoal for cooking by electricity and bottled gas, as they reduce indoor air pollution and excessive deforestation.

But this is not enough. Specific policies to curb greenhouse gas emissions have to be designed and implemented: policies aimed at improving the energy efficiency of buildings and at promoting local energy supply (e.g. the capture and use for electricity generation of methane emissions from huge uncontrolled landfills). These policies all have a social cost, and again it would not be fair to ask urban dwellers whose revenues stand below the poverty line to pay for the provision of local and global public goods like environmental protection. At the very least, it would be fair to proportionate the burden to the relative marginal utility of monetary revenues, which practically means that the cost must be borne by the rich and the middle class, not by the poor.

Again, we find that among the three pillars of a sustainable development in rapidly growing poor and emerging cities, equity is the ultimate driver. In these cities, green growth policies must not only be compatible with initiatives to reduce poverty and combat urban geographic and social fragmentation, these initiatives must be components of green growth policies. In these cities in particular, green growth policies therefore cannot be designed and implemented separately from broader policies aimed at global sustainability.

210. One example of policy complementarities can be achieved through integrated strategies for transportation and land use planning. With limited budgets, cities now face the dual challenges of providing transportation infrastructure that meets the needs of a growing economy while reducing pollution, congestion and greenhouse gas emissions, and providing land and services to expand the tax base while avoiding the negative economic, environmental and social impacts of sprawl. To meet these challenges, many urban areas are putting the priority on orienting development around public transportation and public services delivery (e.g. Copenhagen's Finger Plan). In some cases, this takes the form of spatial plans in which cities aim to direct growth around an urban core or a polycentric system of urban core areas. In other cases, cities have focused primarily on promoting development that extends outward around public transportation networks, public services and urban amenities. What these strategies have in common is their goal of support economic growth through means that also reduce consumption of energy and other resources. They can also address social equity concerns: in seeking to concentrate development around areas of public services, and to better connect existing areas to public transportation, integrated transportation and land use strategies serve as a way of integrating urban populations at risk of being isolated from local employment and economic activities (Jenks et al. 2008). 
211. Multi-modal public transportation delivery also responds to sustainability and job growth priorities. The "New Mobility" models of transportation, with which cities have experimented in both developed (e.g. Toronto, San Francisco, London) and developing countries (e.g. Cape Town, Chennai, Bangalore), search for better integration of multiple transport modes around hubs that are dynamic centres for service provision. The synergy between transportation and economic activities generates new employment opportunities in entertainment, recreation, dining, banking, commerce and community services. Integrated urban strategies for sustainable transportation can serve as incubators for green technology innovations, providing a good framework for evaluating the cost and benefits of new technologies with wide industrial applications, such as hybrid engines, hydrogen fuels and sensor networks. For example, the City of Hamburg has sought to support the development of hydrogen-fuel buses by combining its purchasing power with other cities, Barcelona, Berlin, Cologne and London, with the goal of creating demand for 100-150 hydrogen buses (EurActiv, 2009).

212. Cities can improve their environmental effectiveness and attract new firms and jobs through combined investments in transportation networks and ICT. Efficient intra-urban mobility is crucial to realise the economic advantages of agglomeration - that is, cities that are more connected and more compact. There are important complementarities between ICT and transportation investments. Both respond to the need to improve connections between people and businesses, reducing costs of commuting and information transfers. ICT innovations, when applied to public transportation systems, can improve service quality and thus ridership more cost-effectively than large-scale capital investments.

213. Policy complementarities at the urban level can also be foreseen within sectors as well. In the transport sector, strategies to increase the quality and availability of public transportation, bicycle and foot travel make policies to discourage or restrict vehicle travel and circulation more politically feasible. For example, congestion fees for driving during peak hours worked well in London because they were combined with improvements in the management of the road network and substantial enhancements in bus service. Energy efficiency standards for new buildings can be complemented by projects to also retrofit existing buildings to be more energy efficiency.

214. Compact city policies provide an example of urban policies that can foster complementarities between economic and environmental objectives. In general, successful compact cities rely on transportation linkages, mixed land uses, and high-quality urban services. Different urban forms may have the same density, however, and the policy goals, strategies and tools applied to the concept can vary (OECD, forthcoming (b)) (Figure 16). Applying densification policies or congestion charges can have long-term positive effects on the economy due to technological innovation: high-quality, more-efficient public transport that responds to economic needs and better connects labour with employment, thus increasing firms' productivity, etc.). Land-use zoning policies that allow for higher densities and greater mixing of residential and commercial uses can enhance transportation goals by reducing trip distances while strategic mass transit linkages can attract development and promote compact growth. However, density can also be perceived as a cost that must be outweighed by the benefits of agglomeration and urban amenities, including proximity to highquality public transportation (Chesire and Magrini, 2009). Long-term growth plans in a number of OECD metropolitan areas aim to maximise policy complementarities and prioritise the urban amenities that can mitigate the perecieved disadvantages of higher density-dwellings. (e.g. Paris, New York, London). 
Figure 16. Types of development and density

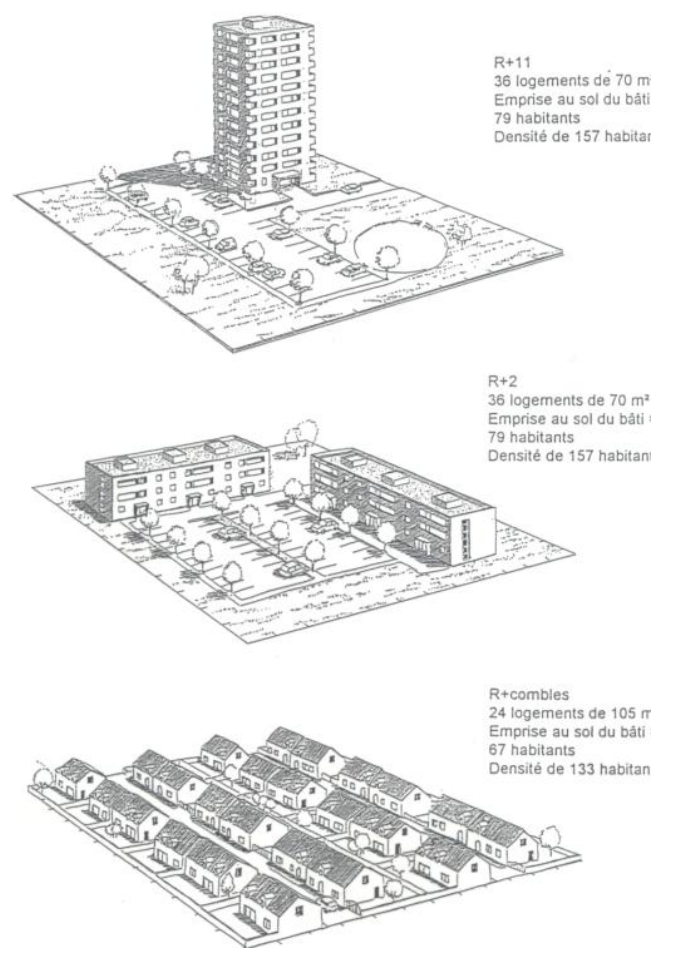

Source: Fouchier (1997).

215. Development of "sustainable neighbourhoods" or "eco-neighbourhoods" takes advantage of policy complementarities by combining transportation, natural resource preservation, building, energy, waste and water policies to reduce the urban environmental footprint and more efficiently deliver urban services. Common principles include increasing energy efficiency and renewable energy generation, using sustainable building materials, and reducing personal vehicle use. The most notable eco-neighbourhoods, either completed or currently under development, are located in Western and Northern Europe, including in Sweden (Bo01 and Augustenborg in Malmö and Hammarby Sjöstad in Stockholm); Finland (Viiki in Helsinki); Germany (Vauban and Rieselfeld in Freiburg; Kronsberg in Hanover); Denmark (Vesterbro in Copenhagen); the Netherlands (Leidsche Rijn in Utrecht); and Great Britain (BedZED in Beddington, zero-carbon communities). However, eco-cities are also under development in Korea, China and Abu Dhabi. Residential density varies among sustainable neighbourhoods projects, although most could be described as low-rise high density; towers or highrise apartments are rare. Sustainable neighbourhoods shape development beyond residential density; cars may be restricted or prohibited (such as in Vauban) and waste collection policies may be more restrictive than elsewhere in the city.

\section{Main challenges to advancing an Urban Green Growth Agenda}

216. Cities and regions nevertheless face a host of challenges in advancing an urban green growth agenda. This section begins with a discussion of the limits to the urban green growth paradigm, including the potential for a zero-sum game and the crucial baseline variables (in terms of the existing resource, policy and economic environment in a given city) that can hamper or accelerate progress toward green growth. Next, through the lens of the OECD Multilevel Governance Framework, we 
examine the "gaps" that can occur across and within different tiers of government that influence the effectiveness of green growth policy implementation. National governments have an essential role to play in enabling progress toward green growth in cities, in terms of providing clear pricing signals on carbon and other goods, technical assistance, funding and knowledge sharing, and strong environmental targets and baseline standards. We then turn our attention to the efforts underway to measure and monitor progress toward green growth, which will be essential to guide policymaking and to determine whether and to what extent green can lead to growth. Finally, we explore the challenges faced by governments to finance urban green growth initiatives and evaluate the existing and potential instruments that can be used to move toward a greener, more sustainable society.

\subsection{Limits to the urban green growth paradigm}

217. Although all regions can enjoy growth (OECD, 2009d), and the logic of pursuing greening initiatives at the city level is clear, there are nonetheless some limitations to the concept of green growth that policymakers at both the national and regional/city level must keep in mind as they move forward.

\section{Potential for a zero-sum game}

218. There is a potential issue of a zero-sum game. Among the proposed green growth scenarios identified in Section 1.4, scenarios 5 (sectoral displacement) and 6 (economic stagnation/de-growth) hint at one of the biggest concerns, namely that there may be winners and losers as cities begin to work towards green growth. Some urban economies may grow a great deal, others will grow less, and some might potentially shrink, if the process is managed poorly. In a similar vein, some business sectors may thrive, while others may see little change in economic activity level. To the extent a city is heavily dependent on businesses likely to decline as a result of competition from green growth-related businesses, the economic impacts could be considerable. National governments will be concerned about the net impacts across all regions in their country; local government officials will naturally be more concerned about the localised impacts. The question of a zero-sum game among territories in the race toward a green growth development is a concern for national policy-makers.

\section{All cities are not equal: the baseline variables}

219. There are several baseline variables that link to how successful urban green growth initiatives will be over different time scales. These include baseline conditions related to the city's natural resources asset base, the technology deployed in a city (which may be creating path dependency or lock-in), local economic conditions with may constrain certain policy choices, etc. Whether these factors put the brakes on or accelerate green growth will depend on how well local officials assess their greening needs and opportunities, and structure an implementation strategy that leverages the support and involvement of other key stakeholders. These variables can fall into two categories: a city's underlying resource environment and its underlying policy and economic environment. Each category includes several subsidiary variables which reference different aspects of the issue (Table 6). 
Table 6. Baseline variables

\begin{tabular}{|c|c|}
\hline \multirow[t]{4}{*}{$\begin{array}{l}\text { Resource } \\
\text { Environment }\end{array}$} & $\begin{array}{l}\text { Natural resource base: Many of the greening strategies being pursued by cities seek to harness } \\
\text { naturally occurring ecosystem services available in or near the city. Water from deepwater lakes might } \\
\text { be used to cool buildings, while differing levels of sun and wind resources will determine the cost } \\
\text { effectiveness of certain renewable power technologies. To the extent a city lacks sufficient renewable } \\
\text { energy assets necessary to provide what it deems to be an acceptable return on its investment, this } \\
\text { will obviously influence technology deployment decisions. Even here, however, circumstances can } \\
\text { change over time as technological innovation and efficiency improvements occur, turning what were } \\
\text { once considered marginal levels of renewable resources into something much more viable. Another } \\
\text { type of natural resource may relate to the dominant power supply sources in a city, as regions with } \\
\text { large amounts of coal deposits may find proximity to these resources gives them an inexpensive and } \\
\text { relatively secure fuel supply. This too can influence the viability of other green growth options. }\end{array}$ \\
\hline & $\begin{array}{l}\text { Climate/geographic conditions: a city's location (e.g. coastal vs. inland) and climatic zone } \\
\text { (e.g. hot/cold/temperate) may frame several key components of its green growth strategy. In the face } \\
\text { of climate change, coastal locations may necessarily focus their green growth plan on climate } \\
\text { adaptation strategies, as the risk of sea level rise or coastal inundation from extreme weather events } \\
\text { may overwhelm all other environmental challenges facing the city. Weather and climate patterns in } \\
\text { cities may also be closely linked to past (and future) technology and infrastructure investment } \\
\text { decisions, such as district heating and cooling technology. Cities with milder climates may have less } \\
\text { need or opportunity to focus on such strategies, as the benefits are less clear-cut. }\end{array}$ \\
\hline & $\begin{array}{l}\text { Technology/infrastructure: Historic investments in technology and essential infrastructure have long } \\
\text { been linked to path dependency or technology lock-in (Unruh, } 2000 \text { and 2002) that are difficult to } \\
\text { overcome, dramatically shaping the type of green growth initiatives to be pursued in the future. These } \\
\text { sunk investments, some of which may have been made over a century ago, frequently offer current } \\
\text { day cost advantages that make it difficult for alternative technologies to effectively compete on price. }\end{array}$ \\
\hline & $\begin{array}{l}\text { Urban form/built environment: It was previously noted how historic land use and transport system } \\
\text { decisions can affect the density of a city or region. As with technology and infrastructure investments, } \\
\text { it is not that these circumstances cannot change, but rather it is a time-consuming process that may } \\
\text { involve vast sums of money, face property rights challenges, or involve significant social upheaval. } \\
\text { Because urban form is related to so many green growth issues, however, (e.g. transport/mobility } \\
\text { options, energy system design, water supply and treatment options, access to green space, amount of } \\
\text { permeable surfaces, etc.), it can exert tremendous influence over the contents of a green growth plan } \\
\text { or the options that can be considered viable over different time scales. }\end{array}$ \\
\hline \multirow[t]{3}{*}{$\begin{array}{l}\text { Policy and } \\
\text { Economic } \\
\text { Environment }\end{array}$} & $\begin{array}{l}\text { Policy competency and level of engagement: A city or urban region's ability to engage on different } \\
\text { green growth initiatives may vary dramatically, based on the policymaking powers specifically } \\
\text { assigned to them by state or national government. The exact powers assigned to them will vary by } \\
\text { topic, and by country or state/region. One key aspect of this issue relates to who owns certain key } \\
\text { infrastructure assets - for example, the local water supply or treatment system, the power grid or } \\
\text { power generation facilities, solid waste collection systems or disposal facilities, or the local public } \\
\text { transport system. In some cities, all of these systems are owned and operated directly by the local } \\
\text { authority; in others, these services are privately held. The ownership arrangements influence the level } \\
\text { of engagement local authorities have on those issues, or the position of policymaking strength or } \\
\text { weakness from which they operate. The local policy milieu will also necessarily reflect a city's } \\
\text { 'willingness to act' (Hammer, 2009), meaning the level of interest local policymakers or politicians } \\
\text { have in tackling certain issues, or the type of policy instruments they are willing to exploit when } \\
\text { addressing that topic. }\end{array}$ \\
\hline & $\begin{array}{l}\text { Industrial/economic base: The current state of the local economy may also influence the types of } \\
\text { issues that are germane to a city or region's green growth strategy. Cities that are home to heavy } \\
\text { industry may find that pollution or high rates of energy demand top the list of issues to be addressed } \\
\text { through a green growth strategy. By contrast, cities that are dominated by a service-focused } \\
\text { economy, including tourism, may target green growth initiatives focused on beautification or the } \\
\text { enhancement of recreational amenities (e.g. waterways, parks, etc.) Either type of city may be } \\
\text { hesitant to pursue policies that result in cost increases for local businesses, fearing such an outcome } \\
\text { might force companies to close or chase them to another city where costs are lower. }\end{array}$ \\
\hline & $\begin{array}{l}\text { Other economic factors: Cities with low per capita income or high corporate tax rates may find it } \\
\text { difficult to finance all of the green growth initiatives they would ideally like to pursue. The local } \\
\text { elasticity of demand for essential services such as energy and transportation may also come into play, } \\
\text { as in many cases, absent other options (such as public transportation), green growth initiatives that } \\
\text { drive up the cost of these services may force consumers to leave the area altogether, having priced } \\
\text { them out of the market. Finally, the type of human capital available in a city can dramatically influence } \\
\text { the type of green growth opportunities pursued, and whether the economic bump provided by these } \\
\text { projects are short or long-lived. A strong education or job training component might be required if } \\
\text { certain green growth strategies are to prove successful. }\end{array}$ \\
\hline
\end{tabular}




\subsection{Addressing gaps in multi-level governance}

\section{Local-national policy linkages}

220. For urban green growth policies to succeed, collaboration across and within different tiers of government is required, as is co-operation with the business community. Given the breadth of issues covered by the green growth agenda, the ability (or interest) of any individual government or nongovernmental stakeholder to drive or actively influence a green growth strategy will vary widely. While some urban authorities enjoy significant policy powers or have influence over different geographic areas, others have much more limited policy competency or scope. Several structural obstacles exist to developing a worldwide green economy that builds from the actions of cities and local governments (Box 8). A multi-level governance framework can help to address many of the challenges to effective policy design and implementation (see OECD, 2011e). Regardless of the constitutional form of government, there is a need for enhanced co-ordination across scales or levels of government (vertical) and across different policy sectors and departments (horizontal) (Bulkeley and Betsill, 2005; Hooghe and Marks, 2003; OECD, 2006; OECD, 2010c).

\section{Box 7. Impediments to developing a worldwide green economy}

\section{David Miller, former Mayor of Toronto and former Chair of C40 Cities - Climate Leadership Group}

While significant progress is being made to green current economic practices in many of the world's leading cities, considerable hurdles remain to fully realise the potential of local economic greening efforts that increase both employment and economic opportunity on a broader scale. International and national structural impediments, stemming from the political history of cities, inhibit cities from linking environmental actions with economic results. Given that key innovations are happening in cities, these impediments are causing international and national institutions to fail to meet their own goals.

The first problem is with international institutions. It is extremely difficult for cities to apply for relevant funding for projects that benefit both the environment and the economy, such as rapid transit. Cities are rarely successful in applying for climate change mitigation funding, as the international community sees these programmes through the eyes of nation-states. The critical role of cities is not yet broadly recognised; hence the need for the OECD to take the lead in studying the positive relationship between the environment and the economy with the right leadership from cities.

Second, in many countries, cities are seen as a subsidiary form of government and lack the legal or financial tools or authority to empower them on this issue. National governments often fail to understand the effectiveness and power of local, small-scale actions. As a result, the potential of the excellent local work in Paris and New York City to reduce greenhouse gas emissions and generate civic engagement and jobs is limited because these programmes are not national in scope.

Third, in certain parts of the developing world in particular, there is a lack of administrative and financial capacity within cities to take advantage of the international resources that do exist. With many such cities dealing with the dayto-day reality of a massive inward migration, today's decisions will determine how these cities are built for the next fifty years. There is thus an urgent priority to help build the necessary institutional capacity and to fund sustainable infrastructure that will help these economies grow greener.

The good news is that these challenges can be overcome. Cities are already demonstrating that they are active leaders now by sharing information, projects, and solutions, because cities and mayors cannot wait: they are a form of government that by definition takes action. International institutions, led by the OECD, are actively seeking ways to support this work. Businesses located in cities are innovating at a rapid pace. And most of all, people understand that these challenges must be overcome if we are to reach our environmental, social, and economic goals. And they will be overcome - in cities. 
221. In many cases, vertical co-ordination is needed for local or regional governments to effectively carry out the policies designed at the national level (climate change, air quality, etc.) and ensure that national mandates are implemented and deliver meaningful results at the local scale. Horizontal co-ordination is an issue at both the national level (in terms of cross-sectoral policy coherence among ministries, for instance) and the sub-nationalsubnational level (among local jurisdictions belonging to the same metropolitan area or between urban and rural areas). There is also increasing evidence of multi-level patterns of governance and transnational networks on climate change and other global environmental issues where actors work across organisational boundaries to influence outcomes. This element is very important for urban development policies in general and economic and environmental issues in particular (OECD, 2006). Within the multi-level regulatory framework, learning, information transmission and co-operation also occurs horizontally with linkages increasingly being forged between cities, regions and national governments (Bulkeley and Moser, 2007). Horizontal governance activities also increasingly include giving "voice" or influence in the policy dialogue process to research and non-governmental organisations (see OECD, 2010c).

222. Enhancing local-national policy linkages is key to achieve urban green growth. Urban green growth and sustainability initiatives both affect and are affected by economy-wide fiscal policies and national sectoral policies (particularly transportation, building, labour, innovation and education policy). At the same time, urban-scale action also has the potential for delivering social and technical innovation that is not possible at a broader scale and can provide insights for understanding the political economy of climate change and green growth (see OECD, 2010c). Action at the local scale may enable or constrain what is possible nationally and vice versa, highlighting a two-way relationship between local and national action on many greening topics (see, for instance, Goulder and Stavins, 2010; and Cooke and Porter, forthcoming).

\section{The role of national governments in enabling the advancement of urban green growth}

223. National governments can enhance cities' capacity to act on green growth:

- There is a need to bridge the gap between national and local approaches to green growth. National plans often do not account for the spatial elements of green growth, nor for cities' existing contributions to green growth. Urban green growth strategies tend be stand-alone, flagship green projects that are dependent on short-term political cycles; long-term sustainable economic growth calls for a systematic, citywide, multi-sectoral approach. This issue is discussed in detail in the remainder of this section.

- Technical assistance, funding and knowledge-sharing is needed for large-scale infrastructure projects - such as smart grids, high-speed trains, and green R\&D - and to help cities measure the economic and environmental impact of green growth initiatives.

- Strong national and international environmental targets and baseline standards are needed to remove policy obstacles, prevent harmful competition among regions and promote incentives for a "race to the top" (OECD, 2010c). Cities also need flexibility to innovate urban-level policy responses that can then be scaled up.

- Green growth is impacted by the way carbon emissions and environmental quality are valued. Urban green growth policies would benefit from national price signals and standards - e.g. through carbon taxes or other pricing mechanisms. Such signals can enhance the incentives for firms to adopt and develop green innovations and help to indicate the commitment of governments to move toward greener growth. They can also enhance efficiency in allocating resources by establishing markets for green innovation and will 
lower the costs of addressing environmental challenges. Carbon taxes and climate change levies are almost always introduced at the national level, as they would distort competition between regions (the city of Boulder, Colorado (USA) is a notable exception). ${ }^{21}$

- Better monitoring of policy impacts is also essential to advance toward greener growth. A common set of urban environmental and economic indicators are needed to compare best practices and measure the impact of green growth projects on environmental, economic and social priorities. National governments can help develop a common methodology and support capacity building at the sub-national level. The next section explores the ongoing OECD efforts to develop better measuring and monitoring tools that can more accurately capture societal well-being and green growth.

- As will be developed in the final section of this paper, national governments could green urban finance by re-designing taxes and grants to sub-national governments to correct incentives for unsustainable behaviour and reward cities that create environmental benefits beyond their borders. A comprehensive greening of urban finance would also increase the coherence between urban finance and urban planning frameworks to enhance urban sustainability and to contain unlimited urban growth.

- As the best policy tool to foster complementarities and synergies, regional policies need to better integrate the green growth agenda in their current policy framework. Surprisingly, the regional component of a national green growth agenda has often been led by sectoral ministries rather than those responsible for regional and spatial planning. Alignment of incentives across sectoral and cross-sectoral policy areas is required to deliver policy coherence and to integrate green growth into regional and territorial development planning. Policymakersmakers in charge of regional development could advance the green growth agenda, but would require a better understanding of the concept based on solid analysis and data.

- It is also essential for national governments to assess the link between territorial and social equity and green growth. We anticipate that as cities and regions localise the green growth concept, tradeoffs or economic dislocation problems will become readily apparent, and officials will necessarily factor them into their decision-making process in ways that they believe are locally appropriate. These factors are particularly important for cities in developing countries, but also for OECD countries. From a territorial development perspective, there is a need to assess the potential for a zero-sum game in a national context.

\section{Bridging the gaps}

224. A multi-level governance framework can provide a helpful starting point for understanding how collaborations between various levels of government and policy sectors can occur. Multi-level governance calls for a narrowing or closing of the "gaps" on effective green growth policy implementation. The OECD Multilevel Governance Framework emphasises seven gaps where disconnects occur that impede policy or programmatic activity can be adapted to the specific case of green growth (Charbit, 2011). This methodology explores the main multi-level governance challenges, institutional obstacles to effective implementation of policymaking, and tools to overcome them. To

21. See also arguments against the establishment of carbon taxes at the local level: OECD (2011g), Interactions between Emission Trading Systems and Other Overlapping Policy Instruments, OECD, Paris. 
adapt the framework to green growth, we have added an eighth gap focussing on the local business environment, given the influence of the current market environment on green growth policy options and the important role the private sector in delivering green growth.

225. The following section describes the eight governance gaps in detail, drawing on the OECD multi-governance framework (Charbit, 2011), and is followed by a demonstration of how the framework can be applied to assess governance challenges within a single sector (e.g. the water sector in the Venice city-region) as well as across sectors in the context of a national green growth strategy (e.g. the case of Korea).

226. An administrative gap occurs when there is a geographical mismatch between the green growth challenge or opportunity and administrative boundaries, which can create environmental and economic impediments. Administrative boundaries (municipalities, regions, and states) are rarely fixed according to the greening challenge/opportunity logic and frontiers, resulting in a mismatch at the sub-national level that hinders policy coherence (Moss, 2007).

227. A policy gap refers to the sectoral fragmentation of policy tasks and powers across ministries and public agencies within the national government administration, as well as among different departments within sub-national government administrations (also referred to as a "silo approach" to policymaking). This can lead to policy inconsistencies (vertical and horizontal) and can create uncertain market conditions that may inhibit companies from entering the marketplace make it difficult to obtain capital for infrastructure investments, business operations or expansion.

228. An information gap happens when there is an asymmetry of information across ministries, between levels of government and across local actors involved in specific policy areas, and can beexacerbated by the lack of capacity, resources or expertise to collect, analyse and interpret data. An asymmetry of information may also occur when knowledge of what is happening "on the ground" is not shared among national and local stakeholders, creating win-lose situations by specific use of information not in the possession of the other party. To the extent that public authorities have access to information that could benefit local green business sector stakeholders, a decision must be made about whether to share this information as a means of promoting sectoral growth.

229. A capacity gap is generated by insufficient scientific and technical expertise, know-how and infrastructure to design and implement policy. The capacity gap is not restricted to the sub-national level; it also applies to the national level (e.g. managing multi-level relations, allocating responsibilities and funds, and ensuring co-ordinated policy approaches among central-level actors).

230. A funding (or fiscal) gap refers to the insufficient or unstable revenues to implement policy across ministries and levels of government. A funding gap can also occur if private capital is too costly because of perceived implementation risks or other factors that make private lenders or investors wary of entering the local marketplace. In the case of green growth initiatives, there may also be a disconnect related to the return on investment requirements of the project sponsor, who seeks a shorter payback period than the project is capable of delivering.

231. An objective gap occurs when diverging or contradictory objectives between levels of government or departments/ministries compromise the adoption of convergent targets over the long run. The objective gap may also arise if local political or policy interests do not align with the interests or needs of private sector stakeholders, causing them to exit the local market entirely or restrict efforts to expand in the city/region. 
232. An accountability gap refers to the lack of transparency in policymaking, as well as integrity and institutional quality issues. With the development of private sector participation in some sectors, the traditional government accountability is changing. In this context, the accountability gap can be reflected in the market entry process, award criteria, as well as contract provisions for unforeseen contingencies.

233. A market gap arises when a policymaking goals or ambitions do not align with the ability of private sector stakeholders to deliver on these goals. Although this could be seen as creating the fundamental conditions necessary for sectoral growth, the reasons for the gap must first be ascertained and addressed by the appropriate array of horizontally or vertically aligned policymakers. The private sector is a critical partner in horizontal co-ordination efforts to advance green growth, because businesses serve many different roles in delivering this growth as:

- direct service providers contracted by government to carry out certain greening functions (e.g. transport provider, energy supplier, water treatment plant operator, contractor responsible for energy efficiency or climate adaptation upgrades, etc.);

- the target of government greening policies or incentives designed to promote behavioural change or rule compliance (e.g. responsible for compliance with solid waste management or air emission rules; the target of efforts to promote resource conservation or more transitoriented development schemes; etc.);

- innovator or the home of environmental or energy research and development efforts designed to address green growth challenges or opportunities; and

- $\quad$ artner in advocating for policy changes by other governmental entities better positioned to drive certain local green growth efforts.

234. To the extent some green business sectors are immature in a city-region, that will inhibit the success of policy solutions and clarify the need for policy action or improved co-ordination between different governmental entities. The involvement of national government stakeholders may be necessary if overall economic conditions in the country are the root cause for the absence of a strong or stable private sector presence in a city/region; such general macroeconomic conditions may make it harder to convince private firms to establish operations in the city-region or even be willing to conduct business in the area. Strategies to remedy this gap will generally follow those outlined in Section 2.2 discussing approaches commonly employed to promote regional growth (e.g. research and development support, human capital and infrastructure development, etc.). Working with private sector players can introduce complexities for government officials, however, because of concerns over corruption, failure to perform, and the fact that some of the most important private sector stakeholders operate as monopolies. Ensuring that they do not unfairly take advantage of customers will be an important consideration

235. Each of these gaps can be addressed by one or more policy instruments under the control of different national and sub-national entities. For example, a city seeking devolved regulatory control powers might employ information dissemination or advocacy strategies as part of their effort to win this capability. A city seeking regional co-ordination on water supply or treatment problems can use their land use or building permitting authority to experiment with certain policy solutions or lead by example. National authorities can provide direct financial support to pay for these regional facilities or provide financial incentives to encourage collaboration by the relevant sub-national authorities. A mayor seeking to force agencies within local government to collaborate across silo boundaries to address greening challenges can impose reporting requirements or establish financial incentives based 
on their level of co-operation. A national government can be helpful by sponsoring training workshops for local government officials to promote cross-silo co-operation. In other words, the four policy instruments discussed in the previous section applies equally well under a multi-layer government framework.

Gaps in multi-level governance for water: the case of Venice

236. The OECD's Territorial Review of the Venice City-Region (OECD, 2010e) incorporated a multilevel review of water governance and provides insights into the value this approach can bring to green growth topics (Table 7). The Venice Review illustrates how a highly fragmented policymaking environment has led, in part, to the degradation of local water quality and elevation of vulnerability to flooding. In particular, several problems threaten the long-term economic vitality of the region that stem from weak or disjointed governance efforts:

- The sustainability of the tourism economy is under constant threat from poor water quality in the Venice Lagoon, which suffers from untreated sewage, atmospheric deposition and the release of contaminants sequestered in sediments originating from industrial activities in nearby Port Marghera. Nowhere is the water quality "sufficient" or "good" and $70 \%$ of monitoring points in the Lagoon are classified as "bad"; $27 \%$ of the rest as "poor" and the remaining 3\% "unattributed" (Rusconi, 2007). Significant levels of hepatitis A and enteroviruses have been detected in Venice's canals where multiple exposure routes proliferate through flooding (Rose et al., 2006).

- Water levels in the Venice Lagoon, along with the frequency of flooding, have risen at an alarming rate since the late nineteenth century, and failure to adequately address the water problem has significant adverse economic consequences. Since the 1880s average water levels have increased by almost 30 centimetres, and the frequency of high-water events has increased more than tenfold (Battistin and Canestrelli, 2006). The constant corrosion of stone and brickwork caused by rising water levels compromises the building fabric in historic Venice. The massive 1966 flood destroyed the homes of more than 5000 people, and was responsible for USD 6 billion in damage to buildings, ancient relics, and artwork (McHugh, 2008, Babington, 2008). A EUR 4.78 billion flood control barrier project called MOSE, Italy's largest infrastructure project, is under construction to protect Venice from tides of up to 3 metres high and from an increase in the sea level of at least 60 centimetres.

237. To the extent policymakers can work across both vertical and horizontal scales to improve the management of these stresses, there could be significant green growth opportunities. Given the experience that Veneto has developed in flood protection, policymakers could emphasise the development of that research and technology sector. The Arsenale, the historic shipyard in Venice, could become a hub of flood-protection research, as in conjunction with MOSE, six warehouses in the area provide monitoring and maintenance facilities for the system. There are also several promising initiatives at Università IUAV di Venezia and the INSULA SpA municipal agency focused on research into water-resistant building materials, tanking systems to reservoir rising water, and floodresistant plumbing technologies, such as one-way valves. As climate change is expected to result in significant global flooding problems, this expertise could be quite lucrative in the coming decades.

238. Economic activity could also stem from efforts to reduce water network leakage in the region (estimated at 37\% in 2006) (Comune di Venezia, 2007), establish a sewage treatment system serving the historic centre and islands, promote restoration of degraded salt marshes and inter-tidal areas or revitalise the fishing industry. The salt marsh cover is one-third of what it was approximately 100 years ago, reducing biodiversity in the region and reducing the Lagoon's natural flood-buffering 
capability. Improved Lagoon water quality could lead to a revitalisation of the fishing industry in the region, which was largely abandoned in the $1980 \mathrm{~s}$ due to serious macro-algae blooms (Nunes et al., 2008). 92\% of sport fisherman in the Venice Lagoon believe that pollution adversely affect catch rates in the lagoon (Alberini et al., 2007). Much work is already underway to remediate toxic waste sites in Port Marghera, and that work is expected to continue for many years, providing on-going opportunity for work in the pollution remediation sector.

\section{Table 7. Selected water governance gaps in the Venice-city region}

\begin{tabular}{|c|c|c|}
\hline Name of gap & What is it about? & How does it occur in Venice? \\
\hline $\begin{array}{l}\text { Administrative } \\
\text { gap }\end{array}$ & $\begin{array}{l}\text { A geographical mismatch } \\
\text { exists between hydrological } \\
\text { and geopolitical/ } \\
\text { administrative boundaries. }\end{array}$ & $\begin{array}{l}\text { Example: Fragmented governance of the Venice Lagoon's } \\
\text { watershed } \\
\text { The land draining into the Venice Lagoon covers an area of } \\
\text { over } 2,000 \text { square kilometres, is administered by } 100 \\
\text { municipalities and lies within two provinces. No single agency } \\
\text { is responsible for overseeing water resources or water quality } \\
\text { management within the Lagoon watershed, and differences of } \\
\text { opinion frequently arise between the different authorities. }\end{array}$ \\
\hline Capacity gap & $\begin{array}{l}\text { Management capacity within } \\
\text { individual agencies is } \\
\text { relatively strong. But co- } \\
\text { ordination capacity } \\
\text { (horizontal or vertical) is } \\
\text { relatively weak. }\end{array}$ & $\begin{array}{l}\text { Example: Fragmented water quality management at the } \\
\text { watershed scale } \\
\text { Each municipality is responsible for water supply and } \\
\text { wastewater treatment, under the auspices of the region. The } \\
\text { Region is responsible for monitoring water quality in areas } \\
\text { upstream from the Lagoon, whereas discharges and } \\
\text { enforcement (including fines/penalties) are the responsibility of } \\
\text { the provinces. Water quality monitoring in the Lagoon, on the } \\
\text { other hand, is carried out by a combination of national } \\
\text { government, regional and municipal agencies. }\end{array}$ \\
\hline Funding gap & $\begin{array}{l}\text { Unstable or insufficient } \\
\text { revenues discourage } \\
\text { sustainable investment and } \\
\text { undermine co-ordinated } \\
\text { governance. }\end{array}$ & $\begin{array}{l}\text { Example: Fluctuations in funding for Lagoon flood protection } \\
\text { year by year } \\
\text { Funding for water-related investment in the region is largely } \\
\text { controlled by the Comitatone, a national-level body. Funding } \\
\text { that it provides for Lagoon protection has fluctuated } \\
\text { significantly from year to year (with, for example, no funds } \\
\text { earmarked at all in } 2003 \text { and } 2004 \text { ). Some observers argue } \\
\text { that the disbursement of funds has been skewed towards flood } \\
\text { protection neglecting other conservation measures. }\end{array}$ \\
\hline Information gap & $\begin{array}{l}\text { Lack of research co- } \\
\text { ordination and lack of } \\
\text { systematic information- } \\
\text { sharing between relevant } \\
\text { agencies has resulted in a } \\
\text { lack of integration of the } \\
\text { best available } \\
\text { scientific/technical } \\
\text { information into policy. }\end{array}$ & $\begin{array}{l}\text { Example: Water quality standards in the Venice Lagoon } \\
\text { There are important instances where EU water quality } \\
\text { standards are ill-adapted to the Lagoon's ecosystem. For } \\
\text { example, assessments of water quality in the Lagoon carried } \\
\text { out according to current regulatory norms do not reflect the } \\
\text { latest knowledge in biochemical speciation. As a result, } \\
\text { "breaches" of EU water quality norms do not always accurately } \\
\text { reflect the quality of the water. }\end{array}$ \\
\hline Market gap & $\begin{array}{l}\text { Policymaking goals or } \\
\text { ambitions do not align with } \\
\text { the ability of private sector } \\
\text { stakeholders to deliver on } \\
\text { these goals. }\end{array}$ & $\begin{array}{l}\text { Example: Direct service providers contracted by government to } \\
\text { carry out certain greening functions do not receive significant } \\
\text { support to enter green markets } \\
\text { Water-resistant building materials, tanking systems to reservoir } \\
\text { rising water, and flood-resistant plumbing technologies are } \\
\text { adapted to Venice's unique situation and have not extensively } \\
\text { penetrated markets outside Italy. }\end{array}$ \\
\hline
\end{tabular}




\begin{tabular}{|l|l|l|}
\hline Policy gap & $\begin{array}{l}\text { Horizontal fragmentation of } \\
\text { water-related tasks amongst } \\
\text { government ministries and } \\
\text { agencies hinders integrated } \\
\text { policy development. }\end{array}$ & $\begin{array}{l}\text { Example: Lack of consideration of water management in land } \\
\text { use planning }\end{array}$ \\
& $\begin{array}{l}\text { Although the Veneto Region governs water quality, } \\
\text { municipalities govern land use planning, resulting in a lack of } \\
\text { comprehensive governance of the impact of land use on water } \\
\text { at the watershed level. For example, the Watershed Plans } \\
\text { drawn up by relevant watershed authorities are not fully } \\
\text { reflected or respected in land development decisions. }\end{array}$ \\
\hline
\end{tabular}

Source: OECD (2010e) adapted from Charbit (2011).

Gaps in multi-level governance for green growth: the case of Korea

239. The OECD National Urban Policy Review of Korea (OECD, forthcoming (c)) identified several governance gaps that can be observed in the context of green growth in Korean cities: $i$ ) the policy gap, ii) the administrative gap; iii) the fiscal gap; and iv) the information and capacity gap (Table 8). Key findings include:

i) Addressing the policy gap: the need for clear market signals and policy coherence. In order for sub-national authorities to effectively implement the National Strategy for Green Growth, the central government will need to provide a more coherent policy message across all sectors and levels of government. This includes (a) establishing clear pricing signals on carbon and greenhouse gas emissions; (b) resolving inter-ministerial conflicts that have led to policy fragmentation; and (c) addressing fragmentation and inconsistencies of planning instruments at the regional and local levels.

ii) Addressing the administrative gap: fostering horizontal collaboration. Co-operation among local governments remains limited in Korea. As the country has moved toward greater decentralisation, local governments have been more concerned with how to use their newly devolved responsibilities and position themselves to attract businesses and national financial support. National programmes like the green growth demonstration projects can further exacerbate competition among local authorities, as municipalities compete to become one of the selected projects. One solution to encourage voluntary modes of co-operation among adjacent municipalities could be to adopt a city-region policy framework to guide policymaking, particularly with respect to inter-municipal partnerships. Local authorities recognise that they can no longer tackle housing, transport and training issues within their own boundaries and instead need to collaborate more with their neighbouring authorities. Ultimately this allows city-regions to pool devolved funding with local resources to deliver transport, training and urban regeneration (Larkin and Marshall, 2008). Experience in OECD countries shows that the central state can play a leading role in voluntary inter-municipal co-operation, often through the use of fiscal or legal instruments (OECD, 2010c). This approach could aid implementation of national green growth objectives in Korea, for instance, with programming terms and conditions including bonus schemes conditional to funding linked not only to infrastructure but also strategic policy planning. In particular, the central government could develop incentives to facilitate co-operation between metropolitan cites and provinces.

iii) Addressing the financial gap: diversify funding sources. Limited local fiscal autonomy threatens the resiliency of local authorities because it limits their capacity to respond to the changing priorities of higher levels of government or sudden budget adjustments. Further, low self-reliance ratios render local authorities especially vulnerable to an eventual political regime shift, which could transfer power to an administration with limited or no support for 
green growth. Seoul, the most financially independent city in Korea, has for decades been a leader in sustainability and green growth policies. While the city benefits from a highly qualified labour force, among many other factors, its financial independence has enabled the city to initiate its own policies and programmes. There has been considerable discussion in Korea over increasing local fiscal autonomy, while focusing on building the revenue base of local taxation such as shifting a portion of the national VAT to local governments (OECD, 2005). However, this highly political debate, due to the inevitable sharing of authority that would be required among different level of governments, suggests that change may not be expected in the short term, suggesting that the central government will need to envision a more strategic approach.

iv) Addressing the information and capacity gap: developing measuring and monitoring tools. To help cities become more effective in the design and delivery of locally tailored policy solutions to climate change, Korea could also pursue the development of harmonised cityscale emissions inventories so that mitigation performance can be monitored, supported and compared across urban jurisdictions. Establishing a common framework for urban inventory remains a challenge in Korea. Emissions data is currently collected nationally, by sector, in each relevant ministry, which in turn submits to GIR "information and statistics about matters under [its] jurisdiction, such as energy, industrial process, agriculture, [waste] and forestry" (Framework Act, Article 45). At the local level, while the guidelines for greening cities developed by the Ministry of Land, Transportation and Maritime Affairs recommends that local jurisdictions establish these inventories from which to base localised action plans, a common framework is still lacking. Since many local jurisdictions lack the technical or financial capacity to develop such inventories, assistance from the national government will be needed to establish and implement a common methodology and monitor progress on the environmental and employment impacts of green growth policies at the metropolitan level. Here, there is potential to expand the current responsibilities of the GIR to include the coordination of regional and local emissions data, in addition to the sectoral data it already collects from other relevant ministries. Nevertheless, the GIR should work closely with international bodies, such as the IPCC, to ensure that Korea's methodology corresponds to the approach adopted internationally.

Table 8. Selected governance gaps for delivering green growth in Korean cities

\begin{tabular}{|l|l|l|}
\hline Name of the gap & What is it about? & How does this occur in Korea? \\
\hline $\begin{array}{l}\text { Administrative } \\
\text { gap }\end{array}$ & $\begin{array}{l}\text { A geographical mismatch exists } \\
\text { between hydrological and } \\
\text { geopolitical/ administrative } \\
\text { boundaries. }\end{array}$ & $\begin{array}{l}\text { Existing administrative boundaries do not always } \\
\text { correspond to the delimitations of functionally } \\
\text { integrated economic regions. As a result, it can be } \\
\text { difficult to address air pollution sources that are } \\
\text { generated across administrative boundaries (e.g. in } \\
\text { the transportation sector). }\end{array}$ \\
\hline Policy gap & $\begin{array}{l}\text { Horizontal fragmentation of water- } \\
\text { related tasks amongst government } \\
\text { ministries and agencies hinders } \\
\text { integrated policy development. }\end{array}$ & $\begin{array}{l}\text { Fragmentation of urban policies in general exists at } \\
\text { the central level in Korea, as well as for green } \\
\text { growth-related tasks involving different government } \\
\text { ministries and agencies. }\end{array}$ \\
& $\begin{array}{l}\text { At the urban scale, there is also a need to harmonise } \\
\text { emerging green growth policies within the already } \\
\text { fragmented local development policy framework, a } \\
\text { result of separate plans for municipal economic } \\
\text { development, spatial development and sectoral } \\
\text { development. To a limited extent, local and regional } \\
\text { governments have incorporated green growth goals } \\
\text { and policies into regional economic development } \\
\text { plans and the development plans of Daily Living }\end{array}$ \\
\hline
\end{tabular}




\begin{tabular}{|l|l|l|}
\hline Name of the gap & What is it about? & How does this occur in Korea? \\
\hline & & $\begin{array}{l}\text { Spheres. For example, in 2011, green growth was } \\
\text { included as one of the ten major tasks for local } \\
\text { areas. However, economic development plans } \\
\text { remain separate from spatial development and } \\
\text { sectoral plans, resulting in fragmented local } \\
\text { development policy. }\end{array}$ \\
\hline Information gap & $\begin{array}{l}\text { Lack of research co-ordination and } \\
\text { lack of systematic information-sharing } \\
\text { between relevant agencies has } \\
\text { resulted in a lack of integration of the } \\
\text { best available scientific/technical } \\
\text { information into policy. }\end{array}$ & $\begin{array}{l}\text { Inconsistent, or nonexistent, methodologies for } \\
\text { establishing local emissions inventories hamper the } \\
\text { ability of cities to assess progress toward green } \\
\text { growth over time and across locations. }\end{array}$ \\
\hline Capacity gap & $\begin{array}{l}\text { Management capacity within } \\
\text { individual agencies is relatively } \\
\text { strong. But co-ordination capacity } \\
\text { (horizontal or vertical) is relatively } \\
\text { weak. }\end{array}$ & $\begin{array}{l}\text { A lack of green growth expertise at the local level } \\
\text { (especially in small and medium-sized cities) hinders } \\
\text { the effective implementation of green growth } \\
\text { strategies at the urban scale. }\end{array}$ \\
\hline Funding gap & $\begin{array}{l}\text { Unstable or insufficient revenues } \\
\text { discourage sustainable investment } \\
\text { and undermine co-ordinated } \\
\text { governance. }\end{array}$ & $\begin{array}{l}\text { Most green growth initiatives have been heavily } \\
\text { financed by the central government, given the } \\
\text { generally low levels of self-reliance of local } \\
\text { governments. }\end{array}$ \\
\hline Source: OECD (forthcoming (c)), adapted from Charbit (2011). & \multicolumn{2}{|l}{} \\
\hline
\end{tabular}

\subsection{Measuring and monitoring green growth}

240. At the core of the OECD Green Cities programme is an effort to assess the potential environmental and economic complementarities that exist at the local level and to determine whether and, if so, to what extent - greening policies have led to positive environmental and economic outcomes. Identifying the gaps in the existing knowledge base will be just as important as collecting and analysing the data that is already available in some cities. The knowledge gap on labour effects and investment costs vs. benefits, for example, limits the capacity of sub-national governments to prioritise their interventions and generates uncertainty, slowing down urgent policies and investments. More systematic data collection and data integration are needed to better know how the local economy uses energy, generates greenhouse gas emissions. Analysis of these data should focus on understanding how local energy use and emissions are related to economic activity. Most of the local investments in the domains of energy provision, transportation and the built environment are likely to yield efficiency gains and multiplier effects in the medium-term to long-term, yet their effect on net employment in the short run is not straightforward and is thus far not well understood. Policy-specific estimates of approximate costs and time-horizons of the investments are also needed. A better understanding of a city's baseline conditions can make prioritisation of expenditures easier and more efficient for local governments.

241. In light of the existing knowledge gaps, green growth strategies should rely on a set of metrics that generate an accurate assessment of markets, local industry and innovation strengths, consumers' expectations and of the national regulatory framework (the evolution of carbon pricing in particular).

242. Developing green growth indicators nevertheless represents a methodological challenge, particularly at the sub-national level. The first challenge is one of definition: as discussed in earlier sections, a universally agreed upon definition of green growth does not yet exist, nor do consistent 
guidelines for identifying green sectors or classifying green jobs, rendering comparison problematic. Further, comparable data is not systematically available across countries or across metropolitan regions; this problem is compounded by the different methodological approaches for data collection (urban greenhouse gas emissions inventories are a classic example). What is more, green growth is an inherently multi-dimensional concept that cannot be captured by a single measure. While extensive work has been undertaken on sustainability indicators (Box 8), there has still been no consistent effort to monitor and evaluate urban policies under the triple metric of job-creation effects, impact on the local environment and the distribution of benefits. For instance, if transportation objectives are only thought in greenhouse gas emission terms, other desired attributes of a smart transportation system quality of service, affordability, accessibility, social costs - may get short shrift (Kahrl et al., 2009). Such a set of integrated indicators could send a cleaner and more effective message to policymakers.

\section{Box 8. Initiatives to develop sustainable city indicators}

Several parallel initiatives are underway in OECD countries to measure sustainability at the sub-national level.

The European Reference Framework for Sustainable Cities is an on-line toolkit to assist actors of urban management and development to improve dialogue and action on sustainability. Monitoring progress constitutes one of the four items in the toolkit, together with developing a strategy, checking integrated approach and focusing on deprived neighbourhoods. The monitoring section includes 33 recommended key indicators, grouping them into four categories: economy, social, environment and governance. There are also four pillars of sustainability, covering European objectives and principles. In addition, the monitoring section provides a selection of hundreds of indicators used by European cities, enabling each city to tailor its measurement and monitoring system to its specific needs. Ongoing work will select up to 70 pilot cities within Europe to help test the tool during the period from February through August 2011.

The Global City Indicators Facility (GCIF) programme is designed to help cities monitor performance and quality of life by providing a framework to facilitate consistent and comparative collection of city indicators. The indicators contain 22 themes, which are grouped into two broad categories, "city services" and "quality of life". City services include services typically provided by city governments and other entities (such as education, energy, solid waste and wastewater). Quality of life includes critical contributors to overall quality of life, recognising that the city government may or may not have direct control (such as civic engagement, culture, economy, well-being, etc.). The programme is a city- led initiative with the pilot cities guiding the initial selection and development of indicators. Thus far, over 130 cities have participated in the programme.

The Global Sustainable Urban Development Indicators (GDI), developed by the White House Office of Urban Affairs and the US Department of Housing and Urban Development, are designed to measure progress in American cities toward sustainable urban development and inform supportive policy, planning and investment. Its framework includes three dimensions of sustainable urban development: social well-being (e.g. health and safety), economic opportunity (e.g. a diversified and competitive local and regional economy) and environmental quality (e.g. efficient land use and use of renewable resources). The indicator selection work is ongoing; future work will include the selection of several American cities to pilot the new system.

Source : European Reference Framework for Sustainable Cities, www.rfsustainablecities.eu; Global City Indicators Facility, www.cityindicators.org; US Department of Housing and Urban Development www.huduser.org.

243. The development of green growth metrics at the sub-national level builds on a body of research and reflection in which the OECD has been engaged for over a decade. The OECD's ongoing work to design a more comprehensive measure of societal progress, which goes beyond GDP to include measures of material living conditions, quality of life and sustainability, has contributed to a richer understanding of societal well-being. More recently, the OECD has developed a green growth measurement framework to guide national policymaking (OECD, 2011b). The framework provides a critical environmental lens through which to measure progress by structuring metrics around 
environmental resource productivity, the natural asset base and the environmental quality of life. Finally, at the sub-national level, the OECD is currently expanding its metropolitan database to include a set of core environmental indicators, which will be complemented by additional economic and environmental data collected on an ad hoc basis in cities as well as empirical evidence of the challenges faced and the progress made toward greener growth in cities.

\section{OECD initiatives to measure progress toward green growth}

Beyond GDP: OECD contributions to measuring progress

244. The OECD has been leading the international reflection on measuring the progress of societies with substantive analysis for nearly ten years. Whilst GDP remains, for the most part, the dominant financial measure of growth, treated as a reasonable indicator of material well being and even as a proxy for the quality of life, there are now debates about whether GDP remains a useful approximation $^{22}$ of societal well-being. GDP ignores some of the value in an economy and hides some of the risks and costs in economic activity. It can continue to grow for a time even as the underlying resources on which it depends are being depleted. In addition, the value of ecosystem services, natural capital, and the effects of pollution are simply not as well measured as other activities directly valued by markets.

245. As a result, the OECD, along with the European Commission (EC), the European Parliament, the Club of Rome and the World Wildlife Fund (WWF), has been one of the global leaders in the Beyond GDP initiative, which aims to develop indicators that are more inclusive of the enviornmental and social aspects of progress. ${ }^{23}$ In parallel to this cross-cutting, international effort, the OECD has proposed a more comprehensive measure of well-being with the launch of its Better Life Index. ${ }^{24}$ The index covers 11 topics (housing, income, jobs, community, education, environment, health...), each of which includes several indicators.

Development of OECD green growth indicators

246. OECD work on measuring progress has helped to inform other horizontal activities, including the development of the OECD Green Growth Strategy and efforts to quantify the inherently multi-dimensional nature of green growth. Environmental quality constitutes a crucial component of a comprehensive assessment of well-being, in terms of both quality of life and sustainability. Monitoring progress towards green growth in both OECD and non-OECD countries requires indicators based on internationally comparable data, which are embedded in a conceptual framework and selected according to well-specified criteria. OECD has developed a measurement framework for green growth (Figure 17).

22. See, for instance Stiglitz, Sen and Fitoussi (2009), or Jackson (2009).

23. See www.beyond-gdp.eu

24. See www.oecdbetterlifeindex.org 
Figure 17. OECD green growth measurement framework

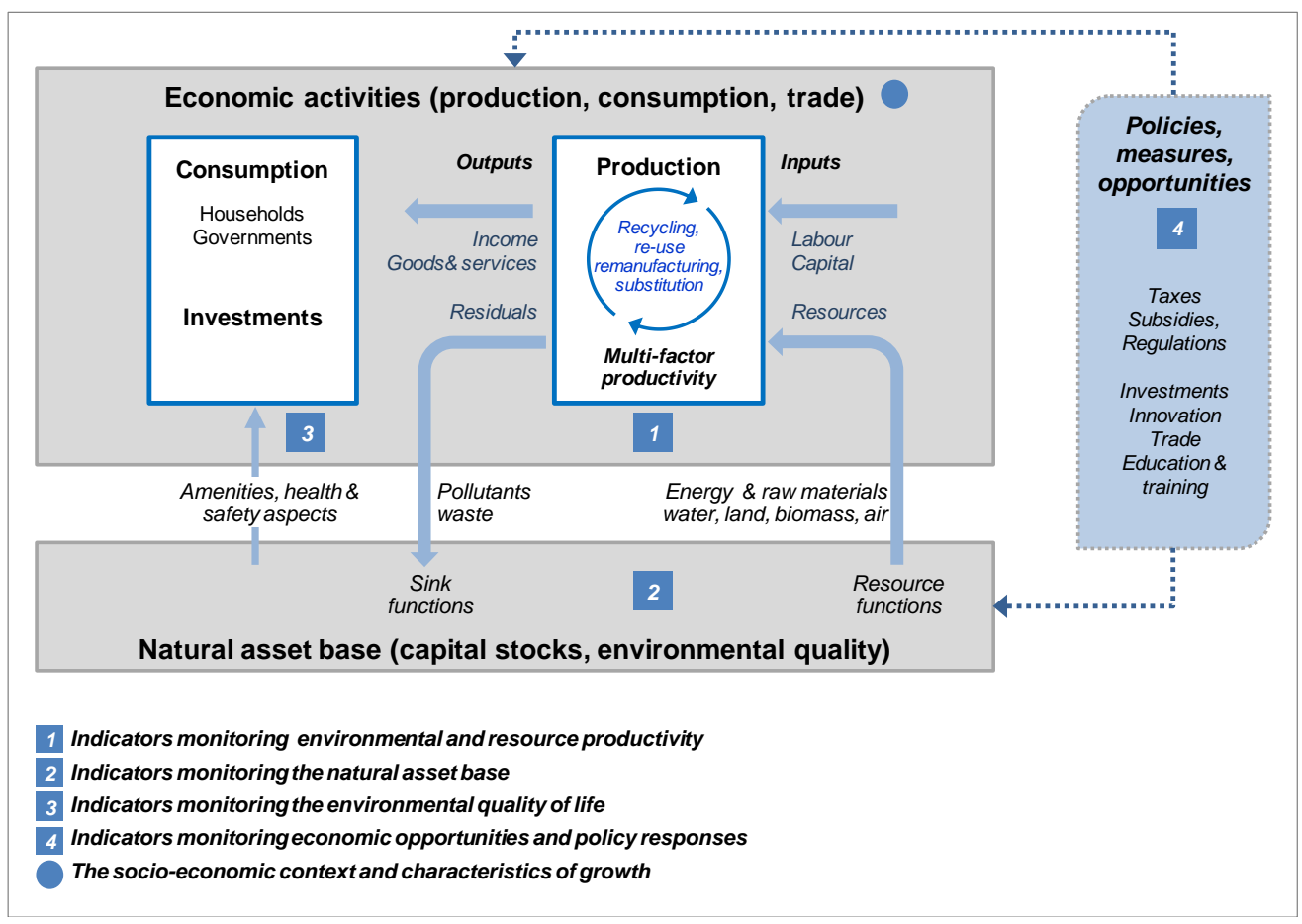

Source: OECD Green Growth Strategy Synthesis Report (2011).

247. The green growth measurement framework, which explores four inter-related groups of indicators, begins with the sphere of production, whereby economic inputs are transformed into economic output (goods and services). Along with inputs such as labour and capital, production also uses services from natural assets, either in the form of natural resource inputs into production (these may be non-renewable assets, such as minerals extracted from the ground, or renewable assets, such as fish stocks) or in the form of disposal services where the natural environment provides services as a sink for pollutants and residuals emitted during production. Services from natural assets are rarely quantified in economic models and accounting frameworks and yet they are central to examining the greening of growth. A first set of indicators is therefore environmental and resource productivity, representing the volume of output per unit of services from natural assets.

248. Nevertheless, the production perspective is not sufficient to monitor the transition toward green growth. For sustained growth, the natural asset base has to be kept intact. One reason is that a declining asset base constitutes a risk to growth and such risks should be avoided. "Asset base" should be understood in a comprehensive way, encompassing produced as well as non-produced assets, and including in particular environmental assets and natural resources. However, absent exact prices for most assets, measurement has to start with monitoring the physical evolution of natural assets and this constitutes the second type of green growth indicators. Over time, measurement efforts should be undertaken to advance on the valuation in at least some important natural assets.

249. Efforts to keep society's asset base intact are directly related to one dimension of the quality of life that is relevant for green growth, namely the direct impact of the environmental on people. The environmental quality of life is an important determinant of health status and well-being more generally. It is also a crucial measure of well-being that may not evolve in line with production and income growth. For instance, air pollution, in particular exposure to particulate matter, is much higher 
in some of the emerging economies than in OECD countries. In addition, a larger share of the population lives under medium to severe water stress, while low levels of wastewater treatment and pollution contribute to the incidence of waterborne and preventable diseases.

250. A fourth dimension of the green growth framework is encompassed by the economic opportunities and policy responses arising from environmental considerations. One way of framing relevant indicators is by examining the role of green industries, trade in green products and the creation of green jobs. Another central aspect in the context of economic opportunities is innovation and technology, which are drivers of multi-factor productivity change (through new products, entrepreneurship and business models) and new consumption patterns. In addition, policy response concerns providing clear and stable market signals to affect the behaviour of producers and consumers. Several of the policy response indicators relate to environmental taxes and transfers. However, constructing indicators of regulation is tricky, as the information is often of a qualitative nature and hard to compare across countries.

251. The four groups of indicators are complemented by generic indicators describing the socioeconomic context and characteristics of growth. A preliminary selection of indicators has been made on the basis of existing work in the OECD, in other international organisations and in member and partner countries (Table 9). Overall, the present set comprises about twenty indicators, not all of them are measurable today. The multi-dimensional nature of green growth requires a sufficient number of indicators to do justice to the various aspects of the issue at hand. The indicators were selected according to their policy relevance, analytical soundness and measurability, and structured to reflect the organisation of the measurement framework.

Table 9. Overview of proposed OECD green growth indicators

\begin{tabular}{|c|c|}
\hline Main indicator groups & Topics covered \\
\hline \multicolumn{2}{|c|}{ The socio-economic context and characteristics of growth } \\
\hline \multirow{2}{*}{$\begin{array}{l}\text { Economic growth, } \\
\text { productivity and competitiveness }\end{array}$} & Economic growth and structure \\
\hline & $\begin{array}{l}\text { Productivity and trade } \\
\text { Inflation and commodity prices }\end{array}$ \\
\hline \multirow[t]{2}{*}{ Labour markets, education and income } & $\begin{array}{l}\text { Labour markets } \\
\text { (employment / unemployment) }\end{array}$ \\
\hline & $\begin{array}{l}\text { Socio-demographic patterns } \\
\text { Income and education }\end{array}$ \\
\hline \multicolumn{2}{|l|}{ Environmental and resource productivity } \\
\hline \multirow[t]{2}{*}{ Carbon and energy productivity } & $\begin{array}{l}\mathrm{CO}_{2} \text { productivity } \\
\text { (demand-based, production-based) }\end{array}$ \\
\hline & Energy productivity \\
\hline \multirow[t]{3}{*}{ Resource productivity } & $\begin{array}{l}\text { Material productivity } \\
\text { (demand-based, production-based) }\end{array}$ \\
\hline & Non-energy materials, waste materials, nutrients) \\
\hline & Water productivity \\
\hline Multi-factor productivity & $\begin{array}{l}\text { Multi-factor productivity } \\
\text { including environmental services }\end{array}$ \\
\hline \multicolumn{2}{|l|}{ Natural asset base } \\
\hline \multirow[t]{3}{*}{ Renewable stocks } & Freshwater resources \\
\hline & Forest resources \\
\hline & Fish resources \\
\hline Non-renewable stocks & Mineral resources \\
\hline \multirow[t]{3}{*}{ Biodiversity and ecosystems } & Land resources \\
\hline & Soil resources \\
\hline & Wildlife resources \\
\hline
\end{tabular}




\begin{tabular}{|l|l|}
\hline Main indicator groups & Topics covered \\
\hline $\begin{array}{l}\text { Environmental health } \\
\text { and risks }\end{array}$ & Environmentally induced health problems and related costs \\
\cline { 2 - 2 } $\begin{array}{l}\text { Environmental services } \\
\text { and amenities }\end{array}$ & Exposure to natural or industrial risks and related economic losses \\
\hline Economic opportunities and policy responses \\
\hline Technology and innovation & R\&D of importance to GG \\
\cline { 2 - 2 } & Patents of importance to GG \\
\hline & Environment related innovation \\
\hline Environmental goods and services & Production of environmental goods and services \\
\hline International financial flows & $\begin{array}{l}\text { International financial flows } \\
\text { of importance to GG }\end{array}$ \\
\hline Prices and transfers & Environmentally related taxation \\
\cline { 2 - 2 } & Energy pricing \\
\cline { 2 - 2 } & Water pricing and cost recovery \\
\hline Training \& skill development & Indicators to be developed: \\
Regulations \& management approaches & \\
\hline
\end{tabular}

Source: OECD (2011b).

Monitoring and evaluation tools to measure progress on green growth in cities

252. At the sub-national level, the development of green growth metrics presents particular opportunities and challenges. On the one hand, the focus on metropolitan regions presents an opportunity to improve data on the stocks and flows of natural assets in urban areas, notably through a better understanding of the effects of urban dynamics on environmental quality and economic performance. On the other hand, data generation and collection at the local level are often impeded by limited technical capacity or funding. A comprehensive assessment of a city's progress toward green growth thus calls for a set of both quantitative and qualitative indicators based on the triple metric of job-creation effects, impact on the local environment and the distribution of benefits. The OECD is currently working to expand its metropolitan database to include a range of economic and environmental statistics for metropolitan regions. These data will be complemented by a set of additional indicators that will be collected on an ad hoc basis through national and city-level surveys. Finally, a series of in-depth case studies will provide a qualitative assessment of the progress toward green growth in select OECD and non-OECD metropolitan regions, highlighting the greening challenges and opportunities, the scope of green growth policy interventions and the economic and environmental impacts of greening policies.

\section{Quantitative indicators: the metropolitan database}

253. The OECD metropolitan database includes a range of socio-economic indicators for OECD metropolitan regions, including population density, labour force characteristics, GDP and productivity rates, and employment and participation rates. To contribute to the understanding of the effects of urban dynamics on the environment and the quality of life of urban residents, the OECD is currently expanding its metropolitan database to include a small set of environmental indicators to monitor the environmental performance of cities. Given the requirement of comparability, the OECD has prioritised indicators that can be derived from global sources, notably data from the Earth's surface collected using Remote Sensing (RS) and Geographic Information Systems (GIS) tools. The environmental indicators under development will measure (i) urban density (high density development index, densification index); (ii) land cover and changes in land cover (percentage of area covered by urbanised, agricultural and forested land; growth of urbanised, agricultural and forested land over time); (iii) forest ecosystem and carbon absorption (net primary productivity of regional vegetation); (iv) $\mathrm{CO}_{2}$ emissions $\left(\mathrm{CO}_{2}\right.$ emissions per capita, $\mathrm{CO}_{2}$ efficiency of production); and (v) air quality 
(average population exposure to PM 2.5, percentage of population exposed to health-damaging PM 2.5) (Table 10). ${ }^{25}$

Table 10. OECD environmental indicators developed for regions and metropolitan areas

\begin{tabular}{|c|c|c|c|}
\hline Indicator & Unit of measure & $\begin{array}{l}\text { Geographical unit of } \\
\text { analysis }\end{array}$ & Data sources \\
\hline \multicolumn{4}{|l|}{ Urban density } \\
\hline $\begin{array}{l}\text { High density development } \\
\text { index }\end{array}$ & $\begin{array}{l}\text { Proportion of people living in highly } \\
\text { densely inhabited residential units } \\
\text { ( } 1 \text { sq km grids) within the } \\
\text { metropolitan area (based on the } \\
\text { Lopez-Hynes indicator of urban } \\
\text { sprawl) }\end{array}$ & metro & $\begin{array}{l}\text { Gridded population } \\
\text { data: LandScan } \\
2009 \text { Global } \\
\text { Population dataset }\end{array}$ \\
\hline Densification index & $\begin{array}{l}\text { Ratio of population change (in } \\
\text { metro, core and hinterland), with } \\
\text { respect to the increase in } \\
\text { urbanised land, i.e. the surface that } \\
\text { is categorised as urban. }\end{array}$ & metro & $\begin{array}{l}\text { Census data; EU } \\
\text { Corine Land Cover } \\
\text { dataset; US } \\
\text { National Land } \\
\text { Cover Database; } \\
\text { Japan National } \\
\text { Land Information } \\
\text { Service; MODIS } \\
\text { Land Cover } \\
\text { Database }\end{array}$ \\
\hline \multicolumn{4}{|c|}{ Land use and changes in land cover } \\
\hline $\begin{array}{l}\text { Share of area covered by } \\
\text { urbanised land }\end{array}$ & $\begin{array}{l}\text { Percentage of total surface area } \\
\text { categoriesed as "urban" }\end{array}$ & TL2; TL3, metro & \multirow{6}{*}{$\begin{array}{l}\text { EU Corine Land } \\
\text { Cover dataset; US } \\
\text { National Land } \\
\text { Cover Database; } \\
\text { Japan National } \\
\text { Land Information } \\
\text { Service; MODIS } \\
\text { Land Cover } \\
\text { Database }\end{array}$} \\
\hline $\begin{array}{l}\text { Share of area covered by } \\
\text { agricultural land }\end{array}$ & $\begin{array}{l}\text { Percentage of total surface area } \\
\text { categoriesed as "agricultural" }\end{array}$ & TL2; TL3, metro & \\
\hline $\begin{array}{l}\text { Share of area covered by } \\
\text { forested land }\end{array}$ & $\begin{array}{l}\text { Percentage of total surface area } \\
\text { categoriesed as "forested" }\end{array}$ & TL2; TL3, metro & \\
\hline Growth of urbanised land & $\begin{array}{l}\text { Amount of land converted to urban } \\
\text { land cover minus the urban land } \\
\text { converted to other classes, as a } \\
\text { fraction of the urban land in the } \\
\text { starting year }\end{array}$ & TL3, metro & \\
\hline Growth of agricultural land & $\begin{array}{l}\text { Amount of land converted to } \\
\text { agricultural land cover minus the } \\
\text { agricultural land converted to other } \\
\text { classes, as a fraction of the } \\
\text { agricultural land in the starting year }\end{array}$ & TL3, metro & \\
\hline Growth of forested land & $\begin{array}{l}\text { Amount of land converted to } \\
\text { forested land cover minus the } \\
\text { forested land converted to other } \\
\text { classes, as a fraction of the } \\
\text { forested land in the starting year }\end{array}$ & TL3, metro & \\
\hline \multicolumn{4}{|c|}{ Forest ecosytem and carbon absorption } \\
\hline $\begin{array}{l}\text { Net primary productivity of } \\
\text { regional vegetation }\end{array}$ & $\begin{array}{l}\text { Difference between the gross } \\
\text { primary productivity (GPP, } \\
\text { calculated as the sum total of light } \\
\text { energy that is converted to plant } \\
\text { biomass) and energy lost during } \\
\text { plant respiration }\end{array}$ & TL2 & $\begin{array}{l}\text { MOD17 (MODIS } \\
\text { database) }\end{array}$ \\
\hline
\end{tabular}

25. See OECD (2011h), "Measuring the environmental performance of metropolitan areas with geographic information sources", presented during the 22nd session of the Working Party on Territorial Indicators, 7 December 2011, OECD, Paris. 


\begin{tabular}{|c|c|c|c|}
\hline \multicolumn{4}{|l|}{$\mathrm{CO}_{2}$ emissions } \\
\hline $\mathrm{CO}_{2}$ emissions per capita & Per capita $\mathrm{CO}_{2}$ levels & TL2; metro & $\begin{array}{l}\text { Emission Database } \\
\text { for Global } \\
\text { Atmospheric } \\
\text { Research (EDGAR) }\end{array}$ \\
\hline $\mathrm{CO}_{2}$ efficiency of production & $\begin{array}{l}\text { Ratio between GDP and } \mathrm{CO}_{2} \\
\text { values }\end{array}$ & TL2; metro & $\begin{array}{l}\text { Emission Database } \\
\text { for Global } \\
\text { Atmospheric } \\
\text { Research (EDGAR) }\end{array}$ \\
\hline \multicolumn{4}{|l|}{ Air quality } \\
\hline $\begin{array}{l}\text { Average population exposure } \\
\text { to PM2.5 }\end{array}$ & & TL2; metro & $\begin{array}{l}\text { Satellite-based } \\
\text { measures of PM2.5 } \\
\text { concentrations }^{1}\end{array}$ \\
\hline $\begin{array}{l}\text { Percentage of population } \\
\text { exposed to health damaging } \\
\text { PM2.5 }\end{array}$ & $\begin{array}{l}\text { Estimated levels benchmarked to } \\
\text { the thresholds specified in the } \\
\text { WHO Air Quality Guidelines for PM }\end{array}$ & TL2; metro & $\begin{array}{l}\text { Satellite-based } \\
\text { measures of PM2.5 } \\
\text { concentrations }^{1}\end{array}$ \\
\hline
\end{tabular}

1. Based on the work of Aaron van Donkelaar and Randall Martin from Department of Physics and Atmospheric Science, Dalhousie University, Halifax, Nova Scotia, Canada, which combines satellite data from NASA's MODIS and MISR instruments and GEOS-Chem global chemical transport model.

Source: OECD (2011h), "Measuring the environmental performance of metropolitan areas with geographic information sources".

254. This set of internationally comparable environmental indicators seeks to complement the existing socio-economic indicators in the OECD metropolitan database and enable international benchmarking across metropolitan regions. Benchmarking the current green job activity and the growth scenarios to other cities can also facilitate the identification of achievable targets and enabling policies. Given the wide heterogeneity in carbon emission factors, industrial and innovation capacities, and market demand within countries, the baseline assessments and the selection of targets must be undertaken locally, case by case. However, cities and agencies can effectively share common or standardised tools that optimise data collection across localities, help defining the relevant geographic scale for measurements, list meaningful and quantifiable indicators such that they are comparable across locations, regions and nationally (Corfee-Morlot in OECD, 2008; OECD, 2010c). To this end, the OECD is contributing to international efforts to harmonise greenhouse gas emissions inventories in cities (see Cochran and Corfee-Morlot, 2011).

255. Because they are based on global data sources, the advantage of these indicators is that they are available for all geographic areas. These data sources are, however, limited in that geo-referenced data are not always at the right level of spatial resolution, and, importantly, many dimensions of urban sustainability (i.e. waste generation, residential electrical use per capita, etc.) cannot be observed through satellites and ground stations.

Selected preliminary results

256. Urban density. The high density development index is inspired by the work of Lopez and Hynes (2003) which assesses the levels of sprawled urban development across US metropolitan areas. The indicator measures the proportion of people in the periphery and in the core living in highly densely populated $1 \mathrm{sq} \mathrm{km}$ grid cells. This high density development index is obtained using as a threshold the median density of the metro area, as defined from the population grid data. The densification index is meant to capture the level of critical land resources lost in relation to human population growth. The indicator is defined as the ratio between the population increase (in the metro, core and hinterland), with respect to the increase in urbanised land (the surface that is categorised as urban). This ratio increases as development becomes more compact (i.e. when a given increase in the developed land hosts a relatively high number of people). 
257. Table 11 presents the results from the derivation of the high density development index for the selected cities of Paris, Milan and Barcelona. The index shows clearly the differences in the distribution of densities between the cores of the metropolitan areas and their hinterlands. Almost the totality of the population of the urban cores of Paris and Barcelona live in high-density residential units, while $10 \%$ of the population in Milan's core lives in relatively low-dense areas. Table 12 presents results from the computation of the densification index in the same three metropolitan areas. We can observe that the efficiency of urban development as measured by the densification index over the period from 1990 to 2006 has been the highest in Paris, mainly due to a large increase of the population in its metropolitan core.

Table 11. High density development index in three OECD metropolitan regions

\begin{tabular}{|l|l|r|}
\hline Paris & Total & 88.75 \\
& Core & 98.88 \\
& Hinterland & 45.20 \\
\hline Milan & Total & 79.38 \\
& Core & 89.66 \\
& Hinterland & 54.00 \\
\hline Barcelona & Total & 93.06 \\
& Core & 99.20 \\
& Hinterland & 50.34 \\
\hline
\end{tabular}

Note: The high density development index is inspired by the Lopez-Hynes indicator of urban sprawl, and it tells the proportion of people living in highly densely inhabited residential units (1 sq km grids) within the metropolitan area.

Source: OECD (2011h), "Measuring the environmental performance of metropolitan areas with geographic information sources"

Table 12. Densification index in three OECD metropolitan regions

1990-2006

\begin{tabular}{|c|c|c|c|c|}
\hline & & New urban areas (ha) & Population change & Densification index \\
\hline \multirow[t]{3}{*}{ Milan } & Metro area & 4504 & 264057 & 58.63 \\
\hline & Core & 1739 & 55253 & 31.77 \\
\hline & Hinterland & 2765 & 208804 & 75.52 \\
\hline \multirow[t]{3}{*}{ Barcelona } & Metro area & 8602 & 560000 & 65.1 \\
\hline & Core & 5347 & 258308 & 48.31 \\
\hline & Hinterland & 3255 & 301692 & 92.69 \\
\hline \multirow[t]{3}{*}{ Paris } & Metro area & 12495 & 966698 & 77.37 \\
\hline & Core & 3766 & 646869 & 171.77 \\
\hline & Hinterland & 8729 & 319829 & 36.64 \\
\hline
\end{tabular}

Note: The densification index is given by the ratio between the population change and the change in hectares covered by urban surfaces. OECD computation based on National Statistics Population data and Corine Land Cover data (EEA).

Source: OECD (2011h), "Measuring the environmental performance of metropolitan areas with geographic information sources"

258. Land cover and changes in land cover. Work has been undertaken to develop static and dynamic regional indicators of land cover. Land cover changes represent a pressing environmental issue, and are both a cause and a consequence of climate change (Herold, 2009). There is increasing evidence that the type and distribution of land cover also affects regional weather and climate patterns. Rapid phenomena of land cover change not only affect ecosystems and landscapes, but can more generally lead to an increased vulnerability of both human and environmental systems. Table 13 shows results for the dynamic indicator on the net growth of urban land in the largest metropolitan area of each country with available land cover change data. Distinct indicators have been produced for the metro cores and for the hinterlands. As expected, we observe in general a much more marked 
increase in urban land in the hinterlands of OECD metropolitan areas. These land conversions have been particularly intense in Ireland, Portugal, Spain and Estonia.

Table 13. Growth of urban land in cores and hinterlands within the largest metropolitan area of each country

\begin{tabular}{|l|l|c|c|c|}
\hline Country & Metropolitan area & $\begin{array}{l}\text { Urban net change } \\
\text { rate (core) }\end{array}$ & $\begin{array}{l}\text { Urban net change } \\
\text { rate (hinterland) }\end{array}$ & $\begin{array}{l}\text { Urban net change } \\
\text { rate (overall) }\end{array}$ \\
\hline Austria & Wien & $0.41 \%$ & $1.67 \%$ & $1.36 \%$ \\
\hline Belgium & Brussel & $0.00 \%$ & $0.23 \%$ & $0.19 \%$ \\
\hline Czech Republic & Praha & $1.33 \%$ & $3.92 \%$ & $2.71 \%$ \\
\hline Denmark & København & $2.45 \%$ & $4.98 \%$ & $3.88 \%$ \\
\hline Estonia & Tallin & $2.61 \%$ & $13.61 \%$ & $8.99 \%$ \\
\hline Finland & Helsinki & $1.91 \%$ & $3.60 \%$ & $2.70 \%$ \\
\hline France & Paris & $0.74 \%$ & $2.83 \%$ & $1.62 \%$ \\
\hline Germany & Berlin & $0.00 \%$ & $1.64 \%$ & $0.37 \%$ \\
\hline Hungary & Budapest & $1.55 \%$ & $3.31 \%$ & $2.44 \%$ \\
\hline Ireland & Dublin & $6.25 \%$ & $33.51 \%$ & $15.67 \%$ \\
\hline Italy & Milano & $2.06 \%$ & $4.79 \%$ & $2.87 \%$ \\
\hline Japan & Tokyo & $4.93 \%$ & $9.30 \%$ & $5.64 \%$ \\
\hline Netherlands & Amsterdam & $6.56 \%$ & $4.55 \%$ & $6.39 \%$ \\
\hline Norway & Oslo & $0.22 \%$ & $0.89 \%$ & $0.73 \%$ \\
\hline Poland & Warsaw & $1.90 \%$ & $1.96 \%$ & $1.91 \%$ \\
\hline Portugal & Lisboa & $5.73 \%$ & $21.15 \%$ & $9.57 \%$ \\
\hline Slovak Republic & Bratislava & $0.81 \%$ & $1.32 \%$ & $1.16 \%$ \\
\hline Slovenia & Ljubljana & $0.61 \%$ & $0.65 \%$ & $0.64 \%$ \\
\hline Spain & Madrid & $17.17 \%$ & $13.89 \%$ & $14.57 \%$ \\
\hline Sweden & Stockholm & $0.84 \%$ & $2.15 \%$ & $1.69 \%$ \\
\hline Switzerland & Zürich & $0.72 \%$ & $0.11 \%$ & $0.33 \%$ \\
\hline United Kingdom & London & $0.17 \%$ & $0.76 \%$ & $0.32 \%$ \\
\hline United States & New York & $0.56 \%$ & $3.50 \%$ & $1.68 \%$ \\
\hline
\end{tabular}

Source: OECD (2011h), "Measuring the environmental performance of metropolitan areas with geographic information sources".

259. Forest ecosystem and carbon absorption. The net primary productivity (NPP) indicator provides local-level information on forest productivity and on the contribution of natural vegetations to carbon absorption. Figure 18 shows the range in average regional values of NPP. They can be interpreted as the contribution of a region's vegetation in carbon sequestration from the atmosphere (e.g. highly urbanised regions are expected to have low values, agricultural regions medium values and forested regions high values of the indicator). There are significant differences within countries in carbon absorption through plant biomass production. In India, United States and Chile, for example, we can observe regions with very high and with very low levels of NPP. The allocation of specific resources to protect the important carbon reserves existing in virtually all countries is justified not only in terms of landscape preservation and biodiversity, but also for the global objective of climate change mitigation. 


\section{Figure 18. Regional range in NPP}

2000-2006

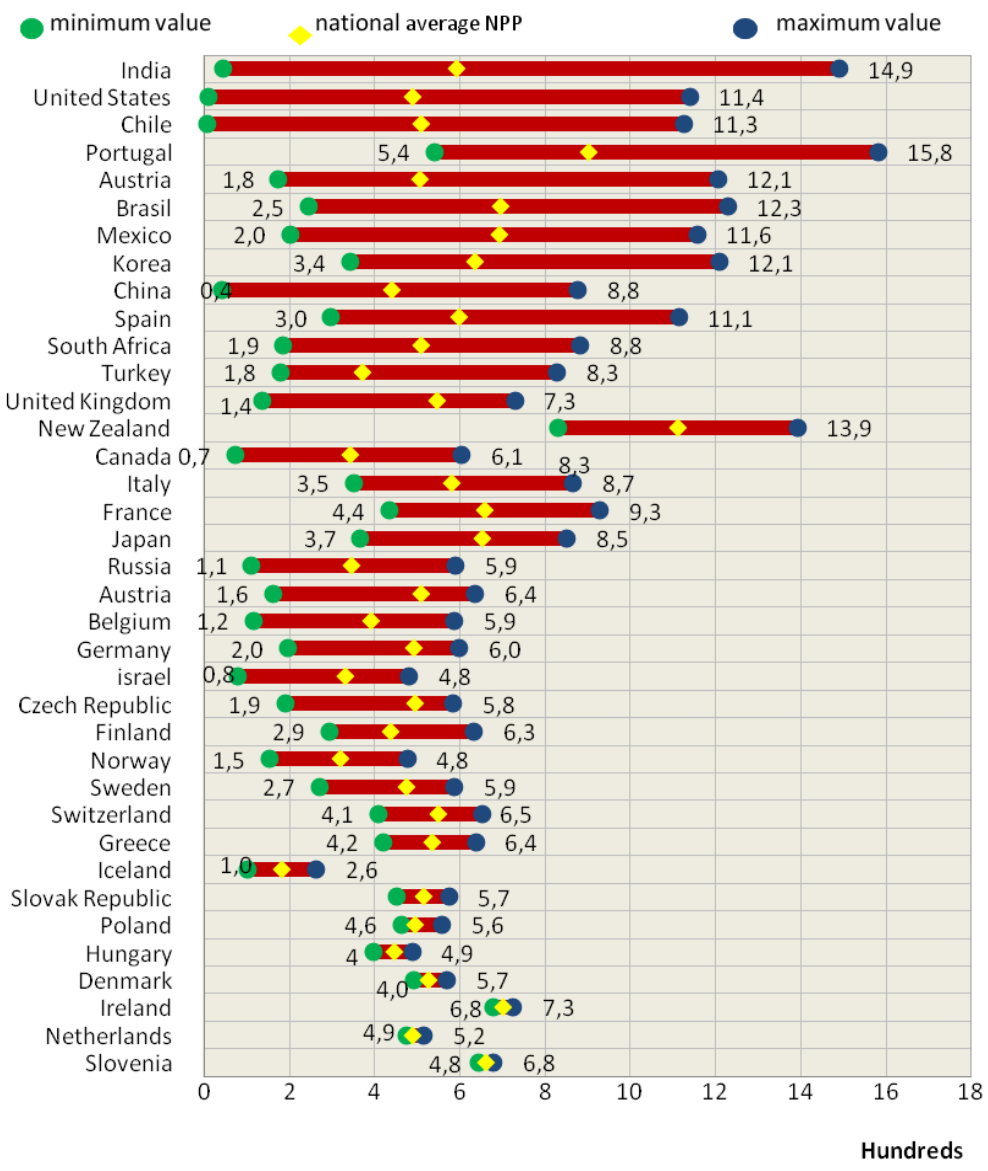

Source: OECD (2011c), Regions at a Glance, OECD, Paris.

260. $\mathrm{CO}_{2}$ emissions. The following two indicators have been selected to describe the overall level of $\mathrm{CO}_{2}$ emissions in regions and metropolitan areas, and the relative decoupling between domestic production and carbon inputs: $\mathrm{CO}_{2}$ emissions per capita and $\mathrm{CO}_{2}$ efficiency of production. The first indicator has been produced aggregating all the measured sources of $\mathrm{CO}_{2}$ emissions, with the exception of international aviation and navigation. $\mathrm{CO}_{2}$ efficiency of production is defined as the ratio between GDP and $\mathrm{CO}_{2}$ values. This second indicator provides information about the carbon intensity of economic activity in cities and regions with a focus on the production side. A complementary indicator under consideration uses income instead of GDP in the calculation of the ratio, so as to inform about the relative decoupling of demand-based emissions from income.

261. Table 14 shows the result from the allocation of EDGAR gridded values to the ten largest OECD metropolitan areas. These large metropolitan areas concentrate a sizable fraction of their countries' total emissions. The estimates show sizable differences in the levels of total $\mathrm{CO}_{2}$ per capita across these major cities. In several cases, it is possible to observe significant differences between the share of country's population living in a metropolitan area and the contribution of the area to the country's total emissions. Figure 19 shows the large differences in the carbon efficiency of production 
that exist within countries. Particularly in Turkey, in the United States, in Brazil and in the Russian Federation, some regions show much higher carbon efficiency than the national average.

Table 14. $\mathrm{CO}_{2}$ emissions in the ten largest OECD metro-regions

2005

\begin{tabular}{|l|l|l|r|r|r|}
\hline Rank & Country & Metropolitan area & \multicolumn{2}{|l|}{$\begin{array}{l}\text { CO } \text { emissions } \\
\text { per capita } \\
\text { (tonnes) }\end{array}$} & \multicolumn{2}{l|}{$\begin{array}{l}\text { Share in } \\
\text { country's total } \\
\text { emissions }\end{array}$} & \multicolumn{2}{l}{$\begin{array}{l}\text { Share in } \\
\text { country's total } \\
\text { population }\end{array}$} \\
\hline 1 & Japan & Tokyo & 7.55 & $22.47 \%$ & $26.64 \%$ \\
\hline 2 & Korea & Seoul & 5.87 & $42.89 \%$ & $42.80 \%$ \\
\hline 3 & Mexico & Mexico City & 3.17 & $12.59 \%$ & $18.86 \%$ \\
\hline 4 & Japan & Osaka & 7.54 & $11.50 \%$ & $13.66 \%$ \\
\hline 5 & United States & New York & 17.45 & $5.00 \%$ & $5.99 \%$ \\
\hline 6 & United States & Los Angeles & 15.07 & $3.88 \%$ & $5 ., 38 \%$ \\
\hline & & & 7.33 & $14.27 \%$ & $17.46 \%$ \\
\hline 8 & United Kingdom & London & 7.44 & $18.83 \%$ & $19.04 \%$ \\
\hline 8 & France & Paris & 18.46 & $2.75 \%$ & $3.11 \%$ \\
\hline 9 & United States & Chicago & 15.15 & $1.69 \%$ & $2.33 \%$ \\
\hline 10 & United States & San Francisco & & & \\
\hline
\end{tabular}

Source: OECD (2011h), "Measuring the environmental performance of metropolitan areas with geographic information sources". 
Figure 19. $\mathrm{CO}_{2}$ efficiency of production

OECD TL2 regions with highest value and country average, 2005

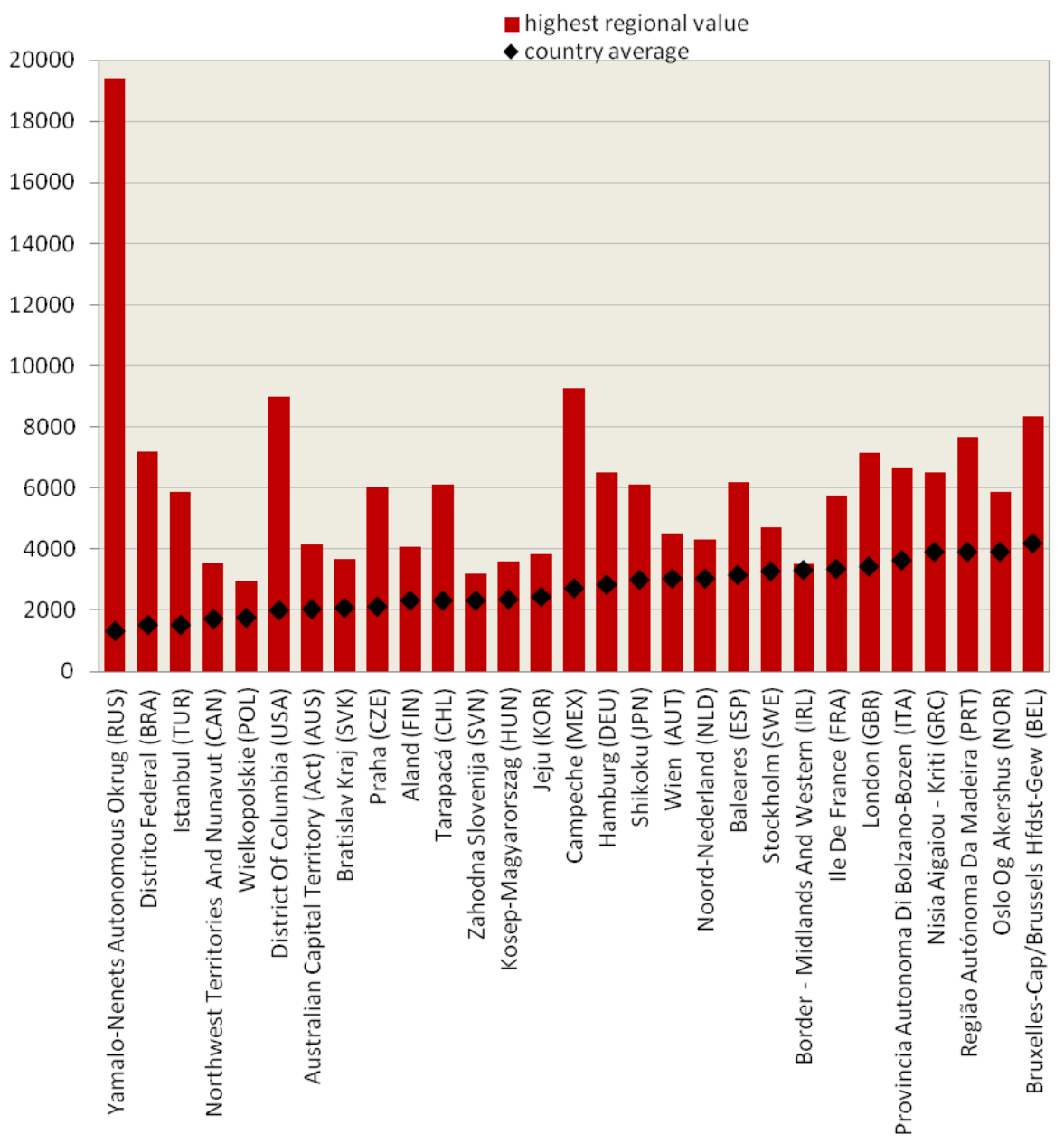

Source: OECD (2011c), Regions at a Glance, OECD, Paris.

262. Air quality. Health-damaging air pollution is often measured by the concentration of particulate matters (PM) in the air, which consist of small liquid and solid particles floating in the air. These include sulphate, nitrate, elemental carbon, organic carbon matter, sodium and ammonium ions in varying concentrations. Of greatest concern to public health are the particles small enough to evade the body defences and thus likely to be inhaled into the deepest parts of the lung and enter the bloodstream. The OECD has chosen to focus on particles are less than 2.5 microns in diameter (PM2.5).Table 15 shows the results of the population weighted average levels of PM2.5 for the largest OECD metropolitan areas. The highest levels of PM2.5 are observed in the metropolitan area of Milan, in part as a consequence of the naturally high levels of particulate concentration that exist throughout region. The inhabitants of San Francisco are exposed to the lowest levels of PM2.5 in this sample of large cities. Figure 20 shows the percentage of population in each country that are exposed to different levels of air pollution, as defined by the WHO Air Quality Guidelines for PM2.5. A large fraction of the population of China and India is exposed to concentrations of PM2.5 that are worryingly high (above 35 micrograms per cubic meter, a level scientifically proved to be healthdamaging). 
Table 15. Air pollution (PM 2.5) in the ten largest OECD metropolitan areas

2001-06

\begin{tabular}{|l|l|l|r|}
\hline Rank & Country & Metropolitan area & $\begin{array}{l}\text { Population weighted average of } \\
\text { PM2.5 concentration }\left[\mu \mathrm{g} / \mathrm{m}^{3}\right]\end{array}$ \\
\hline 1 & Japan & Tokyo & 22.35 \\
\hline 2 & Korea & Seoul & 27.10 \\
\hline 3 & Mexico & Mexico City & 25.75 \\
\hline 4 & Japan & Osaka & 21.16 \\
\hline 5 & United States & New York & 19.28 \\
\hline 6 & United States & Los Angeles & 13.51 \\
\hline 7 & France & Paris & 18.23 \\
\hline 8 & United Kingdom & London & 19.67 \\
\hline 9 & United States & Chicago & 16.38 \\
\hline 10 & United States & San Francisco & 8.13 \\
\hline
\end{tabular}

Source: OECD (2011h), "Measuring the environmental performance of metropolitan areas with geographic information sources". 
Figure 20. Share of population exposed to health-damaging levels of PM2.5

Relative to WHO thresholds

\begin{tabular}{|c|c|c|c|c|c|c|}
\hline & $20 \%$ & $40 \%$ & $60 \%$ & $80 \%$ & $100 \%$ & \\
\hline BELGIUM & & & & & 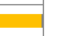 & \\
\hline CZECH REPUBLIC & & & & & 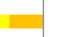 & \\
\hline GERMANY & & & & & 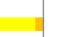 & \\
\hline HUNGARY & & & & & 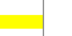 & \\
\hline ISRAEL & & & & 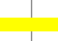 & 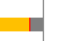 & \\
\hline LUXEMBOURG & & & & & 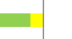 & \\
\hline NETHERLANDS & & & & & - & \\
\hline SLOVENIA & 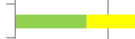 & & & & 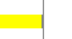 & \\
\hline SWITZERLAND & 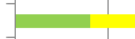 & & & & & \\
\hline SLOVAKIA & & & & & 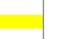 & \\
\hline POLAND & 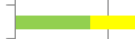 & & & & 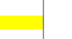 & \\
\hline KOREA, REPUBLIC OF & & & 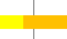 & & I & \\
\hline GREECE & & & & & 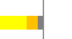 & \\
\hline AUSTRIA & & & & & 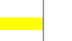 & \\
\hline CHINA & & & & & $=$ & \\
\hline DENMARK & & & & & 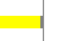 & $\square<10$ \\
\hline INDIA & 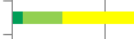 & & - & 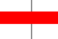 & $=$ & 10 to 15 \\
\hline TURKEY & & & - & & = & \\
\hline UNITED KINGDOM & & & & & & 15 to 25 \\
\hline FRANCE & & 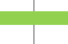 & & & 是 & 25 to 35 \\
\hline JAPAN & & & & & 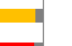 & $>35$ \\
\hline ITALY & & & & & $\mathbf{a}$ & מ \\
\hline SPAIN & & & & & 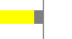 & NoData \\
\hline MEXICO & & 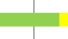 & & 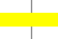 & 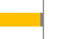 & \\
\hline PORTUGAL & & & & 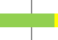 & & \\
\hline UNITED STATES & & & & & & \\
\hline CHILE & & & & & 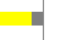 & \\
\hline RUSSIA & & & & & & \\
\hline CANADA & & & & a & & \\
\hline IRELAND & & & & & & \\
\hline SOUTH AFRICA & & & & & & \\
\hline SWEDEN & & & & & & \\
\hline NEW ZEALAND & & & & & & \\
\hline BRAZIL & & & & & & \\
\hline AUSTRALIA & & & & & & \\
\hline ESTONIA & & & & & & \\
\hline NORWAY & & & & & & \\
\hline ICELAND & & 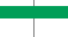 & & & & \\
\hline FINLAND & 1 & & & & & \\
\hline
\end{tabular}

Source: OECD (2011c), Regions at a Glance, OECD, Paris.

\subsection{Financing green growth}

263. Moving towards a low-carbon, more sustainable society will require significant up-front investments. As developed in previous sections, existing urban revenue sources could be "greened": congestion charges and road taxes can reduce car travel and fund green infrastructure; local energy fees that put a price on wasteful energy use can increase efficiency; and property taxes can stop favouring urban sprawl and start encouraging development in the urban core and around transportation linkages. National governments could also green urban finance by re-designing grants to sub-national governments to correct incentives for unsustainable behaviour and reward cities that create environmental benefits beyond their borders. However, acting on green growth in cities requires new financial instruments. This section discusses the potential of developing new financial instruments such as urban use of carbon markets and local cap-and-trade systems. Private financing, such as 
public-private partnerships, will also play a crucial role in the transition to green growth, and can be a desirable option for cities and businesses, provided that the externalities, conditions for risk sharing and economic models underlying the various investment strategies are well-developed and understood (Box 9).

\section{Box 9. Financing green growth in cities}

\section{Remi Dorval, President of Fabrique de la Cité}

The transition to green growth in cities is an essential issue and will entail meeting numerous challenges, in particular with regard to technology, governance and financing. The deployment of facilities and developments that are compatible with the goals of green growth in cities calls for investments that in certain respects are unusual in terms of their:

- Size: Whether the aim is to improve the energy performance of the built environment, organise carbonfree urban mobility or adapt existing networks, ensure the collection and treatment of waste, the entire existing stock of infrastructure will have to renovated, modified and modernised. Urban green growth therefore concerns not only the new infrastructure relating to the development of cities, but also, and above all, the transformation of existing infrastructure. In addition, efforts will need to be made to finance the necessary technological innovations. All this explains why, compared to a "business as usual" scenario, cities will have to face particularly high levels of investment in the years to come.

- Concentration over time: Thethe objectives in terms of a timetable adopted by the various national and international bodies, relating in particular to the urgency of the fight against the impacts of climate change, require that action be taken now to transition towards the green growth of cities. The additional investments required will therefore be concentrated over a relatively short period of time, making it harder to resolve the question of their financing.

- Nature: Since green growth initiatives are intended in particular to improve the long-term environmental impact of cities, the investments required have three particular characteristics:

- They generate positive externalities and are often justified through a collective social benefit that cannot be readily quantified in economic terms. This is the case in particular of infrastructure aimed at reducing greenhouse gases;

- They produce effects over the very long term, which makes it hard to advance conventional economic arguments regarding the financing of investments; and

- They carry a high degree of risk relating in particular to uncertainty over the regulatory and economic environment (energy prices, cost of $\mathrm{CO}_{2}$, etc.).

The financing of these investments therefore poses problems that will require original solutions. The use of public financing, which, given the particular nature of the problem presented, might appear to be the preferred solution, seems to be largely insufficient and economically non-optimal: public budgets are under strong pressure everywhere, and leveraging global investment through the use of private financing would clearly make sense and be possible provided that reasonable conditions of profitability, risk and time horizons can be ensured.

Numerous studies have been conducted to identify strategies that would make it possible to secure the required financing. Among the findings:

- There is a wide variety of investments for green growth in cities: each type of investment must generate its own economic model that can provide a basis for a mode of financing.

- Clear identification and valuation of externalities are key elements in these economic models and therefore in the mobilisation of suitable forms of financing (this is particularly the case with regard to the 


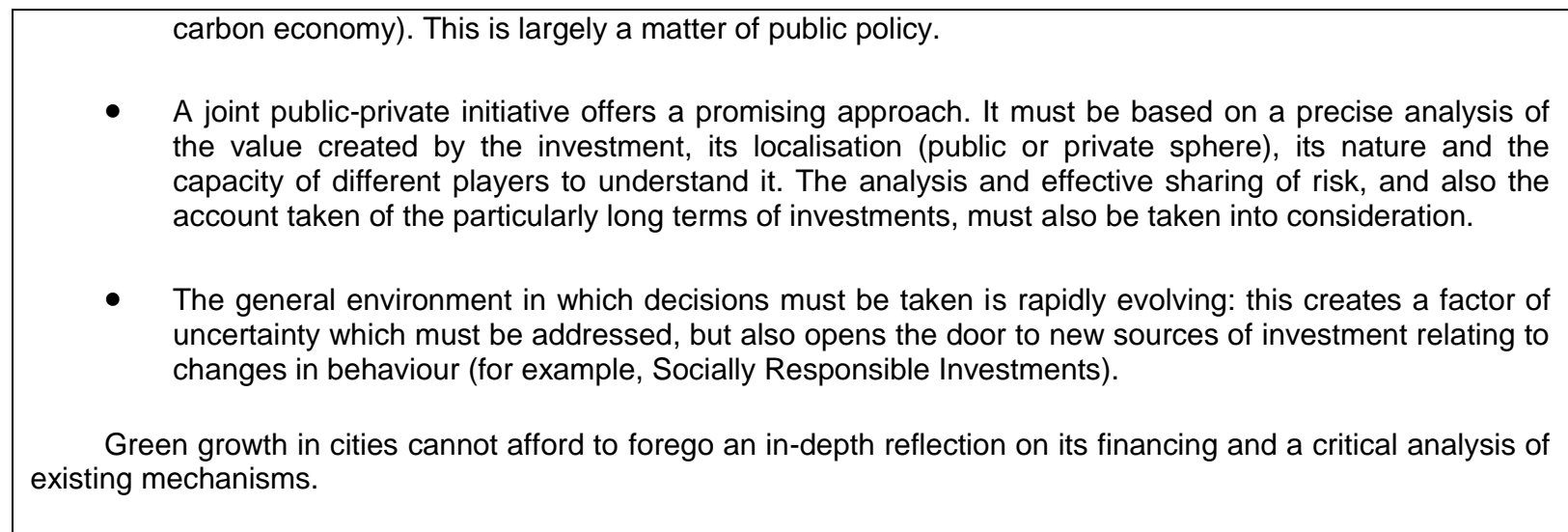

264. Local governments in many OECD countries are responsible for amounts of public spending on environmental protection (which includes waste management, waste water management, pollution abatement, protection of biodiversity and landscapes, and R\&D on environmental protection) that are almost similar to that of their respective national governments (OECD, 2009k). Transportation is in many OECD countries a shared responsibility, with local governments taking care of local infrastructure, regional governments for regional infrastructure and national governments for national infrastructure. Similar shared responsibilities can also be found with respect to the built environment and land use. Debates on environmental federalism have shown that local governments can play an important role in environmental policies, especially when they are able to internalise externalities. As local governments often lack the revenue streams needed to build green infrastructures, measures to stimulate green growth might put additional pressure on city budgets and increase the need for additional resources and reform of national and international mechanisms, most notably carbon markets.

265. Cities could also generate revenues from the two mechanisms that the Kyoto protocol put in place to create carbon offsets, the Clean Development Mechanism $(\mathrm{CDM})^{26}$ for developing countries (non-Annex 1 countries) and Joint Implementation (JI) for developed countries (Annex 1 countries), both certified and issued by the United Nations Framework Convention on Climate Change (UNFCCC). ${ }^{27}$ In addition to this, voluntary carbon markets have been created that are unconnected to an emissions cap. In these voluntary markets, carbon offsets are verified by another carbon market standard, twelve of which are currently operational. Carbon offset markets have been promoted as an important part of the solution to the climate crisis because of their economic and environmental efficiency. Their cost-effectiveness allows for lower caps or voluntary commitments and the potential to deliver sustainable co-benefits as a by-product through technology transfer and capacity building. A recent OECD/CDC Climat Recherche study found that while there is further scope for carbon finance mechanisms to constitute an important source of finance for certain types of mitigation projects in

26. CDM allows developed countries to purchase carbon credits from emission reduction projects in developing countries, and JI from emission projects in other developed countries.

27. Annex 1 countries are Australia, Austria, Belarus, Belgium, Bulgaria, Canada, Croatia, Czech Republic, Denmark, Estonia, European Community, Finland, France, Germany, Greece, Hungary, Iceland, Ireland, Italy, Japan, Latvia, Liechtenstein, Lithuania, Luxembourg, Monaco, Netherlands, New Zealand, Norway, Poland, Portugal, Romania, Russian Federation, Slovakia, Slovenia, Spain, Sweden, Switzerland, Turkey, Ukraine, United Kingdom, and United States of America. (http://unfccc.int/parties_and_observers/parties/annex_i/items/2774.php) 
cities, it is often necessary to supplement this revenue stream with funding from other sources (Box $10)$.

\section{Box 10. Cities and carbon finance}

\section{Gregory Briner and Jan Corfee-Morlot}

Carbon markets and cities are both increasingly part of international and national climate policy frameworks. Yet the rise of carbon markets as a policy instrument to put a price on and limit greenhouse gas emissions and the increased role of urban governance in climate policy frameworks are separate and distinct developments. To date, the actual or potential interaction between carbon markets and city or urban scale mitigation has received little attention from analysts and policymakers.

Analysis by the OECD and CDC Climat Recherche (Clapp et al., 2010) takes stock of experience with urban projects in the context of the international carbon markets as established under the Kyoto Protocol. It considers how city governments have accessed and used the Clean Development Mechanism (CDM) and Joint Implementation (JI) to advance urban mitigation projects. These project-based carbon market mechanisms, together with voluntary offset schemes, have become a significant source of global financing for mitigation activities; the value of total primary transactions in the CDM alone reached a peak of 7.4 billion USD in 2007 and has recently hovered in the 1-3 billion USD range in 2009-10 (World Bank, 2011). However, cities are currently under-represented in the project portfolios of these mechanisms; while cities are estimated to account for over $70 \%$ of energy-related greenhouse gas emissions, urban mitigation projects involving urban authorities account for less than $10 \%$ of CDM and $\mathrm{JI}$ projects to date and are concentrated in just a few sectors. Barriers to the participation of cities in carbon markets can include limited awareness of carbon market, low institutional capacity to develop and monitor projects, overlapping jurisdiction for emissions sources, high risk project types and limited capacity to take on financial risks.

The OECD/CDC Climat Recherche study looked at ten case studies in greater detail; five CDM projects and five $\mathrm{Jl}$ projects, reflecting a range of different project types and national circumstances. It concluded that carbon market finance can provide an important source of finance for certain types of mitigation projects in cities, although it is often necessary to supplement this revenue stream with funding from other sources.

Key success factors identified included:

- Strong local political support for projects

- $\quad$ Strong multilevel governance

- Implementation of suitable project types that bring significant greenhouse gas emissions reductions

- Use of existing and/or simple methodologies

- Implementation of projects with significant local co-benefits

- Partnerships with the private sector, which can help manage risk and provide financial and technical support

Looking forward, effective mechanisms are needed to scale up mitigation activities in cities. Possibilities include programmatic or sectoral approaches, which allow multiple projects to be registered together, streamlining of methodology and registration processes for common urban project types, or other avenues such as domestic offset mechanisms and/or urban cap-and-trade schemes. Future mechanisms should build upon the existing experience and capacity gained from participation in carbon markets to date. National governments and international organisations will also need to consider the role of cities when designing future carbon market mechanisms.

Source : Clapp, C., A. Leseur, O. Sartor, G. Briner, and J. Corfee-Morlot (2010), "Cities and Carbon Market Finance: Taking Stock of Cities' Experience with CDM and JI", OECD and CDC Climat Recherche joint working paper, OECD Publishing, Paris. 
266. Urban projects in carbon offset markets have so far been marginal. Of the $1224 \mathrm{CDM}$ projects currently registered, only a limited number have been urban projects. There have been two urban transportation projects: the Bogotá bus rapid transit, TransMilenio, and the Delhi subway regenerative breaking system. A similar marginal number of CDM projects $(0.57 \%)$ and generated certified emission reductions (CERs) by $2012(0.16 \%)$ deal with energy efficiency in the urban building sector (Fenhann, 2010), such as in Khayelitsha (South Africa). In addition, some projects are implemented in other urban sectors, such as electricity and solid waste (Chandigargh, India and Urimqi, China). JI projects have also been applied in a limited number of metropolitan regions (North Rhine-Westphalia in Germany and Rhône-Alpes in France). Carbon offsets realised by urban projects in the voluntary market are equally marginal: projects have been implemented or prepared in Sao Paolo, Timisoara, Lille and Newcastle (OECD, 2010c; Clapp, 2010).

267. Marginal urban use of carbon markets to raise revenue for greenhouse gas emissionsreduction projects can partly be explained by high measurement costs to prove the additionality of projects. This additionality criterion is part of the Kyoto protocol to ensure that the mechanisms result in additional carbon reductions and are not used to finance activities that would otherwise also have taken place. Several mitigation efforts in cities are however notably difficult to measure, because emissions are diffuse, costly to identify and to aggregate into calculations of total emissions. CDM challenges that are particularly problematic for the urban transport sector are the definition of project boundaries, complex up-stream and down-stream leakages, the establishment of a reliable baseline, and the implementation of a reliable monitoring methodology. There are similar challenges for using $\mathrm{CDM}$ in the urban building sector: fragmentation and complexity of construction projects, as well as small scale and disperse emission points making the registry and the "measurable, reportable and verifiable" procedures (MRV) costly and time-consuming under the current CDM framework. Some "soft" measures taken in cities, such as optimised architecture design for passive heating or cooling, are not quantifiable in terms of greenhouse gas mitigation and thus not recognised and credited in the project provision (Cheng et al., 2008). Additional barriers include devolution of national authority, lack of expertise with these instruments at local level, lack of measurement instruments and expertise, costs and risks associated with project approval by UNFCCC and implementation (Clapp, 2010).

268. The possibilities for cities to use existing carbon finance instruments could be increased. City tools for measurement and monitoring (including standard inventories), as well as expert support from national government and private sector, could facilitate market access and streamline project preparation, lowering transaction costs. If international climate negotiations were to mention transport and buildings as key areas to reduce greenhouse gas emissions, this would provide a rationale to involve urban areas. In order to keep transaction costs down and to take systems dimensions of urban problems into account, these actions should take the form of broad programmes rather than specific projects. Funding from CDM, as it is currently designed, could help to reduce public transport fares, thus increasing transit usage, and also help to finance inter-modality infrastructures, thereby facilitating modal shifts. Other CDM opportunities for the urban sector would be to explore the easily attainable targets on greenhouse gas sources related to urban transportation planning, such as urban forestry, street lighting, waste energy used for transportation purposes, etc. City involvement in CDM might require broadening the project-based approach of CDM, for instance to include a sectoral crediting mechanism beyond 2012. In addition, there is a need to develop carbon emission inventories that are harmonised across cities (OECD, 2010c). The C40 Large Cities Climate Leadership group has partnered with the Government of Switzerland, ECOS and the World Bank on a programme called Carbon Finance Capacity Building as a precursor for cities being given access to new sources of funding currently targeted at national governments.

269. Public-private partnerships (PPPs) can bolster urban green growth goals under certain conditions. The use of PPPs to achieve green growth goals by cities has been growing over the last 
decades. PPPs can be defined as contracts between a government and a private company, under which the private company finances and builds an infrastructure asset, subsequently maintains the asset and, in many cases, operates some element of a public service while using the asset. In return for these activities, the company is paid over a number of years for the construction costs and service operation, either through user charges, public payments or a combination of both. Cities in many OECD countries are responsible for the provision infrastructure for which PPPs are mostly used, such as transport infrastructure and to a slightly lesser extent water (30\%) and buildings (21\%) (OECD , 2010c). The use of PPPs is particularly growing in cities with heavy investments in infrastructure, for example in cities in China where PPPs have recently been introduced to finance wastewater infrastructure (in Beijing and Guangzhou) and solid waste management projects (e.g. in Shenzhen and other cities in the Guangdong province). Other examples include Korea, France and the UK.

270. PPPs can potentially stimulate sustainable investments by private actors. PPPs can, in the right circumstances, provide better value for money, such as lower prices, than traditional infrastructure procurement (which leaves the building of infrastructure to the private sector, but not the maintenance and operation of it) by sharing risks in innovative ways. PPPs could encourage private (as well as public) actors to take a more long-term view on spending by relating maintenance spending more closely to capital investment. As such, PPPs might stimulate energy efficiency in public buildings as the private operator would benefit from the efficiency gains due to its investment in energy efficiency.

271. The use of PPPs can be problematic given that they are in many instances absent from government balance sheets. The private party in a PPP can carry a number of the risks and thus be obliged to record the PPP on its balance sheet. Only the annual PPP-agreement payments are on the government budget. In order to circumvent national or supra-national deficit and debt rules, cities thus might not be interested in assessing a project on its merits, but only on whether it can be done as a PPP. This approach undermines value for money and long-term fiscal sustainability. Some countries have tried to limit this problem by imposing more strict accounting rules, ensuring a mandated valuefor-money process, and imposing a maximum amount of transparency about the deal when it is struck. Some national governments are worried that regional and local governments are using PPPs to get around the fiscal rules set by the centre, resulting in a huge unacknowledged stock of liabilities that national government might suddenly have to take over.

272. There is, however, no indication that PPPs would be better suited to achieve green growth goals than traditional procurement. Although it might create better value for money in some instances, it crucially depends on the fulfilment of certain criteria. The private sector is not always more efficient in operating certain public services: e.g. a study of cities with different types of bus operators found that the most efficient cities were equally likely to be public or private (Pina and Torres, 2006). In addition, PPPs require certain skills - for example in negotiating and the capacity to comprehend longterm capital budgeting - that most public sector officials at the city-level do not have. This might explain the existence of cases, such as the waste water treatment plant in Zagreb, where very little risk has been transferred at great cost to the taxpayer (CEE Bankwatch Network, 2008). Several OECD countries have created PPP units at the national government level to build this public capacity, but similar initiatives at the city- or regional level are hardly existent. Even if PPP contracts would appear to have been well negotiated by city officials, they sometimes choose to (or feel obliged to choose to) to bail out the private operator if its assessment of risks proved to be too optimistic, as was the case with the public bicycle rental scheme of the City of Paris (see Box 11). 


\section{Box 11. PPPs to fund public bicycle rental schemes: the case of Vélib' in Paris}

As part of its strategy to reduce car use, the city of Paris undertook a policy to promote the bicycle as an alternative means of public transport for short distances in Paris. After an open call for tender in 2007, the city of Paris awarded the private company JC Decaux the concession to build, maintain and operate this system for a 10 -year period. The investment and operational costs of the bike rental system are born by the private company, in exchange for a right on $50 \%$ of the total surface of city billboards (which generated EUR 57 million in 2008). Total investment costs for the system was around EUR 110 million; additional Vélib'-infrastructure is financed by the City of Paris (estimated to be EUR 8 million per year). Revenue generated by Vélib', through user payments and subscriptions, goes to the city of Paris (EUR 15 million in 2008), but the private company can earn additional revenue when its operational activity reaches a very high level of quality as determined by six criteria. In order to run the system, 400 employees were hired by JC Decaux.

The public bicycle rental system was inaugurated in July 2007 with 10600 self-service bicycles available at 750 stations, which grew into 24000 bicycles and 1751 stations in June 2009. The Vélib'-system has been conceived as a success: the average number of trips reached 76660 per day in 2008 and bicycle use in the city has increased. The model proved to be a profitable operation for the city, but not for JC Decaux as it underestimated the costs for repairing and replacing damaged bicycles and was responsible for bearing this risk. In order to avoid bankruptcy of JC Decaux and subsequent halt to their operations, the city of Paris felt obliged to re-negotiate the contract and provide more favourable terms for JC Decaux. No analysis of whether this agreement still is better value for money than if it was completely run by municipal workers has been initiated.

Source: Largentaye, H. de (2010), “Velib': a case of successful co-operation between the City of Paris and the private sector in the framework of a sustainable development strategy", Presentation for OECD 3rd Annual Meeting on Public Private Partnerships, 13 April 2010.

\section{Conclusion: a proposal for future research}

273. As this paper demonstrates, knowledge of urban green growth opportunities and impacts remains limited and anecdotal. Better measurement and evaluation of green growth policies are needed to fulfil the potential for green growth at the urban level. The lack of measurable outcomes creates uncertainty and makes it difficult for cities to act, even if they have the political and financial resources to do so. A possible agenda for the OECD could include addressing four key knowledge gaps:

i) What are the key environmental and economic indicators of green growth?

ii) What are the policy and governance best practices to stimulate green growth?

iii) What do urban development models tell us about growth opportunities arising from environmental constraints?

iv) What are the best practices for financing green growth, and what is the appropriate role for PPPs?

What are the key environmental and economic indicators of green growth?

274. More analysis is needed to enable local policymakers to assess development plans based on the triple metric of job-creation effects, impact on the local environment, and the distribution of benefits. While most of the local investments in the domains of energy provision, transportation and the built environment are likely to yield efficiency gains and multiplier effects in the medium-term to long-term, their effect on net employment in the short run is not straightforward. Capacity building 
and information sharing on local green policies is thus of critical importance. Policy-specific estimates of approximate costs and time-horizons of the investments are also needed. The knowledge gap on labour effects and investment costs vs. benefits limits the capacity of sub-national governments to prioritise their interventions and generates uncertainty, slowing down urgent policies and investments.

275. To fill this gap, the OECD has begun to collect additional urban economic and environmental quality indicators on an ad hoc basis through national and city-level surveys. Although these indicators are not generally comparable across cities, they can contribute to a more comprehensive assessment of the environmental quality and performance of a city. This ad hoc set of indicators includes:

- Regional R\&D expenditures on green technology

- Number of green patents registered

- Number firms in green technology sector (if such a sector has been identified)

- Number of green jobs city/metro-wide

- Skill level of employment in green technology sector

- Survival rate of new green-tech start-ups

- Sectors of green firms represented in the metropolitan region

- Air quality $\left(\mathrm{NO}_{\mathrm{x}}, \mathrm{SO}_{\mathrm{x}}, \mathrm{PM}_{10}\right)$, measured as the number of occurrences of pollution over limit values (number of days/year or as a \% of population exposed)

- Municipal waste generated, in $\mathrm{kg} / \mathrm{capita} / \mathrm{year}$

- Percentage of waste going to landfill, measured as the share of municipal waste generated by type of disposal (recycling, composting, incineration, landfill)

- Energy consumption, measured as the Total Final Energy Consumption (TFC) of the building, transport and industrial sector

- Share of energy consumption that comes from renewable sources, in Tonnes of Oil Equivalent (TOE)

- Transportation modal share, measured as the share of trips by personal vehicle, public transport, non-motorised transport, etc.

What are the policy and governance best practices to stimulate green growth?

276. In addition to the data-driven approach, the OECD will seek empirical evidence of cities' progress toward green growth through a series of case studies examining green growth in cities. Each case study assesses the impact of urban green growth and economic greening policies on the economic performance and environmental quality of the metropolitan region, within the context of its unique policy, market, geographic and climatic circumstances. The first case studies include Paris-IDF, the Chicago Tri-state Region, Stockholm and Kitakyushu. 
277. Each case study will include:

- A discussion of the existing natural resources and infrastructure systems, policy environment and market conditions. The existing natural resources (e.g. sun, wind, fossil fuel deposits) or infrastructure systems (e.g. public transport network, district energy system, waste or water treatment facility) can influence current or future greening or green growth opportunities. They may also lead to technological lock-in that hinders the pursuit of alternative greening strategies in the city. The current policy environment also plays a critical role in determining a city's capacity to act in a given various green sector, the policy levers that can be employed, in addition to the ways in which policies explicitly or implicitly impede technology deployment or technological innovation. The existing local green market environment can impact future economic opportunities or vulnerabilities, with an analysis of the extent to which a city may be able to capture some or all of the value chain of certain green growth sectors to influence the types of jobs that can be created locally, and how the expansion of green business sectors might affect the availability of talent in other businesses around the city.

- Assessment of the greening challenges and opportunities in the city/metro region in various green sectors (e.g. energy, mobility, natural resource management, pollution prevention, treatment and abatement, green services (architecture, urban and landscape design) and the built environment).

- Review of policy interventions pursued by the city/metro region, and both the market-based and non-market-based instruments used, which may include (a) policies to improve urban quality and services (e.g. urban revitalisation, enhancing public transport, reducing vehicle emissions, access to open space, improving water and wastewater services); (b) policies to reduce environmental resource consumption (e.g. increasing the energy efficiency of production and buildings, increasing share of energy from renewable sources, limiting urban sprawl, reducing waste disposed of in landfills); and (c) policies to enable the supply of environmental technologies and services (e.g. business support services for green technology firms, lowering barriers to consumption of green tech, enhancing $R \& D$ linkages between universities and local green firms).

- Identification of institutional and financial opportunities and barriers for policy implementation, with particular attention to multi-level governance issues and public-private partnerships for green growth projects.

- Assessment of policy impacts, based on a review of available economic and environmental data. Much of the data gathered for each case study will be qualitative in nature, but it will also report on local performance indicators like those noted in the previous section. To the extent there are datasets available locally that provide insights on certain greening or green growth strategies, these will also be reported, even if comparable data does not exist in the other case study cities. Certain types of social indicators will also be presented for each case study city to provide important contextual information that might help drive future greening or green growth strategies.

- Policy recommendations to achieve greener growth. Each case study will conclude with a series of recommendations for improving green growth and economic greening strategies. Much of the analysis will focus on policy or market initiatives that are necessary to unlock green growth potential in the city. These can include current barriers that must be overcome 
or opportunities that have not yet been fully exploited by local government or business sector stakeholders.

278. The case studies are designed to provide critical empirical evidence of existing or potential green growth opportunities in cities, an assessment of the challenges faced by cities pursuing economic greening or green growth strategies, as well as concrete policy recommendations for facilitating greener growth at the local level. To that end, a horizontal report will seek to discuss the larger themes from the evidence presented in each case study, including:

- Do we have evidence that cities are becoming greener? Is there evidence that greening policies have resulted in local economic growth? If the answer is unclear, what data is necessary to answer these questions?

- Do we have evidence of offsetting impacts in other regions that can be linked to the greening or green growth of our case study cities?

- Are there certain sectors, governance practices or financing strategies that appear to lend themselves to better greening or green growth outcomes? What factors are responsible for differences across cities?

- In the case of policy initiatives with a demonstrable impact on local greening or green growth, where is the genesis of these efforts? Is local policymaking proving effective, or are the most prominent outcomes derived from state/provincial or national government efforts?

- What, if any, are the primary co-benefits that cities are achieving as a result of local greening or green growth initiatives?

- Are there any unexpected findings that make us rethink certain aspects of our current theoretical framework?

- Do the case studies highlight any data gaps or needs that other cities should keep in mind as they launch their own greening or green growth plans?

279. Efforts to develop effective green metrics will continue, with further refinements undoubtedly ahead. Insofar as environment-related problems and solutions call for an unprecedented mix of international, national and sub-national approaches and tools, the OECD can play a key role in facilitating policy dialogue within cities, between local policymakers and stakeholders, and between cities, in an inter-municipal setting. Providing a basis for such dialogue, city-levels surveys and case studies are designed to help replicate successful experiences and identify information gaps. To this end, capacity building and information sharing on local green policies will be of critical importance to measure and monitor progress toward a robust green growth policy framework of reference. Intermunicipal co-operation platforms will need to address the current shortage of usable toolkits designed to help municipalities set the goals, action, evaluation and reporting of local green growth strategies. There is also a need for increased knowledge sharing. Obtaining an optimal design of pilot projects for green growth will require actors at all levels to develop efficient knowledge management approaches with a view to pooling key information pertaining to all the dimensions of green growth policies, from their design to their monitoring for review. Once the pilot phase has been completed, demonstration projects will be indispensible to subsequently guide project selection and scaling, as well as raise public awareness and political support for green growth strategies at the municipal level. With years of pioneering experiences in the core fields of public policies, the OECD will endeavour to help define and measure progress toward green growth in cities. 
What do urban development models tell us about growth opportunities arising from environmental constraints?

280. Treatment of green growth from an economic modeling and policy standpoint ideally requires a combination of dynamic, spatial and economic modeling components. Yet such a framework is still lacking. With few exceptions, the spatial dimension of the economy has not been given the important role it deserves in driving the way towards green growth. The extent to which better spatial co-ordination among economic agents, services and locations can contribute to reduce environmental degradation arising from energy use, while still boosting the economic growth calls for further investigation.

What are the best practices for financing green growth, and what is the appropriate role for PPPs?

281. Efforts to expand green growth in cities will require significant investments in multiple sectors, such as: retrofitting and improving the energy efficiency of existing building stock and equipment; the development of new infrastructure systems, particularly in the energy and transport sectors; and R\&D innovation in new green technologies. In most cases, these investments are characterised by long cost-recovery periods and potentially significant risks.

282. Now, more than ever, financing is a challenge, as cities are faced with stimulating job growth and providing services with diminishing resources. While in previous decades urban development was financed almost exclusively by the public sector, the size of green investments combined with increasing fiscal constraints means that green growth will require co-financing from the private sector in PPPs, in which risks are partially transferred to private financers.

283. The OECD programme of work will include an evaluation of the scale of financing needs for green growth in cities and will identify the financing mechanisms that have been put into place in cities in OECD and non-member countries. This study will focus on three urban policies:

i) The development and adaptation of existing urban infrastructure: $i$ ) increasing building energy efficiency (including thermal retrofitting the use of renewable energies, and positive energy building technologies); and ii) developming new low-carbon transport infrastructures (including public transportation and electric or hybrid vehicles and charging networks). While these investments can be profitable, the cost recovery period can be very long and characterised by high uncertainty (e.g. the installation of a network of electric vehicle charging stations demands high up-front costs that cannot be recovered in case of project failure).

ii) Public utility networks: i) energy distribution systems (including renewable energy generation); $i$ ) water distribution and treatment, waste collection and treatment (e.g. wasteto-heat systems); iii) brownfields redevelopment and eco-neighbourhood development; and iv) the redevelopment of port infrastructure to increase environmental sustainability.

iii) The promotion of green products and innovation: Cities and metropolitan regions can i) influence the greening of production in supporting services that assist firms in meeting conservation objectives; $i$ i) provide assistance to green start-up firms and/or help retrain local workers to meet the demands of the new green economy (e.g. support for incubators, local retraining programmes); and iii) support research for innovative green technologies, particularly for SMEs facing challenges in the early commercialisation of their products. 


\section{BIBLIOGRAPHY}

ACEEE (American Council for an Energy-Efficient Economy) (2010), North Carolina's Energy Future: Electricity, Water and Transportation Efficiency. Washington: American Council for an Energy Efficient Economy

AESN (Agence de l'eau Seine Normandie) (2007), "Bénéfices de l'assainissement", Rapport d'étude, Seine Normandie, France.

Agarwal A, et al. (2005), "Municipal solid waste recycling and associated markets in Delhi, India" Resources Conservation and Recycling (44) pp 73-90.

Akbari, H, et al. (1999), "Cooling energy savings potential of reflective roofs for residential and commercial buildings in the Unites States." Energy (24) pp 391-407.

Alberini, A., V. Zanatta, and P. Rosata (2007), "Combining actual and contingent behavior to estimate the value of sports fishing in the Lagoon of Venice." Ecological Economics (61), p 530-541.

Alliance for Water Efficiency (2008), Transforming water: water efficiency as stimulus and long-term investment. Chicago: Alliance for Water efficiency.

Anderson, R, et al. (2006), "Major Capital Investment in Water and Wastewater Infrastructure. City Practices and Attitudes Concerning the State Revolving Fund Loan Program", US Conference of Mayors - Mayors Water Council, Washington, D.C., July 2006.

Apollo Alliance (2008), Green-Collar Jobs in America's Cities, United States.

Arnott, R., A. de Palma and R. Lindsey, (1991), "Does providing information to drivers reduce traffic congestion?", Transportation Research 25A, 309-318.

Babington, D. (2008), "Venice flooded by highest water levels in 22 years" Reuters, December 1 2008.

Bank of Japan, Kiatkyushu subsidiary (2008), "Recycling Industry in Kitakyushu City", http://www3.boj.or.jp/kitakyushu/sonota/kitarecycle.pdf, accessed 2 October 2009.

Battistin D. and P. Canestrelli (2006), La serie storica delle maree a Venezia, Istituzione Centro Previsioni e Segnalazioni Maree, Comune di Venezia, October, Venice.

Beaudoin, F. (2009), San Diego Sustainable Building Program case study. New York: Columbia University Center for Energy, Marine Transportation and Public Policy. 
Bekkering, M. (2009), From response to OECD "Local Climate Change Governance Practices Questionnaire" by Mark Bekkering, City of Toronto, Environment Department, 11 August 2009.

Bell, M.L. et al. (2006) "The avoidable health effects of air pollution in three Latin American cities: Santiago, Sao Paulo, and Mexico City" Environmental Research 100, pp 431-440.

Berg, L. van den and E. Braun (1999), "Urban Competitiveness, Marketing and the Need for Organising Capacity”, Urban Studies, vol. 36, no. 5-6, pp. 987-999, Sage Publications, Sage Publications, New Delhi/Thousand Oaks/ London.

Bingham, T.H., et al. (2000), "A Benefits Assessment of Water Pollution Control Programs Since 1972: Part 1, The Benefits of Point Source Controls for Conventional Pollutants in Rivers and Streams", US Environmental Protection Agency, Washington, DC., USA, www. epa.gov/waterscienceleconomics/assessment.pdf.

Blake, H. (2009), "Copenhagen climate summit: London should be hub of global carbon market, says CBI", The Telegraph, 07 December 2009.

Bloomberg News (2011), "Online Carbon Exchange Shifts to Sydney from London”, Sydney Morning Herald. April 20, 2011.

Bollen et al. (2009), "Co-benefits of Climate Policy”, Netherlands Environmental Assessment Agency.

Booz Allen Hamilton (2009), Green Jobs Study prepared for the US Green Green Building Council.

Brajer, V. et al. (2006), "Valuing the Health Impacts of Air Pollution in Hong Kong." Journal of Asian Economics (17) pp 85-102.

Briggs C., et al. (2007), Going with the Grain? Skills and Sustainable Business Development: Project Report, Workplace Research Centre, University of Sydney, Australia.

Brown, M.A., et al. (2010), Energy Efficiency in the South. Atlanta: Southeast Energy Efficiency Alliance.

Brueckner, J. and Kim, H. (2003), "Urban Sprawl and the Property Tax", International Tax and Public Finance, Vol. 10, pp. 5-23, Springer Netherlands.

Bulkeley, H. and M. Betsill (2005), "Rethinking Sustainable Cities: Multilevel Governance and the 'Urban' Politics of Climate Change”, Environmental Politics, Vol. 14, No. 1, pp. 42-63.

Bulkeley, H. and S.C. Moser (2007), "Responding to Climate Change: Governance and Social Action beyond Kyoto", Global Environmental Politics, Vol. 7.2, pp. 1-10.

Bulkeley, H., and K. Kern (2006), "Local Government and the Governing of Climate Change in Germany and the UK", Urban Studies, Vol. 43, No. 12, Routledge, Londong, pp 2237-2259.

C40 (C40 Climate Leadership Group) (2007), "Case Study: Energy Savings Partnerships”, C40 Climate Leadership Group, London, UK, www.c40cities.org/docs/casestudies/energy/berlin_energy.pdf. 
C40 (n.d. (a)), Climate Change Action Plans: Participating Cities and Affiliate cities, www.c40cities.org/ccap/, accessed 26 May 2011.

C40 (n.d. (b)), "Seoul to Become a Global Climate-friendly City by 2030", www.c40cities.org/docs/ccap-seoul-131109.pdf, accessed 26 May 2011.

C40 (n.d. (c)), Energy - Copenhagen Denmark. (website), www.c40cities.org/bestpractices/energy/copenhagen_heat.jsp, accessed21 March 2011.

California Energy Commission (2005), California's Water-Energy Relationship, Final Staff Report.

Cambridge Systematics, Inc. (2009), "Moving Cooler: An Analysis of Transportation Strategies for Reducing Greenhouse Gas Emissions", Urban Land Institute, Washington, DC.

Capello, R., P. Nijkamp, and G. Pepping (1999), Sustainable Cities and Energy Policies, Advances in Spatial Sciences. Springer: Berlin \& New York.

Carley, S. et al. (2011), "Energy-based Economic Development", Renewable and Sustainable Energy Reviews, 15, 292-295.

Carson, R.T. and R.C. Mitchell (1993), “The Value of Clean Water: The Public's Willingness to Pay for Boatable, Fishable, and Swimmable Quality Water", Water Resources Research, Vol. 29, No. 7, p. 2445-2454 www.econ.ucsd.edu/ rcarson/papers/CleanWater.pdf.

Castleton, H.F., Stovin, V., Beck, SBM, and J.B. Davison (2010), Green Roofs; Building Energy Savings and the Potential for Retrofit. Energy and Buildings (42), pp 1582-1591.

CDC (Center for Disease Control) (2007), Overweight and obesity: health consequences. Washington: Center for Disease Control.

CEDEFOP (European Centre for the Development of Vocational Training) and ILO (International Labour Organization), 2010. Skills for Green Jobs: European Synthesis Report. Thesselonika: European Centre for the Development of Vocational Training.

CEE Bankwatch Network (2008), "Never mind the Balance Sheet: The Dangers Posed by Publicprivate Partnerships in Central and Eastern Europe", CEE Bankwatch Network, http://bankwatch.org/documents/never_mind_the_balance_sheet.pdf.

Center for Community Innovation (2010), Innovating the Green Economy in California Regions. Berkeley: Institute for Urban and Regional Development.

Chabarra, R. (2008), “Asia Switches on to the Carbon Market” ClimateChangeCorp, 28 July 2008.

Chang, K.F. and P.C. Chou (2010), "Measuring the Influence of the Greening Design of the Building Environment on the Urban Real Estate Market in Taiwan" Building and Environment (45) pp 2057-2067.

Chapple (2008), "Defining the Green Economy: A Primer on Green Economic Development", UC Berkeley Center for Community Innovation, Berkeley. 
Charbit, C. (2011), "Governance of Public Policies in Decentralised Contexts: The Multi-level Approach", OECD Regional Development Working Papers, 2011/04, OECD, Paris.

Cheshire, P. and S. Magrini (2009) "Urban Growth Drivers in a Europe of Sticky People and Implicit Boundaries", Journal of Economic Geography, vol. 9, no. 1, pp. 85-115.

Chicago Metropolitan Agency for Planning (2010), Green Economic Development Strategies for the Chicago Region, prepared by the Delta Redevelopment Institute.

Church, A., et al. (2008), "Water Framework Directive: Valuation of Recreational Benefits of Improvements in Water Quality -Potential Benefits and Data Requirements", report prepared for Defra, Brighton, UK.

City of Boston Redevelopment Authority (2007), Article 37 - Green Buildings, www.bostonredevelopmentauthority.org/pdf/zoningcode/article37.pdf

City of Los Angeles (2008), Climate LA, Municipal Program Implementing the GreenLA Climate Action Plan: Executive Summary, Los Angeles, United States, www.environmentLA.org.

City of New York (2007), PlaNYC 2030 - A Greener, Greater New York, City of New York, United States.

City of New York (2009a), "Transformation to a Green Economy”, City of New York, www.nyc.gov/html/om/pdf/2009/pr465-09_plan.pdf

City of New York (2009b), "Mayor Bloomberg Announces 30 Initiatives to Grow New York City's Green Economy", Press release, Office of the Mayor, City of New York, 22 October 2009.

City of Paris (2009), "Jusqu'à $400 €$ de subvention pour l'achat d'un scooter électrique”, 9 June 2009, City of Paris, France.

www.paris.fr/portail/deplacements/Portal.lut?page_id=2\&document_type_id=2\&document_id6 5582\&portlet_id=21994

City of Paris (2011), "Villes et croissance verte : Le cas de la Ville de Paris", presentation to the OECD by Hélène de Largentaye from the City of Paris, Paris : OECD, 28 April 2011.

City of Seattle (n.d.), "Seattle Climate Action Plan: About the Green Ribbon Commission", City of Seattle, www.seattle.gov/archive/climate/aboutGRC.htm, accessed 3 August 2011.

City of Tokyo (2008), “Introduction of Tokyo’s Mandatory Cap and Trade System”, Tokyo Metropolitan Government.

Clapp, C. et al. (2010), "Expanding Carbon Markets: Cities and Access to Carbon Finance", Presentation at OECD Global Carbon Markets Workshop, 19-20 April, 2010, OECD, Paris.

Cohen, M (2005), "Individual and Household Environmental Behavior: What does economics contribute to the discussion?" Environmental Law Reporter (35) pp 10754-10762.

Comune di Venezia (2007), Rapporto sullo stato dell'ambiente Assessorato all'ambiente, Comune di Venezia. 
Cooke, P. (2008), "Regional Innovation Systems, Clean Technology \& Jacobian Cluster-Platform Policies", Regional Science Policy \& Practice, Vol. 1, No. 1, pp.23-45, Blackwell Publishing, Oxford, UK.

Cooke, P. and N. Porter (forthcoming), "Regional-National Eco-innovation interactions", OECD Environmental Working Paper, OECD, Paris.

Corfee-Morlot, J. (2009), California in the Greenhouse: Regional Climate Change Policies and the Global Environment, PhD. dissertation, Geography Department, University College London, London.

Crassous, R., J-C Hourcade, and O. Sassi (2006), "Endogenous Structural Change and Climate Targets: Modeling experiments within IMACLIM-R”, The Energy Journal, Special Issue \#1, International Association for Energy Economics, pp. 259-276.

Crouzet, P., et al. (1999), "Nutrients in European Ecosystems", Environmental assessment report No. 4, European Environment Agency (EEA), Copenhagen, Denmark.

Curran, A. and I.D. Williams (2010), "The Role of Furniture and Appliance Re-use Organizations in England and Wales", Resources, Conservation and Recycling (54) pp 692-703.

Cutler \& Company Pty Ltd (2008), "Venturous Australia", www.innovation.gov.au/innovationreview/Documents/NIS_review_Web3.pdf, accessed 25 February, 2010.

Day, T, P. Ogumka, and P. Jones (2009), Monitoring the London Plan Energy Policies - Phase 3. Part 1 Report-Final. London: London Southbank University.

De Macedo, J. and J. Oliveira Martins, 2006, "Growth, Reform Indicators and Policy Complementarities", NBER Working Papers 12544, National Bureau of Economic Research, Inc.

Diedrich, A. (2010), "Cruise Ship Tourism in Belize: The Implications of Developing Cruise Ship Tourism in an Ecotourism Destination. Ocean and Coastal Management (53) pp 234-244.

Dumas, C. F. and P. W. Schuhmann (2004), "Measuring the Economic Benefits of Water Quality Improvement with Benefits Transfer: An Introduction for Non-Economists", Wilmington, USA, http://econ.app- state.edu/RePEc/pdf/wp0412.pdf.

ECMT (European Conference of Ministers of Transport) (1995), Urban Travel and Sustainable Development, OECD, Paris.

Energie-Cites (2006), "Save Energy, Save the Climate, Save Money: Guide for Local and Regional Governments". Besancon, France.

EurActiv (2009), “EU to Help Cities Go 'Green', Buy Clean Buses” EurActiv, 12 February 2009, www.euractiv.com/en/transport/eu-help-cities-go-green-buy-clean-buses/article-179366, accessed 23 April 2010.

European Commission (2004), 2004 Environment Policy Review, European Commission, Brussels. 
European Commission (2010), "Exploring Emerging ICT-enabled Governance Models in European Cities" http://is.jrc.es/pages/EAP/documents/EXPGOVSurveyReport22012010_000.pdf.

Fenhann, J. (2010), "Overview of the CDM pipeline" (Excel file), UNEP Risø Centre, http://cdmpipeline.org/publications/CDMpipeline.xlsx, accessed 27 April 2010.

Flores, et al. (1998), "Adopting a Modern Ecological View of the Metropolitan Landscape: the Case of a Greenspace System for the New York City Region", Landscape and Urban Planning, Volume 39, Issue 4, January 1998, Pages 295-308.

Fouchier, V. (1997), Les densités urbaines et le développement durable: Le cas de l'Ile-de-France et des villes nouvelles, SGVN, Paris.

Fuerst, F. and P. McAllister (2009), “An Investigation of the Effects of Eco-labeling on Office Occupancy Rates, Journal of Sustainable Real Estate 1(1) pp 49-64.

Fuerst, F. and P. McAllister (2011a), "Green Noise or Green Value? Measuring the Effects of Environmental Certification", Real Estate Economics (39) pp 45-69.

Fuerst, F. and P. McAllister (2011b), "Eco-labeling in Commercial Office Markets: Do LEED and Energy Star Offices Obtain Multiple Premiums?” Ecological Economics (in press),

Gibbs, D. (2008), "Industrial symbiosis and eco-industrial development: An introduction", Geography Compass, 2/4, 1138-1154.

Girouard, N. "The OECD Green Growth Strategy: Key lessons so far", OECD Observer No. 279, May 2010.

GHK (2009), "The Impacts of Climate Change on European Employment and Skills in the Short to Medium-Term: Company Case Studies", Final Report, Vol. 1, May 2009, London.

Goldewijk, K, et al. (2010), "Long term dynamic modelling of global population and built-up area in a spatially explicit way", The Holocene 20(4): 565-573.

Goodman, J., (2006), "Houses, Apartments and the Incidence of Property Taxes", Housing Policy Debate, Vol. 17, pp. 1-26.

Goulder, L. and R. Stavins (2010), "Interactions between State and Federal Climate Change Policies", Nota di Lavoro, Fondazione Eni Enrico Mattei, Milan.

Gram-Hanssen, K, F. et al. (2007), "Do Homeowners Use Energy Labels? A Comparison between Denmark and Belgium." Energy Policy (35) pp 2879-2888.

Grazi, F., J. van den Bergh and J. van Ommeren (2008), “An Empirical Analysis of Urban Form, Transport, and Global Warming”, The Energy Journal, Vol. 29, No. 4, pp. 97-122.

Green Building Certification Institute (2011), LEED Professional Directory, https://ssl12.cyzap.net/gbcicertonline/onlinedirectory/, accessed 15 May 2011. 
GRU (Gainseville Regional Utilities) (2010), Solar Feed-in Tariff Workshop. June 9, 2010. Gainesville Regional Utility, www.gru.com/Pdf/SolarFIT/SolarFITContractorWorkshop6-910.pdf, accessed 22 March 2011.

Guo, X.R., et al. (2010), "Estimation of Economic Costs of Particulate Air Pollution from Road Transport in China", , Atmospheric Environment 44, pp 3369-3377.

Hall, C.R., et al. (2006), "The Economic Impact of the Green Industry in the United States", Hortechnology, 16(2) pp 345-353.

Hallegatte, S., F. Henriet and J. Corfee-Morlot (2008), "The Economics of Climate Change Impacts and Policy Benefits at City Scale: A Conceptual Framework", OECD Environment Working Paper No. 4, OECD, Paris.

Hammer, S. (2009), "Capacity to Act: the Critical Determinant of Local Energy Planning and Program Implementation." Working Paper, Columbia University Center for Energy, Marine Transportation and Public Policy. Presented at the World Bank's $5^{\text {th }}$ Urban Research Symposium (Cities and Climate Change), Marseilles, France, 28-30 June 2009.

Hammer, S. A. et al (2011), "Climate Change and Urban Energy Systems" in Climate Change and Cities: First Assessment Report of the Urban Climate Change Research Network, C. Rosenzweig, W. D. Solecki, S. A. Hammer and S. Mehrotra (Eds.), Cambridge University Press, Cambridge, UK, 83-109.

He, J. (2006), "Pollution Haven Hypothesis and Environmental Impacts of Foreign Direct Investment: the Case of Industrial Emission of Sulfur Dioxide (SO2) in Chinese provinces", Ecological Economic,s 60, pp 228-245.

Heinz (n.d.), A Survey of Climate Change Adaptation Planning, The Heinz Center, Washington, D.C.

Hicks, M. (2009), Some Preliminary Evaluation of the Cash for Clunkers Program, Center for Business and Economic Research Policy Brief, Ball State University.

Hooghe, L. and G. Marks (2003), "Unravelling the Central State, but How? Types of Multi-level Governance", American Political Science Review, Vol. 97, No. 2, pp. 233-43.

Howarth, A., et al. (2001), "Valuing the Benefits of Environmental Policy: The Netherlands", RIVM report 481505 024, London, UK.

Hu, X. et al. (2010), "Energy for Sustainable Road Transportation in China: Challenges, Initiatives and Policy Implications", Energy (35),

Hunt, A. and P. Watkiss (2007), "Literature Review on Climate Change Impacts on Urban City Centres: Initial Findings", OECD Working Party on Global and Structural Policies, Paris: OECD.

Hyams, M. (2009), Case Study - San Francisco Solar Map, Prepared for the JUCCCE Mayoral Training Program by the Center for Energy, Marine Transportation and Public Policy, Columbia University, New York. 
Hyams, M. et al. (2011), Microgrids: An Assessment of the Value, Opportunities and Barriers to Deployment in New York State. Prepared for the New York State Energy Research and Development Authority.

IAU (Institut d'aménagement et d'urbanisme - Ile-de-France) (forthcoming), Report on social equity and eco-quartiers in the Paris-IDF region, IAU, Paris.

IAU - Insee (Institut national de statistiques et d'études économiques) (2011), CRCI Chiffres clés de la région Ile-de-France 2011, IAU-Insee, Paris.

IDDRI (Institut du développement durable et des relations internationales) (2010), « Habitat Facteur 4: Étude d'une réduction des émissions de $\mathrm{CO}_{2}$ liées au confort thermique dans l'habitat à l'horizon 2050 », Les Cahiers du CLIP, n 20, Paris, nov 2010.

IEA (International Energy Agency) (2005), Evaluating Energy Efficiency Policy Measures \& DSM Programmes, Volume I Evaluation Guidebook, OECD/IEA, Paris.

IEA (2008a), $\mathrm{CO}_{2}$ Emissions from Fuel Combustion, OECD/IEA, Paris.

IEA (2008b), World Energy Outlook 2008, OECD/IEA, Paris.

IEA (2008c), "Energy Efficiency Requirements in Building Codes, Energy Efficiency Policies for New Buildings", IEA information Paper, March 2008, OECD/IEA, Paris.

IEA (2009a), Energy Balances in OECD Countries, OECD/IEA, Paris.

IEA (2009b), Cities and Towns and Renewable Energy - YIMFY: Yes In My Front Yard, OECD/IEA, Paris.

IEA (2009c), Innovations in Multi-Level Governance for Energy Efficiency: Sharing Experience with Multi-level Governance to Enhance Energy Efficiency, OECD/ IEA, Paris.

IEA (2010), Energy Technology Perspectives 2010, Paris.

IEA (2010a), World Energy Outlook 2010. Paris: OECD/IEA.

ILO (International Labour Organization) (2008), "Global Challenges for Sustainable Development: Strategies for Green Jobs", ILO Background Note for the G8 Labour and Employment Ministers Conference, May 2008, Japan.

IAU - Insee (Institut national de statistiques et d'études économiques) (2011), CRCI Chiffres clés de la région Ile-de-France 2011, IAU-Insee, Paris.

Institute for Sustainable Communities (2010), Climate Leadership Academy: Promising Practices in Green Job Creation (Handbook),

ITUC (International Trade Union Confederation) (2009), "Equity, Justice and Solidarity in the Fight against Climate Change", series Trade Unions and Climate Change, Trade Union Statement to COP15, Brussels, December 2009. 
Jacobson, G. and M. Kotchen (2010), “Are Building Codes Effective at Saving Energy? Evidence from Residential Billing Data in Florida", NBER Working Paper No. 16194, July 2010.

Jackson, T. (2009), Prosperity Without Growth?: Economics for a Finite Planet, Report of the Sustainable Development Commission, Earthscan Limited, Oxford.

Jeanneret, B. (2009), From response to OECD "National-Local Climate Change Governance Practices Questionnaire" by Barbara Jeanneret, Swiss Federal Statistical Office, 17 August, 2009.

Jenks, M., D. Kozak and P. Takkanon, eds. (2008), World Cities and Urban Form: Fragmented, Polycentric, Sustainable?, Routledge, Oxford, UK.

Joardar, S.D. (2000), "Urban Residential Solid Waste Management in India: Issues related to Institutional Arrangements", Public Works Management and Policy, Vol. 4, No. 4:319-330.

Jouravlev, A. (2004), "Drinking Water Supply and Sanitation Services on the Threshold of the XXI Century", CEPAL, Serie 74, Recursos Naturals e Infraestructura, Santiago de Chile, Chile, www.eclac.cl/publicaciones/ xml/9/19539/lc12169i.pdf.

Kahrl, F. et al. (2009), "Municipal Climate Policies: Scope, Economics, and Institutions", Center for Energy, Resources, and Economic Sustainability, Berkeley: University of California, Berkeley.

Kamal-Chaoui, L. and A. Robert (eds.), (2009), "Competitive Cities and Climate Change”, OECD Publications, Paris, www.oecd.org/dataoecd/30/36/44232251.pdf.

Kamal-Chaoui, L., E. Leman and R. Zhang (2009), "Urban Trends and Policies in China", OECD Regional Development Working Paper, 2009/1, OECD Publishing, Paris.

Kamal-Chaoui, L. et al. (2011), "The Korean Green Growth Strategy and its Implementation in Urban Areas: Interim report", OECD Regional Development Working Paper, OECD Publishing, Paris.

Kammen, D. et al. (2006), "Putting Renewables to Work: How Many Jobs can the Clean Energy Industry Generate?" RAEL Report, University of California at Berkeley.

Kats, G. (2003), The Costs and Financial Benefits of Green Building. A Report to California's Sustainable Building Task Force, Capital E.

Keirstead, J. and N. Schulz (2010), "London and Beyond: Taking a Closer Look at Urban Energy Policy”, Energy Policy, (38) pp 4870-4879.

Krop, R. et al. (2008), "Local Government Investment in Municipal Water and Sewer Infrastructure: Adding Value to the National Economy", The US Conference of Mayors - Mayors Water Council, Washington, D.C.

Kuo, F.E. and W.C. Sullivan (2001), "Aggression and Violence in the Inner City: Effects of Evironment via Mental Fatigue", Environmental Behavior (33) pp 543-571.

Kuo, F.E., et al. (1998), "Fertile Ground for Community: Inner-city Neighborhood Common Spaces", American Journal of Community Psychology, pp 823-851. 
Largentaye, H. de (2010)", Velib': A Case of Successful Co-operation between the City of Paris and the Private Sector in the Framework of a Sustainable Development Strategy", Presentation for OECD 3rd Annual Meeting on Public Private Partnerships, 13 April 2010.

Leeds City Region Partnership (2010), “A Green Infrastructure Strategy”, www.leedscityregion.gov.uk/gi.htm

Leslie, K. and L. Utter (eds.), (2006), Recycling and Solid Waste in Latin America: Trends and Policies 2006, Raymond Communications, Inc., College Park, Maryland.

Litman, T. (2009), Smart Growth Reforms: Changing Planning, Regulatory and Fiscal Practices to Support More Efficient Land Use, Victoria Transport Policy Institute.

London Development Agency (2010), Green Expectations: London's Low-carbon Job Prospects. Labor Market Research Series 3, September 2010, London: London Development Agency.

London Remade (2007), “The Footprint Project: Reducing London's Ecological Footprint”, http://londonremade.com/lr_footprinting.asp.

Louv, R. (2005), Last Child in the Woods: Saving our Children from Nature-deficit Disorder, Chapel Hill, NC: Algonquin Books of Chapel Hill.

Love, L.L. and J.L. Crompton (1999), “The Role of Quality of Life in Business (Re)Location Decisions." Journal of Business Research (44) pp 211-222.

Mansur and Kahn (forthcoming), "Do Energy Price Differentials Influence Where Manufacturing Agglomerates? A Regression Discontinuity Approach", manuscript.

Mansur E.T. and S.M. Olmstead (2007), "The Value of Scarce Water: Measuring the Inefficiency of Municipal Regulations”, NBER Working Paper No. 13513

Martinez-Fernandez, C et al. (2010), Green Jobs and Skills: Labor Market Implications of Addressing Climate Change. Paris: OECD.

Matthiessen, L. and P. Morris (2007), Cost of Green Revisited: Reexamining the feasibility and cost impact of sustainable design in the light of increased market adoption. Davis Langdon, New York.

McDougall, F. et al. (2001), Integrated Solid Waste Management: A Life Cycle Inventory, Blackwell Science Ltd, London.

McHugh, J. (2008), "The Lost City of Venice”, Wired, November.

Meeus, L. and E. Delarue (2011), Mobilizing Cities towards a Low Carbon Future: Tambourines, Carrots and Sticks. EUI Working Paper RSCAS 2011/4. European University Institute, Robert Schuman Center for Advanced Studies, Florence School of Regulation, Florence, Italy.

Miller, N., J. Spivey and A. Florance (2008), "Does Green Pay Off?" Journal of Real Estate Portfolio Management 14(4) pp 385-399. 
Miller, N. et al. (2009), "Green Buildings and Productivity", The Journal of Sustainable Real Estate, vol. 1 , no. 1 .

Moss, T. (2007), "Solving Problems of 'Fit' at the Expense of Problems of 'Interplay'? The Spatial Reorganisation of Water Management Following the EU Water Framework Directive", in P. P. Mollinga, A. Dixit and K. Athukorala (eds), Integrated Water Resources Management: Global Theory, Emerging Practice and Local Needs, Sage Publications, New Delhi/Thousand Oaks/ London.

Nas, P. and R. Jaffe (2004), "Informal Waste Management: Shifting the Focus from Problem to Potential”, Environment, Development and Sustainability 6:337-353.

Newsham, G.R., et al. (2009), Do LEED-certified buildings save energy? Yes, but..." Energy and Buildings (41) pp 897-905.

Nicholls, R. et al. (2008), "Ranking Port Cities with High Exposure and Vulnerability to Climate Extremes", OECD Environment Working Papers No. 1, OECD, Paris.

Nunes, P. et al. (2008), "Regulation of the Fishing Activities in the Lagoon of Venice, Italy: Results from a Socio-economic Study”, Estuarine, Coastal and Shelf Science (80) pp 173-180.

OECD (Organisation for Economic Co-operation and Development) (2001a), OECD Environmental Outlook, OECD, Paris.

OECD (2001b), Sustainable Development - Critical Issues, OECD, Paris.

OECD (2001c), Policies to Enhance Sustainable Development, OECD, Paris.

OECD (2002), Impact of Transport Infrastructure Investment on Regional Development, OECD, Paris.

OECD (2003a), Environmentally Sustainable Buildings: Challenges and Policies, OECD, Paris.

OECD (2005), OECD Territorial Reviews: Seoul, Korea, OECD Publishing, Paris.

OECD (2006), Competitive Cities in the Global Economy, OECD, Paris.

OECD (2007a), OECD Territorial Reviews: Randstad Holland, Netherlands, OECD, Paris.

OECD (2007b), "Policy Brief: Environmentally Related Taxes: Issues and Strategies", OECD, Paris, www.oecd.org/dataoecd/39/18/2674642.pdf.

OECD (2007c), Environmental Performance Review of China, OECD, Paris.

OECD (2007d), Climate Change in the European Alps: Adapting Winter Tourism and Natural Hazards Management, OECD, Paris.

OECD (2008a), Environmental Outlook to 2030, OECD, Paris.

OECD (2008b), OECD Territorial Reviews: Cape Town, South Africa, OECD, Paris.

OECD (2008c), Cost of Inaction: Technical Report, OECD, Paris. 
OECD (2008d), Costs of Environmental Policy Inaction: Summary for Policy-makers, OECD, Paris.

OECD (2008e), Household Behaviour and the Environment: Reviewing the Evidence, OECD, Paris.

OECD (2009a), Green Growth: Overcoming the Crisis and Beyond, OECD, Paris.

OECD (2009b), Environmental Outlook to 2030, OECD, Paris.

OECD (2009c), Regions Matter: Economic Recovery, Innovation and Sustainable Growth, OECD, Paris.

OECD (2009d), How Regions Grow: Trends and Analysis, Paris: OECD

OECD (2009e), Enabling the Green Growth: Sustainable Manufacturing and Eco-innovation, Synthesis Report, OECD, Paris.

OECD (2009f), OECD Territorial Reviews: Copenhagen, Denmark, OECD, Paris.

OECD (2009g), OECD Territorial Reviews: Toronto, Canada, OECD, Paris.

OECD (2009h), "Cities, Climate Change and Multilevel Governance”, Environment Working Papers, OECD, Paris.

OECD (2009i), Green Cities: New Approaches to Confronting Climate Change, OECD Workshop Proceedings, 11 June 2009, Las Palmas de Gran Canaria, Spain.

OECD (2009j), OECD Territorial Reviews: Trans-border Urban Co-operation in the Pan Yellow Sea Region, OECD, Paris.

OECD (2009k), OECD National Accounts Statistics, Volume 2009, www.sourceoecd.org/database/16081188/nataccounts, OECD, Paris.

OECD (2010a), "Interim Report of the Green Growth Strategy: Implementing our commitment for a sustainable future", OECD, Paris.

OECD (2010b), Trends in Urbanisation and Urban Policies in OECD Countries: What Lessons for China? OECD - China Development Research Foundation, Paris.

OECD (2010c), Cities and Climate Change, OECD, Paris.

OECD (2010d), Eco-innovation in Industry Enabling Green Growth, OECD, Paris.

OECD (2010e), OECD Territorial Reviews. Venice, Italy, OECD Publications, Paris.

OECD (2010f), “Climate Change and Chinese Cities”, Working Paper, OECD, Paris.

OECD (2011a), Making the most of public investment in a tight fiscal environemn=ent: multi-level governance lessons from the crisis, OECD, Paris

OECD (2011b), Towards Green Growth, Green Growth Strategy Synthesis report, OECD, Paris

OECD (2011c), Regions at a Glance, OECD, Paris. 
OECD (2011d), Fostering Innovation for Green Growth, Paris: OECD, March 2011.

OECD (2011e), Water Governance in OECD Countries: A Multi-level Approach, OECD, Paris.

OECD (2011f), Benefits of Investing in Water and Sanitation, OECD, Paris.

OECD (2011g), Interactions between Emission Trading Systems and Other Overlapping Policy Instruments, OECD, Paris.

OECD (2011h), "Measuring the environmental performance of metropolitan areas with geographic information sources", presented during the 22nd session of the Working Party on Territorial Indicators, 7 December 2011, OECD, Paris

OECD (forthcoming (a)), OECD Environmental Data Compendium, OECD, Paris.

OECD (forthcoming (b)), The Compact City Concept in Today's Urban Contexts, OECD, Paris.

OECD (forthcoming (c)), OECD National Urban Policy Review: Korea, OECD, Paris.

Nicholls, R. J., et al. (2008), "Ranking Port Cities with High Exposure and Vulnerability to Climate Extremes: Exposure Estimates", OECD Environment Working Papers, No. 1, http://dx.doi.org/10.1787/011766488208.

Parry, I. (2005), "Is Pay-as-You-Drive Insurance a Better Way to Reduce Gasoline than Gasoline Taxes?”, AEA Papers and Prooceedings, Vol. 95, pp. 288-293.

Patankar, A.M., and P.L. Trivedi (2011), "Monetary burden of health impacts of air pollution in Mumbai, India: Implications for public health policy.” Public Health 125, pp 157-164.

Peper, P.J. et al (2008), City of Indianapolis municipal forest resource assessment. Internal Technical Report. US Department of Agriculture, Forest Service, Pacific Southwest Research Station, Davis, CA.

Pina, V. and Torres, L. (2006), Public-private efficiency in the delivery of services of general economic interest: The case of urban transport, Local government studies, Vol. 32, No. 2, pp. $177-198$

Raissis in OECD (2009i), Green Cities: New Approaches to Confronting Climate Change, OECD. Workshop Proceedings, 11 June 2009, Las Palmas de Gran Canaria, Spain.

Reimsbach-Kounatze, C. (2009), "Towards Green ICT Strategies: Assessing Policies and Programmes on ICT and the Environment", OECD DIgntal Economy Papers, No. 155. doi: $10.1787 / 222431651031$

Rezessy, S. et. al (2006), "Municipalities and energy efficiency in countries in transition: Review of factors that determine municipal involvementin the markets for energy services and energy efficient equipment, or how to augment the role of municipalities as market players." Energy Policy (34) pp 223-237.

Rifkin, J. (2011), "Future of Energy”, Financial Times, May 10, 2011. 
Rusconi, A. (2007), "La salvaguardia della laguna ed il MOSE”, Terzo Forum Nazionale: Pianificazione e Tutela del Territorio.

RW Beck (2001), Us Recycling Economic Information. Prepared for the National Recycling Coalition.

Santos, F. "For Schools, Free Art Supplies, and Much More" New York Times, March 1, 2011, p A23.

Sejong City, (2009), Green City Sejong, Multifunctional Administration City Construction Agency, Yeongi-gun, Korea.

Sharp, L. and D. Luckin (2006), "The community waste sector and waste services in the UK: current state and future prospects" Resources Conservation and Recycling (47) pp 277-294.

Shin, S. (2009), “An Empirical Assessment of the California Utilities' Energy Efficiency Programs”, unpublished Master's thesis.

Silicon Valley Climate Prosperity Initiative (2009), Climate Prosperity: Greenprint for Silicon Valley.

Smith, K. (2009), Climate Change and Radical Energy Innovation: The Policy Issues, TIK Working Papers on Innovation Studies, No. 20090101, Oslo.

Soares, A.L, et al. (2011), "Benefits and cost of street trees in Lisbon, Portugal" Urban Forestry and Urban Greening (in press).

Socher, W. (2009), From response to OECD "Local Climate Change Governance Practices Questionnaire" by Wolfgang Socher, City of Dresden, Department of Urban Ecology, 26 August, 2009.

Stern, N. (2007), The Stern Review Report, Cambridge University Press, Cambridge, UK.

Stiglitz, J., A. Sen and J-P Fitoussi (2009), Report by the Commission on the Measurement of Economic Performance and Social Progress.

Sydney City Council (2008), Sustainable Sydney 2030, www.cityofsydney.nsw.gov.au/2030/thevision/Downloads.asp

Tang, Z. et al. (2011), "Examining locally driven climate change policy efforts in three Pacific states", Ocean \& Coastal Management (in press) pp 1-12.

Tawil, N (1999), "Flow control and rent capture in solid waste management" Journal of Environmental Economics and Management (37) pp 183-201.

TFL (2008), London Freight Plan - Sustainable Freight Distribution: a plan for London. Transport for London, London.

Tulacz, G. (2008), The Top Green Design Firms. Engineering News-Record (260), 21.

Tyrvainen, L. and Miettinen, A. (2000), "Property prices and urban forest amenities." Journal of Environmental Economics and Management (39) pp 205-223.

UN (United Nations) (2003), Waste-water Treatment Technologies: A General Review, New York. 
UN (2007), State of World Population 2007: Unleashing the Potential of Urban Growth, United Nations Publishing.

Unruh, G. (2000), “Understanding carbon lock-in”, Energy Policy 28, pp 817-830.

Unruh, G. (2002), “Escaping carbon lock-in”, Energy Policy 30, pp 317-325.

UNEP, (2007), Assessment of Policy Instruments for Reducing Greenhouse Gas Emissions from Buildings, UNEP Sustainable Buildings \& Construction Initiative and Central European University, Paris.

UNEP (United Nations Environment Programme) (2008), UNEP Background Paper on Green Jobs. Nairobi: United Nations Environment Programme.

UNEP (2011), Towards a Green Economy. Pathways to Sustainable Development and Poverty Eradication, United Nations Environment Programme, www.unep.org/greeneconomy.

UNEP/ILO/IOE/ITUC (2008) Green Jobs: Towards Decent Work in a Sustainable, Low-Carbon World, report produced by Worldwatch Institute and commissioned by UNEP, ILO, IOE, ITUC, Nairobi.

UNFPA (United Nations Population Fund) (2009), World Urbanization Prospects: The 2009 Revision, UNFPA, New York.

UN-Habitat (2010), State of the World's Cities 2010/2011, UN-Habitat, Nairobi.

Van Berkel, R. et al. (2009) Industrial and urban symbiosis in Japan: Analysis of the Eco-Town program 1997-2006. Journal of Environmental Management (90) pp 1544-1556.

Vancouver City Council (2006), Vancouver Economic Development Commission - "Guiding Principles", http://vancouver.ca/sustainability/documents/economic_pe6.pdf.

Vancouver City Council (2009), Vancouver 2020 A Bright Green Future: An Action Plan for Becoming the World's Greenest City by 2020, http://vancouver.ca/greenestcity/PDF/Vancouver2020-ABrightGreenFuture.pdf.

Wackernagel, M. et al. (2006), "The Ecological Footprint of Cities and Regions: Comparing Resource Availability with Resource Demand", Environment and Urbanization, Vol. 18, p. 203.

Wheeler, S. M. (2008), "State and Municipal Climate Change Plans: The First Generation", Journal of the American Planning Association, Vol. 74, No. 4, Routledge, London, pp. 481-496.

World Health Organisation (WHO) (2006), Air Quality Guidelines; Global Update 2005: Particulate Matter, Ozone, Nitrogen Dioxide and Sulphur Dioxide, World Health Organisation Regional Office for Europe, Copenhagen, Denmark.

Wiley, J., J. Benefield and K. Johnson (2010), “Green Design and the Market for Commercial Office Space" Journal of Real Estate Finance and Economics (41) pp 228-243.

Wilson, S. J. (2000), “The GPI Water Quality Accounts: Case Study The Costs and Benefits of Sewage Treatment and Source Control for Halifax Harbour", Measuring Sustainable 
Development, Application of the Genuine Progress Index to Nova Scotia, GPI Atlantic, Glen Haven, Nova Scotia.

World Bank (2005), Waste Management in China: Issues and Recommendations, Urban Development Working papers, East Asia Infrastructure Department, Working Paper No. 9, 146 p, World Bank, Washington DC.

http://siteresources.worldbank.org/INTEAPREGTOPURBDEV/Resources/China-WasteManagement1.pdf.

Zanni, A. and A. Bristow (2010), "Emissions of $\mathrm{CO}_{2}$ from road freight transport in London: Trends and policies for long run reductions." Energy Policy (38) pp 1774-1786.

Zathej, M. (2009), From response to OECD "Local Climate Change Governance Practices Questionnaire" by Maciej Zathej, Dolnoslaskie Region, Poland, Regional Bureau of Spatial Planning, 28 August 2009.

Zhang, D. et al. (2009), "Constructed wetlands in China”, Ecological Engineering (35) pp 13671378.

Zhang, X. et al. (2011), "Green strategy for gaining competitive advantage in housing development: a China study”, Journal of Cleaner Production (19) pp 157-167. 